Teste Estrutural de Integração Par-a-Par de Programas Orientados a Objetos e a Aspectos: Critérios e Automatização 



\title{
Teste Estrutural de Integração Par-a-Par de Programas Orientados a Objetos e a Aspectos: Critérios e Automatização
}

\author{
Ivan Gustavo Franchin
}

Orientador: Prof. Dr. Paulo Cesar Masiero

Dissertação apresentada ao Instituto de Ciências Matemáticas e de Computação - ICMC-USP, como parte dos requisitos para obtenção do título de Mestre em Ciências Ciências de Computação e Matemática Computacional. 



\section{Agradecimentos}

Agradeço inicialmente a Deus pela saúde, força, determinação e bênçãos recebidas durante esta etapa da minha vida.

Agradeço aos meus pais Vitório e Margarida, aos meus irmãos Wagner e Silvana e aos meus parentes Roberto, Márcia, Nátia, Bianca, Benedito, Maria, Rodrigo e Eduardo pelo apoio e confiança.

Agradeço ao meu orientador Prof. Dr. Paulo César Masiero pela orientação e profissionalismo durante todo este trabalho.

Agradeço a todos meus amigos: Otávio Lemos, Fabiano Ferrari, Sandro Bianchini, André Domingues, Marcelo Eler, Érika Höhn, Marcella Letícia, Stanley Pacios, Alessandra Chan, Antonielly Rodrigues, Camila Kozlowski, Paula Herculano, Gustavo Nascimento, Alfraino Diniz, Henderson Silva, Marcio Almeida, Lucas Casagrande, Carlos Alberto, Lúcio Felippe, André Endo e aos demais amigos do LabES e do ICMC.

Agradeço a todos os professores e funcionários do ICMC pela disposição e atenção.

Agradeço ao CNPq pelo apoio financeiro. 

Ma abordagem de teste estrutural de integração par-a-par para programas $\mathrm{OO}$ e OA escritos em Java e AspectJ é apresentada. A finalidade dessa abordagem é descobrir defeitos que possam existir na interface entre os pares de unidades que se relacionam em um programa. Para programas $\mathrm{OO}$ este tipo de teste envolve testar a interação entre os pares de métodos. Já para programas OA, o teste estrutural de integração par-apar envolve testar a interação entre os seguintes pares de unidades: métodométodo, método-adendo, adendo-método e adendo-adendo. Para efetuar o teste estrutural de integração par-a-par deve-se considerar todo o fluxo de execução (fluxo de controle e de dados) que ocorre entre a unidade chamadora e a unidade chamada. Para isso é definido o grafo Def-Uso Par-a-Par $(\mathcal{P W D U})$ que é uma abstração formada pela integração dos grafos Def-Uso Orientado a Aspectos $(\mathcal{A O D U})$ da unidade chamadora e da unidade chamada. Além disso, são propostos três critérios para derivar requisitos de teste para pares de unidades. Dentre eles, dois critérios são baseados em fluxo de controle: todos-nós-integrados e todas-arestas-integradas; e um critério é baseado em fluxo de dados: todos-usos-integrados. Uma ferramenta que apóia o teste estrutural de unidade de programas $\mathrm{OO}$ e OA escritos em Java e AspectJ, chamada JaBUTi/AJ, foi estendida para dar apoio à abordagem de teste de integração proposta. Exemplos de usos são discutidos para explicar a aplicação da abordagem. 

Pairwise integration structural testing approach for $\mathrm{OO}$ and $\mathrm{AO}$ programs implemented with Java and AspectJ is presented. The purpose of this approach is to find faults that may exist in the interface between the pairs of units that relate in a program. For OO programs this type of testing involves testing the interaction among pair of methods. For AO programs, the pairwise integration structural testing involves testing the interaction among the following pairs of units: method-method, methodadvice, advice-method and advice-advice. To perform the pairwise integration structural testing, all the execution flow (control and data flow) that happens between the caller and the called unit must be considered. For this, it is defined the PairWise Def-Use graph $(\mathcal{P W D U})$ that is an abstraction formed by the integration of the Aspect-Oriented Def-Use $(\mathcal{A O D} \mathcal{U})$ graphs of the caller and called unit. Additionally, three new criteria to derive test requirements for pairs of units are proposed. Amongst them, two criteria are based on control flow: all-integrated-nodes and all-integrated-edges; and one criterion is based on data flow: all-integrated-uses. A tool that supports unit structural testing of $\mathrm{OO}$ and $\mathrm{AO}$ programs implemented with Java and AspectJ, called JaBUTi/AJ, was extended in order to support the proposed integration testing approach. Examples are discussed in order to explain the application of the approach. 

Resumo

$\begin{array}{lll}\text { Abstract } & \text { iii }\end{array}$

1 Introdução $\quad 1$

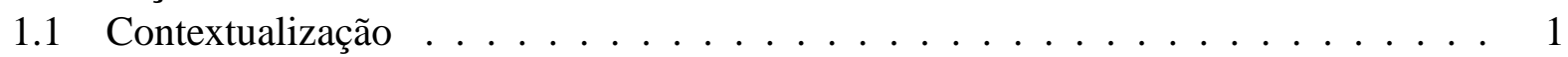

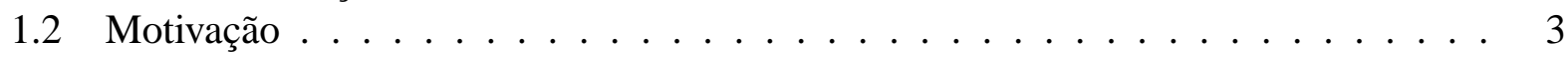

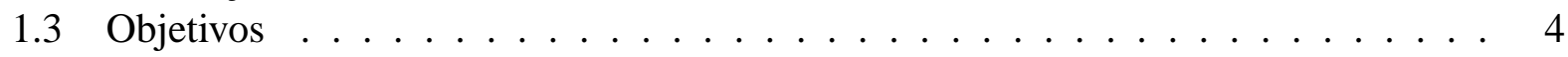

1.4 Organização . . . . . . . . . . . . . . . . . . . . 4

2 Uma Introdução a Programação OO e OA 5

2.1 Considerações Iniciais . . . . . . . . . . . . . . . . . . . . 5

2.2 Programação Orientada a Objetos . . . . . . . . . . . . . . . . 5

2.2.1 Linguagens Orientadas a Objetos: Uma Introdução a Java . . . . . . . . . . . 6

2.3 Programação Orientada a Aspectos . . . . . . . . . . . . . . . . . . . 21

2.3.1 Linguagens Orientadas a Aspectos: Uma Introdução a AspectJ . . . . . . . 23

2.4 Considerações Finais . . . . . . . . . . . . . . . . . . . . . 30

3 Teste de Software OO e OA: Teste Estrutural de Unidade e de Integração 33

3.1 Considerações Iniciais . . . . . . . . . . . . . . . . . . . . . . . . . . . . . . . . . .

3.2 Fundamentos do Teste de Software . . . . . . . . . . . . . . . . 33

3.2 .1 Técnica Funcional . . . . . . . . . . . . . . . . . . . 35

3.2 .2 Técnica Estrutural . . . . . . . . . . . . . . . . . . . 36

3.2.3 Técnica Baseada em Defeitos . . . . . . . . . . . . . . . 39

3.3 Uma Abordagem de Teste Estrutural de Integração para Programas Procedimentais 40

3.4 Teste Estrutural de Programas Orientados a Objetos . . . . . . . . . . . . . . . . 45

3.4.1 Teste Estrutural de Unidade . . . . . . . . . . . . . . . . . 47

3.4 .2 Teste Estrutural de Integração . . . . . . . . . . . . . . . . . . . 53

3.4 .3 Teste Estrutural de Integração Par-a-Par . . . . . . . . . . . . . . . . . . 56

3.5 Teste Estrutural de Programas Orientados a Aspectos . . . . . . . . . . . . . . . 57

3.5.1 Teste Estrutural de Unidade . . . . . . . . . . . . . . . . . . . . . . . 59

3.5 .2 Teste Estrutural de Integração . . . . . . . . . . . . . . . . . . . . 67

3.5.3 Outras Abordagens para Teste de Programas OA . . . . . . . . . . . . 69

3.6 Ferramentas de Teste . . . . . . . . . . . . . . . . . 73

3.7 Considerações Finais . . . . . . . . . . . . . . . . . 78 
4 Teste Estrutural de Integração Par-a-Par de Programas OO e OA 79

4.1 Considerações Iniciais . . . . . . . . . . . . . . . . . . . . . 79

4.2 Tipos de Teste Estrutural de Integração Par-a-Par . . . . . . . . . . . . . . . . . 79

4.3 O Modelo de Fluxo de Dados para a Linguagem Java . . . . . . . . . . . . . . . 83

4.4 Grafo de Fluxo para Teste Estrutural de Integração Par-a-Par . . . . . . . . . . . . 88

4.5 Critérios de Fluxo de Controle e Fluxo de Dados para Teste Estrutural de Integração Par-a-Par . . . . . . . . . . . . . . . . . . . . . . . 92

4.5.1 Critério de Fluxo de Controle . . . . . . . . . . . . . . . . 93

4.5 .2 Critério de Fluxo de Dados . . . . . . . . . . . . . . . . . . . . . 94

4.5.3 Exemplo de Aplicação dos Critérios . . . . . . . . . . . . . . . . . . . . . . . 98

4.6 Considerações Finais . . . . . . . . . . . . . . . . . . . . . . . . . . 99

5 Implementação do Teste Estrutural de Integração Par-a-Par na Ferramenta JaBU$\begin{array}{ll}\text { Ti/AJ } & 101\end{array}$

5.1 Considerações Iniciais . . . . . . . . . . . . . . . . . . . . . 101

5.2 Extensão da Ferramenta JaBUTi/AJ para Apoio ao Teste Estrutural de Integração

Par-a-Par . . . . . . . . . . . . . . . . . . 102

5.2.1 Primeira Etapa: Identificar Pares de Unidades . . . . . . . . . . . . . . . 102

5.2.2 Segunda Etapa: Construir Grafo Def-Uso Par-a-Par . . . . . . . . . . . . . . 104

5.2.3 Terceira Etapa: Implementar Critérios de Integração Par-a-Par . . . . . . . 105

5.2.4 Quarta Etapa: Desenvolvimento dos Ambientes de Teste de Integração . . . 114

5.3 Funcionamento da Ferramenta JaBUTi/AJ e Exemplos de Uso . . . . . . . . . . . 115

5.3.1 A Interface da Ferramenta JaBUTi/AJ . . . . . . . . . . . . . . . . . 115

5.3 .2 Primeiro Exemplo de Uso . . . . . . . . . . . . . . . . . . 116

5.3.3 Segundo Exemplo de Uso . . . . . . . . . . . . . . . . . . . . 126

5.4 Considerações Finais . . . . . . . . . . . . . . . . . . . . 134

6 Conclusão $\quad 135$

6.1 Considerações Finais . . . . . . . . . . . . . . . . . . . . 135

6.2 Contribuições . . . . . . . . . . . . . . . . . . 136

6.3 Trabalhos Futuros . . . . . . . . . . . . . . . . 136

$\begin{array}{ll}\text { Referências } & 144\end{array}$ 


\section{Lista de Figuras}

2.1 O ambiente de programação Java (adaptada de Venners (1997)). . . . . . . . . . . 7

2.2 Classe abstrata OperacaoMatematica. . . . . . . . . . . . . . . . . 12

2.3 Exemplos de declaração de atributos. . . . . . . . . . . . . . . . . . . . . . 13

2.4 Exemplo com declarações de métodos e construtores e uso do thi. s. . . . . . . . . 14

2.5 Exemplo de sobrescrita de métodos. . . . . . . . . . . . . . . . . . 14

2.6 Exemplo de run-time binding. . . . . . . . . . . . . . . . . . . 15

2.7 Exemplo de declaração de interfaces. . . . . . . . . . . . . . . . . . 18

2.8 Arquitetura interna da Máquina Virtual Java (adaptada de Venners (1997)). . . . . . 18

2.9 Interesse ortogonal de atualização de tela. . . . . . . . . . . . . . . . . 22

2.10 Solução OO para o exemplo de atualização de tela. . . . . . . . . . . . . . . . . . 22

2.11 Exemplo de código em AspectJ. . . . . . . . . . . . . . . . . . 25

2.12 Destaque do conjunto de junção nomeado definido no exemplo apresentado na Figura 2.11 (adaptada de Lemos (2005)) . . . . . . . . . . . . . . . . 26

2.13 Código do aspecto AtualizacaoDaTela modificado. . . . . . . . . . . . 28

2.14 Exemplo de declarações inter-tipos. . . . . . . . . . . . . . . . . . . . . . . . . . . . . . . . . . . . . . .

2.15 Sintaxe da declaração declare paterns. . . . . . . . . . . . . . . . . . 29

2.16 Exemplo de declare error e de declare warning. . . . . . . . . . 30

2.17 Exemplo de uma declaração de aspecto (adaptada de Kiczales et al. (2001b)). . . . 31

3.1 Exemplo p-grafo (adaptado de Vilela et al. (1999)). . . . . . . . . . . . . . . . . . 41

3.2 Implementação parcial da classe Symbol Table (adaptado de Harrold e Rothermel (1994)). . . . . . . . . . . . . . . . . . . . . 46

3.3 Grafo de chamadas de classe para a classe Symbol Table (adaptado de Harrold e Rothermel (1994)). . . . . . . . . . . . . . . . . . . . . . 46

3.4 Grafo de fluxo de controle de classe para a classe Symbol Table (adaptado de Harrold e Rothermel (1994)). . . . . . . . . . . . . . . . . . . . . . 55

3.5 Exemplo simples de programa OO para demonstrar a interação par-a-par entre as

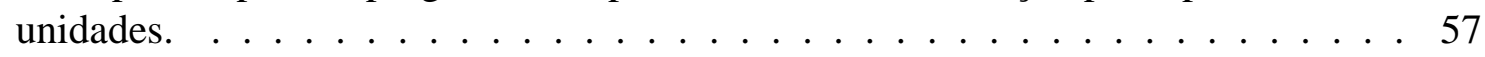

3.6 Exemplo para o teste de programas OA (adaptado de Zhao (2003)). . . . . . . . . . 61

3.7 FCFG para o c-aspecto Point ShadowProtocol e para a c-classe Point (adaptada de Zhao (2003)). . . . . . . . . . . . . . . . . . . . . 62

3.8 Exemplo de um programa OA escrito em AspectJ (adaptado de Lemos (2005)). . . 65

3.9 Grafo $\mathcal{A O D U}$ do método af fectedMet hod com a presença do aspecto AnAspect. Adaptado de Lemos (2005). . . . . . . . . . . . . . . . . . . . . 66

3.10 Grafo $\mathcal{M} \mathcal{A D U}$ do método af fectedMethod (adaptado de Lemos (2005)). . . . 68 
3.11 Código-fonte e modelo FREE da classe Account (adaptado de Xu et al. (2004)). . 70

3.12 Modelo ASM para classe Account (adaptado de Xu et al. (2004)). . . . . . . . . 71

3.13 Árvore de transição para o modelo ASM da Figura 3.12 (adaptado de Xu et al. (2004)).

4.1 Exemplo simples de programa OA para demonstrar interação par-a-par entre as unidades. . . . . . . . . . . . . . . . . . 80

4.2 Exemplo com polimorfismo e chamada de uma unidade a outra mais de uma vez. $\quad 82$

4.3 Código-fonte da aplicação simples de soma e subtração. . . . . . . . . . . . . . . 83

4.4 Grafos $\mathcal{A O D U}$ da unidade chamadora e da unidade chamada. . . . . . . . . . . . . 92

4.5 Grafo $\mathcal{P} \mathcal{W D U}$ do par de unidades. . . . . . . . . . . . . . . . . . 93

5.1 Exemplo de nomeação de um par de unidades. . . . . . . . . . . . . . . . 103

5.2 Exemplo de identificação de pares de unidades com polimorfismo. . . . . . . . . . 103

5.3 Estrutura de mapeamento. . . . . . . . . . . . . . . . . . . 107

5.4 Estrutura de registro def-uso. . . . . . . . . . . . . . . . . . . . . 107

5.5 Exemplo de criação das estruturas de mapeamento e de registro def-uso. . . . . . . . 109

5.6 Exemplo de definição de uma variável de referência. . . . . . . . . . . . . . . . 109

5.7 Exemplo mostrando o mapeamento entre as variáveis de comunicação. . . . . . . . . 110

5.8 Exemplo mostrando a cópia dos parâmetros feita pelo AspectJ antes da chamada e posterior mapeamento. . . . . . . . . . . . . . . . . . 111

5.9 Código-fonte e grafo $\mathcal{P} \mathcal{W D U}$ para o exemplo de derivação de requisitos. . . . . . 112

5.10 Estruturas criadas em $s 1, s 2, s 3, s 4$ e $s 5 \ldots \ldots \ldots \ldots \ldots \ldots$

5.11 Interseção de $C_{a}$ e $C_{b}$ e os requisitos parciais derivados. . . . . . . . . . . . 114

5.12 Interseção de $C_{c}$ e $C_{d}$ e os requisitos parciais derivados. . . . . . . . . . . . . 114

5.13 Tela principal da ferramenta JaBUTi/AJ. . . . . . . . . . . . . . . . . . 115

5.14 Exemplos de interfaces da ferramenta JaBUTi/AJ. . . . . . . . . . . . . . . . . 117

5.15 Diagrama UML das classes e aspectos da aplicação de telefonia. . . . . . . . . . . 118

5.16 Código-fonte das classes da aplicação de telefonia. . . . . . . . . . . . . . . . . 119

5.17 Código dos aspectos da aplicação de telefonia. . . . . . . . . . . . . . . . . 120

5.18 Tela principal da ferramenta JaBUTi/AJ. . . . . . . . . . . . . . . . . . . 120

5.19 Janela de seleção dos pares de unidades inter-módulo. . . . . . . . . . . . . . . . 121

5.20 Grafos $\mathcal{P} \mathcal{W D U}$ dos pares de unidades selecionados. . . . . . . . . . . . . . . 122

5.21 Classe contendo um conjunto de casos de teste da aplicação de telefonia. . . . . . . 123

5.22 Grafos $\mathcal{P W D U}$ dos pares de unidades (1) e (2) após a execução do caso de teste testChamadaLocal. . . . . . . . . . . . . . . . . 124

5.23 Grafos $\mathcal{P W D U}$ dos pares de unidades (1) e (3) após a execução do caso de teste testChamadaLongaDistancia. . . . . . . . . . . . . 125

5.24 Código-fonte do programa de ordenação de array. . . . . . . . . . . . . . . . . 126

5.25 Casos de teste criados para o teste de unidade de calcularMediaPriUltElem. 127

5.26 Classe Stub utilizada no passo A. . . . . . . . . . . . . . . . . . 128

5.27 Tela da ferramenta JUnit mostrando que os casos de teste foram executados com sucesso. . . . . . . . . . . . . . . . . . . . . 128

5.28 Grafo $\mathcal{A O D U}$ do método calcularMediaPriUltElem mostrando a cobertura alcançada para o critério todos-nós-independentes-de-exceção. . . . . . . . . 128

5.29 Casos de teste criados para o teste de unidade do método ordenarArray. . . . . 129

5.30 Grafo $\mathcal{A O D U}$ do método ordenarArray mostrando a cobertura alcançada para o critério todos-nós-independentes-de-exceção. . . . . . . . . . . . . . . . . . . . 129 
5.31 Casos de teste criados para o teste de integração de calcularMediaPriUltElem - ordenarArray. . . . . . . . . . . . . . . . . 130

5.32 Grafo $\mathcal{P W D U}$ do par de unidades calcularMediaPriUltElem - ordenarArray mostrando a cobertura alcançada para o critério todos-nós-integrados. . . . . . . 131

5.33 Casos de teste criados para o teste de unidade do adendo before. . . . . . . . . 131

5.34 Grafo $\mathcal{A O D U}$ do adendo be fore mostrando a cobertura alcançada para o critério todos-nós-independentes-de-exceção. . . . . . . . . . . . . . . . . . . . 132

5.35 Grafo $\mathcal{P W D U}$ do par de unidades calcularMediaPriUltElem - before mostrando a cobertura alcançada para o critério todos-nós-integrados. . . . . . . . . 132

5.36 Grafo $\mathcal{P} \mathcal{W D U}$ do par de unidades calcularMediaPriUltElem-ordenarArray mostrando a cobertura alcançada para o critério todos-nós-integrados. . . . . . . . 133 



\section{Lista de Tabelas}

2.1 Os Tipos Primitivos da linguagem Java. . . . . . . . . . . . . . . . . . . . 8

2.2 Os especificadores de acesso da linguagem Java. . . . . . . . . . . . . . . . . . . 11

2.3 Os modificadores da linguagem Java. . . . . . . . . . . . . . . . . . . . . . 11

2.4 Instruções invokevirtual e invokestatic. . . . . . . . . . . . . . . 20

2.5 Categorias de pontos de junção do AspectJ (adaptado de Kiczales et al. (2001b)). . 25

2.6 Mapeamento entre as categorias de pontos de junção e a sintaxe dos conjuntos de junção correspondente. . . . . . . . . . . . . . . . . 26

3.1 Tabela de caminhos def-uso (adaptada de Linnenkugel e Müllerburg (1990)). . . 44

3.2 Relação entre as fases de teste e o teste de programas OO (adaptada de dos Santos Domingues (2001)) . . . . . . . . . . . . . . . . . 45

3.3 Diferentes classes de instruções de bytecode (Vincenzi, 2004) . . . . . . . . . . . 49

3.4 Pares de unidades identificados no exemplo da Figura 3.5 . . . . . . . . . . . . . 57

3.5 Características apresentadas pelas ferramentas de teste OO e OA (adaptada de Vincenzi (2004)) . . . . . . . . . . . . . . . . . . . . . 77

4.1 Pares de unidades do exemplo da Figura 4.1 e que tipo de interação eles representam. 80

4.2 Pares de unidades do exemplo da Figura 4.1 e o tipo de teste estrutural de integração par-a-par eles representam. . . . . . . . . . . . . . . . . . . . 81

4.3 Pares de unidades identificados no exemplo da Figura 4.2. . . . . . . . . . . . . . 82

4.4 Identificação dos pares de unidades que se relacionam no exemplo da Figura 4.3. $\quad 83$

4.5 Exemplos de sentenças Java genéricas e suas correspondentes definições e usos. . . 87

4.6 Exemplos de sentenças da aplicação de soma e subtração e suas correspondentes definições e usos. . . . . . . . . . . . . . . . . . . . . . . 88

4.7 Conjuntos de requisitos derivados pelos critérios de teste estrutural de integração

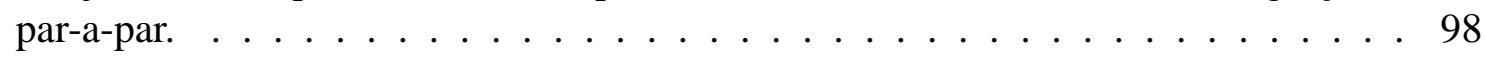

5.1 Pares de unidades identificados no exemplo da Figura 5.2. . . . . . . . . . . . 103

5.2 Identificação das variáveis presentes no método efetuarCalculos conforme são vistas no código-fonte e na ferramenta JaBUTi/AJ. . . . . . . . . . . . . . . . . . . . . . . . . . .

5.3 Pares de unidades inter-módulo selecionados. . . . . . . . . . . . . . . . . 121

5.4 Requisitos de teste para os critérios de integração do par de unidades (1). . . . . 122

5.5 Requisitos de teste para os critérios de integração do par de unidades (2). . . . . . 122

5.6 Requisitos de teste para os critérios de integração do par de unidades (3). . . . . . 122

5.7 Cobertura dos requisitos do par de unidades (1) após a execução do caso de teste testChamadaLocal. . . . . . . . . . . . . . . 123 
5.8 Cobertura dos requisitos do par de unidades (2) após a execução do caso de teste testChamadaLocal. . . . . . . . . . . . . . . . . . . . 124

5.9 Cobertura dos requisitos do par de unidades (3) após a execução do caso de teste test ChamadaLocal. . . . . . . . . . . . . . . . . . . . . 124

5.10 Cobertura dos requisitos do par de unidades (1) após a execução do caso de teste testChamadaLongaDistancia. . . . . . . . . . . . 125

5.11 Cobertura dos requisitos do par de unidades (3) após a execução do caso de teste testChamadaLongaDistancia. . . . . . . . . . . . . 125 


\subsection{Contextualização}

No início da década de 70, o crescimento da demanda e da complexidade de desenvolvimento dos sistemas de software fez com que os paradigmas e linguagens de programação evoluíssem no sentido de permitir a decomposição dos sistemas em partes gerenciáveis de modo a diminuir a complexidade de desenvolvimento e aumentar a reusabilidade, flexibilidade e compreensão dos sistemas (Parnas, 1972). Essa evolução na tecnologia de programação tem contribuído para alcançar uma clara separação dos interesses (concerns) de um sistema. Um interesse pode ser definido como uma funcionalidade ou requisito que o sistema deve ter ou satisfazer (Gradecki et al., 2003) e pode indicar tanto um requisito funcional quanto não funcional (Elrad et al., 2001b). Os requisitos funcionais são definidos como funções ou atividades que o sistema faz, enquanto que os requisitos não funcionais expressam condições de comportamento e restrições que são válidas para qualquer sistema, como por exemplo, tratamento de exceções, segurança e persistência de dados (Cysneiros, 1997; Chung et al., 1999).

Atualmente, o paradigma de programação dominante é o orientado a objetos (POO), que é um paradigma de desenvolvimento de software baseado na composição e interação entre diversas unidades chamadas objetos. A idéia desse paradigma de programação é combinar em uma única entidade (classe) tanto os dados quanto as funções que operam sobre os dados. Isso permite uma melhor separação dos interesses de um sistema. Entretanto, constata-se a existência de certos interesses que não se encaixam em módulos individuais, mas ficam espalhados por várias unidades do software. Assim, verifica-se que tal técnica não permite a clara separação de alguns interesses, geralmente não funcionais (também chamados de interesses transversais). 
Para tentar resolver esses problemas, na segunda metade dos anos 90 foi concebida a programação orientada a aspectos (POA), que oferece mecanismos para a construção de programas em que os interesses transversais ficam isolados e separados dos interesses funcionais, ao invés de espalhados pelo sistema. Dentre as linguagens mais conhecidas que apóiam a programação OA pode-se citar a linguagem AspectJ (The AspectJ Team, 2006). A POA não tem o intuito de ser um novo paradigma de programação, mas uma técnica para ser utilizada em conjunto com as atuais linguagens de programação (Elrad et al., 2001a), possibilitando a construção de sistemas com maior qualidade, melhor arquitetura, facilitando a manutenção dos diferentes interesses e a legibilidade do código.

Contudo, a simples utilização da POA não evita que defeitos sejam introduzidos ao longo do processo de desenvolvimento de software. Para evitar isso é necessário realizar um conjunto de atividades agregadas sob o nome de Garantia de Qualidade de Software, dentre elas a atividade de Teste de Software. A atividade de teste de software tem finalidade de encontrar defeitos presentes em um programa. Ela é realizada em três fases: teste de unidade, teste de integração e teste de sistema (Pressman, 2001). O teste de unidade concentra esforços na menor unidade do programa, ou seja, um procedimento, um método ou uma classe. Já o teste de integração tem a finalidade de conduzir testes para descobrir defeitos associados às interfaces entre as unidades. Por fim, o teste de sistema visa exercitar o sistema completo.

Um ponto crucial na atividade de teste é o projeto e/ou a avaliação da qualidade de um determinado conjunto de casos de teste. Para selecionar e avaliar conjuntos de casos de teste é fundamental a utilização de critérios de teste que forneçam indicações de quais casos de teste devem ser utilizados para aumentar as chances de revelar defeitos em um programa. Em geral, os critérios de teste de software são estabelecidos a partir de três técnicas: a funcional, a estrutural e a baseada em defeitos (Adrion et al., 1982; Zhu et al., 1997). A técnica funcional (ou caixa-preta) utiliza a especificação de requisitos do programa para gerar casos de teste que serão empregados sem se importar com detalhes de implementação; a técnica estrutural (ou caixa-branca) gera os casos de tese a partir do conhecimento das características e detalhes internos de implementação; e, na técnica baseada em defeitos, os casos de teste são oriundos do conhecimento de defeitos típicos inseridos durante o processo de desenvolvimento do software.

A técnica estrutural tem sido uma das mais utilizadas. As primeiras abordagens de teste estrutural foram propostas para o paradigma procedimental. Uma delas foi proposta por Frankl e Weyuker (1988), que propuseram uma abordagem de teste estrutural de unidade. Já Linnenkugel e Müllerburg (1990) e Jin e Offutt (1998) apresentaram uma abordagem de teste estrutural de integração. Muitas dessas abordagens de teste para programas procedimentais foram posteriormente adaptadas para o desenvolvimento de abordagens cujo enfoque é o teste estrutural de programas OO. Harrold e Rothermel (1994) propuseram uma abordagem que envolve tanto o teste estrutural de unidade quanto o teste estrutural de integração OO. Baseado na abordagem de Harrold e Rothermel (1994), outras abordagens de teste estrutural OO foram propostas, como as apresentadas por Vincenzi (2004) e (Alexander e Offutt, 2004). Com o surgimento dos programas OA, sugiram 
algumas abordagens de teste estrutural próprias para o paradigma OA, como as apresentadas por Zhao (2002) e Lemos (2005).

A abordagem de teste estrutural de integração par-a-par (pairwise) (Paradkar, 1996; Vilela et al., 1999) é uma abordagem especial de teste cuja finalidade é testar separadamente a interação entre duas unidades que se relacionam. Para programas OO este tipo de teste envolve testar a interação entre os pares de métodos. Já para programas OA, o teste estrutural de integração para-par deve considerar os seguintes pares de unidades: método-método, método-adendo, adendométodo e adendo-adendo.

\subsection{Motivação}

Alguns pesquisadores propuseram abordagens de teste estrutural de programas OO e OA, porém poucas iniciativas apontam para o teste estrutural de integração, principalmente para programas OA. O teste de integração é de fundamental importância, pois o fato da lógica e funcionalidade das unidades apresentarem indícios de conformidade com as especificações e ausência de defeitos, não implica no seu correto funcionamento quando integradas.

Segundo Alexander e Offutt (2004), no paradigma de programação procedimental a complexidade do teste residia na unidade. A mudança para paradigma de programação orientado a objetos fez com que essa complexidade passasse a residir no modo como as unidades estão conectadas, ou seja, em programas OO o enfoque maior deve ser dado ao teste de integração. Além disso, características particulares de programas $\mathrm{OO}$, tais como herança, polimorfismo e acoplamento dinâmico (dynamic binding), tornam a atividade de teste de programas OO mais trabalhosa.

O mesmo vale para o paradigma de programação Orientada a Aspectos. A POA introduz novas construções e conceitos aos já conhecidos das linguagens de programação. Tais novidades fazem com que o processo de teste de programas OA seja mais difícil e complexo do que o processo de teste para programas implementados com paradigma OO, por exemplo. Segundo Alexander et al. (2004) isso ocorre pelos seguintes motivos: os aspectos não têm identidade ou existência independente, sendo dependentes do contexto de outras classes; os aspectos dependem da representação e implementação interna das classes em que estão combinados; as dependências de controle e dados não são facilmente compreensíveis a partir do código-fonte dos aspectos ou classes; o comportamento emergente do programa, em que o defeito pode estar na implementação da classe ou do aspecto, ou pode ser um efeito colateral de uma particular ordem de combinação de múltiplos aspectos.

Com isso, e levando em conta também o fato de poucos trabalhos de pesquisa terem sido propostos sobre esse tema, observa-se que é uma área de pesquisa interessante a ser explorada. Essa é uma das linhas de trabalho do Laboratório de Engenharia de Software do ICMC-USP. O trabalho proposto será uma continuação do trabalho desenvolvido por Lemos (2005) que propôs uma abordagem de teste estrutural de unidade para programas OA escritos em AspectJ. 


\subsection{Objetivos}

O objetivo deste trabalho é propor uma abordagem de teste estrutural de integração par-a-par para programas orientados a objetos e orientados a aspectos. Para isso, modelos e critérios de fluxo de controle e fluxo de dados anteriormente propostos são revisados e adaptados para essa nova abordagem. Adicionalmente, pretende-se implementar essa abordagem em uma ferramenta chamada JaBUTi/AJ. A ferramenta JaBUTi/AJ foi estendida por Lemos (2005) a partir da ferramenta JaBUTi (Vincenzi, 2004) para apoiar o teste de unidade de programas OA escritos em AspectJ.

\subsection{Organização}

No Capítulo 2 é apresentado uma introdução à programação orientada a objetos e orientada a aspectos. Além disso, a linguagem Java e a linguagem AspectJ são abordadas. No Capítulo 3 é discutido sobre teste de software, dando enfoque ao teste estrutural de programas orientados a objetos e orientados a aspectos. No Capítulo 4 é proposta uma abordagem de teste estrutural de integração par-a-par para programas OO e OA baseados na linguagem Java e AspectJ. No Capítulo 5 é descrita a implementação da abordagem proposta na ferramenta JaBUTi/AJ e são discutidos alguns exemplos de uso. Finalmente, no Capítulo 6 são apresentadas as conclusões finais, contribuições e pesquisas futuras. 


\section{CAPÍTULO}

\section{2}

\section{Uma Introdução a Programação 00 e}

OA

\subsection{Considerações Iniciais}

Neste capítulo é apresentada uma revisão bibliográfica sobre os paradigmas de programação orientado a objetos e orientado a aspectos. Na Seção 2.2 faz-se uma introdução à programação orientada a objetos e à linguagem Java. Na Seção 2.3 são abordados o paradigma de programação orientada a aspectos e a linguagem AspectJ. Por fim, na Seção 2.4 são apresentadas as considerações finais.

\subsection{Programação Orientada a Objetos}

A idéia básica da Programação Orientada a Objetos (POO) é simular a realidade, criando uma abstração do cotidiano, na tentativa de representar as características relevantes dos objetos envolvidos no sistema que se tenta simular. Esses objetos podem enviar e receber mensagens e reagir a mensagens recebidas. Assim, a POO introduz uma abordagem em que o programa é visto como uma coleção de objetos que se relacionam. Além do conceito de objeto, a POO tem como alicerces os conceitos de classe, encapsulamento, herança e polimorfismo (Kung et al., 1995).

Uma classe é uma entidade caracterizada por um conjunto de dados e também pelas operações que podem ser realizadas sobre estes dados. Ao conjunto de dados dá-se o nome de atributos e às operações dá-se o nome de métodos. Um objeto é uma instância de uma classe criado em tempo 
de execução. Cada objeto tem seu próprio valor para cada atributo, mas compartilha os nomes de atributos e métodos com outras instâncias da mesma classe.

O termo encapsulamento (também chamado de ocultação de informações) consiste na separação dos aspectos internos e externos de um objeto de tal forma que os dados internos sejam acessados ou modificados somente pela interface provida pelo encapsulamento, promovendo a proteção e ocultação da estrutura interna de cada objeto. O encapsulamento protege os dados contra usos arbitrários que fujam aos objetivos propostos pelo projeto da classe que deu origem ao objeto.

O conceito de herança é o mecanismo pelo qual uma classe pode estender outra classe. A classe criada (subclasse ou classe derivada) automaticamente herda todas as variáveis e métodos da classe já existente (superclasse), além de definirem suas propriedades específicas. O mecanismo de herança permite ainda que a subclasse inclua ou sobreponha métodos da superclasse. O mecanismo de herança é recursivo, permitindo criar-se uma hierarquia de classes. Nos níveis mais altos da hierarquia estão características comuns a todos os objetos desta classe, enquanto nos níveis inferiores estão especializações das classes superiores.

O termo polimorfismo, originário do grego, significa "muitas formas". No que se refere à POO, é o nome dado à capacidade de uma mesma operação ser implementada por um ou mais métodos. Assim, permite-se que um mesmo identificador de método seja utilizado em mais de uma classe e, ainda, assuma implementações diferentes em cada uma delas. A escolha de qual implementação será executada é feita em tempo de execução por meio da técnica de "late binding" ou "run-time binding".

\subsubsection{Linguagens Orientadas a Objetos: Uma Introdução a Java}

As primeiras linguagens de programação, as linguagens montadoras, somente possibilitavam que os códigos dos programas fossem escritos em um nível muito baixo de abstração que se baseavam em instruções de máquina que manipulavam os conteúdos dos locais de memória (operandos). Nessas linguagens, o entendimento e o processo de depuração dos programas eram muito difíceis. Um grande avanço ocorreu com o surgimento das primeiras linguagens de alto nível nas quais as instruções de máquina passaram a ser chamadas de sentenças e os operandos de constantes, variáveis e estruturas de dados. Nessas linguagens, os programas passaram a ser representados como um conjunto de variáveis e um conjunto de procedimentos que manipulam essas variáveis. As linguagens de programação que dão apoio a essa representação são conhecidas como linguagens de programação procedimentais (ou imperativas), por exemplo: Fortran, Pascal e C.

Apesar das linguagens procedimentais permitirem a representação de tipos abstratos de dados (TADs), que são abstrações de mais alto nível de variáveis e procedimentos, elas possuem algumas deficiências, por exemplo: se dois TADs são similares, mas não idênticos, não existe um modo de expressar essa similaridade nessas linguagens. Essa deficiência foi parcialmente corrigida pelas linguagens de programação orientadas a objetos, que permitem que similaridades entre tipos abstratos de dados sejam expressas por meio de relações de herança (Capretz, 2003). 
No final da década de 60, a linguagem Simula67 já introduzia conceitos hoje encontrados nas linguagens orientadas a objetos. Em meados de 1970, o Centro de Pesquisa da Xerox (PARC) desenvolveu a linguagem Smalltalk, a primeira totalmente orientada a objetos. No início da década de 80, a AT\&T lançou a Linguagem C++, uma evolução da linguagem C em direção à orientação a objetos. Atualmente, a grande maioria das linguagens incorpora características de orientação a objetos, como por exemplo, a linguagem Java.

Quando se fala sobre Java é importante distinguir as quatro tecnologias inter-relacionadas: a Linguagem de Programação Java, o formato de arquivo class do Java, a Java API (Application Programming Interface) e a Máquina Virtual Java (Venners, 1997). A linguagem de programação Java é a linguagem nos quais aplicações Java (applets, servlets, etc) são escritas. Diferentemente de outras linguagens de programação que compilam ou interpretam um programa para que ele seja executado, na linguagem Java os programas são compilados e interpretados. O compilador inicialmente transforma o código-fonte do programa (arquivos com extensão .java) em arquivos class do Java (com extensão .class). Esses arquivos são então interpretados pela Máquina Virtual Java (JVM). Na execução do programa, alguns recursos do sistema, tais como entrada e saída (I/O), que são implementados nas classes da Java API, são acessados. A Figura 2.1 apresenta uma visão geral do relacionamento entre as quatro tecnologias.

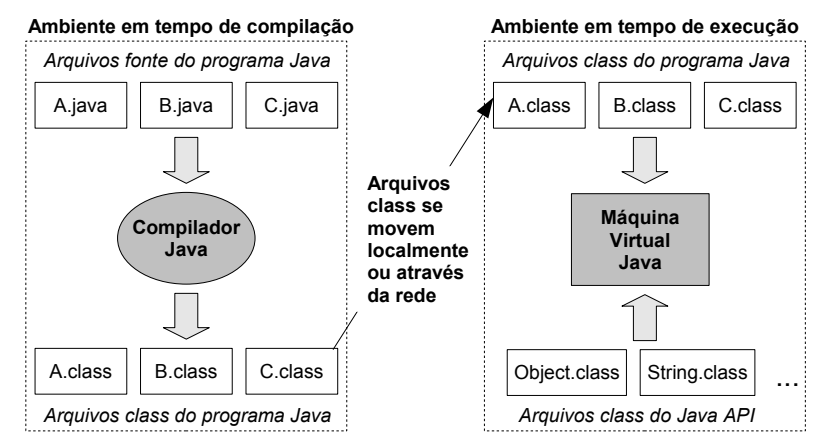

Figura 2.1: O ambiente de programação Java (adaptada de Venners (1997)).

\section{A Linguagem de Programação Java}

A linguagem de programação Java foi desenvolvida pela Sun Microsystems no início da década de 90. Ela pode ser caracterizada como: orientada a objetos, distribuída, independente de plataforma e multitarefa (Microsystems, 2006). A seguir são apresentados alguns conceitos e terminologias utilizadas nessa linguagem.

\section{Tipos Primitivos e de Referência}

Os tipos da linguagem Java são divididos em duas categorias: tipos primitivos e tipos de referência. Os tipos primitivos incluem: um tipo booleano, um tipo caractere, quatro tipos inteiros e dois tipos de ponto flutuante. A Tabela 2.1 resume os tipos de dados primitivos. 
Tabela 2.1: Os Tipos Primitivos da linguagem Java.

\begin{tabular}{|l|l|c|c|}
\hline Tipo & Conteúdo & Valor default & Tamanho \\
\hline \hline boolean & true ou false & false & 1 bit \\
\hline char & Unicode caractere & $\backslash \mathrm{u} 0000$ & $16 \mathrm{bits}$ \\
\hline byte & Inteiro sinalizado & 0 & $8 \mathrm{bits}$ \\
\hline short & Inteiro sinalizado & 0 & $16 \mathrm{bits}$ \\
\hline int & Inteiro sinalizado & 0 & $32 \mathrm{bits}$ \\
\hline long & Inteiro sinalizado & 0 & $64 \mathrm{bits}$ \\
\hline float & ponto flutuante IEEE 754 & 0.0 & $32 \mathrm{bits}$ \\
\hline double & ponto flutuante IEEE 754 & 0.0 & $64 \mathrm{bits}$ \\
\hline
\end{tabular}

O tipo boolean (booleano) representa dois estados booleanos (verdadeiro e falso) representados pelas palavras reservadas true e false.

O tipo char representa caracteres Unicode.

Os tipos inteiros são byte, short, int, e long, cujos valores são 8 bits, 16 bits, 32 bits, e 64 bits, respectivamente. Representam valores inteiros em notação de complemento de dois.

Os tipos de ponto flutuante são float e double, cujos valores são 32 bits e 64 bits respectivamente, e representam números reais. Além dos possíveis valores numéricos, os tipos de ponto flutuante podem assumir também os seguintes valores especiais: infinito positivo e negativo, zero e um valor especial Not-a-Number $(\mathrm{NaN})$ que é usado para representar o resultado de certas operações, tal como divisão por zero.

Cada tipo de dados primitivo possui uma classe correspondente (wrapper class): Boolean, Character, Byte, Short, Integer, Long, Float e Double.

Quanto aos tipos de referência, existem três categorias de tipos, todos de 32 bits: de array, de classe e de interface. Os três tipos possuem valores que são referências a objetos criados dinamicamente, ou seja: um valor do tipo de classe referencia uma instância de classe; um valor do tipo de array referencia um array; por fim, um valor do tipo de interface referencia uma instância de classe que implementa a interface. Um outro valor de referência é o valor nulı, que indica que a variável não referencia nenhum objeto e também é utilizado como valor default quando uma variável de referência não recebe nenhum valor inicial.

Além dos tipos de dados apresentados anteriormente, Java possui um tipo de dados para trabalhar com textos que é o tipo String. Por ser uma classe, o tipo String não é considerado um tipo primitivo da linguagem.

\section{Literais, Expressões e Sentenças}

Literais são valores que aparecem diretamente no código Java. Eles incluem números inteiros e pontos flutuantes, caracteres com aspas simples, strings de caracteres com aspas duplas e as palavras reservadas true, false e null. Os seguintes exemplos são todos literais: 1, 1.0, 'a', "one" e true. 
Uma expressão é uma estrutura em Java que pode ser simples ou complexa. Uma expressão é dita simples quando consiste apenas de literais e variáveis, por exemplo: 1 é um literal inteiro; true é um literal booleano; e soma é uma variável.

Por outro lado, uma expressão é considerada complexa quando se utiliza de operadores para combinar expressões simples. O seguinte exemplo combina em uma expressão complexa de atribuição o operador "=" com duas expressões simples, uma variável e um literal inteiro: soma = 10; Os operadores podem estar presentes também em expressões de alto nível de complexidade, como no exemplo a seguir:

$$
\text { sum }=1+2+3 * 1.2+(4+8) / 3.0
$$

Uma sentença (statement) ou instrução é um comando único executado pelo interpretador Java. $\mathrm{O}$ interpretador executa uma sentença por vez, seguindo a ordem em que foi escrita. Entretanto, existem algumas sentenças conhecidas como sentenças de fluxo de controle, tais como condicionais (if e switch) e laços (for, while e do-while) que alteram a ordem de execução normal.

\section{Arrays}

Um array (ou arranjo) é um tipo especial de objeto que armazena zero ou mais valores. Esses valores são armazenados nos elementos do array, que são variáveis não-nomeadas referidas por sua posição ou índice. O tipo de um array é caracterizado pelo tipo de seu elemento e todos os elementos de um array devem ser daquele tipo, por exemplo: pode-se ter um array de inteiros, ou um array de Strings, mas não se pode ter um array que contenha ambos os objetos Strings e inteiros. A sintaxe para a declaração de arrays é a seguinte:

<Type> [ ] <ArrayName>;
<Type> <ArrayName> [ ]

A declaração de um array inicia com a indicação do tipo do array (<Type>) que pode ser do tipo primitivo ou de referência. Os colchetes ('[' e ']') podem ser posicionados antes ou após o identificador do array (<ArrayName>). Por exemplo: float [ ] vetor;

A declaração, conforme apresentada, não é suficiente para permitir o armazenamento de informações nos elementos que constituem o array. Para isso, é necessário alocar dinamicamente espaço em memória para tais elementos, uma vez que o identificador do array é apenas uma referência a posição de memória onde os elementos do array são armazenados. A sintaxe para a declaração e alocação de memória de um array é a seguinte:

<Type> [] <ArrayName> = new <Type> [ <Number> ];

O operador new deve ser utilizado para a criação da instância desse objeto em memória e o tamanho do array deve ser especificado como um número (<Number $>)$ inteiro não-negativo entre os colchetes. Por exemplo: float [] vetor = new float [10];

Quando um array é criado pelo operador new todos os seus elementos são iniciados com valores default dependendo do tipo que possuem. Pode-se também realizar a declaração de um array de modo simultâneo com sua iniciação: 
float [] vetor $=\{5.6,2.45,56.112\}$

$\mathrm{O}$ acesso a elementos individuais de um array é especificado por meio de um índice inteiro. Se um array for declarado com $\mathrm{N}$ elementos, então as posições que estão disponíveis são as de 0 a $\mathrm{N}$ - 1. No exemplo abaixo, a variável x recebe o valor da sexta posição do vetor:

float $\mathrm{x}=$ vetor [5];

A linguagem Java não possui uma declaração específica para a definição de matrizes ou vetores multidimensionais. Para isso, tais estruturas devem ser declaradas como um array de arrays. O exemplo abaixo mostra a criação de uma matriz de três linhas e três colunas que pode ser entendido como a criação de três arrays, cada um com três elementos.

int matriz[][] = new int[3][3]

\section{Classes e Objetos}

Uma classe é um modelo usado para definir vários objetos com características semelhantes. Um programa é constituído de uma classe ou de um conjunto de classes. Os elementos básicos de uma classe são chamados membros da classe e podem ser divididos em duas categorias:

- atributos, que especificam o estado da classe.

- métodos, que especificam os mecanismos pelos quais a classe ou um objeto desta classe pode operar.

Um objeto é uma instância de uma classe criado em tempo de execução. Para que seja possível acessar os atributos e os métodos de um objeto (para isso, utiliza-se o operador ponto “."), é preciso atribuir uma referência ao objeto. A declaração e a criação um novo objeto instância da classe $<$ ClassName $>$, que será referenciado pela variável <VariableRef $>$ segue a seguinte sintaxe:

$<$ ClassName $><$ VariableRef $>$ new $<$ ClassName $>$ ( <ParamList $>$ );

A memória utilizada para armazenar um objeto é dinamicamente alocada no heap quando o objeto é criado e esta é automaticamente liberada pelo Garbage-Collector quando o objeto não é mais necessário.

Algumas palavras reservadas servem para ampliar ou restringir o acesso a um membro de uma classe. Elas são acrescentadas na declaração do membro da classe e funcionam como especificadoras de acesso. A linguagem Java possui os seguintes especificadores de acesso: public, private e protected que são discutidos na Tabela 2.2. A omissão do especificador na declaração define um membro default ${ }^{1}$.

\footnotetext{
${ }^{1}$ default não é uma palavra reservada; ele é simplesmente um nome dado para um nível de acesso quando nenhum especificador de acesso é informado.
} 
Tabela 2.2: Os especificadores de acesso da linguagem Java.

\begin{tabular}{|l|l|}
\hline Especificador de acesso & Descrição \\
\hline \hline public & $\begin{array}{l}\text { o membro é acessível dentro da classe em que foi declarado e também em } \\
\text { todas as classes de quaisquer pacotes da aplicação. }\end{array}$ \\
\hline private & o membro é acessível somente dentro da classe em que foi declarado. \\
\hline protected & $\begin{array}{l}\text { o membro é acessível dentro da classe em que foi declarado, em todas as } \\
\text { classes que estão no mesmo pacote em que a sua classe foi definida e em } \\
\text { todas as subclasses que estejam ou não no mesmo pacote. }\end{array}$ \\
\hline default & $\begin{array}{l}\text { o membro é acessível tanto dentro da classe em que foi declarado como em } \\
\text { todas as classes que estão no mesmo pacote em que a sua classe foi definida. }\end{array}$ \\
\hline
\end{tabular}

\section{Declaração de Classe}

A sintaxe para a declaração de classe é a seguinte:

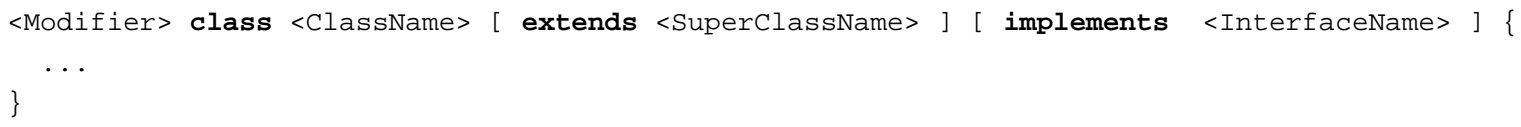

A declaração de uma classe inicia-se, opcionalmente, com a inclusão de modificadores ( $<$ Modifier>): public e/ou abstract ou final, mas não simultaneamente por abstract e final (estes modificadores são discutidos na Tabela 2.3). Em seguida é inserida a palavra reservada class sucedida de um identificador <ClassName>.

Tabela 2.3: Os modificadores da linguagem Java.

\begin{tabular}{|l|l|l|}
\hline Modificador & Uso & Descrição \\
\hline \hline \multirow{2}{*}{ abstract } & Classe & define classes abstratas \\
\cline { 2 - 3 } & Método & $\begin{array}{l}\text { utilizado quando se deseja declarar um método sem, contudo, especificar } \\
\text { seu corpo. Isto funciona como uma espécie de lembrete para que alguma } \\
\text { classe derivada complete a declaração fornecendo um corpo. }\end{array}$ \\
\hline natival & Atributo & $\begin{array}{l}\text { faz com que o atributo seja considerado uma constante. Após a atribuição } \\
\text { inicial, seu valor não poderá ser alterado. }\end{array}$ \\
\cline { 2 - 4 } & Classe & $\begin{array}{l}\text { define uma classe que não pode ser derivada, isto é, não pode ser } \\
\text { superclasse de nenhuma subclasse. }\end{array}$ \\
\cline { 2 - 4 } & Método & faz com que não seja permitida a sobrecarga ou sobrescrita do método. \\
\hline static & Aétodo & $\begin{array}{l}\text { utilizado para designar métodos implementados em outras linguagens, como } \\
\text { por exemplo, C++. }\end{array}$ \\
\cline { 2 - 4 } & Método & define um atributo estático. \\
\hline synchrone um método estático. \\
\hline transient & Método & $\begin{array}{l}\text { utilizado para impedir que dois ou mais métodos que executam concorrente- } \\
\text { mente acessem os dados de uma classe ao mesmo tempo. }\end{array}$ \\
\hline volatile & Atributo & $\begin{array}{l}\text { utilizado para evitar que um certo atributo seja salvo durante uma } \\
\text { operação de serialização de objetos (object serialization). }\end{array}$ \\
\hline
\end{tabular}

A declaração de uma classe pode incluir a palavra reservada extends sucedida de um outro identificador (<SuperClassName>). Isso cria uma relação de herança entre as classes, ou seja, a classe que está sendo declarada (também chamada de subclasse ou classe derivada) é derivada de uma outra classe (chamada de superclasse ou classe-base) que a precede na relação de herança. Além disso, pode ocorrer a inclusão da palavra reservada implement s seguida de um identificador (<InterfaceName〉) ou mais identificadores (separados por vírgulas). Isso indica que a classe 
que está sendo declarada implementa a(s) interface(s) incluída(s) na sua declaração. A declaração de uma interface e discutida mais adiante nesta seção.

As classes que incluem o modificador abst ract na sua declaração são chamadas de classes abstratas. Toda classe abstrata possui ao menos um método abstrato (ou seja, um método que não possue implementação). As classes abstratas são consideradas classes incompletas, pois dependem da definição de uma classe derivada dela para existirem. Por exemplo, a classe OperacaoMatematica definida na Figura 2.2 é uma classe abstrata implementada pelas subclasses Soma e Subtracao.

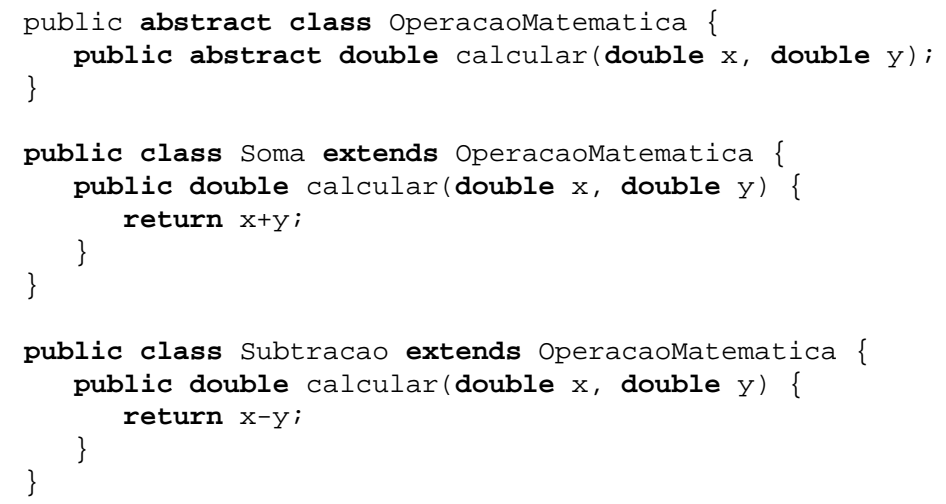

Figura 2.2: Classe abstrata OperacaoMatematica.

\section{Declaração de Atributos}

Uma classe pode possuir dois tipos de atributos: atributos estáticos (ou atributos de classe) e atributos de instância. Um atributo estático é um atributo associado com a classe. Já um atributo de instância é um atributo é associado com a instância da classe. Por padrão da linguagem, um atributo é declarado como de instância. Para declarar um atributo estático, acrescenta-se a palavra reservada static. A sintaxe para a declaração de atributos é a seguinte:

<AccessSpecifier> <Modifier > <Type> <FieldName> [ = <Expression> ] ;

A declaração de um atributo inicia pela indicação do tipo de dado (<Type $\rangle)$ que pode ser do tipo primitivo ou de referência, seguido pelo identificador do atributo ( $\langle$ FieldName $\rangle$ ) e sucedido, opcionalmente, por uma expressão (<Expression>) que é utilizada para atribuir um valor inicial para o atributo. Se nenhum valor inicial é atribuído, o atributo é iniciado com um valor default que depende do tipo que possui. A declaração pode ser precedida por uma especificação de acesso (<AccessSpecifier >) e por modificadores (<Modifier>). Os especificadores de acesso são apresentados na Tabela 2.2. Quanto os modificadores eles podem ser: final, volatile, static ou transient que são discutidos na Tabela 2.3. Na Figura 2.3 estão apresentados alguns exemplos de declarações de atributos em uma classe. 


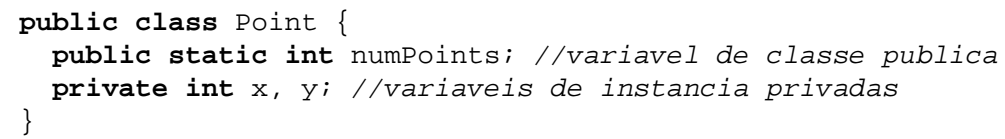

Figura 2.3: Exemplos de declaração de atributos.

\section{Declaração de Métodos}

Uma classe pode possuir dois tipos de métodos: métodos estáticos (ou métodos de classe) e métodos de instância. Um método estático está associado com a classe e só pode acessar os atributos estáticos da classe. Já um método de instância está associado com a instância da classe e pode acessar tanto os atributos de instância quanto os estáticos declarados na classe. Por padrão, um método é declarado como de instância. Para declarar um método estático, adiciona-se a palavra reservada static na declaração. A sintaxe de declaração de métodos é a seguinte:

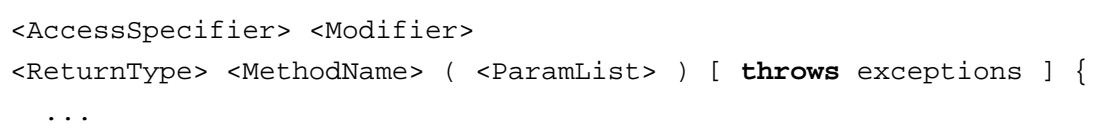

A declaração de um método inicia-se informando o tipo de dado de retorno do método $(<\mathrm{Re}-$ turnType>), que pode ser um tipo primitivo ou de referência, ou ainda pode ser void (situação em que o método não retorna valor algum). Em seguida, deve-se indicar o nome do método ( $<$ MethodName>) sucedido por uma lista de parâmetros (<ParamList>) separados por vírgulas, e colocados entre parênteses, “(" e ")". Tal lista pode também ser nula. A declaração pode ser precedida por uma especificação de acesso (<AccessSpecifier>) ou de modificadores (<Modifier>). Os especificadores de acesso são apresentados na Tabela 2.2. Quanto aos modificadores, eles podem ser: final, abstract, static, native ou transient. Eles que são descritos na Tabela 2.3.

Um construtor é um tipo especial de método. Os construtores possuem o mesmo nome da classe em que são definidos e determinam como um objeto é iniciado quando ele é criado. Toda classe em Java tem ao menos um construtor. Se não houver uma definição explícita de um construtor na classe, Java fornece um construtor default que não tem argumentos e que executa uma iniciação padrão do objeto. A sintaxe de declaração de um construtor é a seguinte:

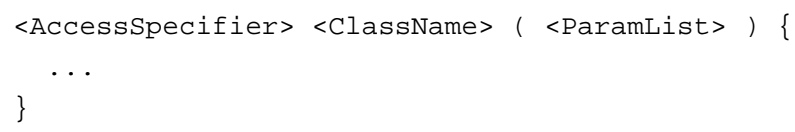

No corpo de um método de instância ou construtor, a palavra reservada this é uma referência para o objeto corrente - o objeto cujo método ou construtor está sendo chamado. Assim, com o this é possível referir-se a qualquer atributo de instância do objeto corrente. Na Figura 2.4 são apresentados alguns exemplos de declarações de métodos e construtores e usos do this.

Em uma mesma classe podem existir métodos que possuem o mesmo nome e o mesmo tipo de retorno, mas que diferem pelo número e/ou pelos tipos dos argumentos. Esta técnica é chamada sobrecarga (overloading) de métodos. A decisão sobre qual deles é executado depende do número 


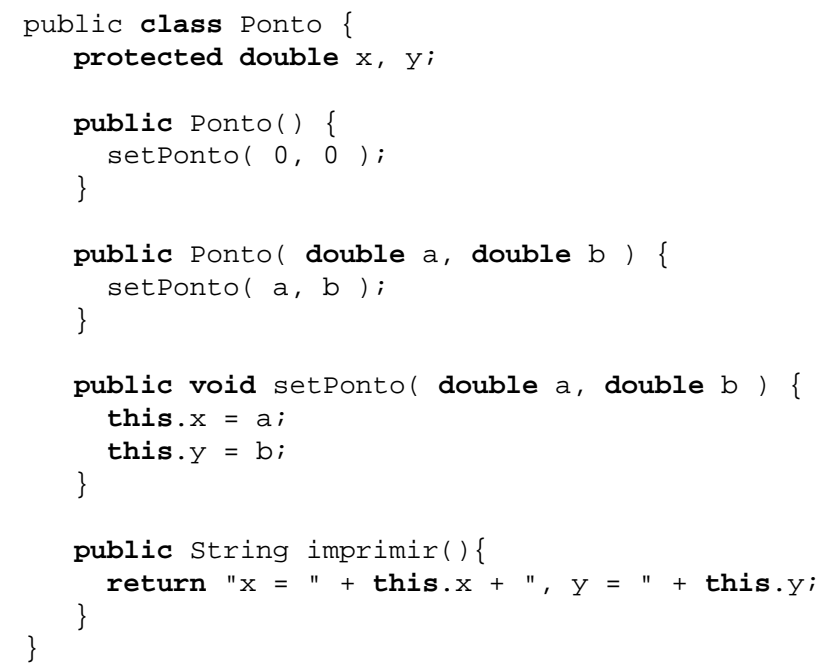

Figura 2.4: Exemplo com declarações de métodos e construtores e uso do this.

e/ou dos tipos dos argumentos passados na chamada do método e pode ser tomada em tempo de compilação (static binding ou early binding). Um exemplo de sobrecarga pode ser observado na Figura 2.4, onde existem dois construtores para a classe Ponto:

public Ponto() \{ \}

public Ponto( double a, double b ) \{\}

Quando uma classe define um método de instância usando o mesmo nome, mesmo tipo de retorno, igual número e mesmos tipos de parâmetros de um método presente em sua superclasse, esse método sobrescreve o método da superclasse. Esta técnica é chamada sobrescrita (overriding) de métodos. Considere o código da Figura 2.5, em que é mostrada a definição da classe Circulo que estende a classe Ponto da Figura 2.4.

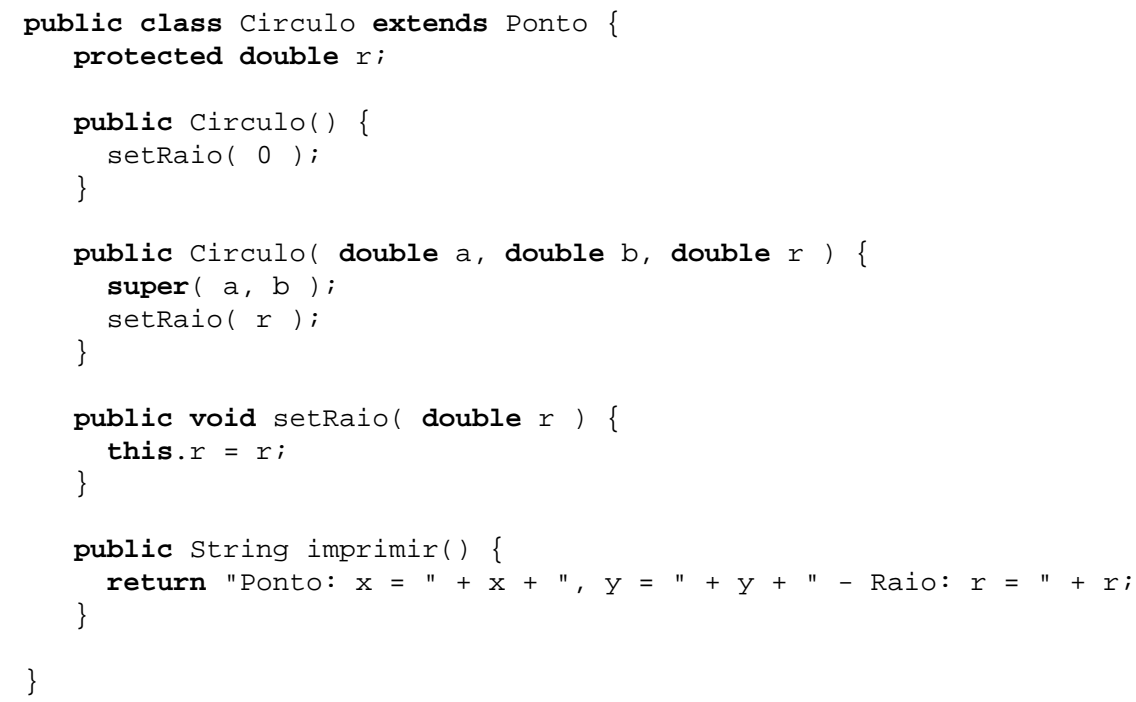

Figura 2.5: Exemplo de sobrescrita de métodos. 
Observe que na classe Circulo o método imprimir() foi sobrescrito por uma versão incrementada cujo valor de retorno inclui também o raio do círculo. Caso necessário, o método sobrescrito ainda pode ser invocado utilizando-se a palavra reservada super. Uma possível alternativa para a construção do método imprimir () seria:

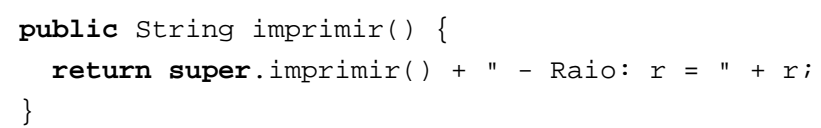

Na sobrescrita, pode ocorrer o caso do compilador não ter como decidir qual método será executado se o método foi sobrescrito em outras classes - afinal, um objeto de uma classe derivada pode estar sendo referenciado como sendo um objeto da superclasse, como ocorre no exemplo da Figura 2.6. Se esse for o caso, o método que deve ser selecionado é o da classe derivada e não o da superclasse. Dessa forma, a decisão sobre qual dos métodos deve ser selecionado, feita de acordo com o tipo do objeto, só pode ser tomada em tempo de execução, pelo mecanismo de ligação tardia (late binding ou run-time binding). O código Java apresentado na Figura 2.6 utiliza as classes definidas na Figura 2.2.

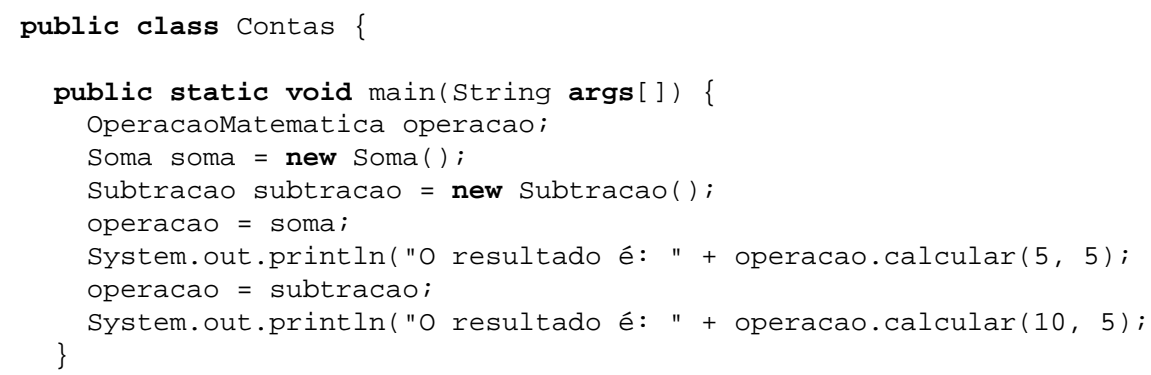

Figura 2.6: Exemplo de run-time binding.

Observe que embora cada chamada ao método calcular seja feita por uma variável do tipo OperacaoMatematica (mas nenhum objeto de OperacaoMatematica existe), o programa é capaz de selecionar o método correto por meio do objeto da subclasse em tempo de execução. Assim, na primeira execução do método cal cular (linha 8) é executado o método redefinido na classe Soma e gera como saída “O resultado é: 10”; já na segunda execução (linha 10), é executado o método sobrescrito na classe Subtracao e a saída é "O resultado é: 5".

As técnicas de sobrecarga e sobrescrita são dois tipos diferentes de polimorfismo presentes na linguagem Java.

\section{Passagem de parâmetros por valor}

Quando um parâmetro (ou argumento) é passado em uma chamada de método, na verdade uma cópia dele é passada. Deste modo, a alteração do valor do parâmetro dentro do método chamado não afeta o dado original. Considere o seguinte exemplo ${ }^{2}$ :

\footnotetext{
${ }^{2} \mathrm{O}$ exemplo foi adaptado de Heller e Roberts (2005).
} 


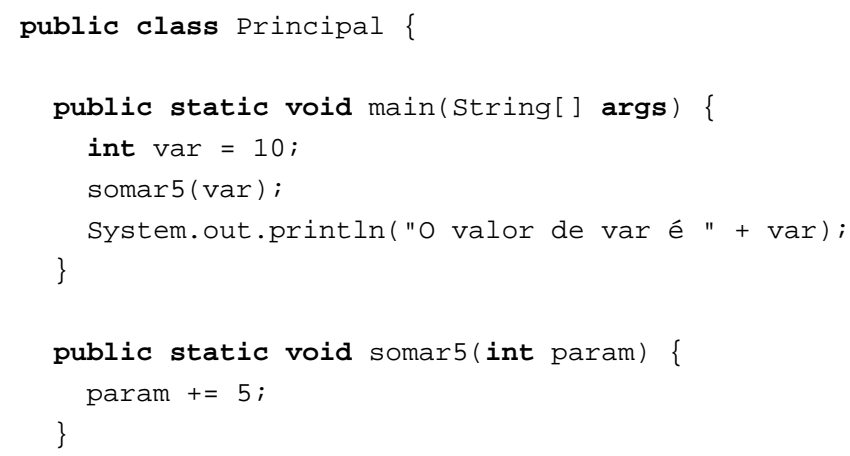

$\mathrm{Na}$ linha 04 a variável do tipo primitivo var é declarada e iniciada com o valor 10. Na linha 05 é feita uma cópia da variável var e esta cópia é passada para o método somar5. Dentro do método somar5, a cópia é incrementada de 5 (linha 10). Como o valor original de var não foi alterado, na linha 06 será impresso que o valor de var continua sendo 10.

O mesmo ocorre quando o parâmetro passado é um objeto ao invés de uma variável primitiva. Entretanto, é importante entender que o efeito é completamente diferente. Programas Java não lidam diretamente com objetos. Quando um objeto é construído, o construtor retorna um valor que o identifica unicamente. Este valor é conhecido como uma referência ao objeto e pode ser pensado simplesmente como o endereço do objeto. Considere o seguinte código:

01. Button botao;

02. botao = new Button ("Confirmar");

$\mathrm{Na}$ linha 02, o construtor da classe Button retorna uma referência para o objeto construído, não o objeto real ou uma cópia do objeto. Esta referência é armazenada na variável botao. Assim, quando o código Java parece armazenar objetos em variáveis ou passar objetos nas chamadas de métodos, na verdade são as referências aos objetos que são armazenados e passados. Considere o seguinte exemplo:

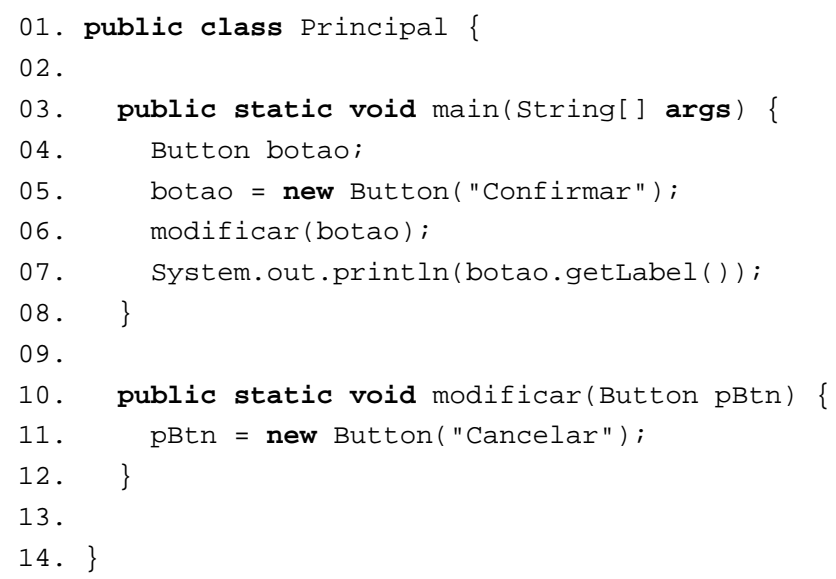

$\mathrm{Na}$ linha 05 é construído um objeto do tipo Button com o rótulo "Confirmar" e a referência ao objeto criado é armazenada em botao. Na linha 06, uma cópia da referência é passada para o método modificar. Antes da execução da linha 11, o valor em pBtn é uma referência ao botão 
com rótulo "Confirmar". Um segundo objeto da classe Button com o rótulo "Cancelar" é construído na linha 11 e sua referência é armazenada em pBtn, sobrescrevendo a referência anterior. Porém, o valor original da referência ao botão com rótulo "Confirmar" no método chamador não é afetada. Assim, na linha 07, a chamada botao.getLabel () invoca o botão original e o texto impresso é "Confirmar".

Percebe-se que o método chamado não pode alterar o valor original de seus argumentos, ou seja, os valores armazenados no método chamador. Entretanto, quando o método chamado opera sobre um objeto via o valor de referência que é passado para ele, há consequiências importantes. Se o método modifica o objeto via referência, diferentemente de modificar o argumento do método, então as alterações serão visíveis no método chamador. Considere o exemplo:

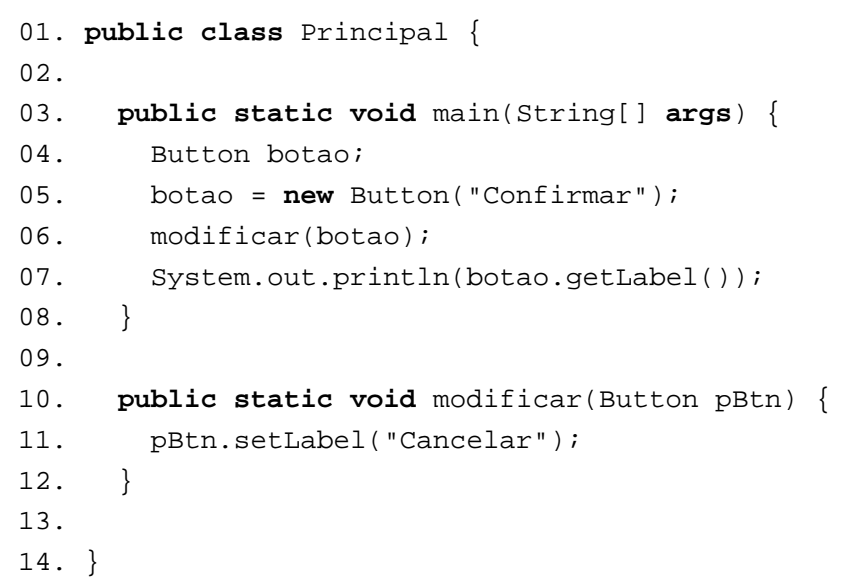

Neste exemplo, a variável pBtn é uma cópia da variável botao que é uma referência ao botão com rótulo "Confirmar". Na linha 11, a cópia da referência é usada para alterar o valor do objeto original, neste caso, o rótulo de bot ao foi alterado para "Cancelar". Pelo fato do objeto ser alterado ao invés da referência, a alteração é visível no método chamador e texto impresso (linha 07) contendo o rótulo do botao é "Cancelar".

\section{Interfaces}

Interface é um tipo de referência, similar a uma classe, que contém somente constantes e métodos abstratos. Uma interface estabelece uma espécie de contrato que é obedecido por uma classe. Quando uma classe implementa uma interface, garante-se que todas as funcionalidades especificadas pela interface serão oferecidas pela classe. A sintaxe para a declaração de uma interface é a seguinte:

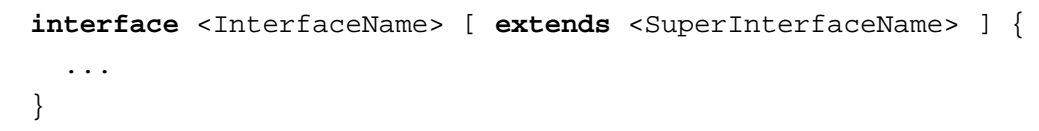

A declaração de uma interface inicia-se com a palavra reservada interface seguida de um identificador, representado por <InterfaceName>. A inclusão da palavra reservada extends seguida de um outro identificador (<SuperInterfaceName $\rangle$ ), indica que a interface que está sendo declarada é derivada de uma outra interface que a precede na relação de herança, definida pela aplicação. 
O corpo de uma interface é constituído por declarações de constantes e métodos abstratos. Todas as constantes são implicitamente public, static e final e todos os métodos são implicitamente public e abstract. Assim, é opcional indicar esses modificadores para declarar métodos e constantes. Na Figura 2.7 é mostrado um exemplo em que são declaradas três interfaces e uma classe:

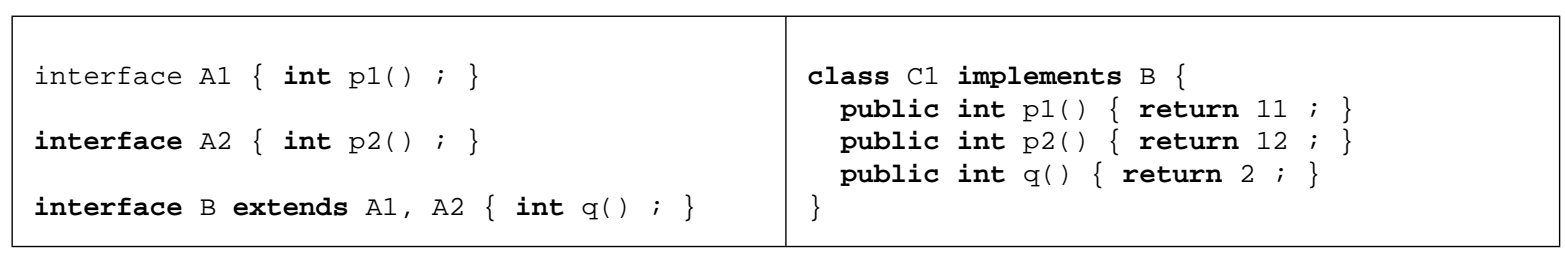

Figura 2.7: Exemplo de declaração de interfaces.

\section{A Máquina Virtual Java}

A Máquina Virtual Java (JVM) é uma máquina abstrata implementada como uma aplicação de software. Seu principal trabalho é carregar arquivos class e executar os bytecodes que eles contêm. A arquitetura da JVM é mostrada na Figura 2.8. Cada JVM contém um carregador de classes (class loader) que é responsável por carregar os arquivos class tanto do programa Java quanto da Java API e um motor de execução (execution engine) cuja tarefa é executar os bytecodes.

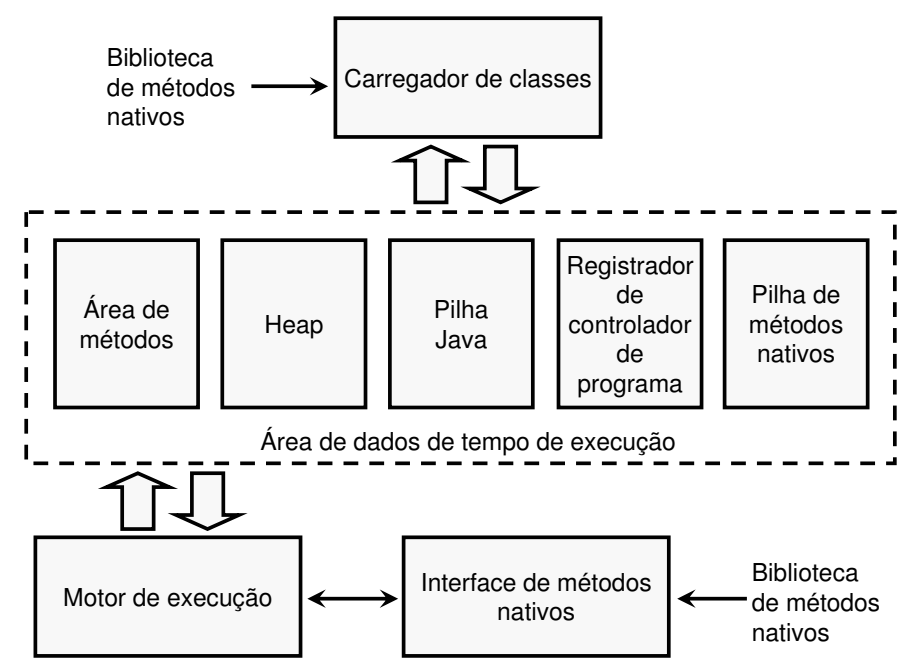

Figura 2.8: Arquitetura interna da Máquina Virtual Java (adaptada de Venners (1997)).

Em Java, existem dois tipos de métodos: métodos Java e métodos nativos. Um método Java é escrito na linguagem Java, compilado para bytecode e armazenado em arquivos class. Um método nativo é escrito em alguma outra linguagem (por exemplo, $\mathrm{C}$ ou $\mathrm{C}++$ ) e compilados para o código

\footnotetext{
${ }^{3}$ A maior parte do texto sobre JVM foi baseado em Venners (1997)
} 
de máquina nativo de um particular processador. Assim, os métodos nativos são dependentes da plataforma em que são executados. O mesmo não ocorre com os métodos Java.

Quando a JVM executa um programa, ela precisa de memória para armazenar muitos dados, tais como: bytecodes e informações extraídas dos arquivos class carregados, objetos instanciados durante a execução do programa, parâmetros passados nas chamadas de métodos, valores de retorno, variáveis locais e resultados intermediários das computações. Para isso, a JVM organiza a memória necessária em diversas áreas de dados de tempo de execução (runtime data areas).

Existem áreas de dados de tempo de execução que são compartilhadas por operações que executam em paralelo e outras que são privativas. As áreas de dados privativas estão associadas a threads e são criadas (alocadas) quando uma thread nova é criada, sendo destruídas (liberadas) quando a thread termina. As áreas ligadas à máquina virtual são compartilhadas entre as threads ativas e são criadas quando a JVM é iniciada e destruídas quando a JVM termina.

Cada JVM possui um heap e uma área de métodos que são áreas compartilhadas por todas as threads ativas dentro da máquina virtual. O heap é a área de dados em que todas as instâncias de classes e arrays são alocados. Ele é criado quando a máquina virtual é iniciada. $\mathrm{O}$ armazenamento de objetos nessa área é monitorado pelo coletor de lixo (garbage collector) cuja função é verificar os objetos que não estão sendo mais utilizados e desalocá-los se for o caso. A área de métodos é a parte do heap usada para armazenar o código compilado de métodos e construtores. Ela é criada quando a máquina virtual inicia. Quando uma classe ou interface é criada pela JVM, ela é alocada na área de métodos em uma espécie de tabela de símbolos (Runtime Constant Pool) que contém vários tipos de constantes, desde valores numéricos conhecidos em tempo de compilação até referências a métodos e atributos que devem ser resolvidos em tempo de execução.

Quando uma thread é criada, ela obtém um próprio registrador de contador de programa (program counter register ou pc register) e uma pilha Java (Java Stack). Se a thread está executando um método Java (não um método nativo), o valor do registrador pc indica a instrução que está sendo executada. A pilha Java armazena o estado das invocações de métodos Java (não nativos) da thread. O estado de uma invocação de método inclui as variáveis locais, os parâmetros passados, o valor de retorno (se houver) e cálculos parciais. O estado de invocações de métodos nativos é armazenado em uma pilha independente denominada pilha de métodos nativos (native method stack).

A pilha Java é composta de frames (quadros), que são estruturas responsáveis por guardar o estado de uma invocação de método. Um frame é criado pela JVM e empilhado na pilha Java toda vez que um método é chamado e desempilhado e destruído quando a chamada termina (normalmente ou por meio de exceção). Todo método tem um frame associado e ele é sempre local ao thread, não podendo ser compartilhado com outros threads. Cada frame possui: um vetor de variáveis locais (array of local variables), uma pilha de operandos (operand stack) e uma referência para a uma espécie de tabela de símbolos (runtime constant pool) da classe do método corrente.

O vetor de variáveis locais é determinado em tempo de compilação e pode armazenar valores de todos os tipos. Valores de 32 bits ocupam um lugar no array e valores de 64 bits ocupam dois 
lugares consecutivos. As variáveis locais são acessadas pelo seu índice. O índice da primeira variável local é 0 . A JVM usa o vetor de variáveis locais para armazenar os valores dos parâmetros e variáveis locais do método.

Cada frame contém uma pilha LIFO (Last-In-First-Out) conhecida como pilha de operandos. A máxima profundidade da pilha de operandos é determinada em tempo de compilação. A pilha de operandos está vazia quando o frame é criado. Algumas instruções da máquina virtual carregam constantes ou valores das variáveis locais ou atributos para a pilha de operandos. Outras pegam os operandos da pilha, operam sobre eles e empilham o resultado de volta para a pilha. Por exemplo, a instrução iadd adiciona dois valores int. Essa instrução requer que os valores que serão somados estejam previamente empilhados na pilha de operandos. Ambos os valores são desempilhados, somados e o resultado da adição é empilhado na pilha de operandos. A pilha de operandos é usada também para preparar os parâmetros a serem passados para os métodos e para receber os retornos dos métodos. Qualquer tipo pode ser armazenado e lido da pilha de operandos. Tipos long e double ocupam duas unidades da pilha.

Além do vetor de variáveis locais e a pilha de operandos, cada frame possui uma referência para a tabela de símbolos de forma a realizar a ligação dinâmica entre referências simbólicas aos métodos e suas referências reais em tempo de execução, carregando classes sob demanda e resolvendo símbolos na medida da necessidade.

Somente um frame, o frame do método em execução, está ativo em uma thread. Esse frame é denominado frame corrente e seu método é chamado de método corrente. A classe na qual o método corrente é definido é conhecida como classe corrente. Um frame deixa de ser corrente quando seu método termina a execução ou quando seu método invoca outro método. No caso de um método ser invocado, um novo frame é criado para ele e este se torna o frame corrente quando a execução é transferida para o método chamado.

A JVM utiliza dois tipos diferentes de instruções para invocar métodos de instância e estáticos de uma classe: invokevirtual para métodos de instância e invokestatic para métodos estáticos. Essas instruções são mostradas na Tabela 2.4.

Tabela 2.4: Instruções invokevirtual e invokestatic.

\begin{tabular}{|l|l|}
\hline Opcode & Descrição \\
\hline \hline invokevirtual & Desempilha a referência ao objeto e os parâmetros e invoca o método de instância \\
\hline invokestatic & Desempilha os parâmetros e invoca o método estático \\
\hline
\end{tabular}

Em uma chamada a um método de instância, a máquina virtual desempilha, da pilha de operandos do frame do método chamador, a referência ao objeto no qual o método de instância esta sendo invocado (this) e os parâmetros. Em seguida, a máquina virtual armazena no novo frame (ou frame do método chamado) a referência ao objeto como variável local 0 e todos os parâmetros como variáveis locais 1, 2 e assim por diante. Já em uma invocação a um método estático, a máquina virtual somente desempilha os parâmetros da pilha de operandos do frame do método chamador e os armazena no novo frame como variáveis locais $0,1,2$ e assim por diante. 
Uma vez que a referência ao objeto e os parâmetros (ou somente os parâmetros, no caso de uma chamada a um método estático) tenham sido armazenados no vetor de variáveis locais do novo frame, a máquina virtual faz com que o novo frame seja o frame corrente e ajusta o contador de programa para apontar para a primeira instrução no novo método. No retorno do método, o frame corrente retorna o resultado de sua chamada (se houver) para o frame anterior. O frame corrente é então descartado quando o frame anterior se torna o frame corrente.

\subsection{Programação Orientada a Aspectos}

Para se construir um sistema simples, legível, de fácil manutenção e com maior potencial de reutilização é fundamental que cada interesse (concern) referente ao sistema seja tratado separadamente dos outros interesses. Um interesse é uma funcionalidade ou requisito que o sistema deve ter ou satisfazer (Gradecki et al., 2003). De maneira geral, um interesse pode indicar tanto um requisito funcional quanto um requisito não funcional de um sistema (Elrad et al., 2001b). Os requisitos funcionais são definidos como funções ou atividades que o sistema faz, enquanto que os requisitos não funcionais expressam condições de comportamento e restrições que devem prevalecer, como por exemplo: tratamento de exceções, segurança e persistência de dados (Chung et al., 1999; Cysneiros, 1997).

A evolução das linguagens de programação a partir de construções de baixo nível - código de máquina e linguagens de montagem — até abordagens de alto nível — programação procedimental, programação lógica, programação funcional e programação orientada a objetos — tem contribuído para se obter uma melhor separação dos interesses de um sistema (Elrad et al., 2001b). De forma geral, todas as técnicas de programação de alto nível oferecem suporte a esse tipo de separação de interesses. Por exemplo, a programação procedimental utiliza procedimentos e funções, enquanto que a programação OO emprega a construção de classes e métodos.

Em meados dos anos 90, alguns pesquisadores constataram a existência de certos interesses (geralmente interesses não funcionais) que, independentemente da técnica de programação utilizada, não se encaixam em módulos individuais, mas ficam espalhados por várias unidades do software (Lemos, 2005). Esses interesses são chamados de crosscutting concerns (interesses entrecortantes ou interesses transversais), pois afetam naturalmente classes e/ou métodos que modularizam outros interesses. A partir daí, dois fenômenos interessantes foram percebidos: espalhamento e entrelaçamento. O espalhamento é o fenômeno em que as linhas de código que cuidam de um único interesse são distribuídas por várias classes; e o entrelaçamento é o fenômeno em que uma única classe contém as linhas de código que cuidam de vários interesses.

Um exemplo de interesse transversal é apresentado na Figura 2.9. O diagrama de classes UML refere-se a um editor de figuras simples. Uma Figura consiste de ElementoDeFigura, que pode ser Ponto ou Linha. Há também uma Tela onde as figuras são desenhadas. Quando um elemento de figura se mover é necessário que a tela seja atualizada. Uma possível solução utili- 
zando orientação a objetos seria chamar o método de atualização da Tela (Tela .atualiza ( ) ) no do corpo dos métodos setX, setY e move da classe Ponto e no corpo dos métodos set P1, setP 2 e move da classe Linha, conforme apresentado na Figura 2.10. Observe que o interesse de atualização de tela não pertence a nenhuma das duas classes, mas entrecorta ambas e, por isso, pode ser entendido como transversal às classes.

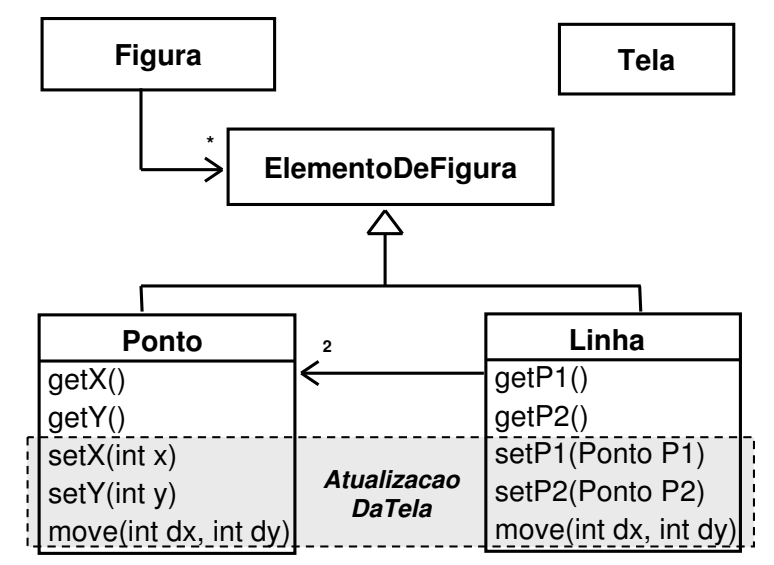

Figura 2.9: Interesse ortogonal de atualização de tela.

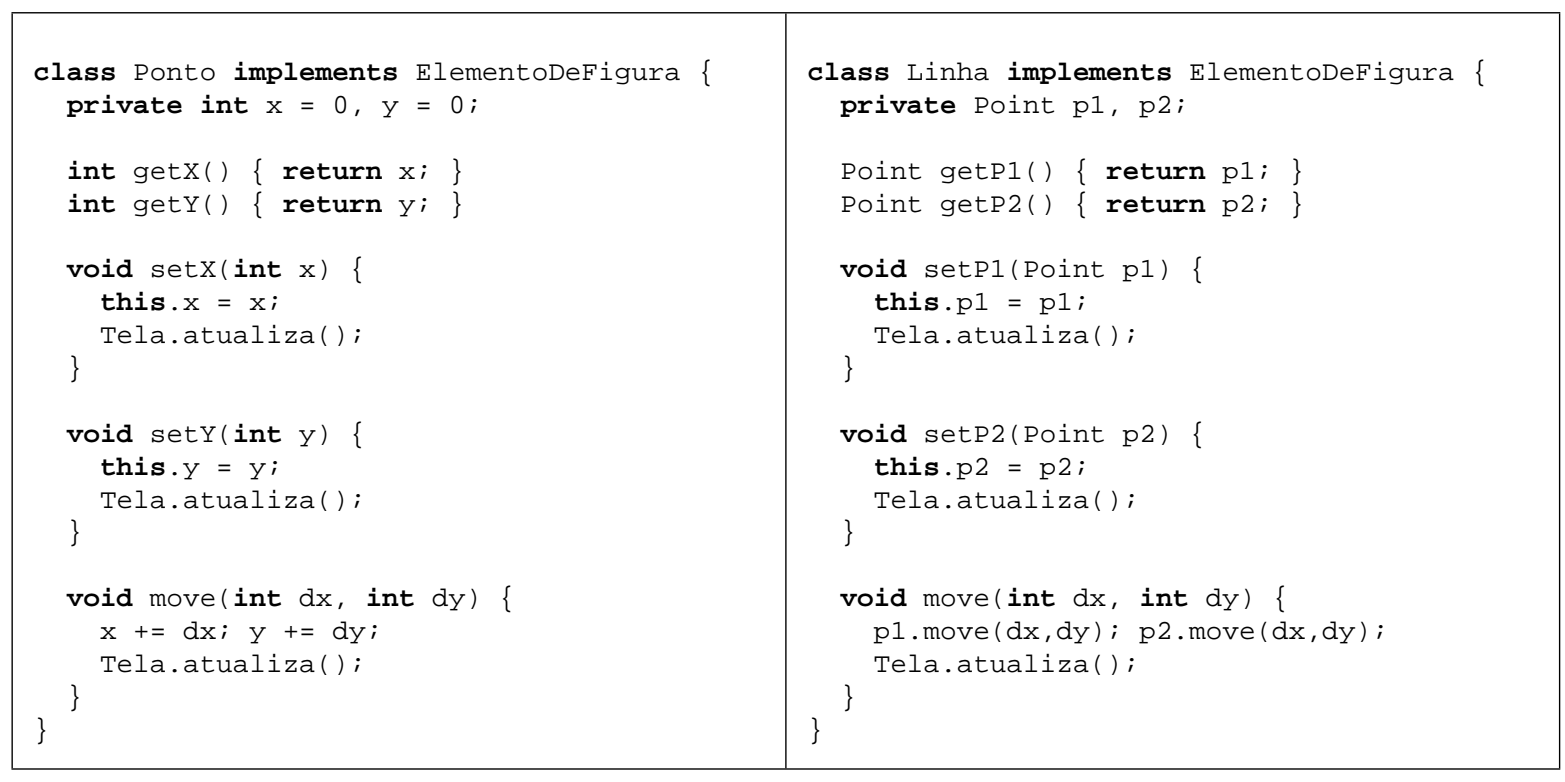

Figura 2.10: Solução OO para o exemplo de atualização de tela.

Para resolver esse problema, uma das soluções mais promissoras é a Programação Orientada a Aspectos (POA), que auxilia a tratar os interesses transversais de maneira localizada. O conceito, originalmente introduzido por Kiczales e sua equipe na Xerox PARC, é resultado de vários estudos em metaprogramação, programação orientada a assuntos, filtros de composição, programação adaptativa e outros (Czarnecki e Eisenecker, 2000).

A POA oferece mecanismos para que os interesses transversais sejam implementados em módulos separados e fornece meios para a definição de pontos do programa onde esses módulos 
(chamados aspectos) possam adicionar comportamento (Kiczales et al., 2001b). A técnica de desenvolvimento de software que utiliza programação orientada a aspectos é conhecida como AOSD (Aspect-Oriented Software Development).

\subsubsection{Linguagens Orientadas a Aspectos: Uma Introdução a As- pectJ}

O objetivo primário de uma linguagem orientada a aspectos é a separação de interesses. Uma aplicação é escrita em uma linguagem que melhor satisfaz suas necessidades e as do desenvolvedor. Essa pode ser Java, C++, Visual Basic, etc; em todas elas, o compilador converte o código-fonte em um formato que possa ser executado pelo computador. No caso do Java, o código-fonte é convertido para bytecode que é posteriormente interpretado durante a execução.

Para que um sistema seja completamente produzido e corresponda às expectativas, todos os requisitos elicitados devem ser satisfeitos. Conforme discutido anteriormente, os requisitos de um sistema podem ser classificados em dois tipos: requisitos funcionais e não funcionais. Os requisitos funcionais e os requisitos não funcionais são também conhecidos como interesses primários e interesses transversais, respectivamente, termos que serão utilizados durante todo este trabalho.

$\mathrm{Na} \mathrm{POA}$, os interesses primários são implementados em uma linguagem apropriada para a aplicação enquanto que os interesses transversais são implementados em uma linguagem orientada a aspectos (Gradecki et al., 2003). As linguagens orientadas a aspectos podem ser classificadas em: linguagens de domínio específico e linguagens de propósito geral.

As linguagens de domínio específico tratam somente de determinados tipos de interesses transversais, ligados a apenas um domínio. Alguns exemplos são: COOL (Lopes, 1997) que implementa interesses de locking/exclusão mútua; RIDL (Lopes, 1997) que implementa interesses de invocação remota; D² AL (Becker, 1998) que implementa interesses referentes a computação distribuída; e QuO (Karr et al., 2001) que implementa interesses referentes a política para o transporte em rede.

As linguagens de propósito geral oferecem mecanismos lingüísticos que permitem codificar qualquer tipo de interesse transversal em unidades separadas e capturar pontos no programa onde esses interesses afetam os interesses primários (Kiczales et al., 2001b). Alguns exemplos são: AspectJ, Hyper/J, CME, JAML, JAsCo, AspectC++ e AspectS.

Para que os interesses transversais possam interagir com os interesses primários da aplicação, é necessário determinar em quais pontos da execução dos interesses primários serão definidos os comportamentos. Esses pontos são chamados de pontos de junção. Após a codificação dos interesses primários e dos interesses transversais com pontos de junção determinados, é necessário um processo que os una em um programa executável. Esse processo é chamado de combinação (weaving). A combinação pode ser realizada tanto em tempo de compilação (combinação estática) quanto em tempo de execução (combinação dinâmica)(Lemos, 2005; Gradecki et al., 2003).

A seguir é discutido brevemente sobre a linguagem AspectJ. 


\section{AspectJ}

A linguagem AspectJ é uma extensão da linguagem Java criada para permitir a programação orientada a aspectos. Foi desenvolvida no Xerox Palo Alto Research Center (PARC) em 1997 e em 2002 foi encorporada ao projeto Eclipse. Nessa linguagem os interesses primários - chamados de módulos básicos do programa (ou componentes) - são representados por classes Java e uma nova construção, denominada aspect, é responsável por implementar os interesses que entrecortam a estrutura das classes.

AspectJ adiciona um novo conceito a Java denominado ponto de junção (join point) que são pontos bem definidos na execução do fluxo de programa. Além disso, adiciona novas construções: conjunto de junção (pointcut) que identifica certos pontos no programa em que o comportamento será adicionado; adendo (advice) que define o comportamento em um dado conjunto de junção; declaração inter-tipos que altera a hierarquia de classes; e aspecto (aspect) que combina especificações de pontos de junção (utilizando os pointcuts) e adendos, além de métodos e atributos. Os conjuntos de junção e adendos afetam dinamicamente o fluxo do programa; declarações intertipo afetam estaticamente a hierarquia de classes do programa; e aspectos encapsulam essas novas construções.

Na Figura 2.11 é mostrada uma implementação em AspectJ para o exemplo de interesse transversal apresentado anteriormente na Figura 2.10. Foi criado o aspecto AtualizacaoDaTela que ficou responsável por atualizar a visualização dos elementos de figura todas as vezes que eles forem alterados. Observe que a chamada ao método de atualização de tela (Tela . atualiza ( ) ) foi retirada do corpo dos métodos setX, setY e move da classe Ponto e do corpo dos métodos setP1, setP2 e move da classe Linha e colocada no aspecto. $O$ aspecto é constituído pelo conjunto de junção chamado mudancaEst ado que identifica três pontos de junção e define dois adendos (before e after) que são executados antes e depois de um ponto de junção alcançado, respectivamente. No adendo before é exibida apenas uma mensagem ao usuário informando que o estado será alterado. Já no adendo after, a atualização da tela é feita por meio da chamada ao método Tela.atualiza().

A seguir discute-se como são tratados alguns conceitos e construções utilizados na linguagem AspectJ.

Pontos de Junção são "pontos" bem definidos na execução do fluxo de programa. Eles podem ser uma chamada de método, a execução de um construtor, ou até mesmo o acesso a um atributo de uma classe específica (Gradecki et al., 2003). Na Tabela 2.5 são mostrados as possíveis categorias pontos de junção da linguagem AspectJ.

Conjuntos de Junção são utilizados para identificar pontos de junção em um programa ${ }^{4}$. Além disso, podem expor as informações de contexto dos pontos de junção alcançados, podendo

\footnotetext{
${ }^{4}$ A maior parte do texto sobre conjuntos de junção foi baseada no livro de Laddad (2003)
} 


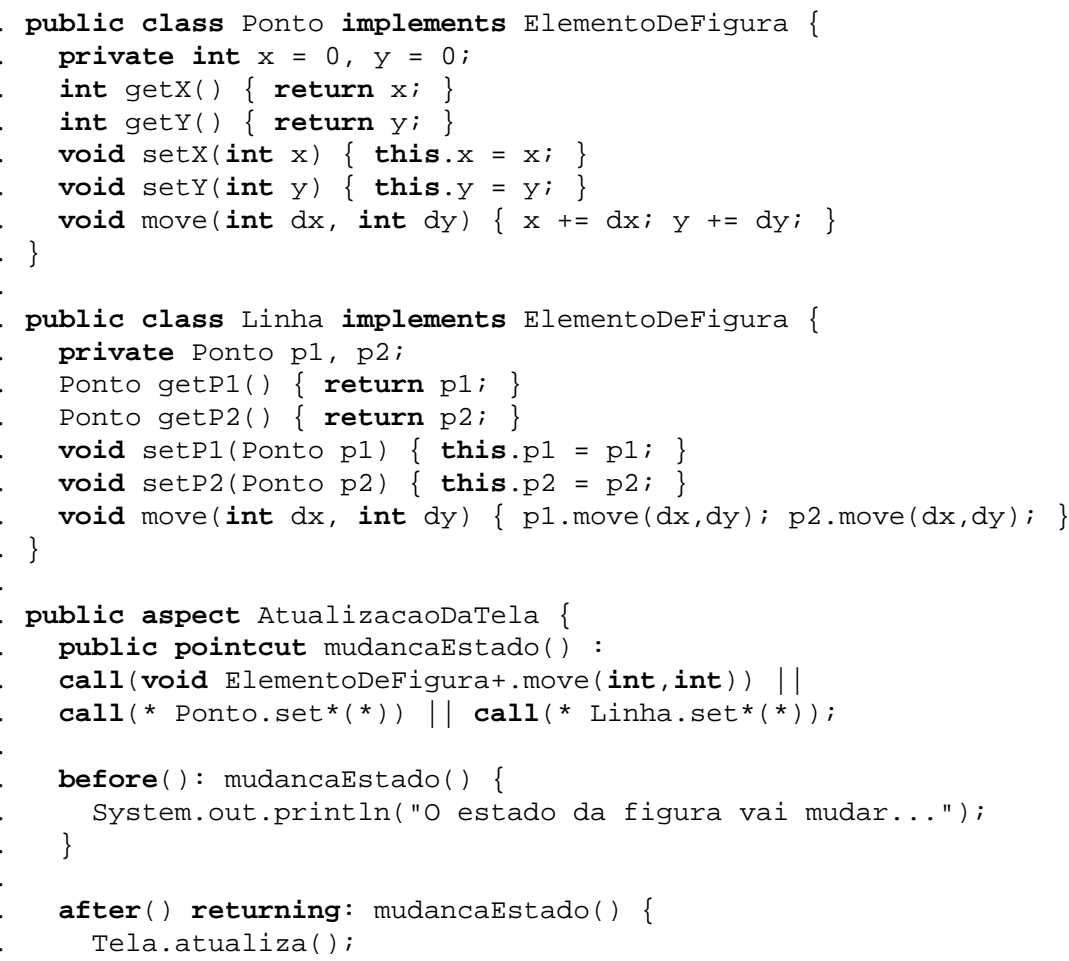

Figura 2.11: Exemplo de código em AspectJ.

Tabela 2.5: Categorias de pontos de junção do AspectJ (adaptado de Kiczales et al. (2001b)).

\begin{tabular}{|l|l|}
\hline Categoria & Descrição \\
\hline \hline Chamada de método \\
Chamada de construtor & $\begin{array}{l}\text { Um método ou um construtor de uma classe é chamado. } \\
\text { Pontos de junção deste tipo encontram-se no objeto chamador } \\
\text { ou possuem valor nulo (se a chamada é feita a partir de um } \\
\text { método estático). }\end{array}$ \\
\hline $\begin{array}{l}\text { Execução de método } \\
\text { Execução de construtor }\end{array}$ & $\begin{array}{l}\text { Um método ou construtor é executado. Pontos de junção } \\
\text { deste tipo ocorrem no objeto chamado, dentro do contexto } \\
\text { do método. }\end{array}$ \\
\hline Leitura de atributo & Um atributo de um objeto, classe ou interface é lido. \\
\hline Escrita de atributo & Um atributo de um objeto ou classe é escrito. \\
\hline Execução de tratador de exceção & Um tratador de exceção é invocado. \\
\hline Iniciação de classe & $\begin{array}{l}\text { Iniciadores estáticos de uma classe (se existirem) são } \\
\text { executados. }\end{array}$ \\
\hline Iniciação de objeto & $\begin{array}{l}\text { Iniciadores dinâmicos de uma classe (se existirem) são } \\
\text { executados durante a criação do objeto, abrangendo desde o } \\
\text { retorno da chamada ao construtor da classe pai até o retorno } \\
\text { do primeiro construtor chamado. }\end{array}$ \\
\hline Pré-inicialização de objeto & $\begin{array}{l}\text { Pré-iniciadores de uma classe são executados, abrangendo } \\
\text { desde a chamada ao primeiro construtor até a chamada ao } \\
\text { construtor da classe pai. }\end{array}$ \\
\hline
\end{tabular}

ser utilizadas pelas ações que afetam esses pontos. No AspectJ, os conjuntos de junção podem conter nomes ou serem anônimos. Na Figura 2.12 é destacado o conjunto de junção nomeado definido no exemplo apresentado na Figura 2.11 (linhas de 20 a 22). 
Um conjunto de junção pode ser definido como uma combinação de vários conjuntos de junção. Para isso são utilizados os operadores lógicos binários 'E' (\&\&) e 'OU' (\|). Além disso, o operador unário de negação (!) também pode ser usado quando não se quer capturar pontos de junção definidos por um determinado tipo de conjunto de junção.

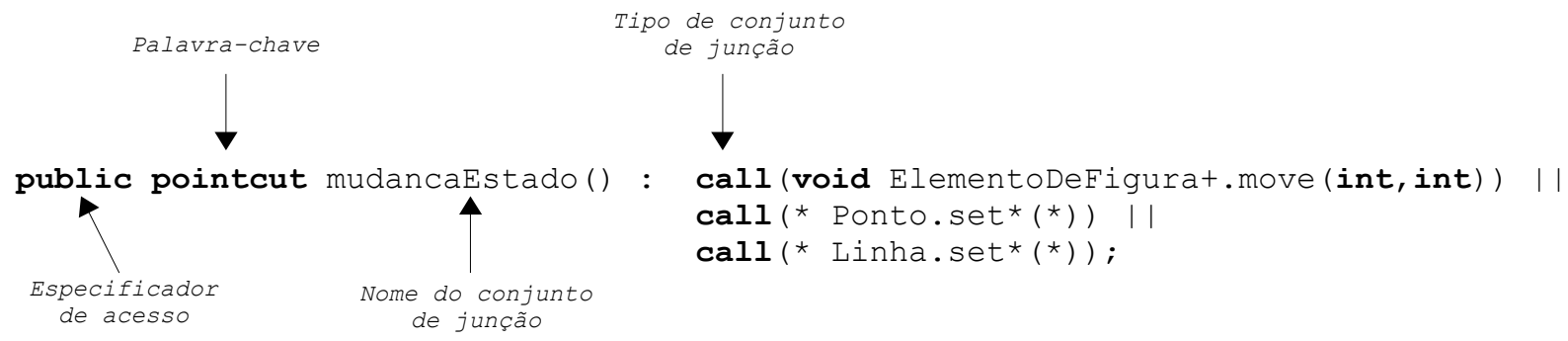

Figura 2.12: Destaque do conjunto de junção nomeado definido no exemplo apresentado na Figura 2.11 (adaptada de Lemos (2005)).

Existem vários tipos de conjuntos de junção ${ }^{5}$ em AspectJ. Estes se diferenciam pelo modo como capturam pontos de junção em um programa. Um dos tipos de conjuntos de junção é o que captura pontos de junção baseado na categoria a que eles pertencem. O mapeamento entre as categorias de pontos de junção (Tabela 2.5) e a sintaxe dos conjuntos de junção correspondente é apresentado na Tabela 2.6.

Tabela 2.6: Mapeamento entre as categorias de pontos de junção e a sintaxe dos conjuntos de junção correspondente.

\begin{tabular}{|c|c|}
\hline Categoria de Pontos de Junção & Sintaxe do Conjunto de Junção \\
\hline \hline Execução de método & execution(AssinaturaDeMétodo) \\
\hline Chamada a método & call(AssinaturaDeMétodo) \\
\hline Execução de construtor & execution(AssinaturaDeConstrutor) \\
\hline Chamada a construtor & call(AssinaturaDeConstrutor) \\
\hline Iniciação de classe & staticinicialization(AssinaturaDeTipo) \\
\hline Acesso de leitura de atributo & get(AssinaturaDeAtributo) \\
\hline Acesso de modificação de atributo & set(AssinaturaDeAtributo) \\
\hline Execução de tratador de exceção & initialization(AssinaturaDeConstrutor) \\
\hline Iniciação de objeto & preinitialization(AssinaturaDeConstrutor) \\
\hline Pré-iniciação de objeto
\end{tabular}

Outro tipo de conjunto de junção presente no AspectJ é o que captura pontos de junção baseado nos tipos de objetos em tempo de execução. Estes objetos podem ser o objeto corrente do método (this) ou o objeto no qual um método é chamado (o objeto alvo ou target object). Para isso existem dois conjuntos de junção: this() e target () que, além de capturar os pontos de junção, podem ser usados para coletar o contexto do ponto de junção.

A sintaxe do conjunto de junção this () é da forma this(AssinaturaDoTipo ou IdentificadorDoObjeto). O this ( ) captura todos os pontos de junção que possuem um objeto corrente associado que seja do tipo especificado por AssinaturaDoTipo ou do tipo do IdentificadorDoObjeto.

\footnotetext{
${ }^{5}$ Neste texto são discutidos os mais relevantes ao assunto da dissertação.
} 
Para capturar pontos de junção e coletar o seu contexto (neste caso, o objeto corrente) utiliza-se a forma com IdentificadorDoObjeto. Se o contexto não for necessário, utiliza-se a forma com AssinaturaDoTipo. O conjunto de junção target () é similar ao this () porém, ao invés de utilizar o objeto corrente, utiliza o objeto alvo do ponto de junção. O target () é normalmente usado, por exemplo, com um ponto de junção da categoria chamada a método. Neste caso, o objeto alvo é o objeto no qual o método é invocado. A sintaxe do conjunto de junção target () é da forma target(AssinaturaDoTipo ou IdentificadorDoObjeto).

Existe também um tipo de conjunto de junção que captura pontos de junção baseado no tipo dos parâmetros do ponto de junção. A sintaxe deste tipo de conjunto de junção é da forma args(AssinaturaDoTipo ou IdentificadorDoObjeto, ...). O comando args () captura todos os pontos de junção que possuem parâmetros que sejam iguais aos dos tipos especificados em sua declaração. Similar aos conjuntos de junção this () e target (), o args () pode ser usado para coletar informações de contexto, neste caso, os valores dos parâmetros. Para isso, deve-se utilizar a forma com IdentificadorDoObjeto.

Em Java, as classes, interfaces, métodos e atributos possuem assinaturas. No AspectJ, quando se quer especificar padrões que designam várias assinaturas contidas em um programa, são utilizados os padrões de assinatura. Para capturar pontos de junção com características comuns, a linguagem AspectJ utiliza três caracteres coringas: '*' denota qualquer número de caracteres, excluindo o caractere '.'; '..' denota qualquer número de caracteres incluindo o '.'; '+' denota qualquer subclasse ou subinterface de um dado tipo ${ }^{6}$.

No exemplo da Figura 2.12, o conjunto de junção nomeado mudancaEstado é composto (por meio do operador binário $(||)$ ) por três conjuntos de junção. Os três utilizam padrões de assinatura para capturar seus correspondentes pontos de junção. O primeiro conjunto de junção que compõe mundancaEstado captura todas as chamadas ao método move definido em alguma classe da hierarquia da interface ElementoDeFigura, que retorna void e contenha dois parâmetros do tipo int. O segundo captura todas as chamadas aos métodos que iniciam com a cadeia set, pertencem à classe Ponto, retornam qualquer tipo e recebem um único parâmetro de qualquer tipo. Por fim, o terceiro conjunto de junção captura todas as chamadas aos métodos que iniciam com a cadeia set, pertencem à classe Linha, retornam qualquer tipo e recebem um único parâmetro de qualquer tipo.

Adendos são construções similares a métodos usados para definir que determinados códigos devem ser executados quando um ponto de junção é alcançado, isto é, eles definem comportamentos adicionais aos pontos de junção. AspectJ tem os seguintes tipos de adendos (Kiczales et al., 2001b,a; Gradecki et al., 2003):

- before () (Anterior), executa antes do ponto de junção;

\footnotetext{
${ }^{6}$ tipo no AspectJ refere-se a uma classe, interface, tipo primitivo ou aspecto
} 
- after () (Posterior), executa depois de cada ponto de junção independente de ele retornar normalmente ou lançar uma exceção. Há mais dois tipos de adendos posteriores específicos:

- after() returning, executa depois de cada ponto de junção que retorna normalmente.

- after() throwing, executa depois de cada ponto de junção que lança uma exceção.

- around ( ) (De contorno) executa em lugar do ponto de junção e tem a habilidade de invocar o ponto de junção usando a sintaxe especial proceed () que tem o mesmo número e tipo de argumentos que o adendo de contorno.

Com o objetivo de demonstrar como é a seqüência de execução dos diferentes tipos de adendos, o aspecto Atuali zacaoDaTela (apresentado na Figura 2.11) foi modificado com a inserção do adendo around () que, da mesma forma que os adendos before () e after () returning, é disparado quando um ponto de junção definido no conjunto de junção mudancaEstado é alcançado. O código modificado do aspecto Atuali zacaoDaTela é exibido na Figura 2.13.

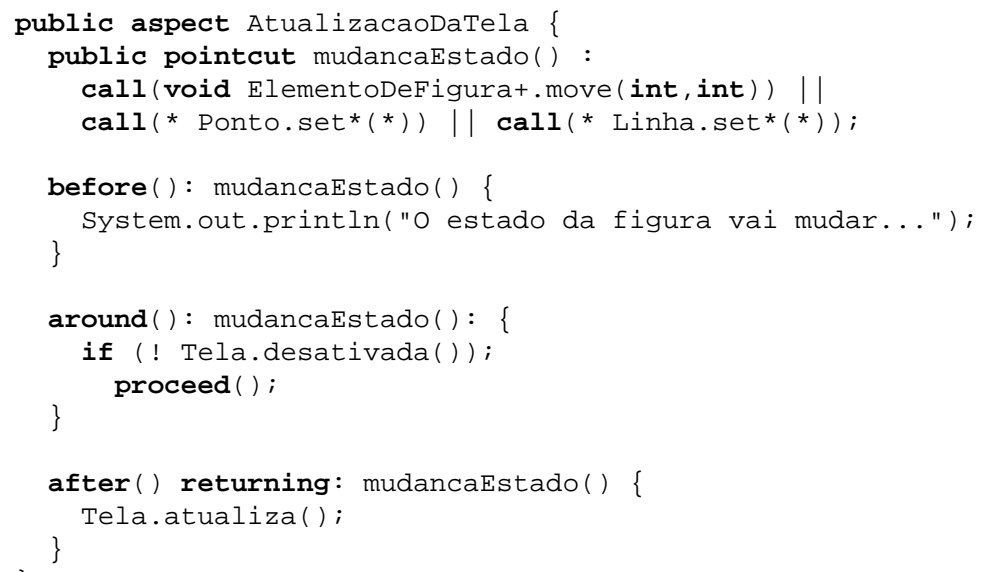

Figura 2.13: Código do aspecto AtualizacaoDaTela modificado.

Assim, no exemplo da Figura 2.13, quando a execução do programa alcançar um ponto de junção, ocorrerá a seguinte sequiência de execução dos adendos: o primeiro adendo a ser executado é o before. Em seguida, o adendo around executa no lugar do ponto de junção. Se a tela não estiver desativada, o adendo around (), por meio do proceed (), invoca o ponto de junção. Finalmente, o adendo after é executado caso o ponto de junção retorne normalmente.

Como se pode notar, a declaração de um adendo parece muito com a declaração de um método. Embora não tenha um nome, o adendo pode receber parâmetros e lançar exceções. Os parâmetros formam o contexto que pode ser utilizado no corpo do adendo para executar as instruções da mesma forma que um método. Enquanto que adendos do tipo posterior e anterior não podem retornar resultados, o adendo de contorno pode e, desta forma, possui um tipo de retorno (Laddad, 2003). Além dessas semelhanças com métodos, existem algumas diferenças, tais como: 
- adendos não têm nome;

- adendos não podem ser chamados diretamente (é trabalho do sistema executá-lo);

- adendos não têm especificadores de acesso;

- o corpo do adendo tem uma sintaxe especial proceed ( ) que esta disponível no adendo de contorno;

- Tem acesso a algumas variáveis especiais além do this que carregam informação sobre o ponto de junção capturado: thisJoinPoint, que encapsula informações estáticas e dinâmicas; thisJoinPointStaticPart, que guarda somente informações de contexto estático; e thisEnclosingJoinpointStaticPart, que guarda informações estáticas do ponto de junção mais próximo acima do interceptado.

Modificações Estáticas são construções que implementam o entrecorte estático em Aspect $^{7}$. Enquanto o entrecorte dinâmico modifica o comportamento de execução do programa, o entrecorte estático altera a estrutura estática dos tipos - classe, interfaces e outros aspectos - e seus comportamentos em tempo de compilação. Existem os seguintes tipos de entrecorte estático: declarações inter-tipos, modificações da hierarquia de classes, e introdução de avisos e erros de compilação.

As declarações inter-tipos permitem que atributos, construtores e métodos sejam adicionados às classes básicas do programa. Na Figura 2.14 é mostrado um exemplo de declaração inter-tipo. O exemplo adiciona na classe Contas o atributo size e dois métodos set Si ze e get Si ze.

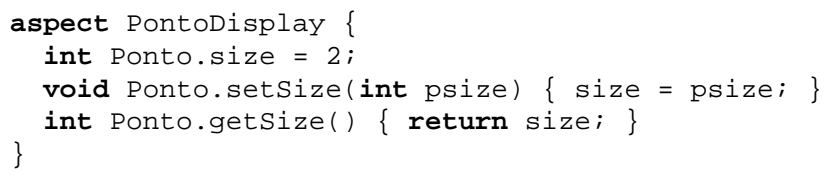

Figura 2.14: Exemplo de declarações inter-tipos.

A modificação na hierarquia das classes é feita por meio da declaração inter-tipo declare parents. Essa declaração permite alterar a hierarquia e indicar que alguma classe herda de outra classe ou implementa certa interface. $\mathrm{O}$ formato geral de declaração de herança e de implementação de interface é apresentado na Figura 2.15.

declare parents : [PadraoDeTipo] implements [ListaDeInterfaces];

declare parents : [PadraoDeTipo] extends [Classe ou ListaDeInterfaces];

Figura 2.15: Sintaxe da declaração declare paterns.

\footnotetext{
${ }^{7}$ A maior parte do texto sobre modificações estáticas foi baseada no livro de Laddad (2003)
} 
Com a introdução dos avisos e erros de compilação, pode-se implementar comportamentos similares às diretivas \#error e \#warning de alguns pré-processadores $\mathrm{C} / \mathrm{C}++$. A declaração declare error permite declarar um erro que interrompe a compilação e mostra uma mensagem toda a vez que o compilador encontra um dado ponto de junção (capturado por um conjunto de junção). A construção declare warning funciona de maneira similar, porém a compilação não pára e somente a mensagem é mostrada. Um exemplo comum de uso desses contrutores é para impor regras de programação de modo a proibir chamadas a determinados métodos ou avisar sobre tais chamadas, conforme mostrado na Figura 2.16. A primeira construção faz com que o AspectJ gere um erro de compilação se um ponto de junção capturado pelo conjunto de junção chamadaDeCodigoInseguro () for encontrado no código que está sendo compilado. Já a segunda construção gera um aviso se um ponto de junção capturado pelo conjunto de junção chamadaAOperacoesBloqueantes () for encontrado durante a compilação.

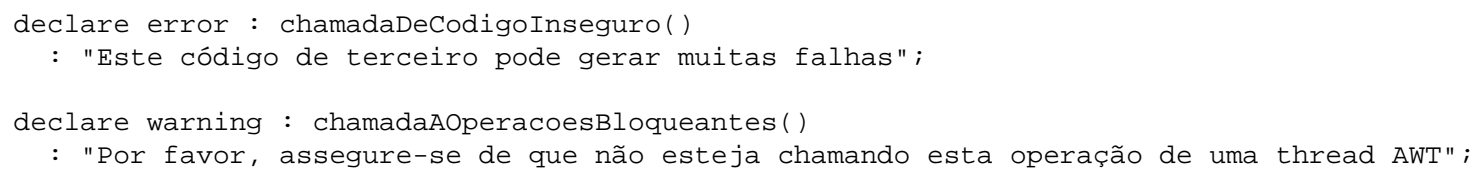

Figura 2.16: Exemplo de declare error e de declare warning.

Aspectos são unidades modulares que implementam os interesses transversais. A declaração de um aspecto é muito similar à declaração de uma classe em Java. Ela pode incluir declarações de conjuntos de junção, declarações de adendos e todos os outros tipos de declarações permitidas na declaração de uma classe, tais como declarações de atributos e métodos (Kiczales et al., 2001b). Assim como classes, aspectos contêm privilégios de acesso, podem herdar de outras classes (ou de aspectos abstratos) e implementar interfaces. Na Figura 2.17 é mostrado um exemplo de declaração de um aspecto. O aspecto MoveTracking implementa o comportamento que informa por meio do atributo flag se um elemento de figura se moveu recentemente.

Em AspectJ existem três tipos de instanciação de aspectos: Singleton, Per-object e Per-control-flow. Nesta dissertação é tratado somente o primeiro tipo. Singleton é o tipo padrão atribuído a todos os aspectos. Um aspecto deste tipo possui uma única instância a qual é criada automaticamente quando o programa é executado e é usada durante toda a aplicação. É no contexto dessa única instância que os adendos do aspecto são executados (Gradecki et al., 2003).

\subsection{Considerações Finais}

Neste capítulo foram apresentados os paradigmas de programação orientado a objetos e orientado a aspectos. Foi discutido que o paradigma de programação OO possibilita a construção de sistemas com uma arquitetura mais organizada na qual os interesses do sistema são implementados 


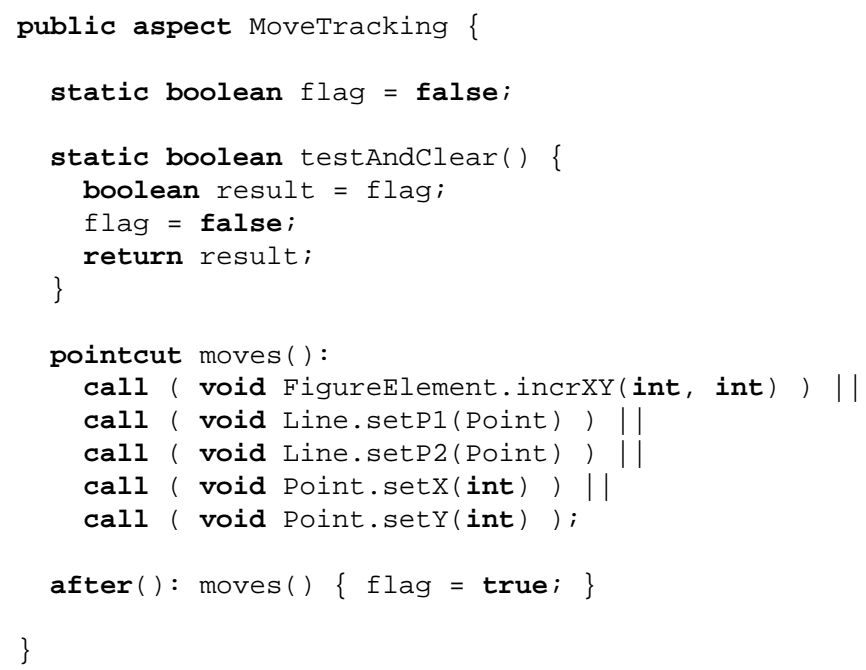

Figura 2.17: Exemplo de uma declaração de aspecto (adaptada de Kiczales et al. (2001b)).

em módulos individuais (classes). Porém, certos interesses (interesses transversais), não se encaixam em módulos individuais e ficam espalhados por várias unidades do software. A programação orientada a aspectos (POA) tenta resolver o problema de espalhamento e entrelaçamento de código por meio de uma construção que implementa os interesses transversais em módulos separados (aspecto, na linguagem AspectJ). Contudo, a simples utilização da POA não evita que defeitos sejam introduzidos e, deste modo, a atividade de teste de software continua sendo necessária. Além disso, fez-se uma breve introdução a linguagem Java e a linguagem AspectJ, que é uma extensão da linguagem Java criada para permitir a programação orientada a aspectos. 



\section{Teste de Software OO e OA: Teste Estrutural de Unidade e de Integração}

\subsection{Considerações Iniciais}

Neste capítulo é apresentada uma revisão bibliográfica sobre a atividade de teste software, dando enfoque ao teste estrutural de programas orientados a objetos e de programas orientados a aspectos. Na Seção 3.2 são descritos os fundamentos do teste de software. Na Seção 3.3 é apresentada uma abordagem de teste estrutural de integração para programas procedimentais que foi utilizada como base para definir o critério baseado em fluxo de dados proposto nesta dissertação. Na Seção 3.4 é abordado o teste estrutural de programas OO e na Seção 3.5 o teste estrutural de programas OA. Na Seção 3.6 é feita uma analise de ferramentas de teste para programas Java e AspectJ. Por fim, na Seção 3.7 são apresentadas as considerações finais.

\subsection{Fundamentos do Teste de Software}

O processo de desenvolvimento de software envolve uma série de atividades nas quais, apesar das técnicas, ferramentas e métodos empregados, erros no produto ainda podem ocorrer. Com o objetivo de minimizar a ocorrência de erros e riscos associados, têm sido introduzidas ao longo de todo o processo de desenvolvimento atividades agregadas sob o nome de Garantia de Qualidade de Software, entre elas atividades de VV\&T - Verificação, Validação e Teste (Maldonado, 1991; Myers e Sandler, 2004). Verificação refere-se ao conjunto de atividades que garante que o software 
implementa corretamente uma função específica. Validação refere-se a um conjunto de atividades que garante que o software construído corresponde aos requisitos (Pressman, 2001). Por fim, teste refere-se a um conjunto de atividades cuja finalidade é encontrar defeitos no programa (Myers e Sandler, 2004).

Existem alguns termos utilizados no contexto de teste de software que, de certo modo, parecem ter o mesmo significado ou definição, por exemplo: erro, falha e defeito. Entretanto, a literatura tradicional estabelece definições específicas para cada um deles. Um defeito (fault) é definido como sendo um passo, processo ou definição de dados incorretos. A ação humana que produz um defeito é definida como engano (mistake). A existência de um defeito pode produzir um estado inconsistente ou inesperado durante uma execução do programa, o que caracteriza a ocorrência de um erro (error). Tal erro pode fazer com que o resultado produzido pela execução seja diferente do resultado esperado, ou seja, pode levar a uma falha (failure). Nesta dissertação procura-se manter o significado desses termos.

A atividade de teste de software envolve basicamente quatro etapas: planejamento do teste, projeto dos casos de teste, execução do teste e avaliação dos resultados do teste. Durante essas etapas, cinco elementos são essenciais: o programa executável, a descrição do comportamento esperado, a observação do comportamento do programa, a descrição do domínio funcional e um método para determinar se o comportamento observado está de acordo com o esperado (Adrion et al., 1982). Os primeiros testes planejados e executados geralmente concentram-se nas unidades, individualmente. À medida que o teste progride, o próximo passo é tentar encontrar defeitos em conjuntos integrados de unidades. Por fim, testa-se o sistema como um todo (Pressman, 2001). Assim, pode-se dizer que a atividade de teste é realizada em três fases: teste de unidade, teste de integração e teste de sistema.

O teste de unidade concentra esforços na menor unidade do software com o objetivo de identificar defeitos de lógica e de implementação em cada unidade, isoladamente (Pressman, 2001). Segundo o padrão IEEE 610.12-1990 (IEEE, 1990), uma unidade refere-se à menor parte funcional de um programa que pode ser executada, como por exemplo, uma sub-rotina, um procedimento ou um método. O teste de cada unidade $U$ requer a implementação de uma unidade especial denominada pseudo-controladora (driver) e de uma ou mais unidade especiais denominadas pseudocontroladas (stubs). A unidade pseudo-controladora é responsável por coordenar o teste de $U$, ler os dados de teste fornecidos, repassar esses dados na forma de parâmetros para $U$, coletar os resultados relevantes produzidos por $U$ e apresentá-los. Já a unidade pseudo-controlada simula, na hora do teste, o comportamento de uma unidade chamada por $U$ (Myers e Sandler, 2004).

O teste de integração é uma atividade sistemática aplicada durante a integração da estrutura do programa visando a descobrir defeitos associados às interfaces entre as unidades; o objetivo é, a partir das unidades testadas na fase de teste de unidade, construir a estrutura de programa que foi determinada pelo projeto (Pressman, 2001).

O teste de sistema verifica a integração de todos os elementos que compõem o sistema e o seu funcionamento com a finalidade de assegurar que o sistema e os demais elementos que 
o compõem (por exemplo, hardware e banco de dados) se combinam adequadamente e que a função/desempenho global desejada é obtida. O teste de sistema consiste de uma série de testes de diferentes tipos, tais como: testes de recuperação, teste de segurança, teste de estresse e teste de desempenho (Pressman, 2001).

Um ponto crucial na atividade de teste, independentemente da fase, é o projeto e a avaliação da qualidade de um determinado conjunto de casos de teste utilizado para testar um determinado programa $P$. Um caso de teste consiste de um par ordenado $(d, S(d))$, no qual $d$ é um elemento de um dado domínio $D(d \in D)$ e $S(d)$ é a respectiva saída esperada para uma dada função quando $d$ é utilizado como entrada. Uma verificação completa de $P$ poderia ser obtida testando $P$ com um conjunto de casos de teste $T$ que inclui todos os elementos do domínio. Porém, isso é geralmente impraticável, pois o conjunto de elementos do domínio pode ser infinito ou muito grande. Assim, por questões de produtividade, torna-se necessária a escolha de um subconjunto de casos de teste que tenham alta probabilidade de encontrar a maioria dos defeitos com um mínimo de tempo e de esforço (Adrion et al., 1982; Maldonado e Barbosa, 2003).

Para selecionar e avaliar conjuntos de casos de teste é fundamental a utilização de critérios de teste. Em geral, os critérios de teste são estabelecidos, basicamente, a partir de três técnicas: a funcional, a estrutural e a baseada em defeitos. A técnica funcional (ou teste caixa-preta) utiliza a especificação de requisitos do programa para gerar casos de teste que serão empregados sem se importar com detalhes de implementação; A técnica estrutural (ou teste caixa-branca) gera os casos de tese a partir do conhecimento das características e detalhes internos de implementação; e, na técnica baseada em defeitos os caso de teste são provenientes do conhecimento de defeitos típicos inseridos durante o processo de desenvolvimento do software. Essas técnicas de teste são consideradas complementares e, dessa forma, devem ser utilizadas de forma que sejam exploradas as vantagens de cada uma.

\subsubsection{Técnica Funcional}

A técnica funcional tem o objetivo de verificar se a funcionalidade do programa satisfaz os requisitos dos usuários. Essa técnica é também denominada teste caixa-preta pelo fato de tratar o software como uma caixa, cujo conteúdo é desconhecido e só é possível visualizar o lado externo. Desse modo, o testador utiliza essencialmente a especificação funcional do programa para gerar os casos de teste que serão empregados sem se importar com os detalhes de implementação (Beizer, 1990).

O teste funcional envolve duas etapas importantes: identificar as funções que o software deve realizar e criar casos de teste capazes de checar se essas funções estão sendo realizadas pelo software (Pressman, 2001). Assim, uma especificação bem elaborada e de acordo com os requisitos do usuário é essencial para esse tipo de teste. Alguns exemplos de critérios de teste funcional são:

- Particionamento em Classes de Equivalência: consiste em particionar o domínio de entrada de um programa em um número finito de classes de equivalência de modo que o teste 
de um elemento representativo de uma classe seja equivalente ao teste de qualquer outro elemento da mesma classe. Assim, se um caso de teste de uma classe detecta um erro, todos os outros casos de teste da mesma classe irão detectar o mesmo erro. Equivalentemente, se um caso de teste não detecta nenhum erro, espera-se também que nenhum outro caso de teste na mesma classe o detecte (Myers e Sandler, 2004).

- Análise do Valor Limite: complementa o particionamento em classes de equivalência (Pressman, 2001). Uma vez identificado um conjunto de partições, escolhem-se então os casos de teste a partir de cada uma dessas partições. Este critério, em vez de selecionar qualquer caso de teste de uma partição, escolhe casos de teste nos limites das partições e também próximos ao ponto médio da partição, pois nesses pontos se concentra um grande número de erros (Sommerville, 2001; Pressman, 2001).

- Grafo de Causa-Efeito: é um critério que oferece uma representação concisa das condições lógicas e das ações correspondentes. Este critério estabelece requisitos de teste baseados nas possíveis combinações das condições de entrada, análise que não é explorada pelos critérios anteriores. O primeiro passo para gerar casos de teste é identificar as possíveis condições de entrada (causas) e as possíveis ações (efeitos) do programa. Em seguida, é construído um grafo relacionando as causas e efeitos identificados. Por fim, o grafo relacionando causas e efeitos é convertido em uma tabela de decisão a partir da qual são gerados os casos de teste (Maldonado e Barbosa, 2003).

\subsubsection{Técnica Estrutural}

A Técnica Estrutural, também chamada de teste caixa-branca, consiste em uma abordagem de teste que baseia-se na estrutura do programa para gerar seus casos de teste. Em geral, a maioria dos critérios dessa técnica utiliza uma representação de programa conhecida como Grafo de Fluxo de Controle $(\mathcal{C F G})$ ou Grafo de Programa, que mostra o fluxo lógico do programa.

Um grafo de fluxo de controle $G=(N, E, s)$ é um grafo dirigido que consiste de um conjunto $N$ de nós, um conjunto $E$ de arestas dirigidas e um nó de entrada $s$. Os nós representam comandos ou uma coleção de comandos sequienciais (bloco de comandos, definido abaixo) e as linhas ou arestas representam o fluxo de controle. O grafo de fluxo possui nós de entrada e nós de saída nos quais a computação começa e termina, respectivamente. Os nós de entrada não possuem nenhuma aresta de entrada, ou seja, não possuem antecessor. Por outro lado, os nós de saída não possuem nenhuma aresta de saída, ou seja, não possuem nenhum sucessor (Zhu et al., 1997).

Um bloco de comandos (ou bloco de instruções) consiste em um conjunto de comandos de um determinado programa $P$, de modo que, quando o primeiro comando do bloco é executado, os outros comandos do mesmo bloco também são executados seqüencialmente de acordo com a ordem estabelecida. Assim, todos os comandos de um bloco têm um único predecessor e um único sucessor, com exceção do primeiro que não tem um predecessor e do último que não tem um 
sucessor. Além disso, o primeiro comando de um bloco é o único comando que pode ser executado depois da execução do último comando do bloco anterior. Cada bloco corresponde a um nó e a transferência de controle de um bloco para outro é representada por arestas dirigidas entre os nós (Zhu et al., 1997; Rapps e Weyuker, 1982).

Um caminho é uma seqüência finita de nós $\left(n_{1}, n_{2}, \ldots, n_{k}\right), k \geq 2$, tal que existe uma aresta de $n_{i}$ para $n_{i+1}$ para $i=1,2, \ldots, k-1$. Um caminho completo é um caminho no qual o primeiro nó é o nó de entrada e o último nó é o nó de saída do grafo $G$ (Rapps e Weyuker, 1982). Um caminho é um caminho simples se todos os nós que compõem esse caminho, exceto possivelmente o primeiro e o último, são distintos. Um caminho livre-de-laço que é um caminho em que todos os nós são distintos, ou seja, nenhum nó aparece mais que uma vez. Um caminho é um caminho livre-de-iteração-de-laço se ele não contém o mesmo nó mais que duas vezes (Linnenkugel e Müllerburg, 1990). No teste estrutural existem também os caminhos não executáveis. Um caminho não executável é um caminho do grafo de fluxo de controle impossível de ser coberto para qualquer elemento do domínio de entrada. Isso acontece quando as condições lógicas que deveriam ser satisfeitas para que a seqüência de nós do caminho fosse executada são contraditórias (Howden, 1986).

Alguns exemplos de critérios de teste estrutural são:

Critérios Baseados em Fluxo de Controle utilizam informações do grafo de fluxo de controle do programa para derivar os requisitos de teste. Os critérios mais conhecidos são:

- Todos-Nós: exige que a execução do programa passe, pelo menos uma vez, em cada nó do grafo de fluxo de controle, ou seja, que cada comando do programa seja executado ao menos uma vez;

- Todas-Arestas: requer que cada aresta do grafo, ou seja, cada desvio de fluxo de controle do programa, seja exercitada pelo menos uma vez;

- Todos-Caminhos: requer que todos os caminhos possíveis do grafo de fluxo de controle sejam executados.

Critérios Baseados em Fluxo de Dados utiliza informações do fluxo de dados do programa para derivar os requisitos de teste. Para isso é necessário adicionar ao grafo de fluxo de controle informações a respeito do fluxo de dados, caracterizando o Grafo Def-Uso (Def-Use Graph) definido por Rapps e Weyuker (1982). Neste grafo são exploradas as interações que envolvem definições de variáveis e subseqüentes usos dessas variáveis. A definição de uma variável ocorre toda vez que um valor é atribuído a ela. O uso de uma variável, por sua vez, pode ser de dois tipos: quando a variável é usada em uma computação, diz-se que seu uso é computacional (c-uso); quando a variável é usada em uma condição, seu uso é predicativo (p-uso). Outro conceito importante é o par def-uso, que se refere a um par de definição e subseqüente c-uso ou p-uso de 
uma variável. Um caminho livre de definição com relação a (c.r.a) uma variável $x$ do nó $i$ ao nó $j$ é um caminho $\left(i, n_{1}, \ldots, n_{m}, j\right)$ para $m \geq 0$, no qual não há definições de $x$ nos nós $n_{1}, \ldots, n_{m}$.

Para que as informações de definição e uso das variáveis sejam adicionadas ao grafo Def-Uso, cada nó $i$ do grafo é associado aos conjuntos c-uso e def, e cada aresta $(i, j)$ ao conjunto p-uso. def $(i)$ é um conjunto de variáveis definidas no nó $i$; c-uso $(i)$ é um conjunto de variáveis para as quais existem c-usos em i; $p$-uso $(i, j)$ é um conjunto de variáveis para as quais existem p-uso na aresta $(i, j)$. Definem-se ainda outros conjuntos necessários na construção do critério def-uso (Rapps e Weyuker, 1982). Considere um nó $i$ e uma variável $x$ tal que $x \in \operatorname{def}(i)$. Assim:

- $d c u(x, i)$ é o conjunto de todos os nós $j$ tais que $x \in c$-uso $(j)$ e para os quais existe um caminho livre de definição (c.r.a) $x$ de $i$ a $j$ (Rapps e Weyuker, 1982);

- $d p u(x, i)$ é o conjunto de arestas $(j, k)$ tais que $x \in p$-uso $(j, k)$ e para as quais existe um caminho livre de definição (c.r.a) $x$ de $i$ a $(j, k)$ (Rapps e Weyuker, 1982);

Seja $P$ um conjunto de caminhos completos para um grafo Def-Uso de um programa. Diz-se que um nó $i$ está incluído em $P$ se $P$ contém um caminho $\left(n_{1}, \ldots, n_{m}\right)$ tal que $i=n_{j}$ para algum $j, 1 \leq j \leq m$. Similarmente, uma aresta $\left(i_{1}, i_{2}\right)$ está incluída em $P$ se $P$ contém um caminho $\left(n_{1}, \ldots, n_{m}\right)$ tal que $i_{1}=n_{j}$ e $i_{2}=n_{j+1}$ para algum $j, 1 \leq j \leq m-1$. Um caminho $\left(i_{1}, \ldots, i_{k}\right)$ está incluído em $P$ se $P$ contém um caminho $\left(n_{1}, \ldots, n_{m}\right)$ tal que $i_{1}=n_{j}, i_{2}=n_{j+1}, \ldots, i_{k}=$ $n_{j+k-1}$ para algum $j, 1 \leq j \leq m-k+1$ (Rapps e Weyuker, 1982).

Os critérios baseados em fluxo de dados são definidos a seguir. Considere $G$ um grafo Def-Uso e $P$ um conjunto de caminhos completos de $G$.

- Todas-Definições: $P$ satisfaz o critério Todas-Definições se para cada nó $i$ do grafo DefUso e para cada $x \in \operatorname{def}(i), P$ inclui um caminho livre de definição (c.r.a) $x$ de $i$ a algum elemento de $d c u(x, i)$ ou $d p u(x, i)$ (Rapps e Weyuker, 1982).

- Todos-C-Usos: $P$ satisfaz o critério Todos-C-Usos se para cada nó $i$ do grafo Def-Uso e para cada $x \in \operatorname{def}(i), P$ inclui um caminho livre de definição (c.r.a) $x$ de $i$ a cada elemento de $d c u(x, i)$ (Rapps e Weyuker, 1982).

- Todos-P-Usos: $P$ satisfaz o critério Todos-P-Usos se para cada nó $i$ do grafo Def-Uso e para cada $x \in \operatorname{def}(i), P$ inclui um caminho livre de definição (c.r.a) $x$ de $i$ a cada elemento de $d p u(x, i)$ (Rapps e Weyuker, 1982).

- Todos-Usos: $P$ satisfaz o critério Todos-Usos se para cada nó $i$ do grafo Def-Uso e para cada $x \in \operatorname{def}(i), P$ inclui um caminho livre de definição (c.r.a) $x$ de $i$ a cada elemento de $d c u(x, i)$ e a cada elemento de $d p u(x, i)$ (Rapps e Weyuker, 1982).

- Todos-C-Usos/Algum-P-Usos: $P$ satisfaz o critério Todos-C-Usos/Algum-P-Usos se para cada nó $i$ do grafo Def-Uso e para cada $x \in \operatorname{def}(i), P$ inclui um caminho livre de definição 
(c.r.a) $x$ de $i$ a cada elemento de $d c u(x, i)$; se $d c u(x, i)$ é vazio, então $P$ deve incluir um caminho livre de definição (c.r.a) x de $i$ a alguma aresta em $d p u(x, i)$ (Rapps e Weyuker, 1982).

- Todos-P-Usos/Algum-C-Usos: $P$ satisfaz o critério Todos-P-Usos/Algum-C-Usos se para cada nó $i$ do grafo Def-Uso e para cada $x \in \operatorname{de} f(i), P$ inclui um caminho livre de definição (c.r.a) $x$ de $i$ a cada elemento de $d p u(x, i)$; se $d p u(x, i)$ é vazio, então $P$ deve incluir um caminho livre de definição (c.r.a) $x$ de $i$ a algum nó em $d c u(x, i)$ (Rapps e Weyuker, 1982).

- Todos-Caminhos-DU: $P$ satisfaz o critério Todos-Caminhos-DU se para cada nó $i$ do grafo Def-Uso e para cada $x \in \operatorname{def}(i), P$ inclui cada caminho livre-de-laço livre de definição (c.r.a) $x$ de $i$ a cada elemento de $d p u(x, i)$ e a cada elemento de $d c u(x, i)$ (Rapps e Weyuker, 1982).

- Todos-Potenciais-Usos: $P$ satisfaz o critério Todos-Potenciais-Usos se para cada nó $i$ do grafo Def-Uso e para cada $x \in \operatorname{def}(i), P$ inclui um caminho livre de definição (c.r.a) $x$ de $i$ a cada nó alcançável $j$ ou aresta $(j, k)$ do grafo Def-Uso, pois em $j$ ou $(j, k)$ pode haver um uso de $x$ (Maldonado e Barbosa, 2003).

\subsubsection{Técnica Baseada em Defeitos}

A técnica de teste baseada em defeitos deriva os requisitos de teste a partir de informações sobre os enganos mais freqüentes cometidos pelo programador ou projetista durante o processo de desenvolvimento de software (DeMillo et al., 1987). Os critérios típicos do teste baseado em defeitos são muito utilizados para medir a qualidade do conjunto de casos de teste de acordo com sua habilidade ou efetividade para detectar defeitos (Zhu et al., 1997). Dentre eles pode-se citar:

- Semeadura de Defeitos: uma quantidade conhecida de defeitos é semeada artificialmente no programa, ou seja, defeitos artificiais são introduzidos aleatoriamente no programa a ser testado e de modo desconhecido para o testador. Em seguida, o programa é testado e os defeitos naturais e artificiais descobertos são contabilizados separadamente. Usando estimativas de probabilidade, o número de defeitos naturais ainda existentes no programa pode ser calculado e é estatisticamente previsto com máxima probabilidade de ser $f / r$, onde $f$ é o número de defeitos naturais encontrados no teste e $r$ a taxa do número de defeitos artificiais encontrados do total de defeitos artificiais semeados (Budd, 1981; Zhu et al., 1997).

- Análise de Mutantes: utiliza um programa $P$ e um conjunto de casos de teste $T$ gerado. O primeiro passo nesse critério é a construção de uma coleção de programas alternativos (mutantes) que diferem ligeiramente do original. Cada mutante é executado sobre cada caso de teste do conjunto $T$. Essa execução termina quando um elemento de $T$ revela que $P$ e o programa mutante produz diferentes respostas ou quando $T$ é consumido completamente. 
No primeiro caso, diz-se que o mutante morreu e, no outro caso, diz-se que ainda está vivo (DeMillo et al., 1987; Zhu et al., 1997).

\subsection{Uma Abordagem de Teste Estrutural de Integração para Programas Procedimentais}

Uma abordagem interessante de teste estrutural de integração para programas procedimentais é apresentada por Linnenkugel e Müllerburg (1990). Embora essa abordagem tenha como finalidade o teste de programas implementados no paradigma de programação procedimental (que não é o foco dessa dissertação), muitos dos termos e critérios nela definidos, principalmente os referentes ao teste de interfaces entre os procedimentos, foram revisados e adaptados para a abordagem teste estrutural de integração par-a-par de programas $\mathrm{OO}$ e OA proposta nesta dissertação. A seguir é discutido um pouco sobre o trabalho das pesquisadoras cuja finalidade foi adaptar o conjunto de critérios baseados em fluxo de controle e em fluxo de dados definidos para o teste de unidade e, a partir dele, propor critérios similares para teste de integração.

Durante o teste de unidade o foco é testar uma única parte (ou módulo ${ }^{1}$ ) do programa, enquanto que durante o teste de integração deve-se testar as relações e as interfaces entre as diversas partes do programa. Na abordagem de Linnenkugel e Müllerburg (1990) um módulo representa um procedimento, as relações entre os módulos são determinadas pelas sentenças de chamadas entre eles e as interfaces são os dados usados tanto pelo módulo chamador quanto pelo módulo chamado.

Para testar as relações, pode-se utilizar critérios similares aos critérios de fluxo de controle, os quais são baseados em um grafo de chamada (call graph), também denominado p-grafo (program graph). Um p-grafo é um multigrafo dirigido $G$ com um distinto nó $s$, chamado de nó raiz, tal que todo nó em um grafo é alcançável a partir de $s$ por algum caminho. Como um p-grafo é um multigrafo, pode haver muitas arestas entre dois nós quaisquer. Os nós neste grafo representam os módulos e as arestas representam as sentenças de chamada. Uma seqüência de nós ou caminho neste grafo representa seqüência de sentenças de chamadas descendentes. Assim, um programa $P$ pode ser representado na forma $G(P)=(N, E, s)$ em que $N$ representa o conjunto de módulos (nós), $E$ o conjunto de sentenças de chamada (arestas) e $s$ o módulo principal (nó raiz). Um exemplo de p-grafo é apresentado na Figura 3.1. Suponha um programa com quatro módulos: um módulo Ma in que chama os módulos A e B e um módulo Sort que é chamado pelo módulo A e pelo módulo B.

Em seu trabalho, Linnenkugel e Müllerburg (1990) adicionaram mais dois novos critérios aos critérios de fluxo de controle previamente formado pelos critérios: todos-nós, todas-arestas e todoscaminhos. Alguns termos usados na definição desses critérios são discutidos na Seção 3.2.2:

\footnotetext{
${ }^{1}$ Observe que Linnenkugel e Müllerburg (1990) utilizam o termo módulo com uma concepção diferente da utilizada nesta dissertação.
} 


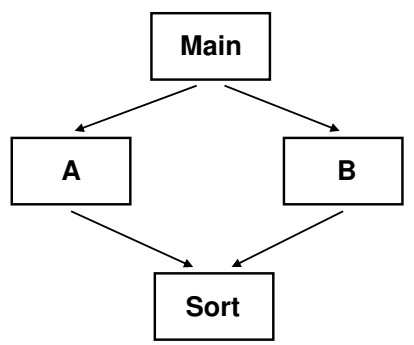

Figura 3.1: Exemplo p-grafo (adaptado de Vilela et al. (1999)).

- todos-caminhos-livres-de-iteração-de-laço, requer que todo caminho livre-de-iteração-delaço seja executado pelo menos uma vez.

- todos-caminhos-simples, requer que todo caminho simples seja executado pelo menos uma vez.

Baseado nos critérios já existentes e nos dois novos critérios definidos, foram propostos os seguintes critérios para testar as relações entre os módulos no teste de integração:

- todos-módulos requer que todos os módulos sejam executados pelo menos uma vez, ou seja, que todo nó do p-grafo seja coberto (todos-nós).

- todas-relações requer que a relação de chamada entre módulos seja executada pelo menos uma vez, ou seja, que ao menos uma das arestas entre dois módulos seja coberta (todas-umadas-múltiplas-arestas)

- todas-múltiplas-relações requer que todas chamadas entre módulos sejam executadas ao menos uma vez, ou seja, que todas as arestas de um p-grafo seja coberta (todas-arestas)

- todas-seqüência-de-chamadas-simples requer que todas seqüências de chamadas descendentes sem repetição de chamadas sejam executadas ao menos uma vez, ou seja, que todo caminho simples do p-grafo seja coberto (todos-caminhos-simples).

- todas-seqüência-de-chamadas-livre-de-iteração-de-laço requer que todas seqüências de chamadas descendentes sem repetição de laços sejam executadas ao menos uma vez, ou seja, que todo caminho livre-de-iteração-de-laço do p-grafo seja coberto (todos-caminhoslivre-de-iteração-de-laço).

- todas-seqüências-de-chamadas requer que toda seqüência de chamadas descendentes seja executada ao menos uma vez, ou seja, que todo caminho do p-grafo seja coberto (todoscaminhos).

Entretanto, esses critérios não são suficientes para testar as interfaces entre os módulos, pois eles não consideram o fluxo de dados através do programa. Para contornar isso, Linnenkugel e 
Müllerburg (1990) adaptaram os critérios de fluxo de dados definidos por Rapps e Weyuker (1982). Para obter as informações de fluxo de dados entre os módulos, são utilizados os grafos de fluxo de dados (ou grafos def-uso) dos módulos.

A interface entre dois módulos é determinada pelos dados usados no módulo chamador e no módulo chamado. Esses dados são denominados variáveis de comunicação e podem ser parâmetros ou variáveis globais. Todas as outras variáveis que não influenciam diretamente a comunicação não são consideradas no teste de integração. Na abordagem desenvolvida pelas pesquisadoras não são considerados os parâmetros que são funções e as variáveis estruturadas. Somente as variáveis simples são tratadas.

Para o teste de integração são considerados somente aqueles caminhos (ou relações def-uso) que diretamente influenciam a comunicação entre os procedimentos, ou seja:

- para as variáveis $x$ que são usadas como entrada, consideram-se os caminhos compostos dos sub-caminhos a partir da última definição de $x$ precedente à chamada até a chamada $\mathrm{e}$ dos sub-caminhos a partir da entrada do procedimento chamado até o primeiro uso de $x$ no procedimento chamado.

- para as variáveis $x$ que são usadas como saída, consideram-se os caminhos compostos dos sub-caminhos a partir da última definição de $x$ no procedimento chamado até a saída do procedimento chamado e dos sub-caminhos a partir da chamada até o primeiro uso de $x$ depois da chamada.

Para definir os critérios para testar as interfaces entre os módulos foram estabelecidos alguns termos e definições. Um programa consiste de módulos $M_{n}$ que são procedimentos e $M_{0}$ que é o programa principal. Nesta abordagem as funções não são consideradas. Para identificar as chamadas usa-se a notação: $M_{i_{h} j}$ que denota a h-ésima chamada do procedimento $M_{i}$ no procedimento $M_{j}$. O módulo $M_{j}$ é o módulo chamador e o módulo $M_{i}$ é o módulo chamado.

Para cada módulo foram definidos os seguintes conjuntos:

- FP-IN $\left(M_{i}\right)$ é o conjunto de parâmetros formais do módulo $M_{i}$ que são usados como entrada.

- FP-OUT $\left(M_{i}\right)$ é o conjunto de parâmetros formais do módulo $M_{i}$ que são usados como saída.

- $G L O-I N\left(M_{i}\right)$ é o conjunto de variáveis globais que são usadas no módulo $M_{i}$.

- GLO-OUT $\left(M_{i}\right)$ é o conjunto de variáveis globais que são definidas no módulo $M_{i}$.

Para cada chamada do módulo $M_{i}$ no módulo $M_{j}$ foram definidos os seguintes conjuntos:

- $A P-I N\left(M_{i_{h} j}\right)$ é o conjunto de parâmetros reais que são usados como entrada. 
- $A P-O U T\left(M_{i_{h} j}\right)$ é o conjunto de parâmetros reais que são usados como saída.

Para descrever as relações entre parâmetros reais e formais foram utilizados dois mapeamentos que são ambos bijetivos. O mapeamento $I_{i_{h} j}$ relaciona cada parâmetro real de entrada da chamada $M_{i_{h} j}$ com o correspondente parâmetro formal do procedimento chamado $M_{i}$ e cada variável global, usada como entrada, com ela mesma.

- $I_{i_{h} j}: A P-I N\left(M_{i_{h} j}\right) \cup G L O-I N\left(M_{i}\right) \rightarrow F P-I N\left(M_{i}\right) \cup G L O-I N\left(M_{i}\right)$, com

$$
\begin{aligned}
& -I_{j_{h} / A P-I N}: A P-I N\left(M_{i_{h} j}\right) \rightarrow F P-I N\left(M_{i}\right) \\
& \text { - } I_{j_{h} / G L O-I N}: G L O-I N\left(M_{i}\right) \rightarrow G L O-I N\left(M_{i}\right)
\end{aligned}
$$

O mapeamento $O_{j_{h}}$ relaciona cada parâmetro real de saída da chamada $M_{i_{h} j}$ com o correspondente parâmetro formal do procedimento chamado $M_{i}$ e cada variável global, usada como saída, com ela mesma.

- $O_{j_{h}}: A P-O U T\left(M_{i_{h} j}\right) \cup G L O-O U T\left(M_{i}\right) \rightarrow F P-O U T\left(M_{i}\right) \cup G L O-O U T\left(M_{i}\right)$, com

$$
\begin{aligned}
& \text { - } \text { O }_{j_{h} / A P-O U T}: A P-O U T\left(M_{i_{h} j}\right) \rightarrow F P-O U T\left(M_{i}\right) \\
& \text { - O } j_{j_{h} / G L O-O U T}: G L O-O U T\left(M_{i}\right) \rightarrow G L O-O U T\left(M_{i}\right)
\end{aligned}
$$

Baseado nestas definições e nos grafos de fluxo de dados dos módulos, alguns conjuntos são definidos. Considere: $x$ uma variável; $\operatorname{de} f(x)$ a definição ou alteração de $x ; c$-uso $(x)$ o uso computacional de $x ; p$-uso $(x)$ o uso predicativo de $x$. Assim, para cada módulo $M_{i}$ foram definidos os seguintes conjuntos:

- C-USE-FP-IN $\left(M_{i}, x\right)$ é o conjunto de nós $n_{k}$ com um c-uso $(x)$ e um caminho livre de definição com relação a $x$ a partir do nó de entrada de $M_{i}$ até o nó $n_{k}$.

- P-USE-FP-IN $\left(M_{i}, x\right)$ é o conjunto de arestas $\left(n_{k}, n_{l}\right)$ com um $p$-uso $(x)$ e um caminho livre de definição com relação a $x$ a partir do nó de entrada de $M_{i}$ até a aresta $\left(n_{k}, n_{l}\right)$.

- DEF-FP-OUT $\left(M_{i}, x\right)$ é o conjunto de nós $n_{k}$ com um def $f(x)$ e um caminho livre de definição com relação a $x$ a partir do nó $n_{k}$ até o nó de saída.

Para cada chamada $M_{i_{h} j}$ foram definidos os seguintes conjuntos:

- DEF-PRE $\left(M_{i_{h} j}, x\right)$ é um conjunto de nós $n_{k}$ com um def $(x)$ e um caminho livre de definição com relação a $x$ a partir de $n_{k}$ até o nó de chamada e $x \in A P-I N\left(M_{i_{h} j}\right)$ ou $x \in G L O-I N\left(M_{i}\right)$.

- C-USE-POST $\left(M_{i_{h} j}, x\right)$ é um conjunto de nós $n_{k}$ com um c-uso(x) e um caminho livre de definição com relação a $x$ a partir do nó de chamada até $n_{k}$ e $x \in \operatorname{AP-OUT}\left(M_{i_{h j}}\right)$ ou $x \in G L O-O U T\left(M_{i}\right)$. 
- P-USE-POST $\left(M_{i_{h} j}, x\right)$ é um conjunto de arestas $\left(n_{k}, n_{l}\right)$ com um $p$-uso $(x)$ e um caminho livre de definição com relação a $x$ a partir do nó de chamada até $\left(n_{k}, n_{l}\right)$ e $x \in A P$ $\operatorname{OUT}\left(M_{i_{h} j}\right)$ ou $x \in G L O-O U T\left(M_{i}\right)$.

A partir dessas definições e termos foram definidos os critérios para testar as interfaces entre os módulos no teste de integração, que são: INT-todas-definições, INT-todos-c-usos/algum-pusos, INT-todos-p-usos/algum-c-usos, INT-todos-caminhos-du e INT-todos-usos. Esses critérios foram adaptados, respectivamente, dos critérios todas-definições, todos-c-usos/algum-p-usos, todos-p-usos/algum-c-usos, todos-caminhos-du e todos-usos (discutidos na Seção 3.2). Segundo Linnenkugel e Müllerburg (1990) os critérios todos-p-usos e todos-c-usos não foram adaptados, pois eles não testam a comunicação entre dois módulos caso não haja um p-uso ou c-uso, respectivamente. Nessa dissertação só é apresentado a definição completa do critério INT-todos-usos a qual é apresentada a seguir. Considere $\Phi$ um conjunto de chamadas $M_{i_{h} j}$.

- INT-todos-usos requer para todas chamadas a execução de um caminho livre de definição com relação a cada variável de comunicação a partir de cada definição relevante até todo c-uso e todo p-uso, ou seja, para cada $M_{i_{h} j} \in \Phi$

- para cada $x \in A P-I N\left(M_{i_{h} j}\right)$ e cada $x \in G L O-I N\left(M_{i}\right)$ um caminho livre de definição a partir de cada $n_{k} \in D E F-P R E\left(M_{i_{h} j}, x\right)$ até cada nó $n_{l} \in C-U S E-F P$ $I N\left(M_{i}, I_{i_{h} j}(x)\right)$ e até cada aresta $\left(n_{l}, n_{m}\right) \in P$-USE-FP-IN $\left(M_{i}, I_{i_{h} j}(x)\right)$ deve ser executado.

- para cada $x \in A P$-OUT $\left(M_{i_{h} j}\right)$ e cada $x \in G L O-O U T\left(M_{i}\right)$ um caminho livre de definição a partir de cada $n_{k} \in D E F-F P-O U T\left(M_{i}, O_{j_{h}}(x)\right)$ até cada nó $n_{l} \in C$ $U S E-P O S T\left(M_{i_{h} j}, x\right)$ e até cada aresta $\left(n_{l}, n_{m}\right) \in P$-USE-POST $\left(M_{i_{h} j}, x\right)$ deve ser executado.

Para construir os caminhos def-uso, Linnenkugel e Müllerburg (1990) utilizam a Tabela 3.1 (definida por Rapps e Weyuker (1982)). A tabela contém entradas para cada variável $x$ (act-in ou act-out) e cada nó com de $f(x)\left(M_{j}\right.$-node-def ou $M_{i}$-node-de $\left.f\right)$ e lista todos os nós com c-uso $(x)$ $\left(M_{i}-D C U\right.$ ou $\left.M_{j}-D C U\right)$ e todas as arestas com $p$-uso $(x)\left(M_{i}-D P U\right.$ ou $\left.M_{j}-D P U\right)$ para os quais existe um caminho livre de definição com relação a $x$ a partir do nó de com $\operatorname{de} f(x)$. O conjunto de nós com c-usos é chamado $D C U$ e o conjunto de arestas com $p$-usos é denominado $D P U$.

Tabela 3.1: Tabela de caminhos def-uso (adaptada de Linnenkugel e Müllerburg (1990)).

\begin{tabular}{|c|c|c|c|}
\hline Variável & Nó de Definição & DCU & DPU \\
\hline \hline act-in & $M_{j}$-node-def & $M_{i}-D C U$ & $M_{i}$-DPU \\
\hline$\ldots$ & $\ldots$ & $\ldots$ & $\ldots$ \\
\hline act-out & $M_{i}$-node-def & $M_{j}$-DCU & $M_{j}$-DPU \\
\hline$\ldots$ & $\ldots$ & $\ldots$ & $\ldots$ \\
\hline
\end{tabular}




\subsection{Teste Estrutural de Programas Orientados a Objetos}

A maioria das abordagens de teste estrutural de programas orientados a objetos foram adaptadas de abordagens anteriormente propostas para o paradigma procedimental. Entretanto, o paradigma $\mathrm{OO}$ apresenta novos desafios para o teste de software. Um programa OO é composto de classes e de objetos, características não encontradas no paradigma procedimental. Além disso, são necessárias abordagens especiais para lidar com herança, polimorfismo e acoplamento dinâmico (dynamic binding). A partir daí, algumas abordagens de teste estrutural foram propostas.

Uma das primeiras abordagens de teste estrutural de programas $\mathrm{OO}$ foi apresentada por Harrold e Rothermel (1994). Essa abordagem apóia o teste estrutural baseado em fluxo de dados para todos os tipos de interações de fluxo em uma classe. Ela considera quatro níveis de teste: intramétodo, inter-método, intra-classe e inter-classe. Muitas das abordagens para teste estrutural OO baseiam-se nesses níveis de teste. Em seu trabalho Harrold e Rothermel (1994) consideram a classe como a menor unidade a ser testada no teste de unidade de um programa OO. Autores como Perry e Kaiser (1990) e Binder (1999) seguem a mesma linha de Harrold e Rothermel (1994). Entretanto, outros autores como dos Santos Domingues (2001) e Vincenzi (2004) consideram os métodos como sendo a menor unidade a ser testada. Na Tabela 3.2 são sintetizados os tipos de teste de software $\mathrm{OO}$ que podem ser aplicados em cada uma das fases de teste considerando o método ou a classe como sendo a menor unidade.

Tabela 3.2: Relação entre as fases de teste e o teste de programas OO (adaptada de dos Santos Domingues (2001)).

\begin{tabular}{|c|c|}
\hline \multicolumn{2}{c}{ Menor Unidade: Método } \\
\hline \hline Fase & Teste de Software Orientado a Objetos \\
\hline Unidade & Intra-método \\
\hline Integração & Inter-método, Intra-classe e Inter-classe \\
\hline Sistema & Toda a aplicação \\
\hline \multicolumn{2}{|c|}{ Menor Unidade: Classe } \\
\hline \hline Fase & Teste de Software Orientado a Objetos \\
\hline Unidade & Intra-método, Inter-método e Intra-classe \\
\hline Integração & Inter-classe \\
\hline Sistema & Toda a aplicação \\
\hline \hline
\end{tabular}

Harrold e Rothermel (1994) definiram o grafo de chamadas de classe (class call graph) para representar a estrutura de chamadas de métodos dentro de uma classe e também as chamadas que podem ser feitas de fora da classe. Nesse grafo os nós representam os métodos e as arestas representam chamadas entre os métodos. A implementação parcial em C++ da classe Symbol Table mostrada na Figura 3.2 será utilizada durante toda esta seção para explicar a abordagem dos pesquisadores. O grafo de chamadas para esta classe é apresentado na Figura 3.3. As linhas pontilhadas 
Seção 3.4.1) é considerado um teste de unidade OO, e os testes inter-método, intra-classe e interclasse (discutidos na Seção 3.4.2) são considerados testes de integração OO. Nas seções a seguir são também descritas abordagens de teste estrutural $\mathrm{OO}$ propostas por outros pesquisadores.

\subsubsection{Teste Estrutural de Unidade}

A primeira abordagem de teste estrutural de unidade para programas OO proposta é o teste intra-método (Harrold e Rothermel, 1994) cuja finalidade é testar cada método individualmente. Para ilustrar o teste intra-método, considere o código-fonte da Figura 3.2. Neste exemplo, o teste intra-método é realizado em cada um dos dez métodos da classe Symbol Table, separadamente. Para avaliar relações de fluxo de dados intra-método em programas OO, Harrold e Rothermel (1994) utilizam o par definição-uso $(d, u)$. Considerando uma classe $C$, uma sentença $d$ que define uma variável e uma sentença $u$ que contém um uso da variável, define-se:

- Par Def-Uso Intra-Método: Seja $M$ um método de $C$. Se $d$ e $u$ estão em $M$ e existe um programa $P$ que chama $M$, tal que $(d, u)$ é um par def-uso exercitado durante uma simples invocação de $M$, então $(d, u)$ é um par def-uso intra-método.

Analisando o código-fonte da Figura 3.2, um exemplo de par def-uso intra-método ocorre no método Lookup com relação a variável index que é definida na linha 27 e usada na linha 28.

Para derivar os pares def-uso intra-método, Harrold e Rothermel (1994) propõem a utilização do algoritmo de Pande, Landi e Ryder ( $P L R$ ) (Pande e Ryder, 1994), concebido para derivar pares def-uso intra e interprocedimentais para a linguagem $\mathrm{C}$.

Uma abordagem de teste de fluxo de controle e de dados intra-método é apresentada por Vincenzi (2004). O pesquisador considera o método como a menor unidade do programa. Em seu trabalho, Vincenzi (2004) utiliza o grafo Def-Uso $(\mathcal{D U})$ para representar o fluxo de controle e o fluxo de dados intra-método tanto durante a execução normal do programa quanto na presença de exceções. Além disso, com base no grafo $\mathcal{D U}$, o pesquisador revisou os critérios baseados em fluxo de controle e em fluxo de dados e definiu alguns critérios para serem aplicados em programas OO. A seguir é discutido um pouco sobre o trabalho de Vincenzi (2004).

De acordo com a abordagem adotada pelo pesquisador, antes de se construir o grafo $\mathcal{D U}$, constrói-se o que é chamado de Grafo de Fluxo de Dados de Instrução (Data-Flow Instruction Graph - $\mathcal{I} \mathcal{G})$ de cada método. Informalmente, um $\mathcal{I} \mathcal{G}$ é um grafo no qual cada nó contém uma única instrução de bytecode e as arestas conectam instruções que podem ser executadas em seqüência.

Para lidar com o mecanismo de tratamento de exceção de Java, o pesquisador optou por utilizar dois tipos diferentes de arestas na construção do $\mathcal{I} \mathcal{G}$ : arestas regulares (regular edges) representando o fluxo de controle "normal", ou seja, quando nenhuma exceção é lançada (thrown); e arestas de exceção (exception edges), representando o desvio de fluxo de controle quando ocorre 
uma exceção. Formalmente, o grafo $\mathcal{I} \mathcal{G}$ de um método $m$ é definido como um grafo dirigido $\mathcal{I} \mathcal{G}(m)=(N I, E I$, si, $T I)$ no qual:

- $N I$ representa o conjunto não vazio de nós de um grafo $\mathcal{I} \mathcal{G}: N I=\left\{n_{i} \mid n_{i}\right.$ corresponde a uma instrução de bytecode $i$, para toda instrução de bytecode alcançável $i$ de $m$ \}.

- $s_{i} \in N I$ é o nó de entrada, ou seja, ele corresponde ao nó que contém a primeira instrução do método $m$.

- $T I \subseteq N I$ é o conjunto de nós de saída.

- $E I=E I_{r} \cup E I_{e}$ é o conjunto completo de arestas de $\mathcal{I} \mathcal{G}$, no qual:

- $E I_{r}$ e $E I_{e}$ correspondem a dois subconjuntos disjuntos de arestas regulares e de exceção, respectivamente;

* $E I_{e}$ é o conjunto de arestas de exceção definido como $E I_{e}=\left\{\left(n_{i}, n_{j}\right) \mid\right.$ a instrução de $n_{i}$ está no escopo de um tratador de exceção que inicia na instrução de $\left.n_{j}\right\}$.

* $E I_{r}$ é o conjunto de arestas regulares definido como $E I_{r}=\left\{\left(n_{i}, n_{j}\right) \mid\right.$ a instrução em $n_{j}$ pode ser executada imediatamente após a instrução em $n_{i}$ e $\left.\left(n_{i}, n_{j}\right) \notin E I_{e}\right\}$.

Uma vez que $\mathcal{I} \mathcal{G}$, representando o fluxo de controle de determinado método, tenha sido computado é necessário inserir nele informações de fluxo de dados. Para isso Vincenzi (2004) definiu um modelo de fluxo de dados que indica quais instruções de bytecode são responsáveis pela definição e uso de variáveis e como variáveis de referência e vetores (arrays) devem ser considerados. A Tabela 3.3 ilustra as 11 classes de instruções que foram definidas para auxiliar a definição do modelo de fluxo de dados. Além disso, foram feitas algumas suposições para identificação de definições e usos de variáveis agregadas, atributos de instância, atributos estáticos e variáveis usadas em uma chamada de método (parâmetros ou argumentos).

Baseado nas suposições para identificação de definições e usos de variáveis e nas diferentes classes de instruções de bytecode, o grafo $\mathcal{I} \mathcal{G}$ de um dado método é percorrido e a cada nó do grafo é associado um conjunto def $(i)$ que representa o conjunto de variáveis definidas naquele nó e um conjunto uso $(i)$ que representa o conjunto de variáveis usadas naquele nó.

$\mathcal{I G}$ oferece uma maneira prática de percorrer o conjunto de instruções de uma dada unidade, identificando definições e usos de variáveis. Entretanto, o número de nós e arestas envolvidos nesse tipo de grafo pode ser muito grande. Dessa maneira, constrói-se o grafo Def-Uso $(\mathcal{D U})$ baseando-se no conceito de bloco de instruções (discutido na Seção 3.2.2).

O grafo $\mathcal{D U}$ representa o modelo base que é utilizado para se derivar requisitos de teste de fluxo de controle e de dados intra-método. Um grafo $\mathcal{D U}$ de um dado método $m$ é definido como um grafo dirigido $\mathcal{D U}(m)=(N, E, s, T)$ no qual cada nó $n \in N$ representa um bloco de instruções: 
Tabela 3.3: Diferentes classes de instruções de bytecode (Vincenzi, 2004).

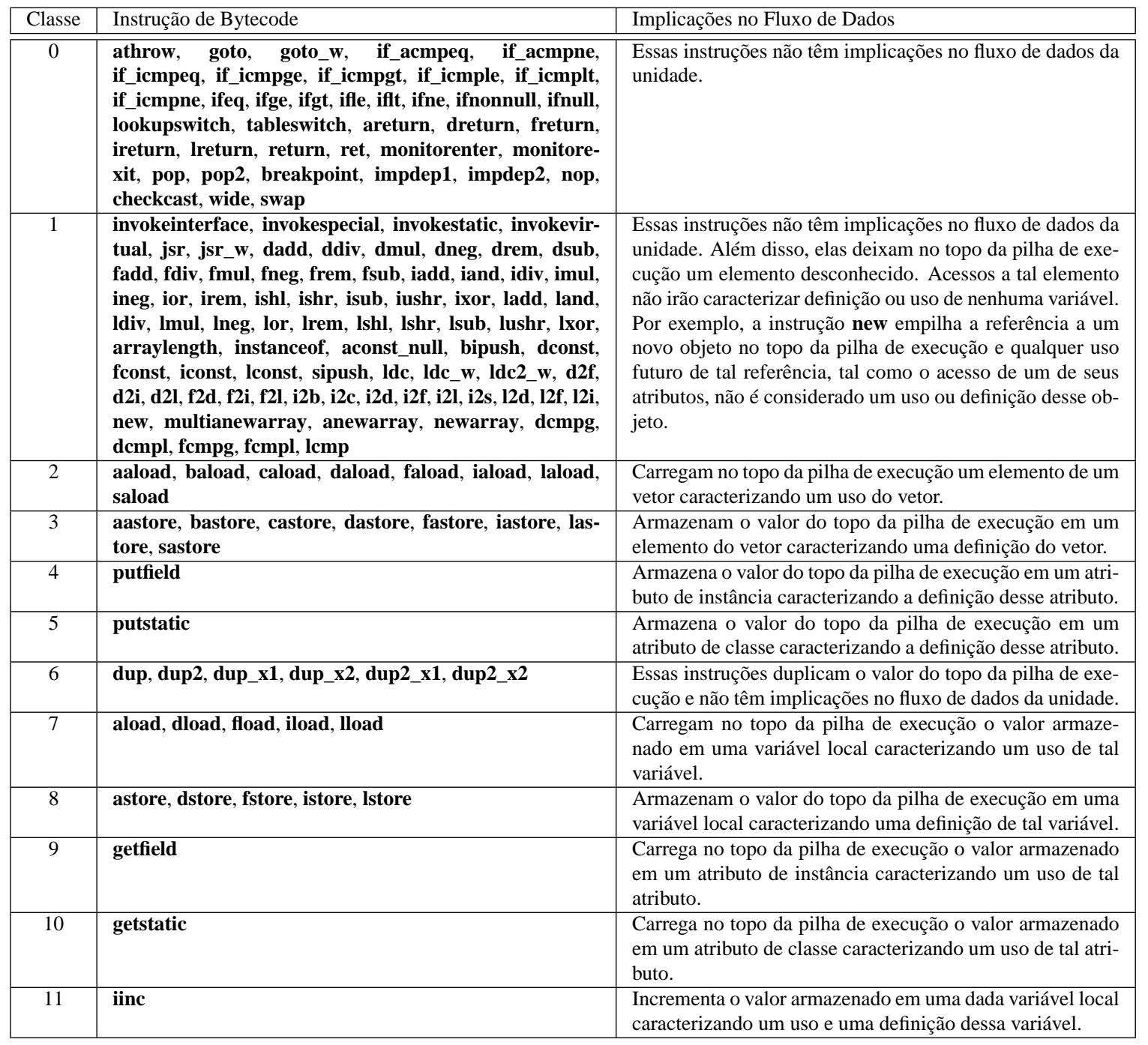

- $N$ representa o conjunto de nós de um grafo $\mathcal{D U}: N=\{n \mid n$ corresponde a um bloco de instruções de bytecode de $m\}$, ou seja, $N$ é um conjunto não vazio de nós, representando todos os blocos de instruções de bytecode de $m ; I_{n}$ é a n-upla ordenada de instruções agrupadas no nó $n$;

- $s \in N$ é o nó de entrada de $m$;

- $T \subseteq N$ é o conjunto (possivelmente vazio) de nós de saída;

- $E=E_{r} \cup E_{e}$ é o conjunto completo de arestas de $\mathcal{D U}$. Seja $\mathcal{I} \mathcal{G}(m)=(N I, E I$, si, $T I)$, tem-se:

- $E_{e}$ é o conjunto de arestas de exceção definido como $E_{e}=\left\{\left(n_{i}, n_{j}\right) \mid\right.$ existe em $\mathcal{I} \mathcal{G}(m)$ uma aresta de exceção do último elemento de $I_{n_{i}}$ para o primeiro elemento de $I_{n_{j}}$; 
- $E_{r}$ é o conjunto de arestas regulares definido como $E_{r}=\left\{\left(n_{i}, n_{j}\right) \mid\right.$ existe em $\mathcal{I} \mathcal{G}(m)$ uma aresta regular do último elemento de $I_{n_{i}}$ para o primeiro elemento de $I_{n_{j}}$;

Vincenzi (2004) também definiu alguns critérios de teste baseados em fluxo de controle e em fluxo de dados para serem aplicados no contexto de programas OO. Considerando o teste de fluxo de controle, o pesquisador utilizou dois critérios de teste: todos-nós (all-nodes) e todas-arestas (alledges) (Myers e Sandler, 2004). Tais critérios foram revisados no contexto do teste de programas OO considerando os aspectos relacionados ao tratamento de exceção.

Antes da definição dos critérios, alguns conceitos precisam ser discutidos. Vincenzi (2004) dividiu os requisitos de teste em dois conjuntos disjuntos: um contendo todos os requisitos que podem ser cobertos durante a execução normal de um programa - denominado independente de exceção - e outro contendo apenas os requisitos que necessitam do lançamento de uma exceção para serem cobertos - denominado dependente de exceção. A partir daí foram definidos os seguintes conceitos:

- Nós predicativos: O conjunto de nós predicativos é o conjunto de todos os nós do grafo $\mathcal{D U}$ que contêm mais de uma aresta regular de saída.

- Caminhos livres de exceção: O conjunto de caminhos livres de exceção é o conjunto $\pi \mid \forall\left(n_{i}\right.$ ,$\left.n_{j}\right) \in \pi \Rightarrow\left(n_{i}, n_{j}\right)$ alcançável por um caminho que não contém nenhuma aresta de exceção.

- Nós dependentes e independentes de exceção: O conjunto de nós dependentes de exceção é definido como $N_{e d}=\{n \in N \mid \nexists$ um caminho livre de exceção $\pi$ tal que $n \in \pi\}$. O conjunto de nós independentes de exceção é o conjunto definido como $N_{e i}=N-N_{e d}$.

- Arestas dependentes e independentes de exceção: As arestas dependentes de exceção formam o conjunto $E_{e d}=\{e \in E \mid \nexists$ um caminho livre de exceção $\pi$ tal que $e \in \pi\}$. As arestas independentes de exceção formam o conjunto $E_{e i}=E-E_{e d}$.

Seja $T$ um conjunto de casos de teste para um programa $P$ (sendo que $\mathcal{D U}$ é o grafo de fluxo de controle/dados de $P$ ), e seja $\Pi$ o conjunto de caminhos exercitados por $T$. Diz-se que um nó $i$ está incluído em $\Pi$ se $\Pi$ contém um caminho $\left(n_{1}, \ldots, n_{m}\right)$ tal que $i=n_{j}$ para algum $j, 1 \leq j \leq m$. Similarmente, uma aresta $\left(i_{1}, i_{2}\right)$ é incluída em $\Pi$ se $\Pi$ contém um caminho $\left(n_{1}, \ldots, n_{m}\right)$ tal que $i_{1}=n_{j}$ e $i_{2}=n_{j+1}$ para algum $j, 1 \leq j \leq m-1$. A seguir são definidos os critérios de fluxo de controle:

- todos-nós (Todos-Nós): ПI satisfaz o critério todos-nós se cada nó $n \in N$ de um grafo $\mathcal{D U}$ está incluído em П. Em outras palavras, este critério requer que cada nó de um grafo $\mathcal{D U}$ seja exercitado ao menos uma vez por algum caso de teste de $T$.

Para utilizar as considerações de tratamento de exceção que foram feitas, Vincenzi (2004) particionou o critério Todos-Nós em dois conjuntos disjuntos de elementos: 
- todos-nós-independentes-de-exceção (Todos-Nós ${ }_{e i}$ ): П satisfaz o critério todos-nósindependentes-de-exceção se cada nó $n_{e i} \in N_{e i}$ está incluído em П. Em outras palavras, este critério requer que cada nó de um grafo $\mathcal{D} \mathcal{U}$ que é alcançável por meio de pelo menos um caminho livre de exceção seja executado ao menos uma vez por algum caso de teste de $T$.

- todos-nós-dependentes-de-exceção (Todos-Nós ${ }_{e d}$ ): П satisfaz o critério todos-nósdependentes-de-exceção se cada nó $n_{e d} \in N_{e d}$ está incluído em П. Em outras palavras, este critério requer que cada nó de um grafo $\mathcal{D U}$ que não é alcançável por meio de um caminho livre de exceção seja executado ao menos uma vez por algum caso de teste de $T$.

- todas-arestas (Todas-Arestas): П satisfaz o critério todas-arestas se cada aresta $e \in E$ de um grafo $\mathcal{D U}$ está incluída em $\Pi$. Em outras palavras, este critério requer que cada aresta de um grafo $\mathcal{D U}$ seja exercitada ao menos uma vez por algum caso de teste de $T$.

Para utilizar as considerações de tratamento de exceção que foram feitas, Vincenzi (2004) particionou o critério Todos-Arestas em dois conjuntos disjuntos de elementos:

- todas-arestas-independentes-de-exceção (Todas-Arestas ${ }_{e i}$ ): $\Pi$ satisfaz o critério todas-arestas-independentes-de-exceção se cada aresta $e_{e i} \in E_{e i}$ está incluída em П. Em outras palavras, este critério requer que cada aresta de um grafo $\mathcal{D} \mathcal{U}$ alcançável a partir de um caminho livre de exceção seja executada ao menos uma vez por algum caso de teste de $T$.

- todas-arestas-dependentes-de-exceção (Todas-Arestas ${ }_{e d}$ ): П satisfaz o critério todasarestas-dependentes-de-exceção se cada aresta $e_{e d} \in E_{e d}$ está incluída em П. Em outras palavras, este critério requer que cada aresta de um grafo $\mathcal{D U}$ não alcançável a partir de um caminho livre de exceção seja executada ao menos uma vez por algum caso de teste de $T$.

Em relação aos critérios de fluxo de dados, Vincenzi (2004) utilizou o critério todos-usos (alluses) (Rapps e Weyuker, 1982) e o critério todos-potenciais-usos (all-potential-uses) (Maldonado e Barbosa, 2003). Tais critérios foram revisados no contexto do teste de programas OO considerando os aspectos relacionados ao tratamento de exceção discutidos anteriormente. A revisão para programas $\mathrm{OO}$ do critério todos-potenciais-usos não é discutida neste texto.

Antes da definição dos critérios de fluxo de dados, alguns conceitos precisam ser definidos:

- Os conjuntos def, c-uso, p-uso, dcu e dpu: para um nó $i$ e uma variável $x$ do grafo $\mathcal{D U}$, são definidos: $\operatorname{def}(\mathrm{i})=\{$ variáveis definidas no nó $i\}$ 
$\mathrm{c}$-uso(i) $= \begin{cases}\text { variáveis com uso global em } i & \text { se } i \text { é computacional } \\ \emptyset & \text { caso contrário }\end{cases}$

$\mathrm{p}$-uso $(\mathrm{i})= \begin{cases}\text { variáveis com uso local ou global em } i & \text { se } i \text { é predicativo } \\ \emptyset & \text { caso contrário }\end{cases}$

$\operatorname{dcu}(x, i)=\{$ nós $j$ de um grafo $\mathcal{D U}$ tal que $x \in \operatorname{c-uso}(j)$ e existe um caminho livre de definição para $x$ de $i$ a $j\}$

$\operatorname{dpu}(x, i)=\{\operatorname{arestas}(j, k)$ de um grafo $\mathcal{D U}$ tal que $x \in \mathrm{p}$-uso $(j)$ e existe um caminho livre de definição para $x$ de $i$ à aresta $(j, k)\}$

- Pares def-c-uso e def-p-uso: Um par def-c-uso é uma tripla $(i, j, x)$ onde $i$ é um nó que contém uma definição de $x$ e $j \in \mathrm{dcu}(x, i)$. Um par def-p-uso é uma tripla $(i,(j, k), x)$ onde $i$ é um nó que contém uma definição de $x$ e $(j, k) \in \mathrm{dpu}(x, i)$. Um par def-uso é um par def-c-uso ou def-p-uso.

- Os conjuntos $\mathrm{dcu}_{e d}, \mathrm{dcu}_{e i}, \mathrm{dpu}_{e d}, \mathrm{dpu}_{e i}$ : Os conjuntos de pares foram particionados, considerando a existência ou não existência de caminhos livres de definição que também são livres de exceção. Assim dcu $\operatorname{ded}_{e d}(x, i)=\{$ nós $j$ de um grafo $\mathcal{D U}$ tal que $x \in \operatorname{c}$-uso $(j)$ e não existe nenhum caminho livre de definição com relação a $x$ que também é um caminho livre de exceção de $i$ a $j\}$. $\mathrm{O} \operatorname{dcu}_{e i}(x, i)=\mathrm{dcu}(x, i)-\operatorname{dcu}_{e d}(x, i)$. O mesmo é feito com relação aos p-usos: o dpu ded $(x, i)=\{\operatorname{arestas}(j, k)$ de um grafo $\mathcal{D U}$ tal que $x \in \mathrm{p}$-uso $(j)$ e não existe nenhum caminho livre de definição com relação a $x$ que também é um caminho livre de exceção de $i$ a $(j, k)\}$. O dpu $\operatorname{de}_{e i}(x, i)=\operatorname{dpu}(x, i)-\operatorname{dpu}_{e d}(x, i)$.

A seguir são definidos os critérios de fluxo de dados:

- todos-usos (Todos-Usos): $\Pi$ satisfaz o critério todos-usos se para todo nó $i \in N$ e para todo $x \in \operatorname{def}(i), \Pi$ inclui um caminho livre de definição com relação a $x$ do nó $i$ para todos os elementos de $d c u(x, i)$ e para todos os elementos de $d p u(x, i)$. Em outras palavras, esse critério requer que todo par def-c-uso $(i, j, x) \mid j \in d c u(x, i)$ e todo par def-p$u s o(i,(j, k), x) \mid(j, k) \in d p u(x, i)$ seja exercitado ao menos uma vez para algum caso de teste de $T$.

Seguindo a mesma idéia que foi aplicada aos critérios Todos-Nós e Todas-Arestas, os requisitos de teste do critério Todos-Usos foram particionados em dois conjuntos disjuntos, como definido nos seguintes critérios:

- todos-usos-independentes-de-exceção (Todos-Usos ${ }_{e i}$ ): $\Pi$ satisfaz o critério todosusos-independentes-de-exceção se para todo nó $i \in N$ e para todo $x \in \operatorname{def}(i)$, П inclui um caminho livre de definição com relação a $x$ do nó $i$ para todos os elementos de $d c u_{e i}(x, i)$ e para todos os elementos de $d p u_{e i}(x, i)$. Em outras palavras, esse critério requer que todo par def-c-uso independente de exceção $(i, j, x) \mid j \in d c u(x, i)$ e todo 
par def-p-uso independente de exceção $(i,(j, k), x) \mid(j, k) \in d p u(x, i)$ seja exercitado ao menos uma vez para algum caso de teste de $T$.

- todos-usos-dependentes-de-exceção (Todos-Usos ${ }_{e d}$ ): П satisfaz o critério todos-usosdependentes-de-exceção se para todo nó $i \in N$ e para todo $x \in \operatorname{def}(i)$, П inclui um caminho livre de definição com relação a $x$ do nó $i$ para todos os elementos de $d c u_{e d}(x, i)$ e para todos os elementos de $d p u_{e d}(x, i)$. Em outras palavras, esse critério requer que todo par def-c-uso dependente de exceção $(i, j, x) \mid j \in d c u(x, i)$ e todo par def-p-uso dependente de exceção $(i,(j, k), x) \mid(j, k) \in d p u(x, i)$ seja exercitado ao menos uma vez para algum caso de teste de $T$.

\subsubsection{Teste Estrutural de Integração}

Harrold e Rothermel (1994) propuseram a primeira abordagem de teste estrutural de integração para programas OO. Essa abordagem considera os testes: inter-método, intra-classe e inter-classe. No teste Inter-Método, os métodos são testados em conjunto com outros métodos da mesma classe. O teste Intra-Classe tem como finalidade testar a interação entre métodos públicos declarados em uma mesma classe quando chamados em diferentes seqüências. Por fim, teste Inter-Classe é responsável por testar a interação entre métodos públicos declarados em classes distintas quando chamados em diferentes sequiências. Para facilitar a apresentação da abordagem, serão analisados primeiro os níveis de teste inter-método e intra-classe (conforme apresentado por Harrold e Rothermel (1994)). Posteriormente, o nível de teste inter-classe é abordado.

Como exemplo para ilustrar os níveis de teste inter-método e intra-classe considere o códigofonte da Figura 3.2. O teste inter-método é realizado, por exemplo, no método AddToTable integrando-o com os métodos AddSymbol, Lookup, AddInfo, Get Symbol e Hash. Como exemplo de teste intra-classe pode-se selecionar seqüências de teste tais como <SymbolTable, AddtoTable, GetfromTable>.

Para os níveis de teste inter-método e intra-classe, Harrold e Rothermel (1994) utilizam o par definição-uso $(d, u)$ que permitem avaliar relações de fluxo de dados em programas OO nesses níveis. Considerando uma classe $C$, uma sentença $d$ que define uma variável e uma sentença $u$ que contém um uso da variável, define-se:

- Pares Def-Uso Inter-Método: Seja $M_{0}$ um método público de $C$ e seja $\left\{M_{1}, M_{2}, \ldots, M_{n}\right\}$ o conjunto de métodos chamados direta ou indiretamente quando $M_{0}$ é invocado. Suponha que $d$ está em $M_{i}$ e que $u$ está em $M_{j}$, sendo que tanto $M_{i}$ quanto $M_{j}$ estão em $\left\{M_{1}, M_{2}, \ldots, M_{n}\right\}$. Se existe um programa $P$ que chama $M_{0}$ tal que, em $P,(d, u)$ é um par def-uso exercitado durante uma simples invocação de $M_{0}$ por $P$, e $M_{i} \neq M_{j}$ ou $M_{i}$ e $M_{j}$ são invocações separadas do mesmo método, então $(d, u)$ é um par def-uso inter-método.

- Pares Def-Uso Intra-Classe: Seja $M_{0}$ um método público de $C$ e seja $\left\{M_{1}, M_{2}, \ldots, M_{n}\right\}$ o conjunto de métodos chamados direta ou indiretamente quando $M_{0}$ é invocado. Seja $N_{0}$ 
um método público de $C$ e seja $\left\{N_{1}, N_{2}, \ldots, N_{n}\right\}$ o conjunto de métodos chamados direta ou indiretamente quando $N_{0}$ é invocado. Suponha que $d$ está em algum dos métodos em $\left\{M_{1}, M_{2}, \ldots, M_{n}\right\}$ e $u$ em algum dos métodos em $\left\{N_{1}, N_{2}, \ldots, N_{n}\right\}$. Se existe um programa $P$ que chama $M_{0}$ e $N_{0}$, tal que em $P,(d, u)$ é um par def-uso e a chamada a $M_{0}$ encerra após a execução de $d$ e antes da execução de $u$, então $(d, u)$ é uma par def-uso intra-classe.

Analisando o código-fonte da Figura 3.2, o par $(29,41)$ é um exemplo de par def-uso intermétodo porque o método AddTable chama o método Lookup passando index como parâmetro. O valor de index é definido na linha 29 (método Lookup). No retorno, a variável index é usada na chamada ao método AddSymbol. Como exemplo de par def-uso intra-classe considere a seqüência <AddtoTable, GetfromTable>. O método AddtoTable pode adicionar uma informação de símbolo na tabela chamando o método AddInfo. O método GetfromTable pode acessar a informação da tabela por meio do método Get Info. Assim, a definição de uma informação na tabela (linha 73) e uso da tabela (linha 82) gera um par def-uso intra-classe.

O mesmo algoritmo PLR (Pande e Ryder, 1994) utilizado para derivar os pares def-uso intramétodo pode ser utilizado para derivar os pares def-uso inter-método. Entretanto, para computar os pares def-uso intra-classe, o algoritmo não pode ser utilizado diretamente. Para isso é gerado o grafo de fluxo de controle de classe $(\mathcal{C C F} \mathcal{F}$ - Class Control Flow Graph), que conecta todos os métodos de uma classe.

Para construir o $\mathcal{C} \mathcal{C} \mathcal{F}$, primeiro é construído o grafo de chamadas de classe. Em seguida, o grafo de chamadas de classe é envolvido por um frame, o qual permite que sejam feitas as chamadas arbitrárias aos métodos públicos. O frame é uma espécie de unidade pseudo-controladora da classe e possui cinco nós: frame entry, frame exit, que representam a entrada e saída do frame; frame loop, que facilita o seqüenciamento dos métodos; frame call e frame return, que representam a chamada e o retorno a qualquer método público que possa ser invocado. $\mathrm{O}$ frame ainda possui quatro arestas: (frame entry, frame loop), (frame loop, frame call), (frame loop, frame exit) e (frame return, frame loop). A partir daí, cada nó que representa um método no grafo de chamadas é substituído pelo seu grafo de fluxo de controle.

Na Figura 3.4 é mostrado o $\mathcal{C} \mathcal{C} \mathcal{F} \mathcal{G}$ parcial da classe Symboltable. Nessa figura apenas são expandidos os nós correspondentes aos métodos AddtoTable, GetFromTable e Lookup com os grafos de fluxo de controle de cada um deles, adicionando também arestas referentes às chamadas de um método a outros da mesma classe. Os $C$ s e $R$ s contidos na figura correspondem às chamadas e retornos de métodos, respectivamente.

Para efetuar teste de integração entre classes, Harrold e Rothermel (1994) definem um quarto nível de teste de fluxo de dados chamado teste Inter-Classe. O teste Inter-classe considera pares def-uso $(d, u)$, tais que a definição ocorre em um método $M_{1}$ de uma $C_{1}$ e o uso ocorre em um 


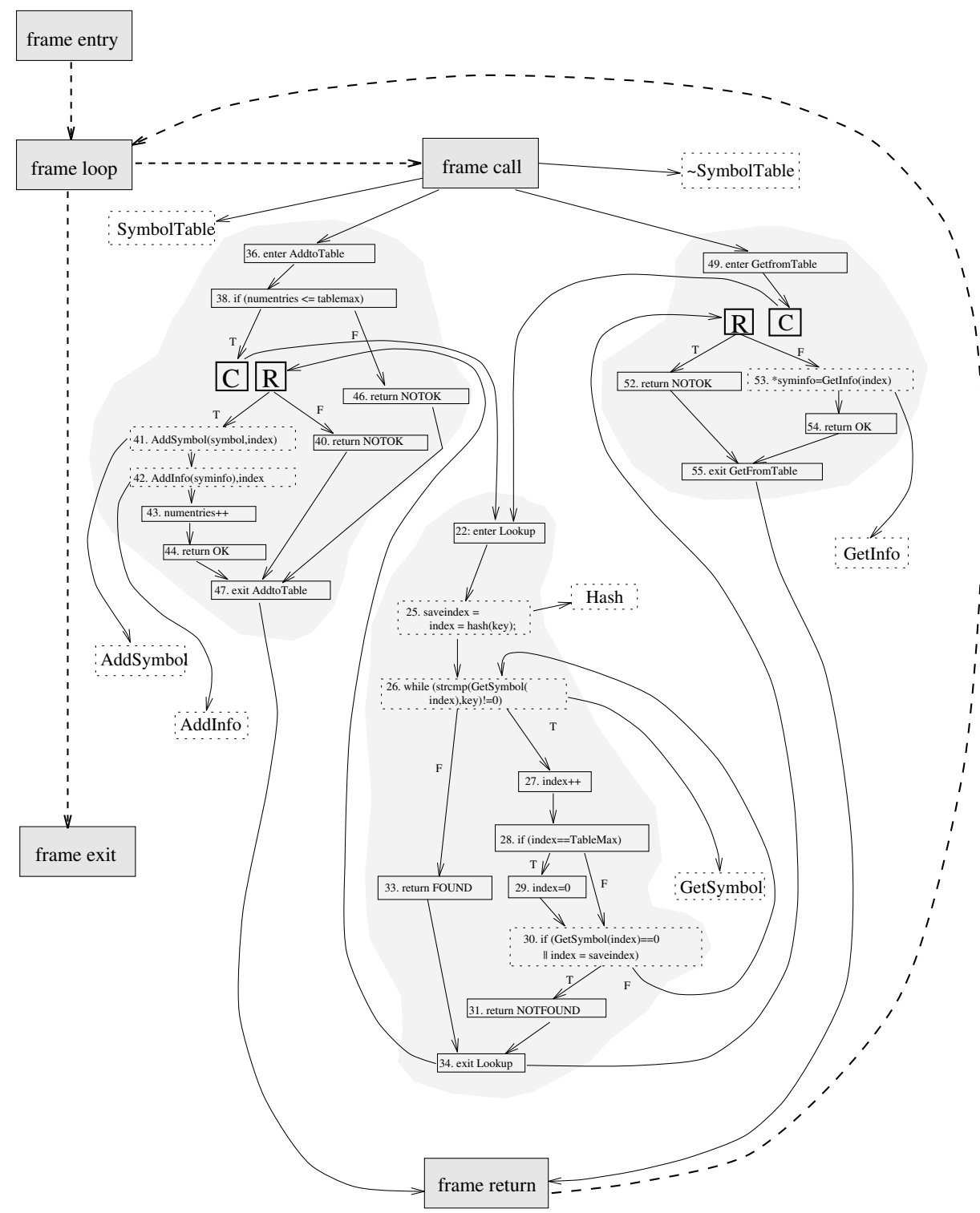

Figura 3.4: Grafo de fluxo de controle de classe para a classe SymbolTable (adaptado de Harrold e Rothermel (1994)).

outro método $M_{2}$ de uma classe $C_{2}$. Para derivar os pares def-uso deve-se construir os $\mathcal{C C F} \mathcal{G}$ s das classes envolvidas ${ }^{2}$.

Algumas abordagens para teste de programas OO no nível intra-classe foram propostas. Dentre elas pode-se citar os trabalhos de Turner e Robson (1993) e os trabalhos de Hong et al. (1995) que apresentaram abordagens de teste intra-classe baseado em estados. Essas abordagens enfatizam a interação entre os métodos e o estado do objeto. Um objeto é representado pelos valores que seus atributos (subestados) armazenam em um determindado momento. Para representar essa interação, os pesquisadores utilizam uma Máquina de Estados Finitos (Finite State Machine - FSM). Outras abordagens de teste intra-classe, como apresentadas nos trabalhos de Doong e Frankl (1994),

\footnotetext{
${ }^{2}$ Em seu trabalho, Harrold e Rothermel (1994) não apresentaram uma definição formal para Pares Def-Uso InterClasse conforme apresentada para outros níveis de teste
} 
Kirani e Tsai (1994) e Daniels e Tai (1999), envolvem selecionar seqüências de métodos que informam a ordem correta em que os métodos de uma classe podem ser chamados. Para detectar defeitos entre os métodos que se interagem, é verificado se uma sequiência de métodos coloca um objeto da classe em um estado inconsistente.

Como as abordagens de teste intra-classe focam o teste de métodos declarados em uma mesma classe, elas não precisam se preocupar com problemas que surgem da interação com métodos declarados em classes distintas, tais como: herança, polimorfismo e acoplamento dinâmico. Esses problemas são tratados por abordagens de teste inter-classe. Uma delas é proposta por Alexander e Offutt (2004). Baseado no trabalho de Jin e Offutt (1998) — que propuseram uma abordagem de teste estrutural de integração para programas procedimentais cujo enfoque são as relações de acoplamento entre procedimentos (semelhante a abordagem apresentada por Linnenkugel e Müllerburg (1990), discutida na Seção 3.3) - Alexander e Offutt (2004) desenvolveram uma abordagem de teste de integração baseada em acoplamentos para analisar e testar as relações polimórficas que ocorrem e são características de programas OO.

\subsubsection{Teste Estrutural de Integração Par-a-Par}

Uma das abordagens de teste estrutural de integração utilizada é a par-a-par (pairwise) que considera as unidades em pares para derivar os requisitos de teste. Em programas procedimentais esta abordagem envolve testar a interação entre pares procedimentos ou funções (p-p). Já em programas $\mathrm{OO}$, considerando o método como a menor unidade de teste, o teste abrange os pares de métodos (m-m). Por fim, em programas OA, considerando um método ou um adendo como sendo a menor unidade a ser testada, essa abordagem de teste compreende os seguintes pares de unidades: método-método (m-m), método-adendo (m-a), adendo-método (a-m) e adendo-adendo (a-a).

A abordagem de teste estrutural de integração par-a-par foi utilizada por Paradkar (1996). Em seu trabalho, o pesquisador definiu uma abordagem de teste estrutural de integração para programas OO. Nele, o pesquisador propõe o AORD (Augmented Object Relationship Diagram), que é uma extensão da representação ORD (Object Relationship Diagram) (Kung et al., 1996) com o objetivo de tratar problemas de integração inter-classe par-a-par na presença de polimorfismo.

Outros pesquisadores que utilizaram a abordagem de teste estrutural de integração par-a-par foram Vilela et al. (1999). Em seu trabalho, os pesquisadores propuseram uma abordagem de teste estrutural de integração para programas procedimentais, no qual se considera o programa principal ou um único subprograma (procedimento ou função) como sendo a menor unidade a ser testada. Baseado no trabalho de Linnenkugel e Müllerburg (1990) (discutido na Seção 3.3), Vilela et al. (1999) estenderam os Critérios Potenciais-Usos (Maldonado, 1991) para teste de integração e definiram, utilizando a abordagem par-a-par, os Critérios Potenciais-Uso de Integração.

Como exemplo de teste estrutural de integração par-a-par e de identificação dos pares de unidades, considere o programa OO simples apresentado na Figura 3.5. Ele contém três classes: A, B 
e C. Na classe A o método $\mathrm{m} 1$ ( ) chama o método $\mathrm{m} 2$ () da mesma classe e o método $\mathrm{m} 2$ (), por sua vez, chama o método m3 ( ) da classe B. Já na classe B, o método m3 ( ) invoca o construtor da classe $\mathrm{C}$ e, a partir do objeto o criado, chama o método $\mathrm{m} 4$ (). Os pares de unidades identificados neste exemplo são resumidos na Tabela 3.4.

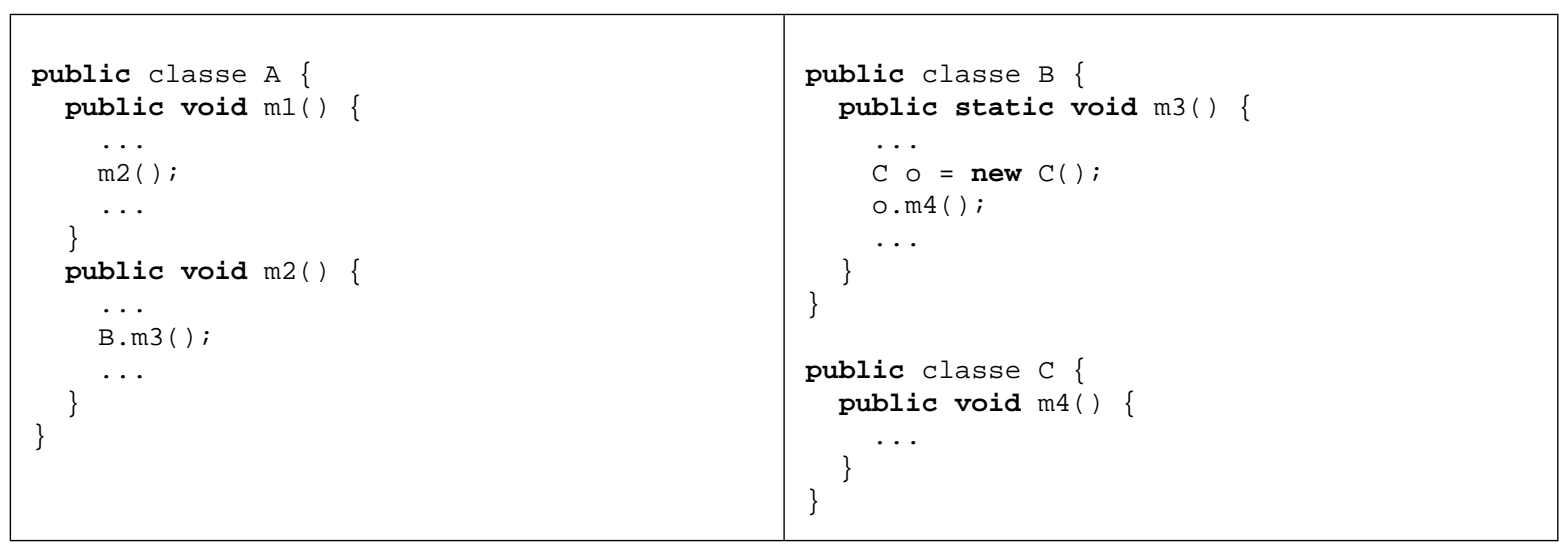

Figura 3.5: Exemplo simples de programa OO para demonstrar a interação par-a-par entre as unidades.

Tabela 3.4: Pares de unidades identificados no exemplo da Figura 3.5.

\begin{tabular}{|l|l|}
\hline & Par de unidades \\
\hline \hline 1 & (A) m1 ( ) - (A) m2 ( ) \\
\hline 2 & (A) m2 ( ) - (B) m3 () \\
\hline 3 & (B) m3 ( ) - (C) <init > ()* \\
\hline 4 & (B) m3 ( ) - (C) m4 () \\
\hline
\end{tabular}

* Um construtor é representado por <init>

\subsection{Teste Estrutural de Programas Orientados a Aspec- tos}

Por ser um tema de pesquisa recente, os pesquisadores da área de POA preocuparam-se, nos primeiros anos, em estabelecer e definir conceitos e técnicas básicos das linguagens orientadas a aspectos. Atualmente, as pesquisas se voltam para o uso da POA em situações reais do processo de desenvolvimento do software, como por exemplo, estudos sobre abordagens de teste para esse contexto.

Programas orientado a aspectos difere significativamente de programas orientado a objetos e orientado a procedimentos em termos de análise, projeto, estrutura e técnicas de desenvolvimento. Por ser um aspecto constituído de pontos de junção, adendos e métodos, ele é uma abstração diferente se comparado a uma classe ou procedimento. A inclusão de pontos de junção em um aspecto, com os quais pedaços de código podem ser introduzidos em uma ou mais classes, torna mais complexo o relacionamento estático e dinâmico entre aspectos e classes (Zhao, 2002). Se- 
gundo Alexander et al. (2004), os motivos que tornam o processo de teste em programas OA mais difíceis de serem efetuados são:

- Aspectos não têm identidade ou existência independente, sendo dependentes do contexto de outras classes;

- A implementação aspectual pode ser fortemente acoplada ao seu contexto de combinação, ou seja, os aspectos dependem da representação e implementação interna das classes em que estão combinados;

- Dependências de controle e dados não são facilmente compreensíveis a partir do códigofonte dos aspectos ou classes;

- O comportamento emergente do programa, em que o defeito pode estar na implementação da classe ou do aspecto, ou pode ser um efeito colateral de uma particular ordem de combinação de múltiplos aspectos.

Essas características específicas presentes em programas OA requer novas abordagens e estratégias de testes apropriadas para testá-las. Embora muitas abordagens tenham sido propostas para programas $\mathrm{OO}$ e procedimentais, elas não podem ser aplicadas a programas OA (Zhao, 2002). A partir daí, Alexander et al. (2004) propuseram que um teste sistemático de programas OA deve ser baseado em um modelo de defeitos que é discutido na Seção 3.5.3.

Para efetuar o teste de unidade em um programa OA é fundamental definir o que se considera a menor unidade a ser testada. Alguns pesquisadores, como Zhao (2003), consideram as classes e os aspectos como sendo a menor unidade, enquanto que outros, como Lemos (2005), consideram como menor unidade os métodos e adendos. Este trabalho segue a linha que considera métodos e adendos as menores unidades de um programa OA.

Baseando-se em Sommerville (2001) e na abordagem de Harrold e Rothermel (1994), Lemos (2005) propôs que a atividade de teste de programas OA poderia ser particionada nas seguintes fases:

1. Teste de Unidade: O teste de cada método (Intra-Método) e cada adendo (Intra-Adendo) isoladamente.

2. Teste de Módulo: O teste de uma coleção de unidades dependentes — unidades que interagem por meio de chamadas ou interações com adendos. Essa fase pode ser dividida nos seguintes tipos de teste (considerando classes e aspectos como entidades diferentes):

- Inter-Método: Consiste em testar cada método público juntamente com outros métodos da mesma classe chamados direta ou indiretamente (chamadas indiretas são aquelas que ocorrem fora do escopo do próprio método, dentro de um método chamado em qualquer profundidade). 
- Adendo-Método: Consiste em testar cada adendo juntamente com outros métodos chamados por ele direta ou indiretamente.

- Método-Adendo: Consiste em testar cada método público juntamente com os adendos que o afetam direta ou indiretamente (considerando que um adendo pode afetar outro adendo). Nesse tipo de teste não é considerada a integração dos métodos afetados com os outros métodos chamados por eles, nem com métodos chamados pelos adendos.

- Adendo-Adendo: Consiste em testar cada adendo juntamente com outros adendos que o afetam direta ou indiretamente.

- Inter-Método-Adendo: Consiste em testar cada método público juntamente com os adendos que o afetam direta e indiretamente, e com métodos chamados direta ou indiretamente. Esse tipo de teste inclui os quatro primeiros tipos de teste descritos acima.

- Intra-Classe: Consiste em testar as interações entre os métodos públicos de uma classe quando chamados em diferentes seqüências, considerando ou não a interação com os aspectos.

- Inter-Classe: Consiste em testar as interações entre classes diferentes, considerando ou não a interação dos aspectos.

3. Teste de Sistema: Fase na qual se testa a integração de todos os módulos, formando um subsistema ou um sistema completo. Para essa fase é geralmente utilizado o teste funcional. Outros tipos de teste são empregados, tais como: testes de recuperação, teste de segurança, teste de estresse e teste de desempenho (Pressman, 2001).

\subsubsection{Teste Estrutural de Unidade}

Em programas orientado a aspectos, um aspecto (ou uma classe) é projetado para ser o mais independente possível do seu ambiente. Assim, é possível exercitá-los individualmente por meio de pequenos programas de teste. Entretanto, um aspecto pode afetar o comportamento de uma ou mais classes por meio de adendos, tornando o relacionamento entre o aspecto e as classes que ele afeta mais complexo. Deste modo, em programas OA é impraticável testar um aspecto ou uma classe isoladamente (Zhao, 2003).

A primeira abordagem de teste estrutural para programas OA foi proposta por Zhao (2002, 2003). Em seus trabalhos, o pesquisador apresenta uma abordagem baseada em fluxo de dados que tem o objetivo de testar dois tipos de unidades: (1) testar os aspectos juntamente com os métodos cujos comportamentos podem ser afetados pelos adendos (perspectiva dos aspectos) e (2) testar as classes juntamente com os adendos que podem afetar o seu comportamento (perspectiva das classes). A partir daí foram definidos alguns conceitos: 
- aspecto combinado (c-aspecto) é um aspecto junto com alguns métodos pertencentes a uma ou mais classes de modo que o comportamento dos métodos pode ser afetado pelo adendo do aspecto;

- classe combinada (c-classe) é uma classe juntamente com alguns adendos de um ou mais aspectos, tal que os adendos podem afetar o comportamento dos métodos da classe;

- método combinado (c-método) é um método junto com um ou mais adendos que pode afetar seu comportamento;

- adendo combinado (c-adendo) é um adendo juntamente com um ou mais métodos que ele afeta.

Na Figura 3.6 é apresentado o exemplo utilizado por Zhao (2003) para ilustrar a abordagem proposta. A classe Point representa pontos e possui atributos $\mathrm{x}$ e y referentes às coordenadas do ponto. A classe Shadow representa sombras de pontos, e também possui atributos $x$ e y para as suas coordenadas. $\mathrm{O}$ aspecto Point ShadowProtocol implementa a relação entre pontos e sombras e introduz um atributo shadow na classe Point para representar a sombra de um dado ponto. Para relacionar os objetos, o aspecto associa uma sombra a cada ponto que é criado, por meio de adendo posterior que executa quando o construtor de Point é chamado. Tal adendo faz uso do método associate para associar a sombra criada ao ponto, atribuindo-a à shadow (o atributo introduzido). Para manter a relação consistente, sempre que um objeto ponto se move como consequiência da execução de um dos métodos que alteram suas coordenadas ( setX e sety), a sua sombra é atualizada pelos adendos posteriores que executam sempre que esses métodos são chamados. O método get Shadow é utilizado pelos adendos posteriores para obter a sombra do objeto ponto interceptado.

De acordo com Zhao (2003), as c-classe e os c-aspectos são considerados as menores unidades do programa. Além disso, o pesquisador argumenta que aspectos e classes são compostos de módulos ${ }^{3}$ que podem ser c-adendo, c-método, método simples, construtor ou método introduzido. A partir daí, baseado no trabalho de Harrold e Rothermel (1994) (discutido na Seção 3.4), define que os casos de teste de fluxo de dados podem ser derivados de três perspectivas: intra-módulo, inter-módulo e intra-aspecto ou intra-classe.

$\mathrm{Na}$ perspectiva intra-módulo são selecionados casos de teste para exercitar pares def-uso internos do módulo. Por exemplo, no aspecto Point ShadowProtocol, o c-método setx, que contém o adendo posterior do ponto de junção settingX, tem um par def-uso (s44, s45) da variável s, porque a definição de s na sentença s44 é usada na sentença s45.

Na perspectiva inter-módulo, por sua vez, são selecionados casos de teste para exercitar pares def-uso que extrapolam o módulo. Por exemplo, no c-aspecto Point ShadowProtocol, o cconstrutor de Point, que contém o adendo posterior do ponto de junção setting, define um

\footnotetext{
${ }^{3}$ Observe que Zhao utiliza o termo módulo com uma concepção diferente da utilizada nesta dissertação. Para o pesquisador, um módulo é apenas uma parte da unidade em teste.
} 


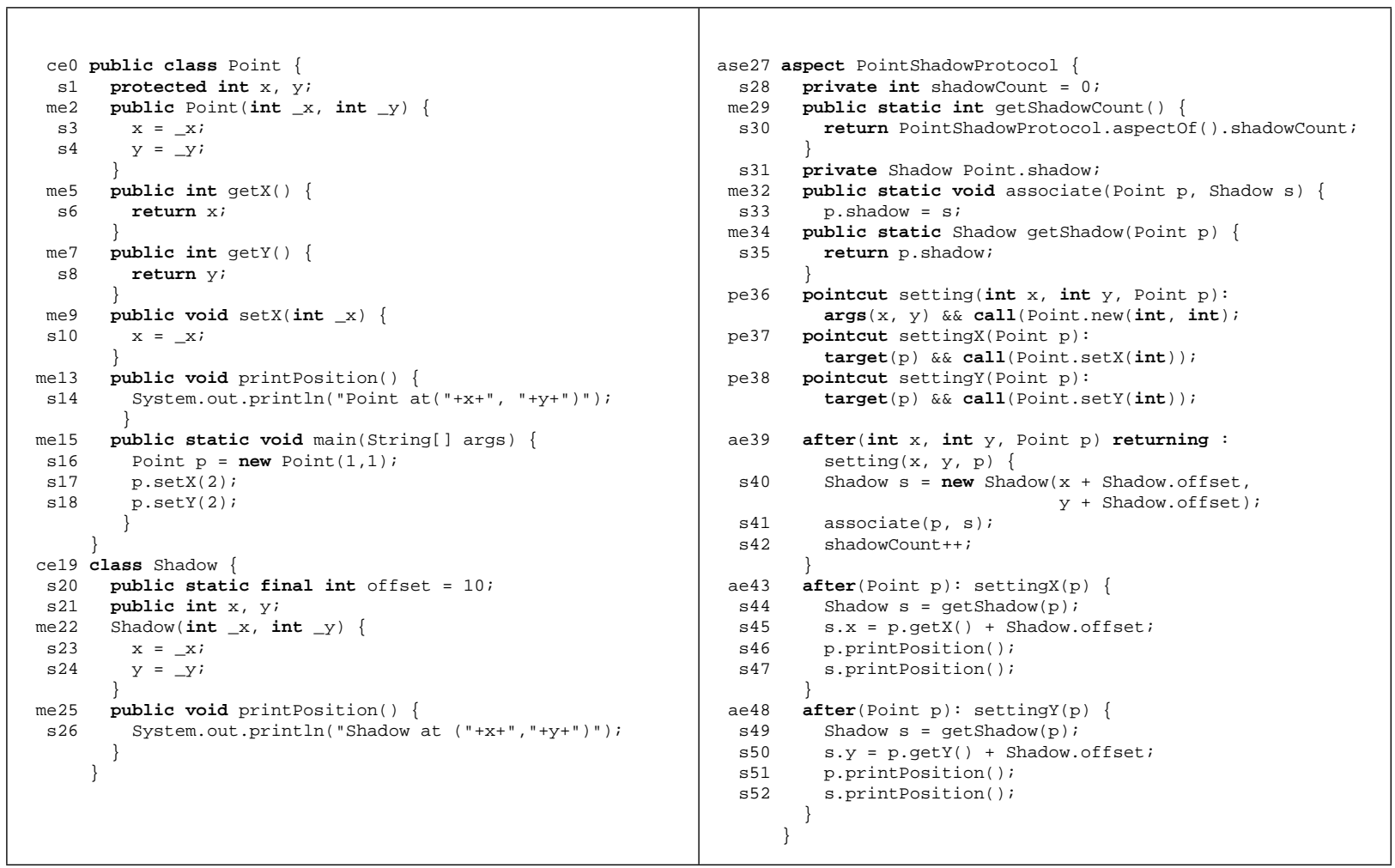

Figura 3.6: Exemplo para o teste de programas OA (adaptado de Zhao (2003)).

novo objeto s da classe Shadow e invoca o método as sociate que associa s a um ponto. O par def-uso (s40, s33) é um par inter-módulo porque a definição de s na sentença s40 do c-construtor de Point é usada na sentença s33 do método associate.

$\mathrm{Na}$ perspectiva intra-aspecto ou intra-classe são selecionados os casos de teste para exercitar os pares def-uso obtidos a partir de uma seqüência de chamadas aleatórias de métodos públicos de um c-aspecto ou c-classe. Por exemplo, considere a seqüência $<$ set $x$, get X $>$ da classe Point. set $x$ pode alterar $o$ valor da variável $x$ e o getx pode obter o valor de $x$. A definição de $x$ na sentença 10 de set $X$ e o uso de $x$ na sentença s6 de get $X$ formam um par def-uso intra-classe.

Para facilitar a geração de casos de teste e assegurar a qualidade dos c-aspectos e c-classes, Zhao propõe um modelo estrutural para teste de unidade de programas OA. O modelo estrutural consiste de três diferentes tipos de grafos de fluxo de controle: Grafo de Fluxo de Controle para módulos individuais, Grafo de Fluxo de Controle Interprocedimental para módulos interativos e Grafo de Fluxo de Controle com Moldura para aspectos e classes.

O Grafo de Fluxo de Controle (Control Flow Graph - CFG) representa o relacionamento de fluxo de controle que existe dentro do módulo e é usado para obter informação de fluxo de dados em um módulo (c-adendo, c-método, etc) de um c-aspecto ou c-classe (esse grafo foi chamado de grafo Def-Uso no parágrafo Critérios Baseados em Fluxo de Dados da Seção 3.2.2 deste capítulo).

O Grafo de Fluxo de Controle Interprocedimental (Interprocedural Control Flow Graph $I C F G$ ) representa o relacionamento de fluxo de controle que existe dentro e entre um grupo de 
módulos e é usado para obter informação de fluxo de dados que envolve mais que um módulo em um c-aspecto ou c-classe. O ICFG é composto de um grafo de chamada que representa as possíveis chamadas de cada módulo mais o grafo de fluxo de controle de cada um dos módulos.

O Grafo de Fluxo de Controle com Moldura (Framed Control Flow Graph - FCFG) é usado para derivar a informação de fluxo de dado em um c-aspecto ou c-classe. O FCFG pode simular uma seqüência de chamadas aleatórias entre módulos de um c-aspecto ou c-classe. $\mathrm{Na}$ Figura 3.7 é mostrado o FCFG para as duas unidades.
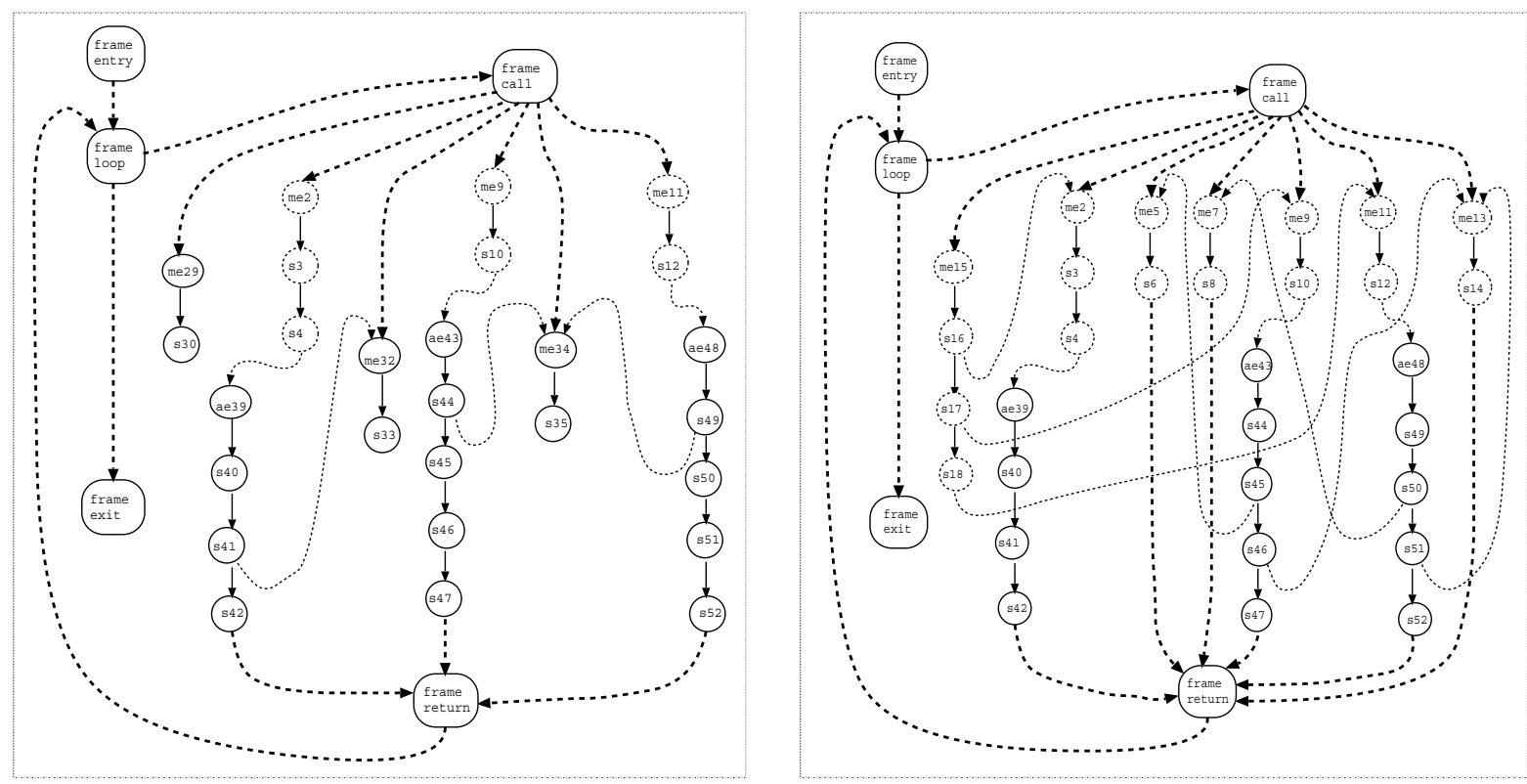

Figura 3.7: FCFG para o c-aspecto Point ShadowProtocol e para a c-classe Point (adaptada de Zhao (2003)).

Outra abordagem de teste estrutural de programas OA (escritos em AspectJ) é apresentada por Lemos (2005). Nos seus trabalhos, cada método e cada adendo declarado são considerados como sendo as menores unidades do programa. Para representar os nós e as arestas transversais dos programas OA, o pesquisador estendeu o grafo de fluxo de controle $(\mathcal{C F} \mathcal{G})$ e o grafo Def-Uso $(\mathcal{D U})$. Dessa extensão, definiu o Grafo de Fluxo de Controle Orientado a Aspectos $(\mathcal{A O C F} \mathcal{G})$ e o Grafo Def-Uso Orientado a Aspectos $(\mathcal{A O D} \mathcal{U})$. Além disso, o pesquisador definiu critérios de teste baseados em fluxo de controle e dados específicos para teste de unidade de programas OA.

$\mathrm{O} \mathcal{A O C F} \mathcal{F}$ é um grafo do qual requisitos de teste de fluxo de controle são derivados. Esse grafo é construído para representar qualquer unidade de um programa $\mathrm{OA}$, ou seja, tanto métodos quanto adendos. Um $\mathcal{A O C F} \mathcal{F}$ de uma dada unidade $u$ é definido como um grafo dirigido $\mathcal{A O C F} \mathcal{G}(u)=$ $(N, E, s, C, T)$, tal que:

- $N$ representa o conjunto de nós de um $\mathcal{A O C F \mathcal { F }}: N=\{n \mid n$ corresponde a uma sequiência linear de computações de $u\}$; 
- $E \subseteq N X N$ é o conjunto completo de arestas do $\mathcal{A O C F \mathcal { G }}$. Cada aresta $e \in E$ representa a transferência de controle que pode ocorrer entre dois nós;

- $s \in N$ é o nó de entrada de $u$. $s$ é o único nó do grafo que não possui nenhuma aresta de entrada;

- $C \subseteq N$ é o conjunto (possivelmente vazio) de nós transversais que representam um nó no qual ocorre uma interação com um adendo de um dado aspecto;

- $T \subseteq N$ é o conjunto (possivelmente vazio) de nós de saída, ou seja, cada $t \in T$ não possui nenhuma aresta de saída.

O grafo $\mathcal{A O D U}$ é o $\mathcal{A O C F} \mathcal{F}$ com informações de definições e usos de variáveis utilizado para a aplicação de critérios baseados em fluxo de dados. Segundo Lemos (2005), como o grafo $\mathcal{A O D U}$ é o $\mathcal{A O C F} \mathcal{F}$ estendido, é necessária apenas a construção do grafo $\mathcal{A O D U}$ para derivar requisitos de teste tanto para o fluxo de controle quanto para o fluxo de dados do programa.

Antes da construção do grafo $\mathcal{A O D U}$, constrói-se o Grafo de Instruções $(\mathcal{I} \mathcal{G}$ ) (adaptado de Vincenzi (2004)) de cada unidade. Informalmente, o $\mathcal{I} \mathcal{G}$ é um grafo no qual os nós contêm uma única instrução de bytecode e as arestas conectam instruções que podem ser executadas seqüencialmente. Para construir o grafo $\mathcal{I} \mathcal{G}$, deve ser feita uma análise estática das instruções de bytecode. A idéia do grafo $\mathcal{I G}$ é de abstrair o fluxo de controle envolvido em cada instrução de bytecode. Formalmente o grafo $\mathcal{I} \mathcal{G}$ de uma dada unidade $u$ é definido como um grafo dirigido $\mathcal{I} \mathcal{G}(u)=(N I, E I$, si, TI,CI), tal que:

- $N I$ representa o conjunto não-vazio de nós de um grafo $\mathcal{I} \mathcal{G}: N I=\left\{n_{i} \mid n_{i}\right.$ corresponde a uma instrução de bytecode $i$, para todo bytecode $i$ alcançável de $u\}$.

- $E I=E I_{r} \cup E I_{e}$ é o conjunto completo de arestas do $\mathcal{I} \mathcal{G}$ tal que:

- $E I_{r}$ e $E I_{e}$ correspondem a dois subconjuntos disjuntos de arestas regulares e de exceção, respectivamente:

* $E I_{r}$ é o conjunto de arestas regulares definido como $E I_{r}=\left\{\left(n_{i}, n_{j}\right) \mid\right.$ a instrução em $n_{j}$ pode ser executada imediatamente após a instrução em $n_{i}$ e $\left.\left(n_{i}, n_{j}\right) \notin E I_{e}\right\}$.

* $E I_{e}$ é o conjunto de arestas de exceção definido como $E I_{e}=\left\{\left(n_{i}, n_{j}\right) \mid\right.$ a instrução de $n_{i}$ está no escopo de um tratador de exceção que inicia na instrução de $\left.n_{j}\right\}$.

- $s_{i} \in N I$ é o nó de entrada que corresponde ao nó que contém a primeira instrução de $u$.

- $T I \subseteq N I$ é o conjunto de nós de saída de $u$.

- $C I \subseteq N I$ é o conjunto (possivelmente vazio) de nós transversais, isto é, nós que representam a execução de adendos de determinados aspectos. De fato, esses nós correspondem aos nós cujas instruções de bytecode são invocações aos métodos correspondentes aos adendos. 
Para adicionar informações de fluxo de dados no $\mathcal{I} \mathcal{G}$ de uma unidade, Lemos (2005) adotou a solução de Vincenzi (2004) que classificou as instruções de bytecode Java, relacionando cada uma com o fluxo de dados envolvido (apresentada na Tabela 3.3). Essa decisão foi baseada no fato de que o compilador/combinador do AspectJ produzir bytecode Java comum como resultado da compilação/combinação. Além disso, o pesquisador utilizou algumas suposições (adaptadas de Vincenzi (2004)) para identificar as definições e usos de variáveis.

Apesar do $\mathcal{I G}$ oferecer uma maneira prática de percorrer o conjunto de instruções de uma dada unidade, identificando usos e definições de variáveis, o número de nós e arestas presentes nesse tipo de grafo pode ser muito grande. Dessa maneira, constrói-se o grafo $\mathcal{A O D U}$ baseando-se no conceito de bloco de instruções (discutido na Seção 3.2.2). Formalmente, o grafo $\mathcal{A O D U}$ de uma dada unidade $u$ é definido como $\mathcal{A O D U}(u)=(N, E, s, T, C)$, tal que cada nó $n \in N$ representa um bloco de instruções de bytecode:

- $N$ representa o conjunto de nós de um grafo $\mathcal{A O D U}: N=\{n \mid n$ corresponde a um bloco de instruções de bytecode de $u\}$. Isto é, $N$ é o conjunto não-vazio de nós, representando as instruções de bytecode de $u$. $I_{n}$ é uma n-tupla ordenada de instruções agrupadas no nó $n$;

- $E=E_{r} \cup E_{e}$ é o conjunto completo de arestas do grafo $\mathcal{A O D U}$. Considere o $\mathcal{I G}(u)=$ $(N I, E I$, si $, T I, C I)$ :

- $E_{r}$ é o conjunto de arestas regulares definido como $E_{r}=\left\{\left(n_{i}, n_{j}\right) \mid\right.$ existe uma aresta regular que vai do último elemento de $I_{n_{i}}$ ao primeiro elemento de $I_{n_{j}}$ no $\left.\mathcal{I} \mathcal{G}(u)\right\}$;

- $E_{e}$ é o conjunto de arestas de exceção definido como $E_{e}=\left\{\left(n_{i}, n_{j}\right) \mid\right.$ existe uma aresta de exceção que vai do último elemento de $I_{n_{i}}$ ao primeiro elemento de $I_{n_{j}}$ no $\left.\mathcal{I} \mathcal{G}(u)\right\}$;

- $E_{c} \subseteq E_{r}$ é o conjunto de arestas transversais (crosscutting edges) definido como $E_{c}=$ $\{(x, y) \in E \mid(x \in C) \vee(y \in C)\}$ (componente $C$ definida abaixo);

- $s \in N$ é o nó de entrada de $u$;

- $T \subseteq N$ é o conjunto (possivelmente vazio) de nós de saída;

- $C \subseteq N$ é o conjunto (possivelmente vazio) de nós transversais. Nesse caso um nó transversal corresponde a um bloco de instruções no qual uma das instruções representa uma invocação de um método correspondente a um adendo de um dado aspecto.

A representação gráfica do grafo $\mathcal{A O D U}$ é definida da seguinte forma: conjuntos cu, pu e d correspondem aos c-usos, p-usos e definições de variáveis; nós regulares são representados por círculos com o rótulo contendo a primeira instrução de bytecode do bloco; nós de chamada são representados por círculos duplos; nós transversais são representados por elipses tracejadas que informam o tipo de adendo que afeta aquele ponto (before, after ou around) e o aspecto que pertence; nós em negrito representam nós de saída; e arestas de exceção $\left(E_{e}\right)$ são representadas 
por arestas tracejadas, mostrando o fluxo de controle do ponto onde uma exceção é gerada até o primeiro nó correspondente ao tratador da exceção. Na Figura 3.8 é mostrada uma aplicação OA simples escrita em AspectJ. O grafo $\mathcal{A O D U}$ do método af fectedMethod com a presença do aspecto é mostrado na Figura 3.9.

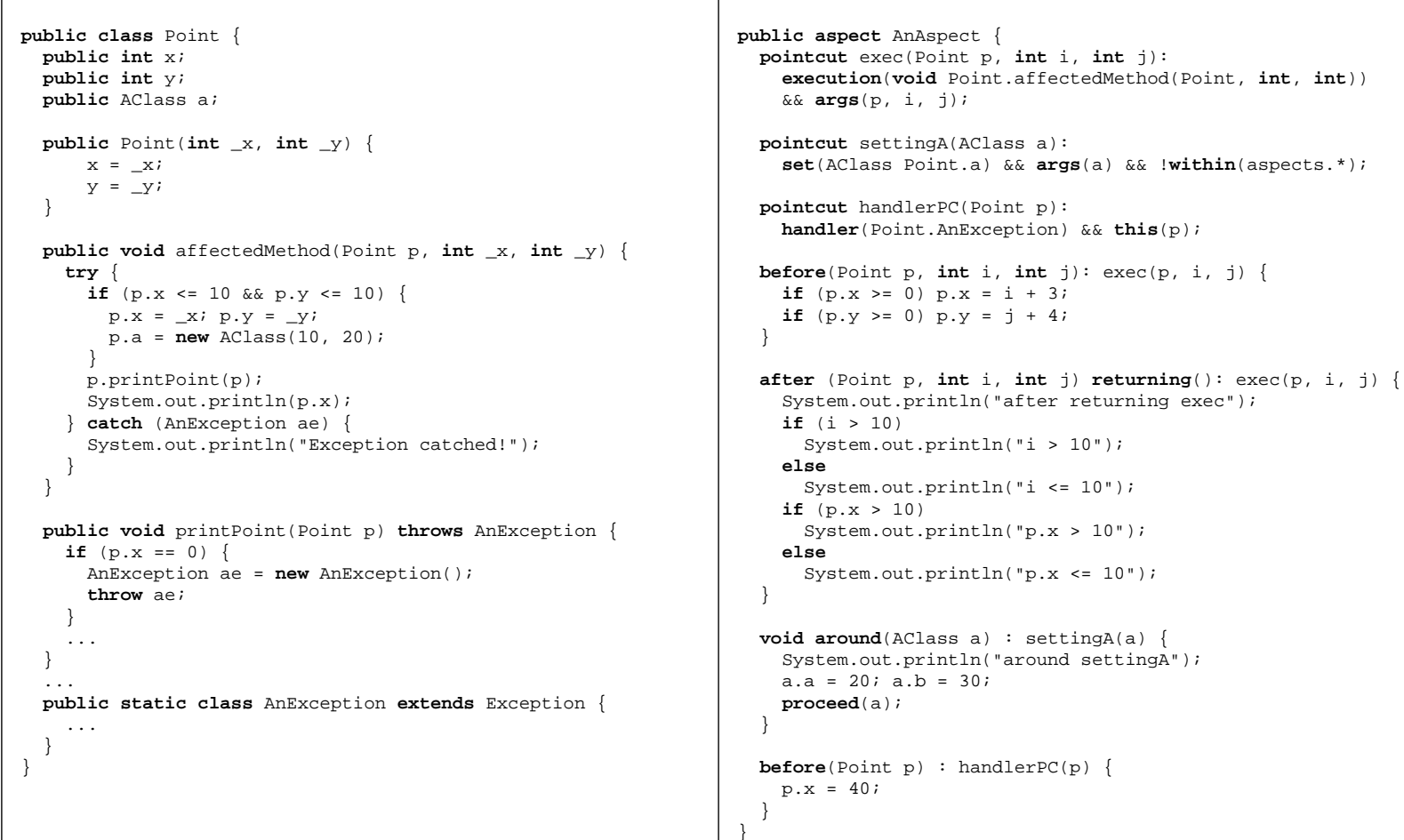

Figura 3.8: Exemplo de um programa OA escrito em AspectJ (adaptado de Lemos (2005)).

Em seu trabalho, Lemos (2005) também revisou e definiu alguns critérios de teste baseados em fluxo de controle e em fluxo de dados para serem aplicados no teste de programas OA. Considerando o teste de fluxo de controle, os critérios de teste todos-nós, todos-arestas, todosnós-independentes-de-exceção, todos-nós-dependentes-de-exceção, todos-arestas-independentesde-exceção e todos-arestas-dependentes-de-exceção (discutidos no trabalho de Vincenzi (2004) (Seção 3.4.1)) foram revisados para contexto do teste de programas OA. Além disso, o pesquisador definiu mais dois novos critérios de fluxo de controle específicos de programas OA: o critério todos-nós-transversais e o critério todos-arestas-transversais, definidos a seguir. Alguns conceitos utilizados para a definição desses critérios foram discutidos na Seção 3.4.1.

Considere $T$ um conjunto de casos de teste para um programa $P$ (sendo que $\mathcal{A O D U}$ é o grafo de fluxo de controle/dados de $P$ ), e seja $\Pi$ o conjunto de caminhos exercitados por $T$. Diz-se que um nó $i$ está incluído em $\Pi$ se $\Pi$ contém um caminho $\left(n_{1}, \ldots, n_{m}\right)$ tal que $i=n_{j}$ para algum $j, 1 \leq j \leq m$. Similarmente, uma aresta $\left(i_{1}, i_{2}\right)$ é incluída em $\Pi$ se $\Pi$ contém um caminho $\left(n_{1}, \ldots, n_{m}\right)$ tal que $i_{1}=n_{j}$ e $i_{2}=n_{j+1}$ para algum $j, 1 \leq j \leq m-1$.

- todos-nós-transversais (Todos-Nós ${ }_{C}$ ): П satisfaz o critério todos-nós-transversais se cada nó $n_{i} \in C$ de um grafo $\mathcal{A O D U}$ está incluído em $\Pi$. Em outras palavras, esse critério requer 


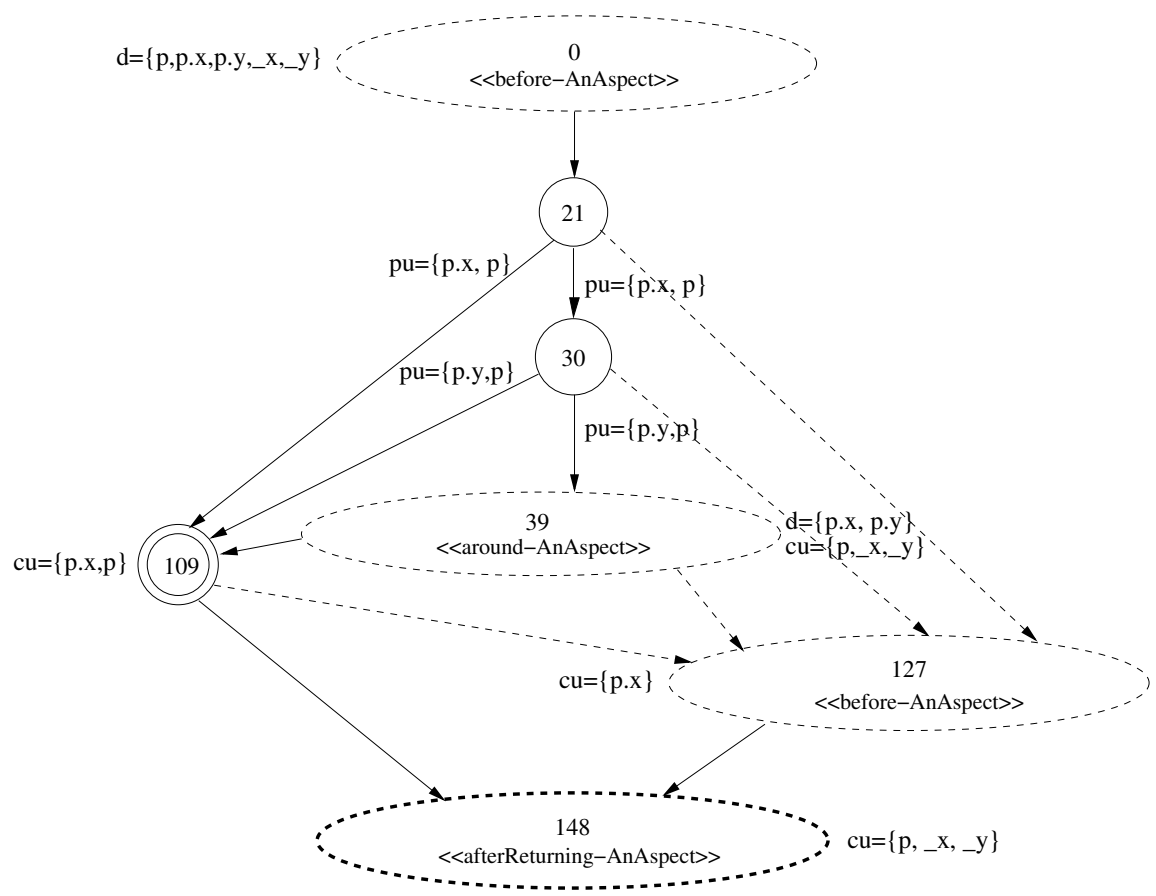

Figura 3.9: Grafo $\mathcal{A O D U}$ do método af fectedMethod com a presença do aspecto AnAspect. Adaptado de Lemos (2005).

que cada nó transversal, e portanto cada execução de adendo que ocorre na unidade afetada, seja exercitado pelo menos uma vez por algum caso de teste de $T$.

- todas-arestas-transversais (Todas-Arestas $C$ ): $\Pi$ satisfaz o critério todas-arestas-transversais se cada aresta $e_{i} \in E_{i}$ de um grafo $\mathcal{A O D U}$ está incluída em $\Pi$. Em outras palavras, esse critério requer que cada aresta do grafo $\mathcal{A O D U}$ que tem um nó transversal como nó de início ou destino seja exercitada por algum caso de teste de $T$.

Com relação ao critério de fluxo de dados, Lemos (2005) revisou no contexto do teste de programas OA os critérios todos-usos, todos-usos-independentes-de-exceção e todos-usos-dependentes-de-exceção (discutidos no trabalho de Vincenzi (2004) (Seção 3.4.1)) e definiu um novo critério específico para programas OA denominado todos-usos-transversais. Alguns conceitos utilizados para a definiões dos critérios foram discutidos na Seção 3.4.1.

- todos-usos-transversais (Todos-Usos ${ }_{C}$ ): П satisfaz o critério todos-usos-transversais se para cada nó $i \in \operatorname{def}(i)$ de um grafo $\mathcal{A O D U}$, П inclui um caminho livre de definição para $x$ de $i$ a cada elemento de $d c u(x, i)$ que é um nó transversal e a todos elementos de $d p u(x, i)$ nos quais o nó início da aresta é um nó transversal. Em outras palavras, esse critério requer que cada par def-c-uso $(i, j, x) \mid j \in d c u(x, i)$ tal que $j \in C$ e cada par def$p$-uso $(i,(j, k), x) \mid(j, k) \in d p u(x, i)$ tal que $j \in C$ seja exercitado ao menos uma vez para algum caso de teste de $T$. 


\subsubsection{Teste Estrutural de Integração}

Uma das abordagens para teste de integração de programas OA foi proposta por Lemos (2005). Em seu trabalho, o pesquisador foca no teste do tipo Método-Adendo, considerando somente as interações diretas com adendos. O modelo base para o teste de fluxo de dados de integração MétodoAdendo é o grafo $\mathcal{M A D U}$ (Method-Advice Def-Use) o qual é composto pelo grafo $\mathcal{A O D U}$ do método em si e pelos grafos $\mathcal{A O D U}$ dos adendos que o afetam diretamente. Os nós transversais do grafo $\mathcal{A O D U}$ do método são quebrados em um nó de aprimoramento (enh - enhancement node) e um nó de retorno (ret - return node). Arestas adicionais são criadas para conectar os nós enh com os nós de entrada dos grafos $\mathcal{A O D U}$ dos adendos e para conectar os nós de saída dos grafos $\mathcal{A O D U}$ dos adendos com os nós de ret. O grafo $\mathcal{M A D U}$ deve ser construído para cada método afetado por adendos. O escopo do método corresponde ao grafo $\mathcal{A O D U}$ do método (incluindo os nós enh e ret) e os escopos de adendos correspondem aos grafos $\mathcal{A O D U}$ dos adendos.

Cada nó do grafo $\mathcal{M A D U}$ é associado um conjunto c-uso e um conjunto def e a cada aresta do grafo é associado um conjunto $p$-uso. Além disso, são definidos os conjuntos: $d c u(x, i)$ que é o conjunto de todos os nós $j$ de um dado grafo $\mathcal{M A D U}$, tal que $x \in c$-uso $(j)$ e existe um caminho livre de definição para $x$ de $i$ a $j$; e $d p u(x, i)$ que é o conjunto de todas as arestas $(j, k)$ de um dado grafo $\mathcal{M A D U}$, tal que $x \in p$-uso $(j, k)$ e existe um caminho livre de definição para $x$ de $i$ a $(j, k)$.

Um exemplo de grafo $\mathcal{M A D U}$ é mostrado na Figura 3.10. O grafo (construído a partir da análise do bytecode combinada) é do método a f fectedMet hod mostrado anteriormente (Figura 3.8). Nota-se que cada par de nós enh e ret substitui cada nó transversal do grafo $\mathcal{A O D U}$ do método affectedMethod (Figura 3.9). Além disso, informação de fluxo de dados é obtida para cada nó e aresta, para os escopos do método e dos adendos.

Baseando-se nas diferentes interações de dados que podem ocorrer em um método afetado por aspectos e nos diferentes escopos representados no grafo $\mathcal{M} \mathcal{A D} \mathcal{U}$, Lemos (2005) definiu quatro tipos de pares def-uso aspectuais. Considere um componente como sendo uma classe Java, $M$ um método afetado por adendos, $d$ uma sentença contendo uma definição de uma variável $x$ e $u$ uma sentença contendo um uso de $x$, os seguintes pares são definidos:

- componente-componente: Se $d$ e $u$ estão em $M$, e existe um caminho livre de definição com relação a $x$ de $d$ a $u$, então $(x, d, u)$ é um par def-uso componente-componente.

- componente-aspecto: Seja $\left\{A_{1}, A_{2}, \ldots, A_{n}\right\}$ o conjunto de adendos que interagem com $M$ em uma invocação de $M$. Se $d$ está em $M, u$ está em $A_{i}$, e existe um caminho livre de definição com relação a $x$ de $d$ a $u$, então $(x, d, u)$ é um par def-uso componente-aspecto.

- aspecto-componente: Seja $\left\{A_{1}, A_{2}, \ldots, A_{n}\right\}$ o conjunto de adendos que interagem com $M$ em uma invocação de $M$. Se $d$ está em $A_{i}$, tal que $A_{i} \in\left\{A_{1}, A_{2}, \ldots, A_{n}\right\}$, u está em $M$, e existe um caminho livre de definição com relação a $x$ de $d$ a $u$, então $(x, d, u)$ é um par def-uso aspecto-componente. 


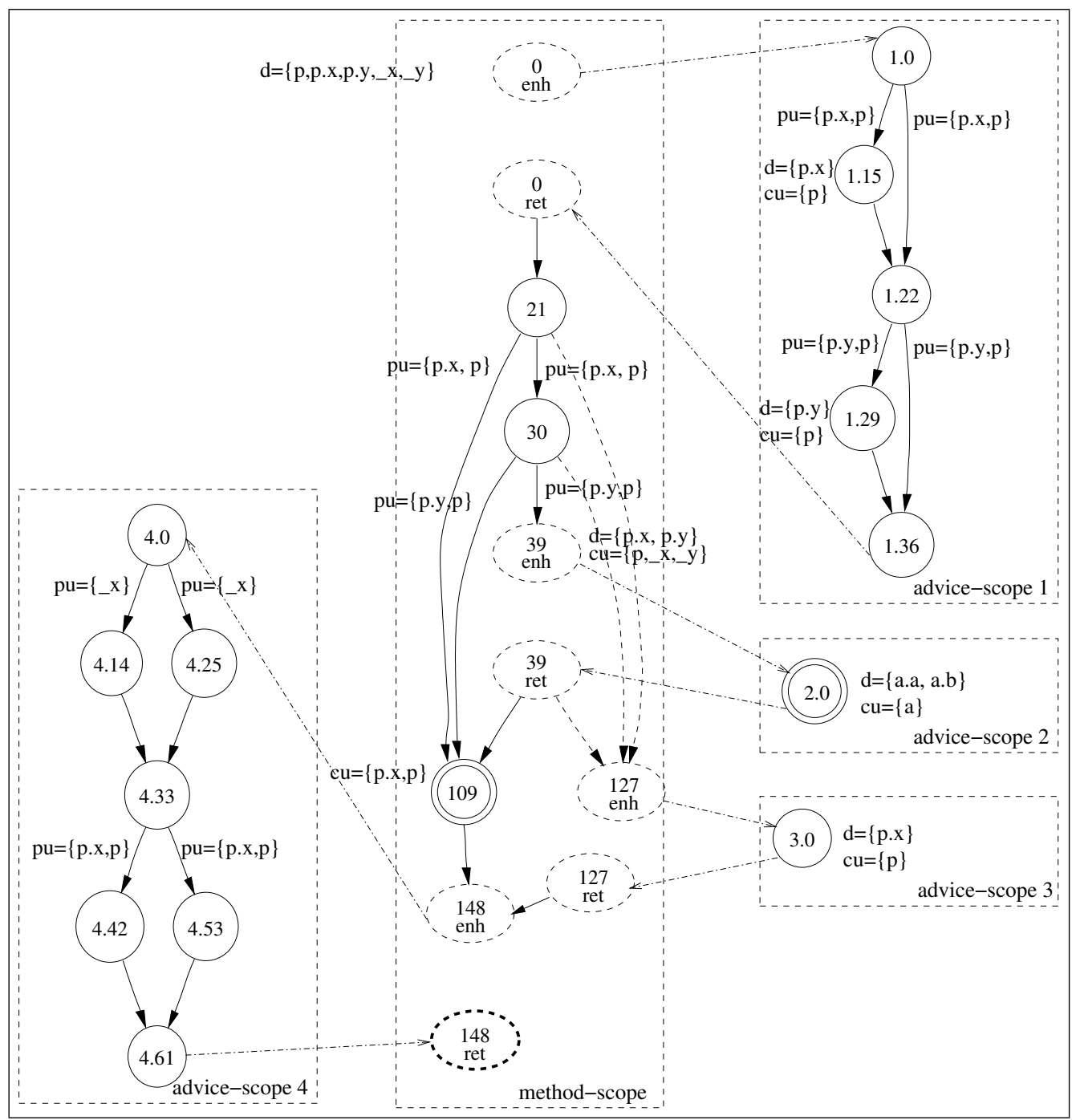

Figura 3.10: Grafo $\mathcal{M A D U}$ do método af fectedMet hod (adaptado de Lemos (2005)).

- aspecto-aspecto: Seja $\left\{A_{1}, A_{2}, \ldots, A_{n}\right\}$ o conjunto de adendos que interagem com $M$ em uma invocação de $M$. Se $d$ está em $A_{i}$, tal que $A_{i} \in\left\{A_{1}, A_{2}, \ldots, A_{n}\right\}$, $u$ está em $A_{j}$, tal que $A_{j} \in\left\{A_{1}, A_{2}, \ldots, A_{n}\right\}$, e existe um caminho livre de definição com relação a $x$ de $d$ a $u$, então $(x, d, u)$ é um par def-uso aspecto-aspecto.

A partir daí, o pesquisador define alguns critérios de Teste de Integração Baseados em Fluxo de Dados. Considere $T$ um conjunto de casos de teste para o teste de um programa $P$, e $\Pi$ o conjunto de caminhos exercitados a partir da execução de $T$. Baseado nos tipos de pares Def-Uso definidos anteriormente, e nos critérios Todos-Usos, são definidos os seguintes critérios de teste Método-Adendo:

- todos-cc-usos (todos-usos-componente-componente): $T$ satisfaz o critério todos-cc-usos se para cada nó $i$ no escopo do método do grafo $\mathcal{M} \mathcal{A D U}$ e para cada $x \in \operatorname{def}(i)$, $\Pi$ inclui um caminho livre de definição com relação a $x$ de $i$ para cada elemento de $d c u(x, i)$ e para cada elemento de $d p u(x, i)$ que estão no escopo do método. 
- todos-ca-usos (todos-usos-componente-aspecto): $T$ satisfaz o critério todos-ca-usos se para cada nó $i$ no escopo do método do grafo $\mathcal{M A D U}$ e para cada $x \in \operatorname{def}(i)$, $\Pi$ inclui um caminho livre de definição com relação a $x$ de $i$ para cada elemento de $d c u(x, i)$ e para cada elemento de $d p u(x, i)$ que estão no escopo de adendos.

- todos-ac-usos (todos-usos-aspecto-componente): $T$ satisfaz o critério todos-ac-usos se para cada nó $i$ no escopo de adendo do grafo $\mathcal{M A D U}$ e para cada $x \in \operatorname{def}(i)$, $\Pi$ inclui um caminho livre de definição com relação a $x$ de $i$ para cada elemento de $d c u(x, i)$ e para cada elemento de $d p u(x, i)$ que estão no escopo de método.

- todos-aa-usos (todos-usos-aspecto-aspecto): $T$ satisfaz o critério todos-aa-usos se para cada nó $i$ no escopo de adendo do grafo $\mathcal{M A D U}$ e para cada $x \in \operatorname{def}(i)$, $\Pi$ inclui um caminho livre de definição com relação a $x$ de $i$ para cada elemento de $d c u(x, i)$ e para cada elemento de $d p u(x, i)$ que estão no escopo de adendo.

Lemos (2005) também definiu o critério Todos-Usos para esse contexto, que inclui os quatro critérios definidos acima:

- todos-usos: Um conjunto $\Pi$ de caminhos executados por um conjunto de casos de teste satisfaz o critério todos-usos se para cada nó $i$ do grafo $\mathcal{M} \mathcal{A D U}$ e para cada $x \in \operatorname{def}(i), \Pi$ inclui um caminho livre de definição com relação a $x$ de $i$ para cada elemento de $d c u(x, i) \mathrm{e}$ para cada elemento de $d p u(x, i)$.

\subsubsection{Outras Abordagens para Teste de Programas OA}

Segundo Alexander et al. (2004), o paradigma de desenvolvimento orientado a objetos está ainda na infância e, portanto, pouca pesquisa sobre teste de programas OA têm sido publicada. A seguir são discutidos alguns trabalhos propostos relacionados a teste de programas OA.

\section{Teste Baseado em Estados}

Inspirado pelos trabalhos de Binder (1999) sobre padrões de projeto de teste baseado em FREE (Flattened Regular Expression) para programas OO, Xu et al. (2004) propuseram uma abordagem de teste baseado em estados e estrutural para programas OA. A idéia principal é estender o modelo baseado em estados FREE para um Modelo de Estados Aspectual (Aspectual State Model - ASM).

O modelo FREE representa os estados e comportamentos dinâmicos de objetos e oferece diretrizes para a implementação. Na Figura 3.11 é mostrado o código-fonte e modelo FREE da a classe Account de uma aplicação de contas bancárias. Os estados de um objeto Account são: Open, Frozen, Inactive e Closed. As relações de transição de estado que determinam as mudanças de estado de um objeto Account são disparadas pelos métodos públicos: open, debit, credit, balance, freeze, unfreeze, close e settle. 


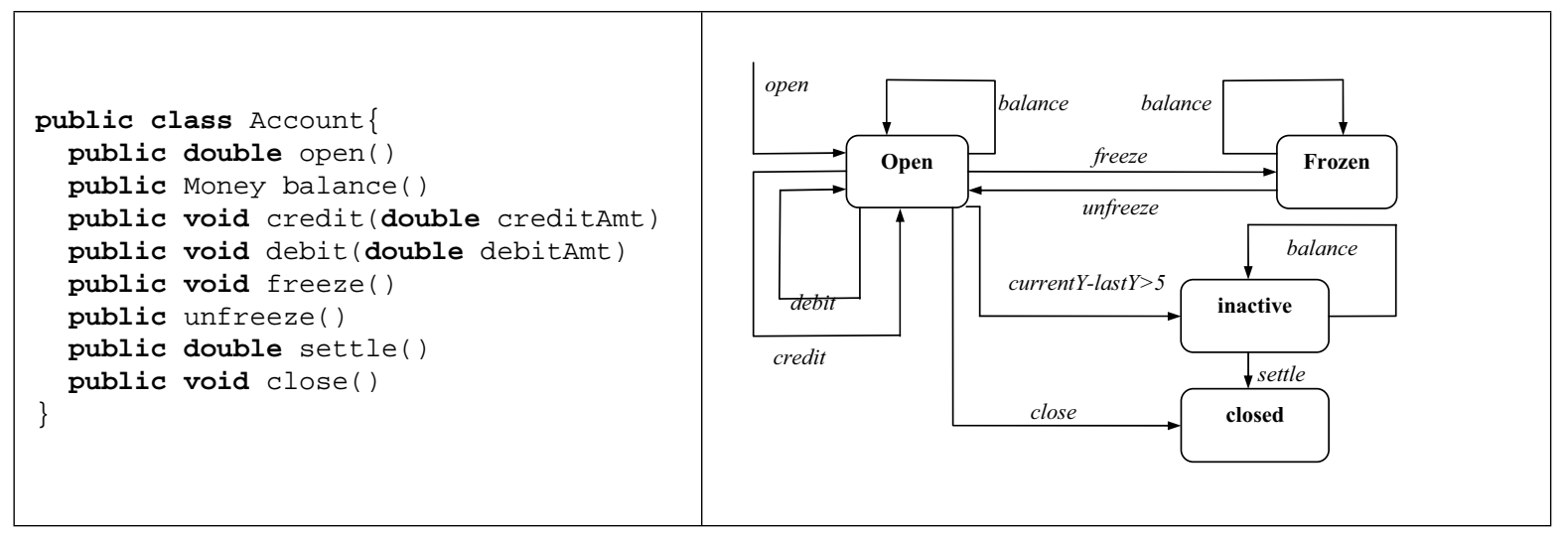

Figura 3.11: Código-fonte e modelo FREE da classe Account (adaptado de Xu et al. (2004)).

A modelagem de estruturas orientadas a aspectos requer três elementos: elementos base, elementos transversais e relacionamentos transversais. Os elementos base são representados pelo modelo FREE. Para representar os elementos e relacionamentos transversais são introduzidas algumas notações para construções básicas de POA — conjuntos de junção, pontos de junção e adendos. A partir daí é construído o modelo ASM. Como ilustração, Xu et al. (2004)) insere, no exemplo de contas bancárias, um novo interesse para tratar overdraft (saque a descoberto), que ocorre quando o cliente retira mais dinheiro do que possui na conta. Este novo interesse é implementado por um aspecto. Na Figura 3.12 é mostrado o modelo ASM para representar a classe juntamente com os aspectos que interagem com ela. O estado Overdrawn é o novo estado introduzido pelo aspecto, $\mathrm{b}$ refere-se ao saldo real da conta e amt refere-se a quantidade movimentada por uma operação de crédito ou débito.

Em um modelo ASM, a utilização de caixas e setas sólidas é empregada para preservar as transições e estados de uma classe. As caixas e setas tracejadas representam os mecanismos transversais (conjuntos de junção, adendos, etc) e novos estados introduzidos pelos aspectos. A execução dos adendos anteriores e posteriores inicia em um losango preenchido perto do início ou do final da transição, respectivamente. A execução de adendos de contorno inicia com um círculo preenchido no ponto de junção referente.

A partir do modelo ASM é derivada uma árvore de transições da qual são criados casos de teste que definem seqüências de transições (invocações de métodos ou mensagens). Na árvore de transições cada caminho da raiz ao nó folha é um requisito de teste para avaliar o comportamento do objeto. Na Figura 3.13 é mostrada a árvore de transições baseada no modelo ASM da Figura 3.12 usando Open como estado inicial.

\section{Modelo de Defeitos}

Um modelo de defeitos para programação orientada a aspecto deve basear-se nos tipos de defeitos e falhas únicos desse novo tipo de programação. Quando uma falha ocorre, o primeiro desafio é diagnosticar a falha e detectar o defeito. Em um programa não orientado a aspecto devese examinar o código das classes ou procedimentos na tentativa de isolar o defeito. Em POA, 


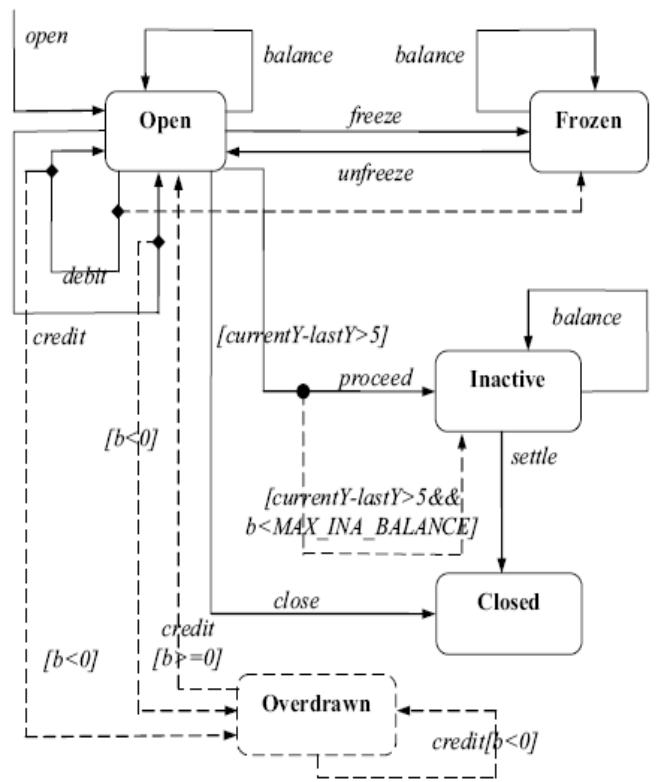

Figura 3.12: Modelo ASM para classe Account (adaptado de Xu et al. (2004)).

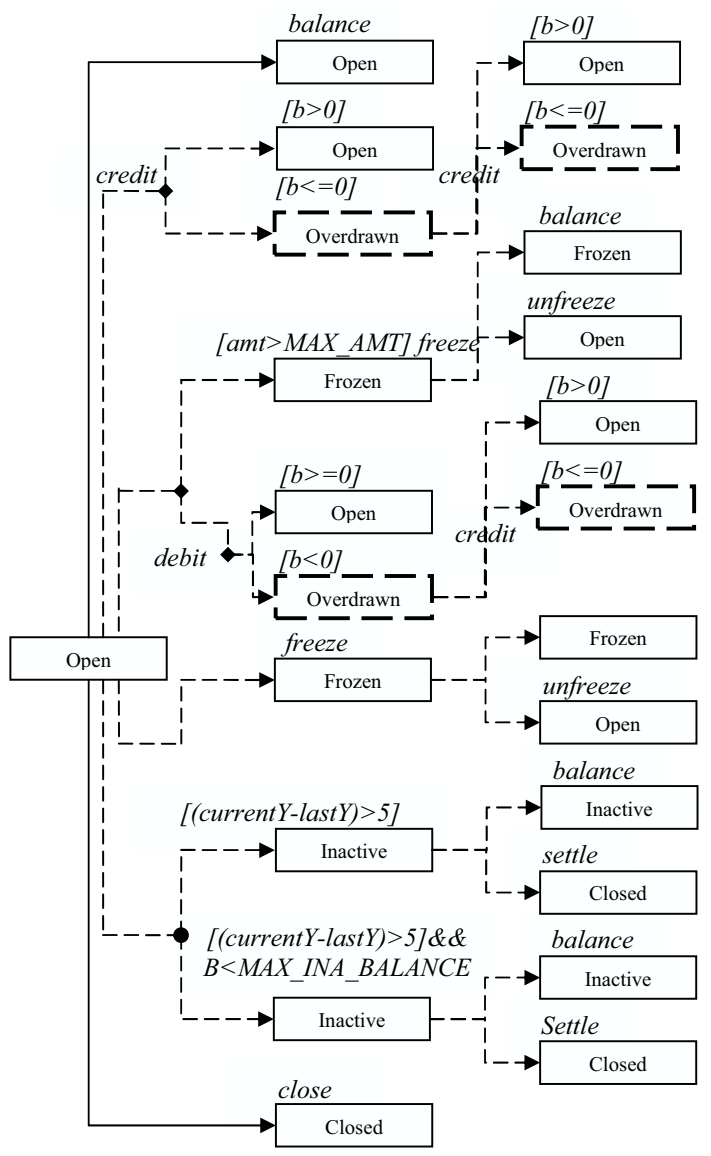

Figura 3.13: Árvore de transição para o modelo ASM da Figura 3.12 (adaptado de Xu et al. (2004)). 
por sua vez, não é diferente. Entretanto, para detectar um defeito existente em um programa OA, é necessário examinar também o código dos aspectos que estão combinados com o código que implementa os interesses primários do programa. Assim, para um programa OA pode-se definir quatro fontes potenciais de defeitos (Alexander et al., 2004): (1) O defeito está na classe que não é afetada por um aspecto; (2) O defeito está no código específico do aspecto, isolado do contexto; (3) $\mathrm{O}$ defeito surge na interação entre um aspecto e a classe; (4) $\mathrm{O}$ defeito surge quando mais que um aspecto é combinado com uma classe.

Baseado nessas particularidades, Alexander et al. (2004) propuseram um Modelo de Defeitos (Fault Model) para POA, o qual foi definido levando em conta as construções específicas do AspectJ e reflete uma avaliação inicial de classes de defeitos potenciais. Os tipos de defeitos presentes no modelo proposto são os seguintes:

1 - Restrição incorreta em padrões de conjuntos de junção: Os conjuntos de junção contêm as especificações para selecionar pontos de junção de acordo com uma assinatura que inclui um padrão. A restrição na assinatura do padrão determina quais pontos de junção são selecionados. Se o padrão é muito fraco, pontos de junção que deveriam ser ignorados serão selecionados. Se o padrão for muito forte, alguns pontos de junção necessários não serão selecionados. Ambos os casos causam comportamento incorreto do programa.

2 - Precedência de aspecto incorreta: A ordem na qual os adendos de múltiplos aspectos são combinados afeta o comportamento do sistema. Em AspectJ, a ordem de combinação é determinada pela especificação de precedência do aspecto, ou seja, aspectos com maior precedência executam seus adendos anteriores primeiramente que os aspectos com menor precedência.

3 - Falha em estabelecer pós-condições esperadas: Antes de chamar um método é necessário que as pré-condições indispensáveis para que ele possa executar conforme o esperado estejam presentes. Dadas as pré-condições, é esperado que as pós-condições sejam satisfeitas independente se há ou não aspectos interferindo no comportamento do método. Deste modo, para o correto funcionamento do método, o adendo do aspecto deve permitir que o método satisfaça suas póscondições.

4 - Falha na preservação de invariantes de estado: O comportamento de um interesse é definido em termos da representação física de seu estado e métodos que agem sobre o estado. Para estabelecer suas pós-condições, os métodos devem garantir que as invariantes de estado sejam satisfeitas, ou seja, que elas não sejam violadas na combinação.

5 - Foco incorreto no fluxo de controle: A seleção de quais métodos devem ser capturados é definida no conjunto de junção e é determinada em tempo de combinação. Entretanto, existem casos em que a informação necessária para tomar tais decisões corretamente está disponível somente em tempo de execução. Isso ocorre quando alguns pontos de junção devem ser somente selecionados em um contexto de execução particular, como por exemplo, dentro da estrutura de controle de um determinado objeto. 
6 - Mudanças incorretas nas dependências de controle: Um exemplo de mudança, em AspectJ, é o adendo de contorno (around) que executa em lugar do ponto de junção e pode alterar o fluxo de controle e a dependências de dados de um método.

A partir do modelo de defeitos, Alexander et al. (2004) propuseram alguns critérios de teste. Os pesquisadores assumem uma estratégia que requer que todos os interesses primários tenham sido testados antes da combinação e que estejam livres de defeitos relacionados a algum critério de teste. $\mathrm{O}$ critério de teste foca no comportamento do interesse primário, no comportamento de cada aspecto e no comportamento do combinador. A seguir estão as descrições resumidas dos critérios para cada tipo de defeito descrito no modelo de defeitos:

1 - Restrição incorreta em padrões de conjuntos de junção: esses defeitos podem causar a falha dos aspectos ao invés da funcionalidade primária. Deste modo, um teste de aspecto é requerido.

2 - Precedência de aspecto incorreta: esses defeitos ocorrem quando há a interação de múltiplos aspectos e são afetados pela ordem de combinação dos aspectos. Testar todas as ordens de combinação pode revelar esses defeitos.

3 - Falha em estabelecer pós-condições esperadas: esses defeitos podem causar a falha dos métodos que implementam os interesses primários. Um critério é re-testar todos os métodos que são interceptados por aspectos usando um conjunto de testes original.

4 - Falha na preservação de invariantes de estado: esses defeitos podem também causar a falha dos métodos que implementam os interesses primários. É conveniente re-testar os métodos.

5 - Foco incorreto no fluxo de controle: esses defeitos podem causar a ativação dos adendos erroneamente. Um critério para descobrir esses defeitos pode ser uma forma de cobertura de condição do designador do ponto de junção.

6 - Mudanças incorretas nas dependências de controle: esses defeitos afetam o comportamento dos interesses primários, conforme ocorre com os tipos 3 e 4 .

\subsection{Ferramentas de Teste}

A atividade de teste propriamente dita é uma atividade muito propensa a erros, além de demorada, se aplicada manualmente. Para efetuar um teste com qualidade e produtividade é necessário utilizar, além das técnicas e critérios de teste anteriormente discutidos, ferramentas de teste. Com o uso delas é possível, por exemplo: obter maior eficiência e redução do esforço necessário para a realização do teste; diminuir o número de erros causados pela execução manual dessa atividade; produzir software com alta qualidade; e conduzir estudos empíricos que visem a avaliar e a comparar os diversos critérios de teste existentes.

Em geral, as ferramentas de teste utilizam o conceito de cobertura para medir o quanto um critério foi satisfeito em relação aos seus requisitos. Coberturas de nós, arestas e definições-uso 
constituem alguns exemplos utilizados pelas ferramentas. A análise de cobertura permite identificar áreas do programa não exercitadas por um conjunto de casos de teste e, dessa forma, avaliar a qualidade desse conjunto. Além disso, por meio da análise de cobertura é possível medir o progresso do teste e decidir quando finalizar essa atividade.

Para obter medidas de cobertura, muitas das ferramentas de teste fazem a instrumentação do programa em teste. A instrumentação consiste em inserir novos códigos (ou instruções) no programa em teste de modo que, por meio desses novos comandos adicionados, o testador possa observar o comportamento do programa e obter informações ou medidas referentes à sua execução (Huang, 1978). A instrumentação pode ser realizada em tempo de compilação ou dinamicamente e pode modificar o código-fonte ou o código intermediário. Algumas ferramentas como Java Instrumentation Engine (Tromer, 2006) permitem a instrumentação direta sobre o código-fonte Java. Outras como BCEL (Dahm, 2006) instrumentam o bytecode Java.

A seguir é apresentada a descrição de uma série de ferramentas comerciais e não comerciais que se encontram disponíveis para o teste de programas OO e OA escritos em Java e AspectJ. A descrição das ferramentas foi parcialmente extraída dos trabalhos de dos Santos Domingues (2001), que consistiu em avaliar ferramentas de teste para programas OO, e também de Vincenzi (2004) e Lemos (2005). As informações sobre essas ferramentas foram obtidas por meio de pesquisa na World Wide Web (WWW) e baseadas na documentação existente de cada uma.

Jtest (Parasoft Corporation, 2006) é uma ferramenta de teste de classes Java que executa os seguintes tipos de teste: análise estática, teste funcional, teste estrutural e teste de regressão (quando manutenções são feitas no programa e os casos de teste armazenados são executados novamente para a validação da aplicação modificada). No teste funcional, a ferramenta gera automaticamente um conjunto essencial de casos de teste. O testador pode fornecer um conjunto adicional de casos de teste que serão testados juntamente com os casos de teste gerados pela ferramenta. Em seguida, todos os casos de teste são executados e seus respectivos resultados são mostrados em uma representação de árvore. O testador pode então visualizar esses resultados e validá-los. Para evitar a introdução de defeitos em códigos previamente testados e corretos, a ferramenta executa automaticamente o teste de regressão. Outro recurso utilizado pela ferramenta para evitar que defeitos sejam inseridos é a análise estática. Com ele, a ferramenta faz uma analise gramatical do códigofonte Java e checa se ele segue um conjunto de padrões de codificação estabelecido. Qualquer violação no padrão é relatada como um defeito.

JProbe Suite (Quest Software, 2006) é um conjunto de três ferramentas composto por: JProbe Profiler, que ajuda a diagnosticar e eliminar gargalos de execução em códigos Java; JProbe Memory Debugger, que detecta desperdício de memória e auxilia na redução do uso de memória em aplicações Java; e JProbe Coverage, que localiza códigos não testados e mede quanto do código está sendo exercitado, permitindo ao testador estimar qual a confiança dos testes executados.

Panorama for Java (International Software Automation (ISA), 2006) é um conjunto de cinco ferramentas composto por: J_Test, J_SQA, J_Analyser, J_Browser, e J_Diagrammer. Estas ferramentas são úteis no teste de software, garantia de qualidade e reengenharia. Elas também dão 
suporte às etapas de codificação e documentação do projeto de software. $J \_T e s t$ executa a análise de cobertura de arestas, análise das freqüências das arestas executadas, análise da eficiência dos casos de teste e minimização do conjunto de casos de teste. Todos os resultados das análises são exibidos em gráficos.

JCover (Man Machine Systems, 2006) é um analisador de cobertura de código para programas Java. Ele funciona tanto com arquivos fonte ou arquivos compilados. Obtém medidas de cobertura de arestas, sentenças, métodos e classes. $\mathrm{O}$ analisador gera vários relatórios e gráficos que mostram a cobertura alcançada. Por meio do recurso de análise de dados é possível ver como a cobertura evoluiu durante as diversas execuções de testes e analisar as áreas do código que foram ou não cobertas.

Clover (Cenqua, 2006) é uma ferramenta de análise de cobertura de programas Java que obtém medidas de cobertura de métodos, arestas e sentenças. Para isso, a Clover instrumenta o códigofonte. A ferramenta pode rastrear a cobertura de toda a vida de um projeto e produz relatórios históricos mapeando o progresso da cobertura e outras métricas do projeto. Com a ferramenta é possível também gerar relatórios em vários formatos e identificar códigos no programa que ainda não foram testados.

JUnit é um framework que possibilita a criação de testes unitários em Java. O framework JUnit é de código aberto e pode ser utilizado para escrever, executar e avaliar casos de teste (Beck e Gamma, 2006). A idéia básica desse framework é implementar algumas classes específicas que armazenam informações sobre os dados de entrada e a respectiva saída esperada para cada caso de teste. Após a execução de um caso de teste, a saída obtida é comparada com a saída esperada e as discrepâncias são relatadas.

Para gerar um caso de teste, cria-se uma classe de teste que é subclasse da classe Testcase (declarada no pacote do junit.framework do arquivo junit.jar) e implementam-se os métodos para fazer os testes. O nome da classe pode ser qualquer um desde que siga as regras para a definição de identificadores em Java. Já os métodos devem ser identificados seguindo o padrão test $\mathrm{Xxx}$ (), onde Xxx é, normalmente, o nome do método a ser testado. Os métodos de uma classe de teste devem ser públicos e não ter argumentos. Ao executar o JUnit as saídas esperadas de um processamento são validadas por métodos chamados assertXxx, onde Xxx pode ser True, False, Equals ou outra condição.

O principal problema do JUnit é que ele não fornece informação a respeito da cobertura obtida pelos casos de teste. JUnit pode ser utilizado mesmo que somente o bytecode e a especificação do programa estejam disponíveis.

JaBUTi (Java Bytecode Understanding and TestIng) (Vincenzi, 2004) é uma ferramenta de teste desenvolvida pelo Grupo de Pesquisa em Engenharia de Software do ICMC, em colaboração com outros grupos de pesquisa. A ferramenta JaBUTi é um ambiente completo para o entendimento e teste de programas e componentes Java que fornece diferentes critérios de teste estruturais para a análise de cobertura, um conjunto de métricas estáticas para avaliar a complexidade das 
classes que compõem o programa/componente e implementa ainda algumas heurísticas de particionamento de programas que visam a auxiliar a localização de defeitos ${ }^{4}$.

Para permitir a análise de cobertura de um programa Java, a ferramenta implementa seis critérios de teste intra-métodos (discutidos na Seção 3.4.1), dos quais quatro são critérios de teste baseado em fluxo de controle (todos-nós-independentes-de-exceção, todos-nós-dependentesde-exceção, todas-arestas-independentes-de-exceção e todas-arestas-dependentes-de-exceção) e dois são critérios de teste baseados em fluxo de dados (todos-usos-independentes-de-exceção e todos-usos-dependentes-de-exceção). Os pares de critérios todos-nós-independentes-de-exceção e todos-nós-dependentes-de-exceção, todas-arestas-independentes-de-exceção e todas-arestas-dependentes-de-exceção compõem os critérios todos-nós e todas-arestas, respectivamente (Roper, 1995), da mesma forma que o par de critério todos-usos-independentes-de-exceção e todos-usosdependentes-de-exceção compõe o critério todos-usos (Rapps e Weyuker, 1985).

A decisão por dividir esses critérios foi tomada em virtude da distinção entre partes de código relacionadas com a execução "normal" do programa daquelas relacionadas com o tratamento de exceções. Tal distinção permite ao testador se concentrar em aspectos diferentes do programa, um de cada vez, realizando a atividade de teste de modo incremental e respeitando as restrições de tempo e custo que lhe forem impostas.

Os principais passos para realizar a análise de cobertura são: instrumentar os arquivos .class, coletar informação de cobertura durante a execução do programa (execution trace information) e determinar quão bem cada um dos métodos de todas as classes foram testados de acordo com os critérios de teste disponíveis.

Para facilitar a geração de casos de teste com o objetivo de aumentar a cobertura em relação aos critérios de teste, utilizando o conceito de dominadores e super-bloco (Agrawal, 1994), a ferramenta atribui diferentes pesos aos requisitos de teste indicando qual o requisito de teste que, se coberto, aumentaria ao máximo a cobertura em relação ao critério considerado. Para avaliar o andamento da atividade de teste, relatórios de teste com diferentes níveis de granularidade (por projeto, por classe, por método, por caso de teste) podem ser gerados para auxiliar o testador a decidir quando parar os testes ou quais partes ainda não foram suficientemente testadas.

JaBUTi/AJ (Java Bytecode Understanding and TestIng for AspectJ) (Lemos, 2005) é uma extensão da ferramenta JaBUTi para apoiar teste de unidade de programas orientados a aspectos escritos em Java e AspectJ. Deste modo, por ser uma extensão da ferramenta JaBUTi, tudo o que foi discutido anteriormente quanto às funcionalidades e classes da JaBUTi pode ser considerado como presente na JaBUTi/AJ.

Entretanto, para dar suporte a teste de programas OA, a ferramenta JaBUTi/AJ possui algumas diferenças em relação à versão somente OO. Uma dessas diferenças diz respeito aos critérios de teste. Além dos critérios existentes na JaBUTi (discutidos na Seção 3.4.1), na JaBUTi/AJ são implementados mais três novos critérios de teste (discutidos na Seção 3.5.1), dos quais dois são cri-

\footnotetext{
${ }^{4}$ A maior parte do texto sobre a ferramenta JaBUTi foi retirada de Vincenzi (2004)
} 
térios de teste baseado em fluxo de controle: todos-nós-transversais e todas-arestas-transversais; e um é critério de teste baseados em fluxo de dados: todos-usos-transversais. Outra diferença diz respeito ao grafo Def-Uso $(\mathcal{D U})$ da JaBUTi. Este foi estendido para um novo grafo chamado grafo Def-Uso Orientado a Aspectos $(\mathcal{A O D U})$ o qual passou a exibir informações referentes aos nós transversais. Mais informações sobre a interface e algumas funcionalidades da ferramenta JaBUTi/AJ são discutidas na Seção 5.3.1

Na Tabela 3.5 são apresentadas algumas comparações entre as ferramentas de teste anteriormente analisadas. As colunas referentes as características são: (1) Análise Estática, (2) Teste de Unidade, (3) Teste de Integração, (4) Teste de Sistema, (5) Critérios Funcionais, (6) Critérios de Fluxo de Controle, (7) Critérios de Fluxo de Dados, (8) Exigência de código-fonte, (9) Teste de Regressão e (10) Apóia teste de programas OA.

Tabela 3.5: Características apresentadas pelas ferramentas de teste OO e OA (adaptada de Vincenzi (2004)).

\begin{tabular}{|c|c|c|c|c|c|c|c|c|c|c|}
\hline \multirow{2}{*}{ Ferramentas } & \multicolumn{9}{|c|}{ Características } \\
\hline & $(1)$ & $(2)$ & $(3)$ & $(4)$ & $(5)$ & $(6)$ & $(7)$ & $(8)$ & $(9)$ & $(10)$ \\
\hline JProbe Suite & $\sqrt{ }$ & $\sqrt{ }$ & & $\sqrt{ }$ & & $\sqrt{ }$ & & $\sqrt{ }$ & & \\
\hline Panorama for Java & & $\sqrt{ }$ & & & & $\sqrt{ }$ & & $\sqrt{ }$ & & \\
\hline JCover & & $\sqrt{ }$ & & & & $\sqrt{ }$ & & & & \\
\hline JUnit & & $\sqrt{ }$ & & & $\sqrt{ }$ & & & & & \\
\hline Jtest & $\sqrt{ }$ & $\sqrt{ }$ & & $\sqrt{ }$ & $\sqrt{ }$ & $\sqrt{ }$ & & $\sqrt{ }$ & $\sqrt{ }$ & \\
\hline Clover & & $\sqrt{ }$ & & & & $\sqrt{ }$ & & $\sqrt{ }$ & & \\
\hline JaBUTi & & $\sqrt{ }$ & & & & $\sqrt{ }$ & $\sqrt{ }$ & & & \\
\hline JaBUTi/AJ & & $\sqrt{ }$ & & & & $\sqrt{ }$ & $\sqrt{ }$ & & & $\sqrt{ }$ \\
\hline
\end{tabular}

Analisando a Tabela 3.5 observa-se que somente a ferramenta JaBUTi/AJ apóia o teste de programas OA. Com relação às fases de teste de software, dentre as ferramentas analisadas, o teste de unidade é apoiado por todas elas. Entretanto, poucas (somente JProbe Suíte e JTest) dão suporte ao teste de sistema e nenhuma apóia o teste de integração. A ferramenta Jtest é a única que realiza teste de regressão. Quanto aos critérios de teste, os critérios de fluxo de controle são aplicados em todas as ferramentas analisadas. O mesmo não ocorre com os critérios de fluxo de dados, que só são analisados nas ferramentas JaBUTi e JaBUTi/AJ, e com os critérios de teste funcionais, que estão presentes somente no JUnit e Jtest. O framework JUnit e as ferramentas JCover, JaBUTi e JaBUTi/AJ são ferramentas que funcionam tanto com arquivos fonte ou arquivos compilados. Por fim, a análise estática é efetuada somente nas ferramentas JProbe Suíte e Jtest.

Conforme analisado anteriormente, nenhuma ferramenta de teste de programas existente atualmente dá suporte ao teste estrutural de integração de programas Java. Para suprir essa deficiência, a ferramenta JaBUTi/AJ foi estendida para apoiar este tipo de teste. A abordagem de teste estrutural de integração par-a-par (pairwise) foi a abordagem utilizada para implementar o teste de integração na ferramenta. Mais detalhes sobre a extensão são discutidos na Seção 5.2. Vale destacar que esta extensão só pode ser realizada dentro do tempo do programa de mestrado graças a toda a estrutura e funcionalidades (tais como, análise e instrumentação do bytecode, construção dos grafos 
e execução dos casos de teste) já existentes na ferramenta JaBUTi/AJ para a execução de testes de unidade.

\subsection{Considerações Finais}

Neste capítulo foi discutido sobre a atividade de teste software, dando enfoque ao teste estrutural de programas orientados a objetos e de programas orientados a aspectos. Inicialmente, comentou-se brevemente sobre os fundamentos e conceitos envolvidos no teste de software. Em seguida, algumas abordagens de teste estrutural OO e OA, tanto de unidade quanto de integração, foram abordadas. Disso, verificou-se que poucos tratam o teste de integração, principalmente para teste de programas OA. Por fim, foram analisadas algumas ferramentas utilizadas para teste de programas OO e OA escritos em Java e AspectJ. Dentre elas observou-se que nenhuma dá suporte ao teste estrutural de integração.

Dessa revisão constata-se que seria muito interessante o desenvolvimento de uma abordagem de teste de integração para o teste de programas OO e OA e a implementação dessa abordagem em uma ferramenta de teste. No próximo capítulo é proposta uma nova abordagem de teste estrutural de integração par-a-par de programas OO e OA. 


\section{Teste Estrutural de Integração Par-a-Par de Programas OO e OA}

\subsection{Considerações Iniciais}

Neste capítulo é apresentada uma abordagem de teste estrutural de integração par-a-par para programas $\mathrm{OO}$ e OA. A finalidade dessa abordagem é descobrir defeitos que possam existir na interface entre os pares de unidades que se relacionam em um programa.

$\mathrm{Na}$ Seção 4.2 são discutidos os tipos de teste estrutural de integração par-a-par. Na Seção 4.3 é apresentado o modelo de fluxo de dados que é utilizado para identificar o que caracteriza uma definição ou um uso de uma variável em uma sentença Java. Na Seção 4.4 é definido o grafo de fluxo utilizado pela abordagem de teste proposta. Na Seção 4.5 os critérios de teste estrutural de integração par-a-par são abordados. Finalmente, na Seção 4.6 são apresentadas as considerações finais do capítulo.

\subsection{Tipos de Teste Estrutural de Integração Par-a-Par}

Programas OO ou OA são constituídos de módulos que definem unidades. Estas unidades podem se relacionar com o objetivo de produzir um determinado comportamento no programa. Em um programa $\mathrm{OO}$, os módulos são as classes e as unidades são os métodos. Já em um programa OA, os módulos são classes e aspectos e as unidades são métodos e adendos. 
O teste estrutural de integração par-a-par (discutido na Seção 3.4.3) de um programa OO ou OA tem como objetivo testar a interação entre os pares de unidades que se relacionam. Para programas $\mathrm{OO}$ este tipo de teste envolve testar a interação entre os pares de métodos (m-m). Já para programas OA, o teste estrutural de integração par-a-par deve considerar os seguintes pares de unidades: método-método (m-m), método-adendo ( $\mathrm{m}-\mathrm{a})$, adendo-método (a-m) e adendo-adendo (a-a). Na Figura 4.1 é mostrado um exemplo simples de programa OA contendo duas classes $\mathrm{C} 1$ e C2 e um aspecto A1. A classe C1 possui os métodos $m 1$ (), m2 () e m3 (). A classe C2 tem um método $\mathrm{m} 4$ ( ). Já o aspecto $A 1$ possui o conjunto de juncão (pointcut) pc1 que captura as execuções do método $\mathrm{m} 2$ () da classe $\mathrm{C} 1$ e o conjunto de junção pc2 que captura as chamadas ao método m3 () da classe C1. O adendo anterior (before ()) é disparado antes da execução dos pontos de junções selecionados pelo conjunto de junção pc1 e o adendo posterior (after ( ) ) é disparado após a chamada dos pontos de junções selecionados pelo conjunto de junção pc2. Na Tabela 4.1 são mostrados os pares de unidades que se relacionam neste exemplo e o tipo de par de unidades que eles representam.

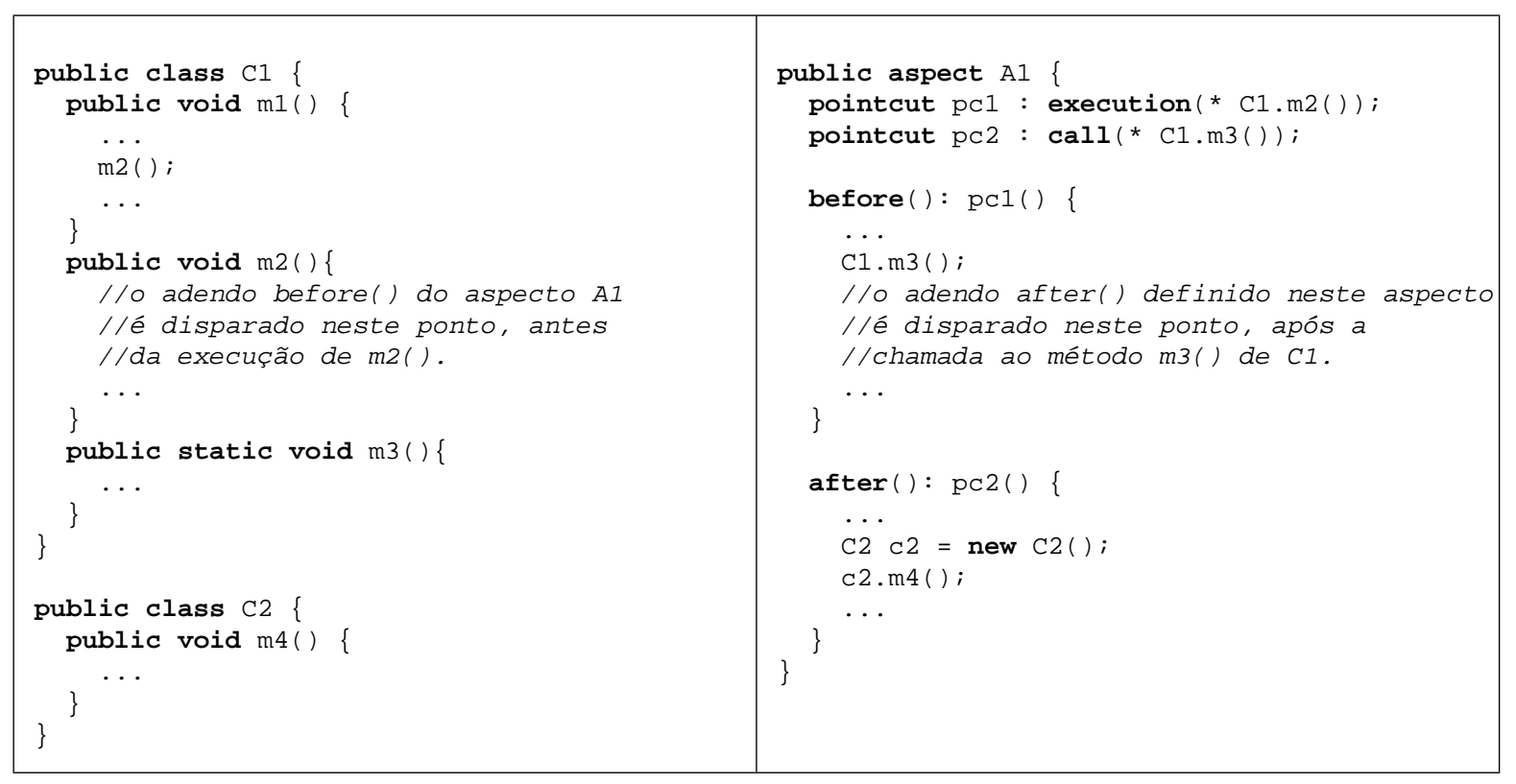

Figura 4.1: Exemplo simples de programa OA para demonstrar interação par-a-par entre as unidades.

Tabela 4.1: Pares de unidades do exemplo da Figura 4.1 e que tipo de interação eles representam.

\begin{tabular}{|l|c|}
\hline Par de unidades & Tipo de interação \\
\hline \hline$(\mathrm{C} 1) \mathrm{m} 1()-(\mathrm{C} 1) \mathrm{m} 2()$ & $\mathrm{m}-\mathrm{m}$ \\
\hline$(\mathrm{C} 1) \mathrm{m} 2()-(\mathrm{A} 1)$ before () & $\mathrm{m}-\mathrm{a}$ \\
\hline$(\mathrm{A} 1)$ before ()$-(\mathrm{C} 1) \mathrm{m} 3()$ & $\mathrm{a}-\mathrm{m}$ \\
\hline$(\mathrm{A} 1)$ after ()$-(\mathrm{C} 2)<$ init $>() *$ & $\mathrm{a}-\mathrm{m}$ \\
\hline$(\mathrm{A} 1)$ after ()$-(\mathrm{C} 2) \mathrm{m} 4()$ & $\mathrm{a}-\mathrm{m}$ \\
\hline$(\mathrm{A} 1)$ before ()$-(\mathrm{A} 1)$ after () & $\mathrm{a}-\mathrm{a}$ \\
\hline
\end{tabular}

* Um construtor é representado por <init> 
Um par de unidades pode estar definido em um mesmo módulo ou em módulos diferentes. Considerando este fato, são definidos dois tipos de teste estrutural de integração par-a-par: intramódulo e inter-módulo. O tipo de teste intra-módulo tem como objetivo testar a integração entre os pares de unidades que se relacionam e estão em um mesmo módulo. O tipo de teste intermódulo, por sua vez, tem como finalidade testar os pares de unidades que se relacionam e estão definidos em módulos diferentes. Na Tabela 4.2 são mostrados os pares de unidades que se relacionam no exemplo da Figura 4.1 e o tipo de teste estrutural de integração par-a-par que eles representam.

Tabela 4.2: Pares de unidades do exemplo da Figura 4.1 e o tipo de teste estrutural de integração par-a-par eles representam.

\begin{tabular}{|l|c|}
\hline Par de unidades & Tipo de TI par-a-par \\
\hline \hline$(\mathrm{C} 1) \mathrm{m} 1()-(\mathrm{C} 1) \mathrm{m} 2()$ & Intra-módulo \\
\hline$(\mathrm{C} 1) \mathrm{m} 2()-(\mathrm{A} 1)$ before () & Inter-módulo \\
\hline$(\mathrm{A} 1)$ before ()$-(\mathrm{C} 1) \mathrm{m} 3()$ & Inter-módulo \\
\hline$(\mathrm{A} 1)$ after ()$-(\mathrm{C} 2)<\mathrm{init}>() *$ & Inter-módulo \\
\hline$(\mathrm{A} 1)$ after ()$-(\mathrm{C} 2) \mathrm{m} 4()$ & Inter-módulo \\
\hline$(\mathrm{A} 1)$ before ()$-(\mathrm{A} 1)$ after () & Intra-módulo \\
\hline
\end{tabular}

$*$ Um construtor é representado por <init>

No tipo de teste estrutural de integração par-a-par inter-módulo pode ocorrer casos de polimorfismo da linguagem Java denominado sobrescrita (discutido na Seção 2.2.1). Nestes casos o compilador não tem condições de decidir qual método instância será executado naquele ponto do programa, pois o método pode ter sido sobrescrito em outras classes (classes derivadas). Essa decisão é tomada apenas em tempo de execução e depende do tipo do objeto em que o método de instância está sendo invocado. Assim, para estes casos especiais, decidiu-se por criar um par de unidades entre a unidade chamadora e cada método que sobrescreve o método chamado (se houver algum). Vale ressaltar que no caso de uma chamada a um método abstrato (ou seja, um método que não possui implementação), não é criado um par de unidades entre a unidade chamadora e o método abstrato.

Além disso, em um programa pode ocorrer o caso de uma unidade chamar uma outra unidade mais de uma vez em seu corpo. Quando isso ocorre, é criado um par de unidades para cada chamada encontrada.

Na Figura 4.2 é apresentado um exemplo com polimorfismo e que aborda a situação de uma unidade chamar outra unidade mais de uma vez. Observe que no método $\mathrm{m}(\mathrm{)}$ da classe $\mathrm{M}$ ocorre uma chamada ao método $\mathrm{n}($ ) da classe P. Porém, o parâmetro formal $\mathrm{x}$ do método $\mathrm{m}$ (), que é utilizado para invocar o método $\mathrm{n}(\mathrm{)}$, pode estar referenciando tanto um objeto do tipo $\mathrm{P}$ quanto um objeto das classes derivadas de $\mathrm{P}$, neste caso, as classes A e B. Como as classes A e B sobrescrevem o método n (), é impossível prever, em tempo de compilação, qual versão do método n() será executada. Assim, são criados três pares de unidades: um par entre o método $\mathrm{m}($ ) e o método $\mathrm{n}$ () da classe P, outro par entre o método $\mathrm{m}($ ) e o método $\mathrm{n}($ ) da classe A e, finalmente, um par entre o método m ( ) e o método n () da classe B. Além disso, repare que no método ma in ( ) 
são feitas duas chamadas ao método m ( ). Deste modo, são criados dois pares de unidades entre o método main () e o método $\mathrm{m}($ ). Na Tabela 4.3 são mostrados alguns dos pares de unidades identificados neste exemplo. Observe que as chamadas aos construtores das classes A e B não foram consideradas.

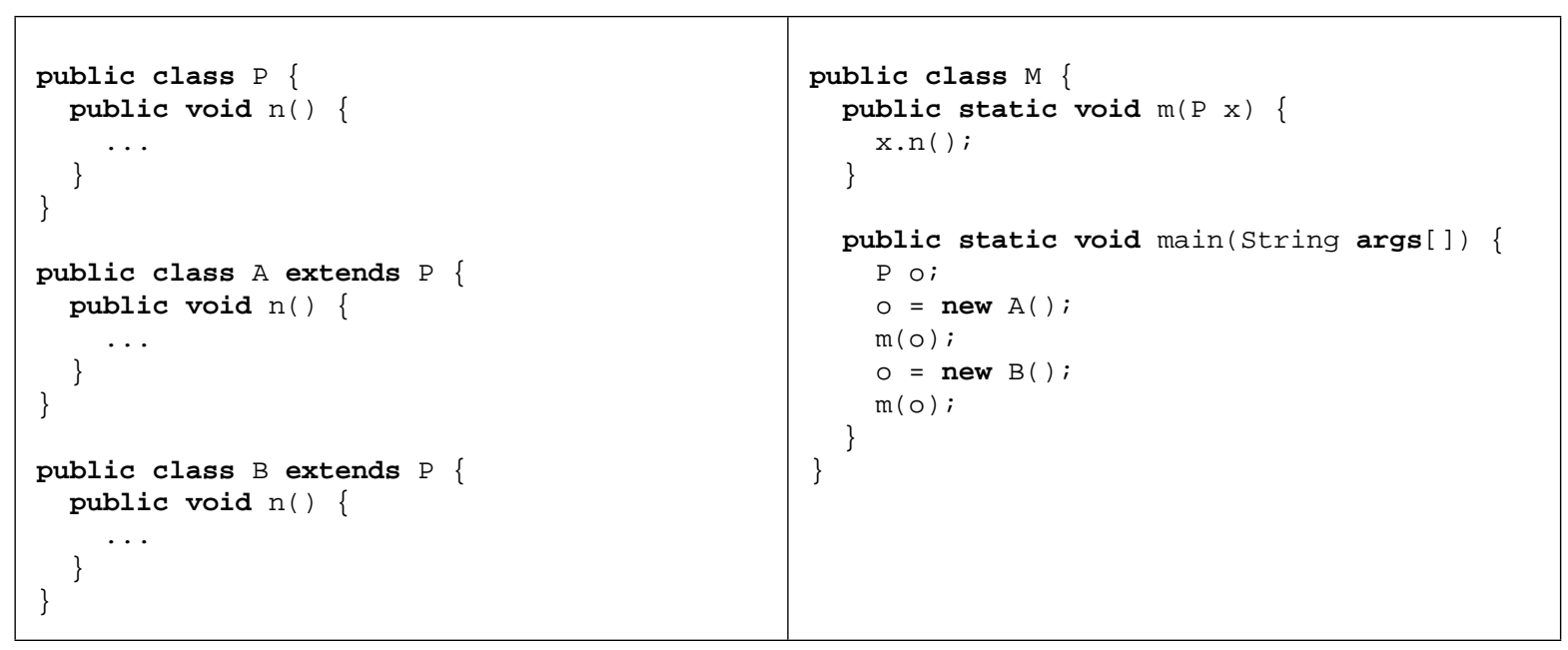

Figura 4.2: Exemplo com polimorfismo e chamada de uma unidade a outra mais de uma vez.

Tabela 4.3: Pares de unidades identificados no exemplo da Figura 4.2.

\begin{tabular}{|l|l|}
\hline & \multicolumn{2}{|l|}{ Par de unidades } \\
\hline \hline 1 & $(\mathrm{M}) \mathrm{m}()-(\mathrm{P}) \mathrm{n}()$ \\
\hline 2 & $(\mathrm{M}) \mathrm{m}()-(\mathrm{A}) \mathrm{n}()$ \\
\hline 3 & $(\mathrm{M}) \mathrm{m}()-(\mathrm{B}) \mathrm{n}()$ \\
\hline 4 & $(\mathrm{M}) \mathrm{main}()-(\mathrm{M}) \mathrm{m}()$ \\
\hline 5 & $(\mathrm{M}) \mathrm{main}()-(\mathrm{M}) \mathrm{m}()$ \\
\hline
\end{tabular}

Para analisar a identificação de pares de unidades, na Figura 4.3 é mostrado um exemplo real de aplicação orientada a aspectos. Este exemplo será utilizado ao longo deste capítulo. O códigofonte é de uma aplicação simples que realiza a soma e a subtração de dois números. A aplicação possui duas classes e um aspecto. A classe Calculo possui o método calcular que efetua os cálculos de soma e subtração dos números e armazena os resultados em atributos de instância. A classe Principal possui o método efetuarCalculos que cria um objeto da classe Calculo e, a partir deste objeto, chama o método calcular. Por fim, o aspecto Aspect Log tem o conjunto de junção pcLog que captura toda execução do método calcular da classe Calculo. O adendo anterior, responsável por imprimir registros de log que contêm os números que serão calculados, é disparado nos pontos de junção selecionados pelo conjunto de junção pcLog.

A partir do código-fonte apresentado na Figura 4.3, os seguintes pares de unidades podem ser identificados. Estes pares de unidades estão resumidos na Tabela 4.4. O padrão de nomeação utilizado para identificar os pares de unidades na Tabela 4.4 é explicado na Seção 5.2.1.

1. o método efetuarCalculos da classe Principal relaciona-se com o construtor da classe Calculo; 


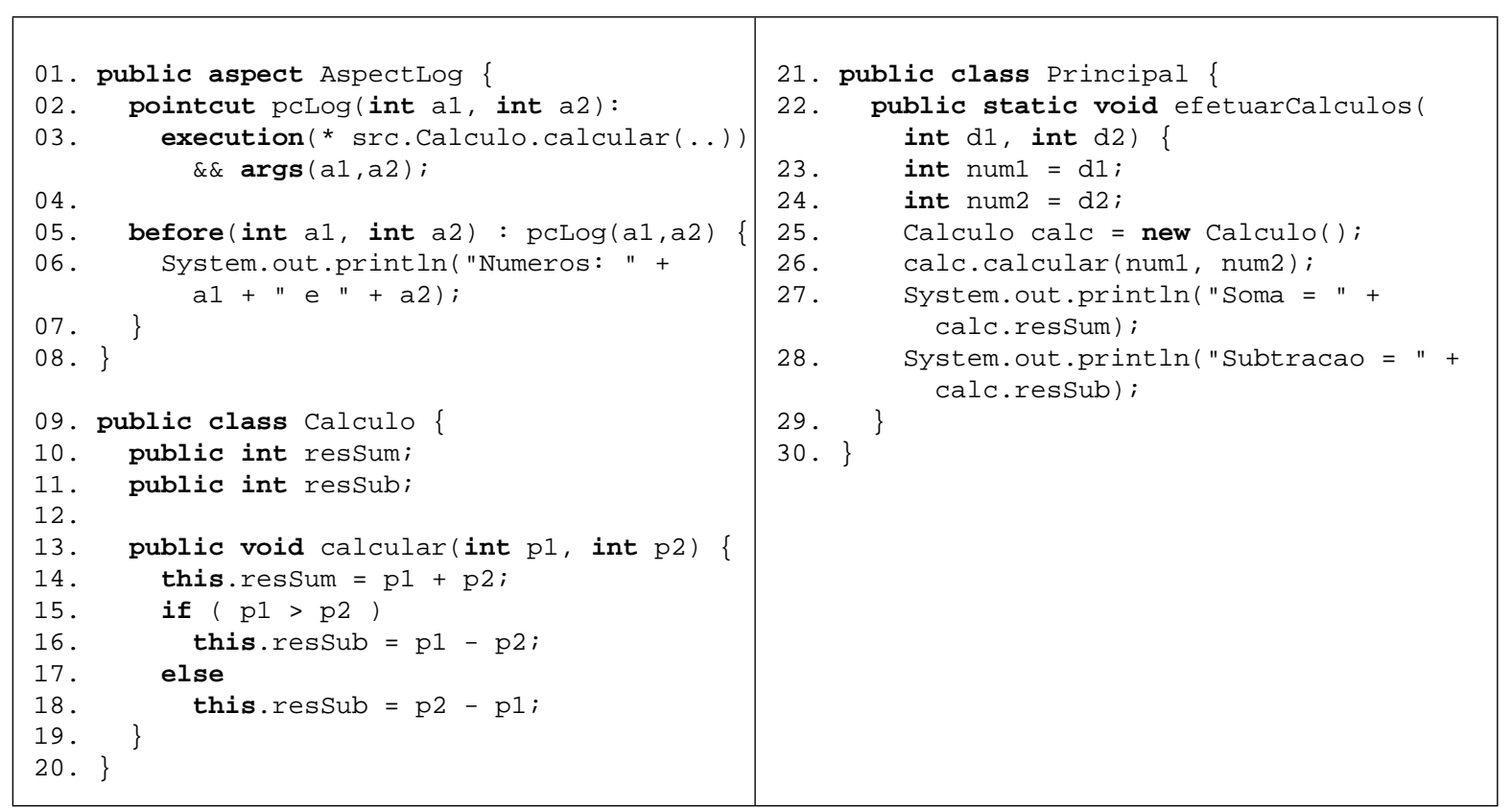

Figura 4.3: Código-fonte da aplicação simples de soma e subtração.

2. o método efetuarCalculos da classe Principal relaciona-se com o método calcular da classe Calculo;

3. o método calcular da classe Calculo relaciona-se com o adendo anterior (before) do aspecto Aspect Log que é disparado nos pontos de junção selecionados pelo conjunto de junção pcLog.

Tabela 4.4: Identificação dos pares de unidades que se relacionam no exemplo da Figura 4.3.

\begin{tabular}{|c|l|c|}
\hline & Par de unidades & $\begin{array}{c}\text { Tipo de TI } \\
\text { par-a-par }\end{array}$ \\
\hline \hline 1 & (Principal) efetuarCalculos (DD) V-(Calculo) <init>() V* & Inter-módulo \\
\hline 2 & (Principal) efetuarCalculos (DD) V-(Calculo) calcular (DD) V & Inter-módulo \\
\hline 3 & (Calculo) calcular (DD) V-(Aspect Log) before (DD) V & Inter-módulo \\
\hline
\end{tabular}

* Um construtor é representado por <init>

\subsection{O Modelo de Fluxo de Dados para a Linguagem Java}

Um modelo de fluxo de dados é utilizado para determinar o que caracteriza uma definição ou um uso de uma variável em uma sentença ou instrução. Esta dissertação propõe um modelo de fluxo de dados para bytecode Java. Porém, antes de descrever o modelo proposto, é importante ressaltar que, para facilitar a elaboração do mesmo, são utilizados apenas classes e métodos, desconsiderando aspectos e adendos pelos seguintes motivos: (1) neste texto está sendo tratado apenas aspectos do tipo Singlet on (discutido na Seção 2.3.1), ou seja, aspectos que possuem uma única instância que é criada automaticamente quando o programa é executado e é usada durante toda a 
aplicação; (2) baseado no fato do compilador/combinador do AspectJ produzir, como resultado da compilação/combinação, um bytecode Java idêntico para métodos e adendos, considera-se que os adendos são similares aos métodos.

O modelo proposto foi adaptado de Vincenzi (2004) que, primeiramente, classificou as instruções bytecode Java, relacionando cada uma com o fluxo de dados envolvido, ou seja, se uma instrução caracteriza uma definição, um uso, uma definição e uso (no caso da instrução iinc) ou uma instrução que não tem implicações. Essa classificação é apresentada na Tabela 3.3. Em seguida, Vincenzi (2004) fez algumas suposições para identificação de definições e usos dos diferentes tipos de variáveis em Java. Uma variável é um local de armazenamento que possui um tipo associado que pode ser primitivo ou de referência. Uma variável sempre contém um valor compatível com seu tipo, ou seja, uma variável primitiva sempre armazena valores do exato tipo primitivo e uma variável de referência pode armazenar ou uma referência nula ou uma referência para qualquer objeto cuja classe (ou array) seja compatível com o tipo da variável. Na linguagem Java, pode-se encontrar cinco tipos de variáveis, a saber: variáveis locais, variáveis agregadas, atributos estáticos, atributos de instância e parâmetros. Os tipos de variáveis são discutidos a seguir.

1. Variáveis locais são unicamente visíveis dentro do escopo dos métodos nos quais elas são declaradas. Elas podem ser do tipo primitivo (variáveis primitivas) ou do tipo de referência (variáveis de referência). Uma variável local não é iniciada até que sua sentença de declaração seja executada.

2. Variáveis Agregadas (ou elementos de array) são variáveis não nomeadas que são criadas e iniciadas sempre que um novo array é criado. Pode existir também array de arrays, que são denominados multi-arrays (matrizes ou vetores multidimensionais). Para tratar variáveis agregadas foi utilizada a abordagem proposta por Horgan e London (1991), que consideram uma variável agregada unidimensional como sendo uma única localização de memória de tal modo que, quando ocorre uma definição (uso) de qualquer um de seus elementos, considerase que a variável agregada em si é que está sendo definida (usada) e não apenas o elemento particular.

3. Atributos estáticos são atributos declarados em uma classe utilizando a palavra reservada static. Eles são criados e recebem um valor inicial quando a classe é carregada. $\mathrm{O}$ valor de um atributo estático é associado a classe onde ele é definido e é compartilhado com todas as instâncias da classe.

4. Atributos de instância são atributos declarados em uma classe sem utilizar a palavra reservada stat ic. Se uma classe $C l$ tem um atributo de instância $a$, então esse atributo é criado e iniciado assim que um novo objeto da classe $C l$ é criado. Diferentemente dos atributos estáticos, os atributos de instância armazenam valores que são específicos para cada instância da classe. 
5. Parâmetros formais representam valores de argumentos passados para um método. Para todo parâmetro presente na declaração do método, uma nova variável local é criada no corpo do método toda vez que ele for invocado. Um parâmetro formal é iniciado com o correspondente valor de argumento passado na chamada.

A partir daí, são definidas as seguintes suposições para identificação da definição e uso de variáveis:

1. Não é considerado o uso de um literal $c$.

2. A definição ou uso de uma variável primitiva $p$ é considerada como sendo unicamente a definição ou uso de $p$.

3. A definição de uma variável de referência $r$ pode envolver uma referência nula ou uma referência a um objeto (que esta sendo construído ou que já existe na memória), que pode ser um array ou uma instância de uma determinada classe. Assim, a definição de uma variável de referência $r$ envolvendo uma referência nula é considerada como sendo somente a definição de $r$. A definição de uma variável de referência $r$ envolvendo uma referência a um objeto é considerada como sendo a definição de $r$ e, no caso de um array, a definição das variáveis agregadas $r[]$ ou, no caso de uma instância da classe $C l$ que possua $f$ como atributo de instância, a definição do atributo de instância $r . f$. O uso de uma variável de referência $r$ é considerada como sendo unicamente o uso de $r$.

4. Variáveis agregadas são consideradas como sendo uma única posição de memória. Assim, a definição de uma variável agregada $a[]$, que é um elemento de um array referenciado pela variável de referência $a$, é considerada como sendo a definição de $a[]$ e a definição do array referenciado por $a$ (representado como definição de $a$ ). O uso de uma variável agregada $a$ [] é considerado como sendo o uso da variável de referência $a$, que permite o acesso ao elemento, e o uso da variável agregada $a[]$.

5. A definição de um atributo de instância $f$ de uma variável de referência $r$ do tipo da classe $C l$ é considerada como sendo o uso da variável de referência $r$, que permite o acesso ao atributo, a definição do atributo de instância (representado por $r f$ ) e a definição do objeto referenciado pela variável de referência $r$ (representado como definição de $r$ ). O uso de um atributo de instância $f$ é considerado como sendo o uso da variável de referência $r$ (para acessar o atributo) e uso do atributo de instância $r . f$.

6. O acesso aos atributos estáticos (ou de classe) é feito sem a necessidade de se ter uma variável de referência. Assim, a definição ou uso de qualquer atributo estático $s$ de uma classe $C l$ é considerada como sendo somente a definição ou uso do atributo estático representado por Cl.s. Mesmo que a definição ou uso do atributo estático seja feita por meio de uma variável 
de referência $r$ do tipo da classe $C l$, no nível de bytecode, tal variável de referência é automaticamente convertida no nome da classe, não sendo caracterizado um uso da variável de referência nesse caso.

7. Na invocação de um método de instância mi, tal como r.mi $\left(t_{1} ; t_{2} ; \ldots ; t_{n}\right)$, onde $t_{i}$ é um parâmetro que pode ser um literal ou um dos tipos de variáveis, considera-se que ocorre um uso da variável de instância $r$ e uso dos parâmetros $t_{1}, t_{2}, \ldots, t_{n}$ segundo as regras descritas nos itens de 1 a 6 . Na invocação de um método estático $m s$, tal como $C l . m s\left(t_{1} ; t_{2} ; \ldots ; t_{n}\right)$, considera-se que ocorrem usos dos parâmetros $t_{1}, t_{2}, \ldots, t_{n}$ segundo as regras descritas nos itens de 1 a 6.

8. Em uma atribuição de uma expressão a uma variável $v$ da forma $v=e_{1} o p e_{2} o p \ldots e_{n}$, onde $e_{i}$ é um item da expressão que pode ser um literal ou um dos tipos de variáveis e op é um operador, considera-se que ocorre uso de $e_{1}, e_{2}, \ldots, e_{n}$ conforme as regras descritas nos itens 1 a 6 , e definição de $v$.

Na Tabela 4.5 são apresentados alguns exemplos de sentenças genéricas de Java e suas correspondentes definições e usos. Antes de analisar os exemplos deve-se considerar os seguintes termos:

- $c$ : um literal;

- $n$ : um valor primitivo do tipo inteiro;

- $p$ : uma variável primitiva;

- $a$ : uma variável de referência a um array;

- a[] uma variável agregada (ou elemento do array) que pode ser do tipo primitivo ou referência;

- $C l$ : uma classe que possui: um atributo de instância $f$, um atributo estático $s$, um método de instância mi e um método estático $m s$.

- Cl.s: um atributo estático da classe $\mathrm{Cl}$ que pode ser do tipo primitivo ou referência;

- $r$ : uma variável de referência a um objeto do tipo da classe $C l$;

- r.f: um atributo de instância de $r$ que pode ser do tipo primitivo ou referência;

- null: referência a nenhum objeto ou array;

- v: uma variável que pode ser $p, a, a[], r, r . f$ ou Cl.s;

- $t$ : um parâmetro que pode ser $c$ ou $v$;

- $e$ : uma expressão simples ou complexa;

Além das sentenças usadas para ilustrar o modelo de fluxo de dados na Tabela 4.5, podem ser consideradas todas as sentenças válidas na linguagem, como por exemplo: $r a[n]=p_{1}+C l . m s(c$, $\left.p_{2}\right)$. Neste caso tem-se uso de $p_{1}$, uso de $p_{2}$, uso de $r$, uso de $a$, definição de $a[]$, definição do array referenciado por $a$ e definição do objeto referenciado por $r$ (representado como definição de $r$ ). Essa sentença é ilustrada pelas linhas 26 e 15 da Tabela 4.5. 
Tabela 4.5: Exemplos de sentenças Java genéricas e suas correspondentes definições e usos.

\begin{tabular}{|c|c|c|}
\hline Tipo & Sentença & Usos/Definições das variáveis \\
\hline 1 & $p=c$ & definição de $p$ \\
\hline 2 & $p=v$ & uso de $v$ e definição de $p$ \\
\hline 3 & $v=p$ & uso de $p$ e definição de $v$ \\
\hline 4 & $a=$ new type $[n]$ & $\begin{array}{l}\text { definição do array referenciado por } a \text { (representado como definição de } a \text { ) } \\
\text { e definição de } a[]\end{array}$ \\
\hline 5 & $a=n u l l$ & definição de $a$ \\
\hline 6 & $a_{1}=a_{2}$ & uso de $a_{2}$, definição de $a_{1}$ e definição de $a_{1}[]$ \\
\hline 7 & $a[n]=c$ & $\begin{array}{l}\text { uso de } a \text {, definição de } a[] \text {, definição do array referenciado por } a \\
\text { (representado como definição de } a \text { ) }\end{array}$ \\
\hline 8 & $a[n]=v$ & $\begin{array}{l}\text { uso de } v \text {, uso de } a \text {, definição de } a[] \text { e definição do array referenciado por } a \\
\text { (representado como definição de } a \text { ) }\end{array}$ \\
\hline 9 & $v=a[n]$ & uso de $a$, uso de $a[]$ e definição de $v$ \\
\hline 10 & $r=$ null & definição de $r$ \\
\hline 11 & $r=n e w C l()$ & $\begin{array}{l}\text { definição do objeto referenciado por } r \text { (representado como definição de } r \text { ) } \\
\text { e definição de } r . f\end{array}$ \\
\hline 12 & $r=n e w C l\left(t_{1}, \ldots, t_{n}\right)$ & $\begin{array}{l}\text { uso de } t_{1}, \ldots \text {, uso de } t_{n} \text {, definição do objeto referenciado por } r \\
\text { (representado como definição de } r \text { ) e definição de } r f\end{array}$ \\
\hline 13 & $r_{1}=r_{2}$ & uso de $r_{2}$, definição de $r_{1}$ e definição de $r_{1} . f$ \\
\hline 14 & $r . f=c$ & $\begin{array}{l}\text { uso de } r \text {, definição de } r . f \text { e definição do objeto referenciado por } r \\
\text { (representado como definição de } r \text { ) }\end{array}$ \\
\hline 15 & $r f=v$ & $\begin{array}{l}\text { uso de } v \text {, uso de } r \text {, definição de } r f f \text { e definição do objeto referenciado por } r \\
\text { (representado como definição de } r \text { ) }\end{array}$ \\
\hline 16 & $v=r f$ & uso de $r$, uso de $r f$ e definição de $v$ \\
\hline 17 & $C l . s=c$ & definição de $C l . s$ \\
\hline 18 & $C l . s=v$ & uso de $v$ e definição de $C l . s$ \\
\hline 19 & $v=C l . s$ & uso de Cl.s e definição de $v$ \\
\hline 20 & $v=C l . m s(c)$ & definição de $v$ \\
\hline 21 & $v_{1}=C l . m s\left(v_{2}\right)$ & uso de $v_{2}$ e definição de $v_{1}$ \\
\hline 22 & $v=C l . m s\left(t_{1}, \ldots, t_{n}\right)$ & uso de $t_{1}, \ldots$, uso de $t_{n}$ e definição de $v$ \\
\hline 23 & $v=r \cdot m i(c)$ & uso de $r$ e definição de $v$ \\
\hline 24 & $v_{1}=\operatorname{r.mi}\left(v_{2}\right)$ & uso de $r$, uso de $v_{2}$ e definição de $v_{1}$ \\
\hline 25 & $v=r . m i\left(t_{1}, \ldots, t_{n}\right)$ & uso de $r$, uso de $t_{1}, \ldots$, uso de $t_{n}$ e definição de $v$ \\
\hline 26 & $v=e_{1}$ op $\ldots e_{n}$ & uso dos fatores de $e_{1}, \ldots$, uso dos fatores de $e_{n}$ e definição de $v$ \\
\hline
\end{tabular}

O programa OA cujo código-fonte é mostrado na Figura 4.3 é utilizado como exemplo real não exaustivo de aplicação do modelo de fluxo de dados. A partir de algumas sentenças do programa são identificados definições e usos das variáveis. Essa identificação é apresentada na Tabela 4.6, onde: a coluna 'Exemplo' contém uma numeração seqüencial dos exemplos, a coluna 'Tipo' corresponde a um ou mais exemplos genéricos da Tabela 4.5, a coluna 'Linha' corresponde à linha da sentença no código-fonte da Figura 4.3 e a coluna 'Definições/Usos' mostra as definições e usos das variáveis nas sentenças. 
Tabela 4.6: Exemplos de sentenças da aplicação de soma e subtração e suas correspondentes definições e usos.

\begin{tabular}{|l|l|l|l|}
\hline Exemplo & Tipo & Linha & Definições/Usos \\
\hline \hline 1 & 2 & 23 & Ocorre o uso do parâmetro d1 e definição da variável primitiva num1. \\
\hline 2 & 12 & 25 & $\begin{array}{l}\text { Ocorre a definição da variável de referência ca lc que referencia o novo } \\
\text { objeto criado. Ao criar o objeto, todos seus atributos de instância são } \\
\text { iniciados. Deste modo, ocorre a definição dos atributos de instância } \\
\text { calc. res Sum e calc. res Sub. }\end{array}$ \\
\hline 3 & 24 & 26 & $\begin{array}{l}\text { Ocorre o uso da variável de referência calc para acessar o método de } \\
\text { instância calcular e os usos das variáveis primitivas num1 e num2 } \\
\text { passadas como parâmetro. }\end{array}$ \\
\hline 4 & 16 & 28 & $\begin{array}{l}\text { Ocorre o uso da variável de referência calc para acessar os atributos de } \\
\text { instância e uso do atributo de instância calc.res Sub. }\end{array}$ \\
\hline 5 & 15, & 14 & $\begin{array}{l}\text { Ocorre o uso da referência ao objeto corrente this, uso do parâmetro p1 } \\
\text { e uso do parâmetro p2. Depois de calculada a soma de p1 e p2, ocorre a } \\
\text { definição do atributo de instância this . res Sum. Por fim, como se está } \\
\text { alterando um dos atributos do objeto corrente, ocorre também a definição } \\
\text { do objeto referenciado por this (representado como definição do this). }\end{array}$ \\
\hline
\end{tabular}

\subsection{Grafo de Fluxo para Teste Estrutural de Integração Par-a-Par}

Para efetuar o teste estrutural de integração par-a-par entre os pares de unidades de programas OO (m-m) ou OA (m-m, m-a, a-m ou a-a) deve-se considerar todo o fluxo de execução (fluxo de controle e de dados) que ocorre entre a unidade chamadora e a unidade chamada. Por exemplo, no fluxo de execução de um programa $\mathrm{OO}$ um método pode chamar um outro método. Quando é feita a chamada, o fluxo de execução é passado para o método chamado. Após a execução do método chamado, o fluxo retorna ao método que chamou e este continua sua execução. Já em programas OA a execução pode envolver, além dos métodos, os adendos. Assim, no fluxo de execução de um programa OA um método ou um adendo pode chamar um outro método ou ser interceptado por um adendo que é disparado quando um determinado ponto de junção é alcançado. Deste modo, quando é feita uma chamada a um método ou quando um ponto de junção é alcançado, o fluxo de execução é passado para o método chamado ou para o adendo que afeta o ponto de junção. Após a execução do método chamado ou do adendo que foi disparado, o fluxo retorna ao método que chamou ou ao ponto de junção onde o adendo foi disparado e a execução continua.

Para representar todo o fluxo de execução que ocorre entre um par de unidades, torna-se necessária a definição de um grafo que seja a integração dos grafos das unidades que se relacionam. Para isso é proposto um grafo de integração par-a-par. Este grafo foi baseado no Grafo Def-Uso Método-Adendo (MADU) (Lemos, 2005) (discutido na Seção 3.5.2) e tem a finalidade de integrar os Grafos Def-Uso Orientado a Aspectos $(\mathcal{A O D U})$ (Lemos, 2005) das unidades que se relacionam.

Porém, antes de definir o grafo de integração par-a-par é necessário adaptar o grafo $\mathcal{A O D U}$. O grafo $\mathcal{A O D U}$ de uma determinada unidade $u$ é da forma $\mathcal{A O D U}(u)=(N, E, s, T, C)$ (discutido na Seção 3.5.1). Conforme definido por Lemos (2005), o componente $C$ é o conjunto de nós 
transversais que representam um nó do grafo em que ocorre uma interação com um adendo de um dado aspecto. Entretanto, o teste estrutural de integração par-a-par aqui proposto não trata apenas interações com adendos, mas também interações com métodos, estas representadas pelos nós de chamada (Vincenzi, 2004). Assim, a definição formal do grafo $\mathcal{A O D U}$ de uma determinada unidade $u$ foi revista e alterada para a seguinte forma: $\mathcal{A O D U}(u)=(N, E, s, T, I)$, em que o componente $C$ foi substituído pelo componente $I$, este último definido como um conjunto de nós de interação, isto é, um conjunto que contém tanto os nós transversais - que representam um nó no qual ocorre uma interação com um adendo de um dado aspecto - quanto os nós de chamada — que representam um nó no qual ocorre uma interação com um método de uma dada classe ou aspecto.

A partir daí, pode-se definir o Grafo Def-Uso Par-a-Par (PairWise Def-Use - PWDU). Ele é um grafo dirigido cuja utilização tem como objetivo apoiar o teste estrutural de integração para-par das unidades de um programa $\mathrm{OO}$ ou OA. O grafo $\mathcal{P} \mathcal{W} \mathcal{D} \mathcal{U}$ é uma abstração formada pela integração do grafo $\mathcal{A O D} \mathcal{U}$ da unidade chamadora (ou que chama) e do grafo $\mathcal{A O D U}$ da unidade chamada. Essa integração é feita de modo que o grafo $\mathcal{A O D U}$ da unidade chamada seja integrado ao grafo $\mathcal{A O D U}$ da unidade chamadora. Para diferenciar os nós e as arestas das unidades integradas, são definidos um novo tipo de nó - nó integrado (integrated node) que representa os nós da unidade chamada - e dois novos tipos de aresta - aresta integrada (integrated edge) que é a aresta entre dois nós integrados e a aresta de integração (integration edge) que representa a aresta entre um nó da unidade chamadora e um nó da unidade chamada, ou vice-versa.

Para construir o grafo $\mathcal{P W D U}$ de um par de unidades deve-se aplicar o algoritmo a seguir. Suponha o par de unidades $u_{1}$ e $u_{2}$, sendo que $u_{1}$ chama $u_{2}$, ou seja, $u_{1}$ representa a unidade chamadora e $u_{2}$ representa a unidade chamada.

1. Construir o grafo $\mathcal{A O D U}$ da unidade $u_{1}$.

(a) Durante a construção, identificar o nó onde ocorre a chamada da unidade $u_{2}$ (nó de interação);

(b) Após identificado o nó de interação, deve-se identificar o nó adjacente ao nó de interação (nó de retorno $)^{1}$;

2. Construir o grafo $\mathcal{A O D U}$ da unidade $u_{2}$.

(a) Durante a construção definir todos os nós de $u_{2}$ como nós integrados;

3. Remover as arestas entre o nó de interação e os nós de retorno;

4. Criar uma aresta de integração entre o nó de interação e o nó de entrada do grafo $\mathcal{A O D U}$ da unidade $u_{2}$.

5. Criar arestas de integração entre os nós de saída do grafo $\mathcal{A O D U}$ da unidade $u_{2}$ e os nós de retorno.

6. Redefinir os conjunto de definição e uso de cada nó do grafo $\mathcal{P} \mathcal{W} \mathcal{D U}$ e fazer o mapeamento das variáveis que se comunicam entre as unidades.

\footnotetext{
${ }^{1}$ Neste trabalho considera-se apenas um nó de retorno pois, por meio da análise do bytecode e de como os grafos são construídos na ferramenta JaBUTi/AJ, constatou-se que sempre haverá um único nó de retorno
} 
O grafo $\mathcal{P} \mathcal{W D U}$ do par de unidades $u_{1}$ e $u_{2}$ terá como nó de entrada o mesmo nó de entrada do grafo $\mathcal{A O D U}$ da unidade $u_{1}$ (chamadora). O mesmo vale para os nós de saída, ou seja, os nós de saída do grafo $\mathcal{P} \mathcal{W D U}$ de $u_{1}$ e $u_{2}$ serão os mesmos nós de saída do grafo $\mathcal{A O D U}$ da unidade $u_{1}$. A definição formal do grafo $\mathcal{P} \mathcal{W D U}$ de $u_{1}$ e $u_{2}$ é apresentada a seguir. Considere o grafo $\mathcal{A O D} \mathcal{U}$ das unidades $u_{1}$ e $u_{2}$ da forma:

- $\mathcal{A O D U}\left(u_{1}\right)=\left(N_{1}, E_{1}, s_{1}, T_{1}, I_{1}\right)$

- $\mathcal{A O D U}\left(u_{2}\right)=\left(N_{2}, E_{2}, s_{2}, T_{2}, I_{2}\right)$

O grafo $\mathcal{P} \mathcal{W} \mathcal{D U}$ do par $u_{1}$ e $u_{2}$ é definido como um grafo dirigido $\mathcal{P} \mathcal{W} \mathcal{D} \mathcal{U}\left(u_{1}, u_{2}\right)=(N, E, s$, $T, I, i, r)$, tal que:

- $N=N_{1} \cup N_{2}$ representa o conjunto completo de nós do grafo $\mathcal{P} \mathcal{W D} \mathcal{U}$, tal que:

- $N_{1}$ é o conjunto de nós de $u_{1}$;

- $N_{2}$ é o conjunto de nós de $u_{2}$, também denominado conjunto de nós integrados $-N_{i}$;

- $E=E_{1} \cup E_{2} \cup E_{l}$ é o conjunto completo de arestas do grafo $\mathcal{P} \mathcal{W D} \mathcal{U}$, tal que:

- $E_{1} \subseteq N_{1} X N_{1}$ é o conjunto de arestas de $u_{1}$ definido como $E_{1}=\{(x, y) \in E \mid(x \in$ $\left.\left.N_{1}\right) \wedge\left(y \in N_{1}\right)\right\} . E_{1_{r}}$ e $E_{1_{e}}$ são subconjuntos disjuntos de $E_{1}$ de arestas regulares e de exceção, respectivamente.

- $E_{2} \subseteq N_{2} X N_{2}$ é o conjunto de arestas de $u_{2}$, também denominado conjunto de arestas integradas $-E_{i}$, definido como $E_{2}=\left\{(x, y) \in E \mid\left(x \in N_{2}\right) \wedge\left(y \in N_{2}\right)\right\} . E_{2_{r}}$ e $E_{2_{e}}$ são subconjuntos disjuntos de $E_{2}$ de arestas regulares e de exceção, respectivamente.

- $E_{l}$ é o conjunto de arestas de integração, criadas para integrar os dois grafos $\mathcal{A O D U}$, definido como $E_{l}=\left\{(x, y) \in E \mid\left(\left(x \in N_{1}\right) \wedge\left(y \in N_{2}\right)\right) \vee\left(\left(x \in N_{2}\right) \wedge\left(y \in N_{1}\right)\right)\right\}$ sendo que:

* se $x \in N_{1}$ e $y \in N_{2}$, então $x=c$ (o componente $i$ é definido abaixo) e $y=s_{2}$ (o componente $s_{2}$ é definido abaixo);

* se $x \in N_{2}$ e $y \in N_{1}$, então $x \in T_{2}$ (o componente $T_{2}$ é definido abaixo) e $y=r$ (o componente $r$ é definido abaixo);

- $s \in N$ e $s=s_{1}$ é o nó de entrada do grafo $\mathcal{P} \mathcal{W D U}$, tal que:

- $s_{1} \in N_{1}$ é o nó de entrada de $u_{1}$;

- $s_{2} \in N_{2}$ é o nó de entrada de $u_{2}$;

- $T \subseteq N$ e $T=T_{1}$ é o conjunto de nós de saída do grafo $\mathcal{P} \mathcal{W} \mathcal{D} \mathcal{U}$, tal que:

- $T_{1}$ é o conjunto de nós de saída de $u_{1}$; 
- $T_{2}$ é o conjunto de nós de saída de $u_{2}$;

- $I=I_{1} \cup I_{2}$ é o conjunto completo de nós de interação (ou seja, nós transversais e nós de chamada) do grafo $\mathcal{P} \mathcal{W D U}$, tal que:

- $I_{1} \subseteq N_{1}$ é o conjunto de nós de interação de $u_{1}$;

- $I_{2} \subseteq N_{2}$ é o conjunto de nós de interação de $u_{2}$;

- $i \in I_{1}$ é o nó onde ocorre a chamada a $u_{2}$;

- $r \in N_{1}$ é o nó de retorno da chamada a $u_{2}$.

A representação gráfica do grafo $\mathcal{P W D U}$ é definida da seguinte forma:

- Um nó regular é representado por um círculo desenhado com linha simples e seu rótulo contém a primeira instrução de bytecode do bloco;

- Um nó de chamada é representado por um círculo desenhado com linhas duplas e seu rótulo contém a primeira instrução de bytecode do bloco;

- Um nó transversal é representado por uma elipse desenhada com linha tracejada. Seu rótulo informa, além da primeira instrução de bytecode do bloco, qual o tipo de adendo afeta aquele ponto (before, after ou around) e a qual aspecto o adendo pertence;

- Um nó de saída é representado por um circulo desenhado com uma linha simples negritada e seu o rótulo contém a primeira instrução de bytecode do bloco;

- Um nó integrado é representado como um nó regular, um nó de chamada, um nó transversal ou um nó de saída ${ }^{2}$. Como diferencial, seu rótulo é iniciado com o símbolo “i .”;

- Uma aresta regular é representada por uma linha contínua, representando o fluxo de controle normal;

- Uma aresta de exceção é representada por uma linha tracejada, representando o fluxo de controle do nó no qual uma exceção é gerada até o primeiro nó correspondente ao tratador daquela exceção;

- Uma aresta integrada é representada como uma aresta regular ou uma aresta de exceção;

- Uma aresta de integração é representada como uma aresta regular;

\footnotetext{
${ }^{2}$ Um nó de saída é transformado em nó regular na integração.
} 
Os conjuntos de definições e usos dos nós do grafo $\mathcal{P} \mathcal{W} \mathcal{D U}$ são derivados a partir das instruções presentes no bloco de instruções de cada nó. Com o grafo $\mathcal{P} \mathcal{W} \mathcal{D U}$ criado da integração dos dois grafos $\mathcal{A O D} \mathcal{U}$ das unidades já é possível derivar os requisitos de teste para os critérios de fluxo de controle e fluxo de dados, conforme é discutido na Seção 4.5.

Como exemplo, é construído o grafo $\mathcal{P W D U}$ do par de unidades (Principal) efetuarCalculos (DD) V - (Calculo) calcular (DD) V a partir do grafo $\mathcal{A O D U}$ da unidade chamadora (Figura 4.4(a)) e do grafo $\mathcal{A O D U}$ da unidade chamada (Figura 4.4(b)). O nó 11 do grafo $\mathcal{A O D U}$ do método efetuarcalculos é o nó onde ocorre a chamada ao método calcular. O grafo $\mathcal{P W D U}$ contruído é apresentado na Figura 4.5. Nessa figura também são mostrados os conjuntos de definições $(\mathrm{d})$, usos computacionais $(\mathrm{cu})$ e usos predicativos (pu) das variáveis de interface entre as unidades (também consideradas variáveis de comunicação, discutidas na Seção 4.5.2). Além disso, é mostrada uma tabela de mapeamento entre as variáveis de comunicação.

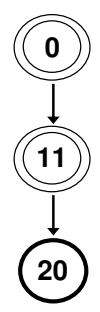

(a) Grafo $\mathcal{A O D U}$

do método

efetuarCalculos

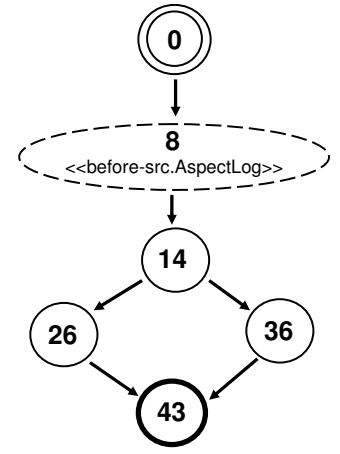

(b) Grafo $\mathcal{A O D U}$ do método calcular

Figura 4.4: Grafos $\mathcal{A O D U}$ da unidade chamadora e da unidade chamada.

\subsection{Critérios de Fluxo de Controle e Fluxo de Dados para Teste Estrutural de Integração Par-a-Par}

Os critérios de teste são de fundamental importância, pois fornecem um mecanismo para sistematizar a seleção de casos de teste e a avaliação da qualidade de conjuntos de teste já definidos (Vincenzi, 2004). Nesta seção são apresentadas as definições dos critérios de teste estrutural de integração par-a-par, os quais podem ser utilizados para derivar requisitos de testes de integração par-a-par intra-módulo e inter-módulo para programas OO e OA. Após a definição de cada critério é mostrado um exemplo do conjunto de requisitos de teste gerado por ele. 


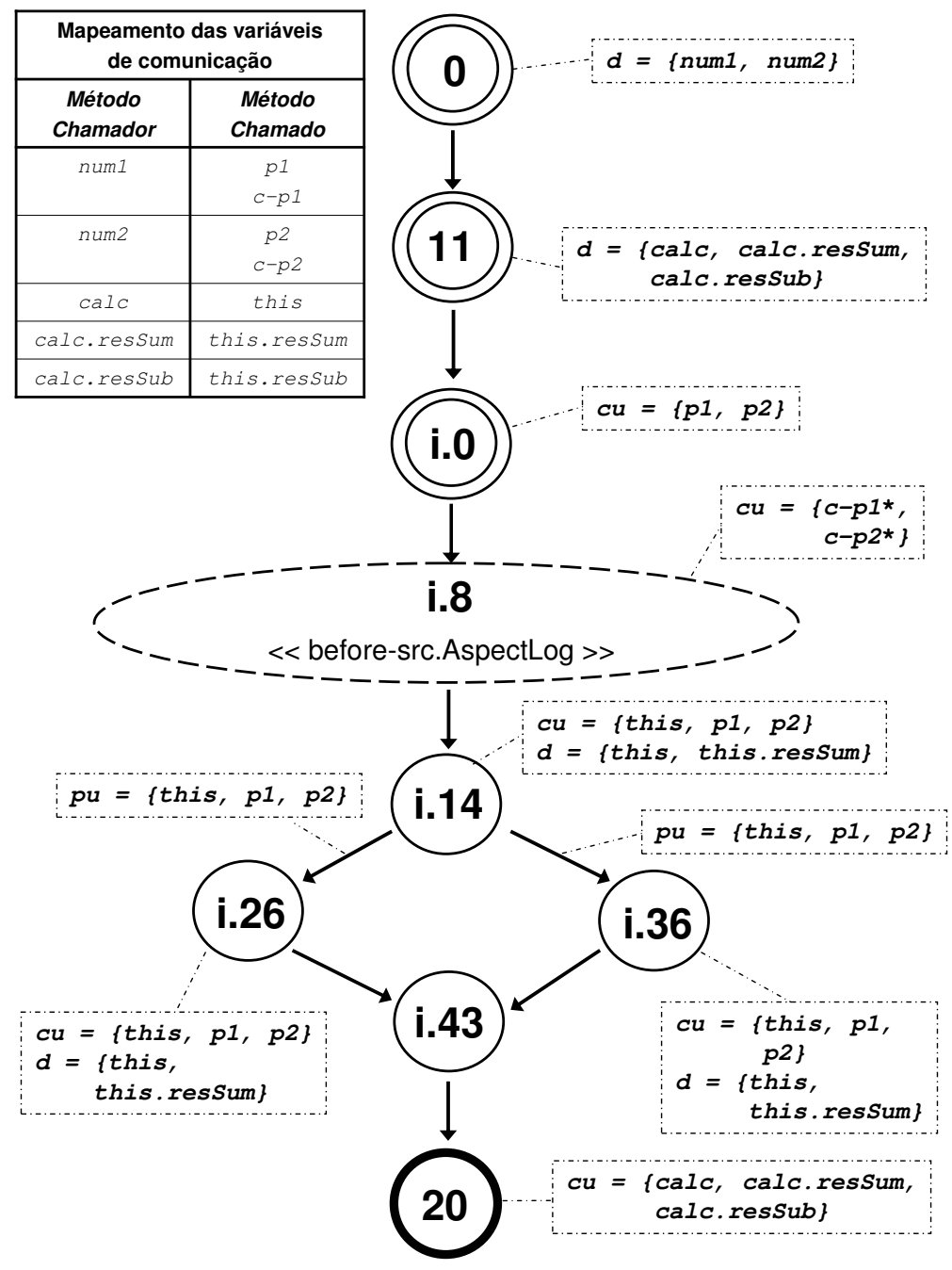

*As variáveis c-p1 e c-p2 são cópias de p1 e p2, respectivamente. Elas são criadas pelo AspectJ durante a combinação. Esse processo de cópia é discutido na Seção 5.2.3

Figura 4.5: Grafo $\mathcal{P} \mathcal{W} \mathcal{D U}$ do par de unidades.

\subsubsection{Critério de Fluxo de Controle}

Considerando o teste de fluxo de controle, decidiu-se por utilizar os critérios de teste todos-nós (all-nodes) e todas-arestas (all-edges). Tais critérios foram revisados no contexto do teste estrutural de integração par-a-par de programas $\mathrm{OO}$ e $\mathrm{OA}$ considerando os nós e arestas integradas. $\mathrm{Na}$ aplicação do critério todos-nós seria interessante a existência de um critério de teste que requeresse a cobertura dos nós integrados, com o objetivo de auxiliar a revelação de defeitos particulares nesses nós. O mesmo ocorre para a aplicação dos critérios todas-arestas, ou seja, seria interessante também a informação de quais arestas integradas são exercitadas. Assim, foram definidos critérios: todos-nós-integrados (all-integrated-nodes) e todas-arestas-integradas (all-integrated-edges). 
Antes da definição dos critérios, considere: $T$ um conjunto de casos de teste para um programa $P$ (sendo que o grafo $\mathcal{P W D U}$ é o grafo de fluxo de controle/dados dos pares de unidades de $P$ ), e seja $\Pi$ o conjunto de caminhos exercitados por $T$. Diz-se que um nó $i$ está incluído em $\Pi$ se $\Pi$ contém um caminho $\left(n_{1}, \ldots, n_{m}\right)$ tal que $i=n_{j}$ para algum $j, 1 \leq j \leq m$. Similarmente, uma aresta $\left(i_{1}, i_{2}\right)$ é incluída em $\Pi$ se $\Pi$ contém um caminho $\left(n_{1}, \ldots, n_{m}\right)$ tal que $i_{1}=n_{j}$ e $i_{2}=n_{j+1}$ para algum $j, 1 \leq j \leq m-1$. Assim, definem-se:

- todos-nós-integrados (Todos-Nós ${ }_{i}$ ): П satisfaz o critério todos-nós-integrados se cada nó integrado $n_{i} \in N_{i}$ de um grafo $\mathcal{P} \mathcal{W D U}$ está incluído em $\Pi$. Em outras palavras, este critério requer que cada nó integrado de um grafo $\mathcal{P} \mathcal{W D U}$ seja exercitado ao menos uma vez por algum caso de teste de $T$.

- todas-arestas-integradas (Todas-Arestas ${ }_{i}$ ): $\Pi$ satisfaz o critério todas-arestas-integradas se cada aresta integrada $e_{i} \in E_{i}$ de um grafo $\mathcal{P} \mathcal{W D U}$ está incluída em $\Pi$. Em outras palavras, este critério requer que cada aresta integrada de um grafo $\mathcal{P} \mathcal{W D U}$ seja exercitada ao menos uma vez por algum caso de teste de $T$.

\subsubsection{Critério de Fluxo de Dados}

Em relação aos critérios de fluxo de dados, decidiu-se por utilizar o critério de teste todosusos (all-uses). Tal critério foi revisado no contexto do teste estrutural de integração par-a-par de programas $\mathrm{OO}$ e OA levando em consideração a interface entre as unidades. Para definir o fluxo de dados entre duas unidades, tomou-se como base a abordagem de teste de interfaces proposta por Linnenkugel e Müllerburg (1990) para programas procedurais (discutida na Seção 3.3).

Durante o teste de integração deve-se testar a interface entre as unidades que se relacionam em um programa, ou seja, testar as variáveis que influenciam diretamente a comunicação entre as unidades. Essas variáveis são denominadas variáveis de comunicação (Linnenkugel e Müllerburg, 1990). Elas podem ser de qualquer tipo da linguagem Java, isto é, do tipo primitivo ou de referência (discutidos na Seção 2.2.1). Em um programa $\mathrm{OO}$ ou OA pode-se identificar as seguintes variáveis de comunicação:

- Parâmetros formais (FP — Formal Parameter);

- Parâmetros reais (AP - Actual Parameter);

- Atributos estáticos do(s) módulo(s) do par de unidades ou de outras classes do programa (SF-Static Field);

Os atributos de instância (IF — Instance Field) declarados em um determinado módulo também podem ser considerados variáveis de comunicação nos casos em que a unidade chamada é um método de instância. Entretanto, eles são tratados como parâmetros reais $(A P)$ e parâmetros formais $(F P)$. Um atributo de instância é um atributo cujo valor é específico ao objeto e não à classe. 
Em Java, para chamar um método de instância de uma classe é necessário criar um objeto dessa classe e, a partir desse objeto, chamar o método. Todo método de instância tem um parâmetro implícito chamado this que é usado para passar a referência do objeto que o está chamando. Deste modo, nos casos em que a unidade chamada é um método de instância, a referência ao objeto, a partir da qual os atributos de instância podem ser acessados ${ }^{3}$, é passada como parâmetro.

O teste estrutural de integração par-a-par deve considerar somente os caminhos (ou relações definição-uso) que influenciam diretamente a comunicação entre as unidades, ou seja:

- para as variáveis de comunicação $x$ que são usadas como entrada, consideram-se os caminhos compostos dos sub-caminhos a partir da última definição de $x$ precedente à chamada até a chamada na unidade chamadora e dos sub-caminhos a partir da entrada na unidade chamada até o uso de $x$ na unidade chamada.

- para as variáveis de comunicação $x$ que são usadas como saída, consideram-se os caminhos compostos dos sub-caminhos a partir da última definição de $x$ na unidade chamada até a saída da unidade chamada e dos sub-caminhos a partir do retorno da chamada na unidade chamadora até o uso de $x$ na unidade chamadora.

Um programa $\mathrm{OO}$ ou OA consiste de unidades $U_{n}$. Para cada unidade $U_{n}$ são definidos os seguintes conjuntos:

- $F P-I N\left(U_{n}\right)$ é o conjunto de parâmetros formais de $U_{n}$ usados como entrada.

- FP-OUT $\left(U_{n}\right)$ é o conjunto de parâmetros formais de $U_{n}$ usados como saída.

- $S F-I N\left(U_{n}\right)$ é o conjunto de atributos estáticos usados em $U_{n}$.

- $S F-O U T\left(U_{n}\right)$ é o conjunto de atributos estáticos definidos em $U_{n}$.

Seja $U_{a}$ a unidade chamadora e $U_{b}$ a unidade chamada. A chamada de $U_{b}$ em $U_{a}$ é representada por $U_{b a}$. Para essa chamada são definidos os seguintes conjuntos:

- $A P-I N\left(U_{b a}\right)$ é o conjunto de parâmetros reais usados como entrada na chamada $U_{b a}$.

- $A P-O U T\left(U_{b a}\right)$ é o conjunto de parâmetros reais usados como saída da chamada $U_{b a}$.

Para descrever as relações entre parâmetros reais e seus correspondentes parâmetros formais e entre os atributos estáticos usados pelas unidades são definidos dois mapeamentos $I_{b a}$ e $O_{b a}$. Antes da definição dos mapeamentos é importante ressaltar que ao fazer o mapeamento dos parâmetros e dos atributos estáticos que são do tipo de referência, ocorre tanto o mapeamento deles com seus correspondentes quanto o mapeamento dos seus atributos de instância (caso sejam uma referência

\footnotetext{
${ }^{3}$ Nesta seção não está considerando os especificadores de acesso da linguagem Java (public, private e protected)
} 
a um objeto), ou o mapeamento das suas variáveis agregadas (caso sejam uma referência a um array). Outra observação diz respeito aos atributos estáticos. Eles possuem a mesma identificação tanto na unidade chamadora quanto na unidade chamada.

O mapeamento $I_{b a}$ relaciona cada parâmetro real de entrada da chamada $U_{b a}$ com o correspondente parâmetro formal de entrada da unidade chamada $U_{b}$ e cada atributo estático usado como entrada, com ele mesmo.

$$
\begin{aligned}
-I_{b a} & : A P-I N\left(U_{b a}\right) \cup S F-I N\left(U_{b}\right) \rightarrow F P-I N\left(U_{b}\right) \cup S F-I N\left(U_{b}\right), \text { com } \\
& -A P-I N\left(U_{b a}\right) \rightarrow F P-I N\left(U_{b}\right) \text { e } S F-I N\left(U_{b}\right) \rightarrow S F-I N\left(U_{b}\right)
\end{aligned}
$$

O mapeamento $O_{b a}$ relaciona cada parâmetro real de saída da chamada $U_{b a}$ com o correspondente parâmetro formal de saída da unidade chamada $U_{b}$ e cada atributo estático usado como saída, com ele mesmo.

$$
\begin{aligned}
&-O_{b a}: A P-O U T\left(U_{b a}\right) \cup S F-O U T\left(U_{b}\right) \rightarrow F P-O U T\left(U_{b}\right) \cup S F-O U T\left(U_{b}\right), \text { com } \\
& \text { - } A P-O U T\left(U_{b a}\right) \rightarrow F P-O U T\left(U_{b}\right) \text { e } S F-O U T\left(U_{b}\right) \rightarrow S F-O U T\left(U_{b}\right)
\end{aligned}
$$

Com base nessas definições e no grafo $\mathcal{P W D U}$ das unidades, alguns conjuntos são definidos. Para isso considere: def $(i)$ é o conjunto de variáveis definidas no nó $i$; c-uso $(i)$ é o conjunto de variáveis para as quais existem $c$-usos em $i$; e $p$-uso $(j, k)$ é o conjunto de variáveis para as quais existem $p$-usos na aresta $(j, k)$ (Rapps e Weyuker, 1982). Assim, para cada unidade chamada $U_{b}$ foram definidos os seguintes conjuntos:

- $C$-USE-CALLED $\left(U_{b}, x\right)$ é o conjunto de nós $i$ de $U_{b}$ tal que $x \in c$-uso(i) e existe um caminho livre de definição com relação a $x$ a partir do nó de entrada de $U_{b}$ até o nó $i$, sendo que $x \in F P-I N\left(U_{b}\right)$ ou $x \in S F-I N\left(U_{b}\right)$.

- P-USE-CALLED $\left(U_{b}, x\right)$ é o conjunto de arestas $(j, k)$ de $U_{b}$ tal que $x \in p$-uso $(j, k) \mathrm{e}$ existe um caminho livre de definição com relação a $x$ a partir do nó de entrada de $U_{b}$ até a aresta $(j, k)$, sendo que $x \in F P-I N\left(U_{b}\right)$ ou $x \in S F-I N\left(U_{b}\right)$.

- DEF-CALLED $\left(U_{b}, x\right)$ é o conjunto de nós $i$ de $U_{b}$ tal que $x$ pertence def $f(x)$ e existe um caminho livre de definição com relação a $x$ a partir do nó $i$ até o nó de saída de $U_{b}$, sendo que $x \in F P$-OUT $\left(U_{b}\right)$ ou $x \in S F-O U T\left(U_{b}\right)$.

Para a chamada $U_{b a}$ foram definidos os seguintes conjuntos:

- DEF-CALLER $\left(U_{b a}, x\right)$ é um conjunto de nós $i$ de $U_{a}$ tal que $x \in \operatorname{def}(i)$ e existe um caminho livre de definição com relação a $x$ a partir de $i$ até o nó de interação, sendo que $x \in A P-I N\left(U_{b a}\right)$ ou $x \in S F-I N\left(U_{b}\right)$. 
- C-USE-CALLER $\left(U_{b a}, x\right)$ é um conjunto de nós $i$ de $U_{a}$ tal que $x \in c$-uso $(i)$ e existe um caminho livre de definição com relação a $x$ a partir dos nós de retorno até $i$, sendo que $x \in A P-O U T\left(U_{b a}\right)$ ou $x \in S F-O U T\left(U_{b}\right)$.

- P-USE-CALLER $\left(U_{b a}, x\right)$ é um conjunto de arestas $(j, k)$ de $U_{a}$ tal que $x \in p$-use $(i)$ e existe um caminho livre de definição com relação a $x$ a partir dos nós de retorno até $(j, k)$, sendo que $x \in A P-O U T\left(U_{b a}\right)$ ou $x \in S F-O U T\left(U_{b}\right)$.

A partir das definições anteriores é definido o critério todos-usos-integrados (all-integrateduses) utilizado para derivar requisitos de teste estrutural de integração par-a-par baseados nas interfaces entre as unidades.

- todos-usos-integrados (Todos-Usos ${ }_{i}$ ): $\Pi$ satisfaz o critério todos-usos-integrados se:

1. para cada $x \in A P-I N\left(U_{b a}\right)$ e cada $x \in S F-I N\left(U_{b}\right)$, $\Pi$ inclui um caminho livre de definição com relação a $x$ a partir de cada nó $i \in D E F-C A L L E R\left(U_{b a}, x\right)$ até cada nó $j \in C$-USE-CALLED $\left(U_{b}, I_{b a}(x)\right)$ e até cada aresta $(j, k) \in P$-USE$C A L L E D\left(U_{b}, I_{b a}(x)\right)$. Em outras palavras, esse critério requer a execução de um caminho livre de definição com relação a cada variável de comunicação a partir de cada definição relevante na unidade chamadora até todo uso computacional e todo uso predicativo na unidade chamada.

2. para cada $x \in A P-O U T\left(U_{b a}\right)$ e cada $x \in S F-O U T\left(U_{b}\right)$, $\Pi$ inclui um caminho livre de definição com relação a $x$ a partir de cada nó $i \in D E F-C A L L E D\left(U_{b}, O_{b a}(x)\right)$ até cada nó $j \in C$-USE-CALLER $\left(U_{b a}, x\right)$ e até cada aresta $(j, k) \in P$-USE$C A L L E R\left(U_{b a}, x\right)$. Em outras palavras, esse critério requer a execução de um caminho livre de definição com relação a cada variável de comunicação a partir de cada definição relevante na unidade chamada até todo uso computacional e todo uso predicativo na unidade chamadora.

Há uma exceção na clausula (2) da definição do critério todos-usos-integrados, com relação a definições dos parâmetros formais dentro da unidade chamada e seus posteriores usos, após o retorno da chamada, na unidade chamadora. Em Java, conforme discutido na Seção 2.2.1, a passagem de parâmetros é feita por valor, ou seja, se o parâmetro real for do tipo primitivo, o parâmetro formal correspondente recebe e armazena o dado do parâmetro real. Caso o parâmetro real seja do tipo de referência, o parâmetro formal correspondente recebe e armazena o endereço do objeto em memória referenciado pelo parâmetro real. Pode-se dizer que o parâmetro formal é uma cópia do parâmetro real. Assim, qualquer alteração no valor da cópia de um parâmetro real não vai afetá-lo, seja o parâmetro real do tipo primitivo ou de referência. Deste modo, caso haja um uso posterior do parâmetro real depois da chamada, não será caracterizado um par definição-uso.

O mesmo não ocorre se um parâmetro real for do tipo de referência e sua cópia definir/alterar, por meio do endereço de referência, os dados do objeto referenciado pelo parâmetro real. Nesta 
situação, a definição terá efeito no parâmetro real, pois o objeto que ele referencia foi modificado. Deste modo, caso haja um eventual uso do parâmetro real depois da chamada, um par definição-uso será caracterizado.

\subsubsection{Exemplo de Aplicação dos Critérios}

Na Tabela 4.7 são mostrados os conjuntos de requisitos de teste derivados pelos critérios TodosNós $_{i}$, Todas-Arestas $i$ e Todos-Uso $i$ para o par de unidades (Principal) efetuarCalculos (DD) V - (Calculo) calcular (DD) V cujo código-fonte e grafo $\mathcal{P W D U}$ são exibidos na Figura 4.3 e Figura 4.5, respectivamente.

Tabela 4.7: Conjuntos de requisitos derivados pelos critérios de teste estrutural de integração par-a-par.

\begin{tabular}{|c|c|}
\hline Critério & Conjuntos de Requisitos de Teste \\
\hline Todos-Nós ${ }_{i}$ & $\mathrm{R}_{n}=\{i .0, i .8, i .14, i .26, i .36, i .43\}$ \\
\hline Todas-Arestas $_{i}$ & $\begin{array}{l}\mathrm{R}_{e}=\{(i .0, i .8),(i .8, i .14),(i .14, i .26),(i .14, i .36),(i .26, i .43), \\
(i .36, i .43)\}\end{array}$ \\
\hline Todos-Usos $_{i}$ & $\begin{array}{l}\mathrm{R}_{u}=\{(\text { num } 1,0, i .0),(\text { num } 2,0, i .0),(\text { num } 1,0, i .8),(\text { num } 2,0, i .8), \\
(\text { calc }, 11, i .14),(\text { calc }, 11,(i .14, i .26)),(\text { calc }, 11,(i .14, i .36)), \\
(\text { num } 1,0, i .14),(\text { num } 1,0,(i .14, i .26)),(\text { num } 1,0,(i .14, i .36)), \\
(\text { num } 2,0, i .14),(\text { num } 2,0,(i .14, i .26)),(\text { num } 2,0,(i .14, i .36)), \\
(\text { num } 1,0, i .26),(\text { num } 2,0, i .26),(\text { num } 2,0, i .36),(\text { num } 1,0, i .36), \\
\text { (calc.resSum, } i .14,20),(\text { calc.resSub }, i .26,20),(\text { calc }, i .26,20), \\
\text { (calc.resSub, } i .36,20),(\text { calc }, i .36,20)\}\end{array}$ \\
\hline
\end{tabular}

Dos conjuntos de requisitos de teste apresentados na Tabela 4.7 nota-se que: o conjunto $\mathrm{R}_{n}$ contém todos os nós integrados do grafo $\mathcal{P W D U}$ do par de unidades; o conjunto $\mathrm{R}_{e}$ contém todas as arestas integradas; o conjunto $\mathrm{R}_{u}$ contém todos os pares de definições-usos das variáveis de comunicação. As notações $(x, i, j)$ e $(x, i,(j, k))$ utilizadas para representar os requisitos de $\mathbf{R}_{u}$ indicam que a variável $x$ é definida no nó $i$ e existe um uso computacional de $x$ no nó $j$ ou um uso predicativo de $x$ na aresta $(j, k)$, respectivamente, bem como pelo menos um caminho livre de definição do nó $i$ ao nó $j$ ou à aresta $(j, k)$. Nesta notação, para identificar $x$ é utilizado o nome da variável de comunicação conforme declarado na unidade chamadora. Considere como exemplo os requisitos (num1, $0,(i .14, i .26)$ ) e (calc.resSum, i.14,20). O primeiro indica que a variável num 1 é definida no nó 0 e existe um uso predicativo na aresta $(i .14, i .26)$. Observe que o uso na aresta $(i .14, i .26)$ não é exatamente da variável num 1 e sim de $p 1$, que é a variável de comunicação correspondente a num 1 . O segundo requisito indica que a variável calc.resSum é definida no nó $i .14$ e existe um uso computacional no nó 20. Observe que, neste caso, a definição que ocorre no nó $i .14$ é de this.resSum, que é a variável de comunicação corespondente de calc.resSum.

Para cobrir todos os requisitos de $\mathbf{R}_{n}, \mathbf{R}_{e}$ e $\mathbf{R}_{u}$ deve-se gerar pelo menos dois casos de teste. Um que percorre o caminho $(0,11, i .0, i .8, i .14, i .26, i .43,20)$ e outro que passa pelo caminho $(0,11, i .0, i .8, i .14, i .36, i .43,20)$. 


\subsection{Considerações Finais}

Neste capítulo foi apresentada uma abordagem de teste estrutural de integração par-a-par para programas OO e OA. Foi definido um modelo de fluxo de dados (adaptado de Vincenzi (2004)) que é utilizado para identificar o que caracteriza uma definição ou um uso de uma variável em uma sentença Java. Para representar o fluxo de execução entre as unidades foi definido o grafo $\mathcal{P} \mathcal{W} \mathcal{U}$ (PairWise Def-Use) que é uma abstração formada pela integração dos grafos $\mathcal{A O D U}$ da unidade chamadora e da unidade chamada. Por fim, foram propostos três critérios específicos para derivar requisitos de teste para os pares de unidades. Dentre eles, dois critérios são baseados em fluxo de controle: todos-nós-integrados e todas-arestas-integradas; e um critério é baseado em fluxo de dados: todos-usos-integrados.

Após a definição da abordagem de teste é interessante implementá-la em uma ferramenta de teste. A implementação da abordagem proposta é apresentada no próximo capítulo. 



\section{Implementação do Teste Estrutural de Integração Par-a-Par na Ferramenta JaBUTi/AJ}

\subsection{Considerações Iniciais}

Para efetuar um teste com qualidade e produtividade é fundamental utilizar, além das técnicas e critérios de teste, ferramentas de teste. Deste modo, é interessante implementar a abordagem de teste estrutural de integração par-a-par proposta em uma ferramenta de teste. Para isso, foi estendida a ferramenta JaBUTi/AJ (discutida na Seção 3.6) que é uma ferramenta de teste de unidade de programas OO e OA escritos em Java e AspectJ. Essa ferramenta apresenta uma base ideal de funcionalidades, tais como análise e instrumentação do bytecode, construção dos grafos e execução dos casos de teste, que tornou a implementação dessa abordagem exeqüível dentro do tempo do programa de mestrado.

Na Seção 5.2 é descrita a extensão da ferramenta JaBUTi/AJ para o teste estrutural de integração par-a-par. Na Seção 5.3 é apresentado sucintamente o funcionamento da JaBUTi/AJ e são discutidos dois exemplos de uso. Por fim, na Seção 5.4 são apresentadas as considerações finais do capítulo. 


\subsection{Extensão da Ferramenta JaBUTi/AJ para Apoio ao Teste Estrutural de Integração Par-a-Par}

A ferramenta JaBUTi/AJ foi estendida para possibilitar a utilização da abordagem de teste estrutural de integração par-a-par de programas OO e OA escritos em Java (e AspectJ, no caso dos programas OA) proposta nesta dissertação. Para isso, o processo de implementação da extensão da ferramenta foi dividido em quatro etapas: a primeira etapa consistiu em identificar os pares de unidades que se relacionam no programa; a segunda etapa envolveu a construção do grafo $\mathcal{P W D U}$ entre os pares de unidades; a terceira etapa teve como objetivo implementar os critérios de teste estrutural de integração par-a-par, ou seja, os critérios todos-nós-integrados, todas-arestasintegradas e todos-usos-integrados; por fim, a quarta etapa teve como finalidade desenvolver os ambientes de teste de integração intra-módulo e inter-módulo. As quatro fases de desenvolvimento estão detalhadas a seguir.

\subsubsection{Primeira Etapa: Identificar Pares de Unidades}

A identificação dos pares de unidades que se relacionam em um programa $\mathrm{OO}$ ou OA é feita por meio do bytecode Java dos módulos do programa que foram selecionados para serem instrumentados e testados pela ferramenta, denominados "módulos do projeto". A partir deles é feita uma varredura no bytecode de cada unidade que eles definem em busca das instruções de chamada do bytecode Java: invokevirtual, invokespecial, invokestatic e invokeinterface. Com estas instruções é possível saber que dentro de uma determinada unidade está ocorrendo uma chamada a uma outra unidade. Além disso, por meio das instruções de chamada do bytecode é possível saber qual unidade está sendo chamada e a qual módulo essa unidade pertence. Deste modo, além de identificar o par de unidades, pode-se determinar qual é o tipo de interação que ocorre entre o par de unidades identificado. Conforme discutido na Seção 4.2, o tipo de interação pode ser: intra-módulo se as unidades do par estão definidas em um mesmo módulo; ou intermódulo se as unidades do par estão definidas em módulos diferentes. Vale ressaltar que chamadas a unidades definidas em módulos que não pertencem aos módulos do projeto não são consideradas (por exemplo, chamadas a métodos definidos em alguma classe da Java API).

Após identificados os pares de unidades que se relacionam e o tipo de interação que eles representam é estabelecido um nome para eles. O nome que é atribuído segue um padrão de nomeação. Ele é composto de duas partes: a parte da unidade chamadora e a parte da unidade chamada. Cada parte é formada pela assinatura da unidade no nível de bytecode (Lindholm e Yellin, 1999) precedida pelo nome do módulo (incluindo o pacote) em que a unidade foi implementada entre parêntesis "(" e ")". O símbolo "-" é usado como separador das partes. Na Figura 5.1 é mostrado um exemplo de nomeação para um par de unidades do programa cujo código-fonte é apresentado 
de referência operacao da classe OperacaoMatematica está referenciando uma instância da classe Soma. Do mesmo modo, é impossível executar o método calcular da classe Soma na segunda chamada, isto é, testar o par de unidades 3 da Tabela 5.1, pois, neste caso, a variável de referência operacao está referenciando uma instância da classe Subtracao. Estes pares de unidades que são impossíveis de serem executados durante o teste estrutural de integração par-apar damos o nome de pares de unidades não executáveis.

\subsubsection{Segunda Etapa: Construir Grafo Def-Uso Par-a-Par}

A construção do grafo Def-Uso Par-a-Par $(\mathcal{P W D U})$ e a identificação dos novos tipos de nós e arestas foram discutidos na Seção 4.4. Nesta seção é tratada a implementação que foi realizada para criar os nós e arestas integradas e como foi implementada a construção do grafo $\mathcal{P} \mathcal{W} \mathcal{D}$ a partir dos grafos $\mathcal{A O D U}$ (Lemos, 2005) da unidade chamadora e chamada.

Os nós integrados utilizados para representar os nós do grafo $\mathcal{A O D U}$ da unidade chamada podem ser de qualquer tipo, ou seja, um nó regular, um nó de chamada, um nó transversal ou um nó de saída. Assim, para implementá-los, foi adicionado na classe CFGNode, que implementa um nó de um grafo e é superclasse das outras classes que implementam os outros tipos de nós, um atributo que indica se o nó é um nó integrado ou não. Já a identificação das novas arestas criadas é feita pelos nós que elas conectam. Uma aresta integrada conecta dois nós integrados enquanto que uma aresta de integração conecta um nó normal e um nó integrado ou vice-versa.

Com relação à implementação da construção de um grafo $\mathcal{P} \mathcal{W} \mathcal{D U}$ de um par de unidades, esta ocorreu da seguinte maneira: primeiramente é construído, por meio de um método anteriormente implementado na ferramenta, o grafo $\mathcal{A O D U}$ da unidade chamadora. O método que constrói o grafo $\mathcal{A O D U}$ foi alterado com o objetivo de que, durante a construção, sejam identificados os nós de interação e os nós de retorno que são fundamentais para a posterior integração dos grafos. Após a construção do grafo $\mathcal{A O D U}$ da unidade chamadora, o grafo $\mathcal{A O D U}$ da unidade chamada é construído. No decurso de sua construção, todos os nós criados são nós integrados. Após a construção dos dois grafos $\mathcal{A O D U}$ é realizada a integração entre eles. Porém, antes disso, é necessário excluir todas as arestas entre o nó de interação e os nós de retorno do grafo $\mathcal{A O D U}$ da unidade chamadora. Isso abre um "buraco" onde o grafo $\mathcal{A O D U}$ da unidade chamada será integrado. Para integrar os grafos $\mathcal{A O D U}$ são criadas arestas de integração entre o nó de interação e o nó de entrada do grafo $\mathcal{A O D U}$ da unidade chamada e entre os nós de saída do grafo $\mathcal{A O D} \mathcal{U}$ da unidade chamada e os nós de retorno da unidade chamadora. Após a integração dos grafos $\mathcal{A O D U}$ a representação gráfica do grafo $\mathcal{P} \mathcal{W} \mathcal{D} \mathcal{U}$ está pronta. Entretanto, os conjuntos de definições e usos dos nós precisam ser atualizados. Para isso é feita uma análise das variáveis de comunicação entre as unidades. Essa análise é abordada na terceira etapa de implementação. 


\subsubsection{Terceira Etapa: Implementar Critérios de Integração Par-a-Par}

Para implementar os critérios de teste estrutural de integração par-a-par (definidos na Seção 4.5), ou seja, os critérios todos-nós-integrados, todas-arestas-integradas e todos-usos-integrados, foi utilizado o pacote criteria. Três novas classes foram criadas: All IntegratedNodes, All IntegratedEdges e All IntegratedUses, cada uma estendendo a classe AbstractCriterion. A classe AllintegratedNodes foi implementada com o objetivo de filtrar os requisitos de teste que incluem somente os nós integrados. Uma estratégia similar foi seguida para a classe $A l l$ IntegratedEdges, a qual foi implementada para incluir como requisitos somente as arestas integradas. Com relação à classe $A l l$ IntegratedUses, esta foi implementada com a finalidade de incluir somente como requisitos de teste aqueles cujas variáveis são definidas nos nós antes da chamada (unidade chamadora) e usadas nos nós ou arestas integradas (unidade chamada) ou cujas variáveis são definidas nos nós integrados (unidade chamada) e usadas nos nós ou arestas após a chamada (unidade chamadora).

A implementação das classes AllintegratedNodes e AllintegratedEdges foi de certo modo simples, pois somente bastava identificar, por meio do grafo $\mathcal{P W D U}$, os nós integrados e as arestas integradas, respectivamente. Já com relação à classe All IntegratedUses precisou-se de uma análise mais detalhada para derivar os pares definição-uso (def-uso) das variáveis. Porém, antes de discutir essa análise, é importante comentar como as variáveis são identificadas na ferramenta JaBUTi/AJ.

\section{Identificação das Variáveis na JaBUTi/AJ}

O nome das variáveis não é tratado pela ferramenta JaBUTi/AJ conforme ele é definido no código-fonte. A identificação de uma variável é baseada em informações do bytecode e de algumas estruturas da JVM (discutidas na Seção 2.2.1). Os parâmetros formais e as variáveis declaradas em uma unidade são tratados como variáveis locais e são associadas ao vetor de variáveis locais do frame da unidade. Eles são representados por L@N, que significa: variável local $\mathrm{N}$ do vetor de variáveis locais do frame. Em um método de instância, a variável local zero, referenciada como L@ 0, recebe o valor da referência para o objeto corrente (this); os parâmetros formais, caso exista algum, são associados às variáveis locais um (L@1), dois (L@2), e assim por diante, dependendo do tipo ${ }^{1}$ e do número de parâmetros; finalmente, as variáveis declaradas dentro do método são associadas às demais variáveis locais, também dependendo do tipo e do número de variáveis. Se for um método estático, a variável local zero é associada ao primeiro parâmetro formal do método, e as demais variáveis locais são associadas aos demais parâmetros e às variáveis declaradas no método, nesta ordem. Uma variável agregada é representada por L@N [ ], em que L@N é a variável local $\mathrm{N}$ que armazena o endereço de referência de um array. Para atributo estático a indicação é da forma $S Q<$ nome_módulo>.<nome_atributo>, onde <nome_módulo> é o nome do

\footnotetext{
${ }^{1}$ Os parâmetros formais e variáveis declaradas em uma unidade que são do tipo primitivo long ou double ocupam duas posições no vetor de variáveis locais do frame.
} 
módulo (classe ou aspecto) ao qual o atributo pertence e <nome_atributo> é o nome do atributo estático. Para atributo de instância, a indicação é da forma L@N. <nome_atributo>, onde L@N é a variável local $\mathrm{N}$ que armazena o valor da referência ao objeto e < nome_atributo> é o nome do atributo de instância.

Como exemplo, considere o código-fonte do método efetuarCalculos da classe Principal (linhas 22 a 29 da Figura 4.3). Como o método efetuarCalculos é estático, a posição zero do vetor de variáveis locais do frame do método, ou seja, a variável local L@ 0, é ocupada pelo primeiro parâmetro do método, o parâmetro formal d1, e a variável local L@ 1 é ocupada pelo segundo parâmetro do método, o parâmetro formal d2. As variáveis locais num1, num2 e calc são associadas às posições dois ( $\mathrm{Q} @ 2$ ), três ( $\mathrm{C} @ 3$ ) e quatro ( $\mathrm{C} @ 4$ ) do vetor de variáveis locais, respectivamente. No corpo desse método é feito um acesso (linhas 20 e 21) a dois atributos de instância da classe Calculo: resSum e resSub. Como são atributos de instância, eles precisam de uma referência a um objeto da classe Calculo. Neste caso, a variável calc é utilizada. Assim, os atributos de instância res Sum e res Sub são referenciados como L@ 4 . res Sum e L@ 4 . resSub, respectivamente. Na Tabela 5.2 é apresentado um mapeamento das variáveis discutidas anteriormente quanto a identificação no código-fonte e a identificação na ferramenta JaBUTi/AJ.

Tabela 5.2: Identificação das variáveis presentes no método efetuarCal culos conforme são vistas no código-fonte e na ferramenta JaBUTi/AJ.

\begin{tabular}{|l|l|}
\hline Código-fonte & JaBUTi/AJ \\
\hline \hline$d 1$ & L@ 0 \\
\hline$d 2$ & L@ 1 \\
\hline num1 & L@2 \\
\hline num2 & L@ 3 \\
\hline calc & L@4 \\
\hline calc.resSum & L@4.resSum \\
\hline calc.resSub & L@4.resSub \\
\hline
\end{tabular}

\section{Variáveis de comunicação e estruturas criadas}

Para derivar os pares def-uso do critério todos-usos-integrados foram consideradas apenas as variáveis que realmente estão envolvidas na interface entre as unidades que se relacionam. Essas variáveis são denominadas "variáveis de comunicação". As variáveis de comunicação podem ser: parâmetros formais; parâmetros reais; e atributos estáticos do(s) módulo(s) do par de unidades que está sendo testada ou de outras classes do programa. Conforme foi discutido na Seção 4.5.2, os atributos de instância também podem ser considerados variáveis de comunicação nos casos em que a unidade chamada é um método de instância. Entretanto, eles são tratados como parâmetros reais e parâmetros formais.

Para descrever as relações entre parâmetros reais e seus correspondentes parâmetros formais e entre os atributos estáticos usados pelas unidades é necessário estabelecer um mapeamento entre eles, ou seja: 
- um mapeamento entre os parâmetros reais da unidade chamadora e os parâmetros formais da unidade chamada;

- um mapeamento entre os atributos estáticos presentes no escopo tanto da unidade chamadora como da unidade chamada;

Para isso foi criada uma estrutura, denominada "estrutura de mapeamento" (mostrada na Figura 5.3). Uma estrutura de mapeamento representa um valor (primitivo ou de referência) que é usado no programa e quais variáveis, presentes tanto ao escopo da unidade chamadora quanto ao escopo da unidade chamada, possuem este valor. Para identificar o valor é atribuído um nome a ele. Para representar as variáveis que possuem tal valor são criadas duas listas: uma formada por variáveis que estão no escopo da unidade chamadora e outra composta por variáveis do escopo da unidade chamada. A notação textual da estrutura de mapeamento é da forma:

| $I \mid[L 1] /[L 2]$ |, em que $I$ é a identificação do valor, $L 1$ é a lista de variáveis no escopo da unidade chamadora e $L 2$ a lista de variáveis no escopo da unidade chamada.

\begin{tabular}{|l|l|}
\hline \multirow{2}{*}{$\begin{array}{l}\text { Identifi- } \\
\text { cador do } \\
\text { valor }\end{array}$} & $\begin{array}{l}\text { Lista de variáveis no escopo da } \\
\text { unidade chamadora }\end{array}$ \\
\cline { 2 - 2 } & $\begin{array}{l}\text { Lista de variáveis no escopo da } \\
\text { unidade chamada }\end{array}$ \\
\hline
\end{tabular}

Figura 5.3: Estrutura de mapeamento.

Além da estrutura de mapeamento, foi criada uma outra estrutura denominada "estrutura de registro def-uso" (mostrada na Figura 5.4). Uma estrutura de registro def-uso representa cada definição ou uso de uma variável. Além da informação de qual variável foi definida ou usada (1), essa estrutura informa: se foi uma definição ou uso (2), onde (na unidade chamadora ou na unidade chamada) ocorreu a definição ou uso (3), o nó onde ocorreu a definição ou uso (4) e armazena informações da estrutura de mapeamento do valor da variável no momento em que ocorreu a definição ou uso (5). A notação textual da estrutura de registro def-uso é da forma:

$|V| D U|U| N|I|[L 1] /[L 2] \mid$, em que $V$ corresponde a (1), $D U$ corresponde a (2), $U$ corresponde a (3), $N$ corresponde a (4) e " $I \mid[L 1] /[L 2]$ ” corresponde a (5).

\begin{tabular}{|c|c|c|c|c|c|}
\hline (1) & (2) & (3) & (4) & \multicolumn{2}{|r|}{ (5) } \\
\hline \multirow{2}{*}{ Variável } & \multirow{2}{*}{ Def/Uso } & \multirow{2}{*}{$\begin{array}{l}\text { Unidade } \\
\text { onde } \\
\text { ocorre a } \\
\text { def/uso }\end{array}$} & \multirow{2}{*}{$\begin{array}{l}\text { Nó onde } \\
\text { ocorre a } \\
\text { def/uso }\end{array}$} & \multirow{2}{*}{$\begin{array}{l}\text { Identifi- } \\
\text { cador do } \\
\text { valor }\end{array}$} & $\begin{array}{l}\text { Lista de variáveis no escopo da } \\
\text { unidade chamadora }\end{array}$ \\
\hline & & & & & $\begin{array}{l}\text { Lista de variáveis no escopo da } \\
\text { unidade chamada }\end{array}$ \\
\hline
\end{tabular}

Figura 5.4: Estrutura de registro def-uso. 


\section{Processo de identificação das definições e usos das variáveis e mapeamentos}

Para identificar definições e usos das variáveis é realizada uma análise seqüencial das instruções presentes no bloco de instruções de cada nó do grafo $\mathcal{P} \mathcal{W D} \mathcal{U}$ em busca de instruções que impliquem no fluxo de dados (resumidas na Tabela 3.3). Essa análise é denominada "processo de identificação das definições e usos das variáveis" e ocorre da seguinte maneira:

- se for encontrada uma instrução de definição de uma variável, verifica se existe uma estrutura de mapeamento para representar o valor atribuído e, caso não exista, é criada uma estrutura de mapeamento para representar o valor e qual variável recebeu o valor. A informação da variável é colocada em uma das duas listas da estrutura, dependendo de onde ocorreu a definição, ou seja, na unidade chamadora ou na unidade chamada. Se a estrutura de mapeamento que representa o valor já existe, então ela é atualizada com a informação da variável que recebeu o valor. Em seguida, cria-se uma estrutura de registro def-uso para representar a definição da variável.

- se for encontrada uma instrução de uso de uma variável, é criada apenas a estrutura de registro def-uso para representar o uso da variável.

Um exemplo desse processo é mostrado na Figura 5.5. No exemplo observa-se que em (1) ocorre a definição de L@1 com o valor de 10. Como nenhuma estrutura de mapeamento existe para representar o valor que L@1 recebe, então é criada a estrutura de mapeamento B1 e, em seguida, cria-se uma estrutura de registro def-uso para representar a definição de L@ 1 , conforme mostrado em (I). Já em (2) ocorre o uso de L@1 e a definição de L@2. Assim, é criada uma estrutura de registro def-uso para o uso de L@1, a estrutura de mapeamento B1 é atualizada com a informação da variável L@2, indicando que agora L@2 também possui este valor e, finalmente, uma estrutura de registro def-uso é criada para representar a definição da variável L@2, conforme apresentado em (II).

Um caso especial de identificação de definição ocorre quando uma variável de referência passa a referenciar um novo objeto ou array criado. Conforme discutido na Seção 4.3, ao criar um novo objeto, todos os seus atributos de instância são iniciados. Com relação à criação de um novo array, todas as suas variáveis agregadas são iniciadas no momento da criação. Assim, pode-se dizer que na definição de uma variável de referência ocorre tanto a definição dela mesma (que representa também a definição do novo objeto ou array criado) quanto a definição dos atributos de instância, no caso de um objeto, ou a definição das variáveis agregadas, no caso de um array. Na Seção 4.3 também é discutido que as variáveis agregadas (ou elementos de um array) são consideradas como sendo uma única localização de memória de tal modo que, quando ocorre uma definição ou uso de qualquer um de seus elementos, considera-se que as variáveis agregadas em si é que estão sendo definidas ou usadas e não apenas um elemento particular. Na Figura 5.6 é apresentado um exemplo para estes casos especiais de identificação de definição. Neste exemplo não são representadas estruturas de registro def-uso. 


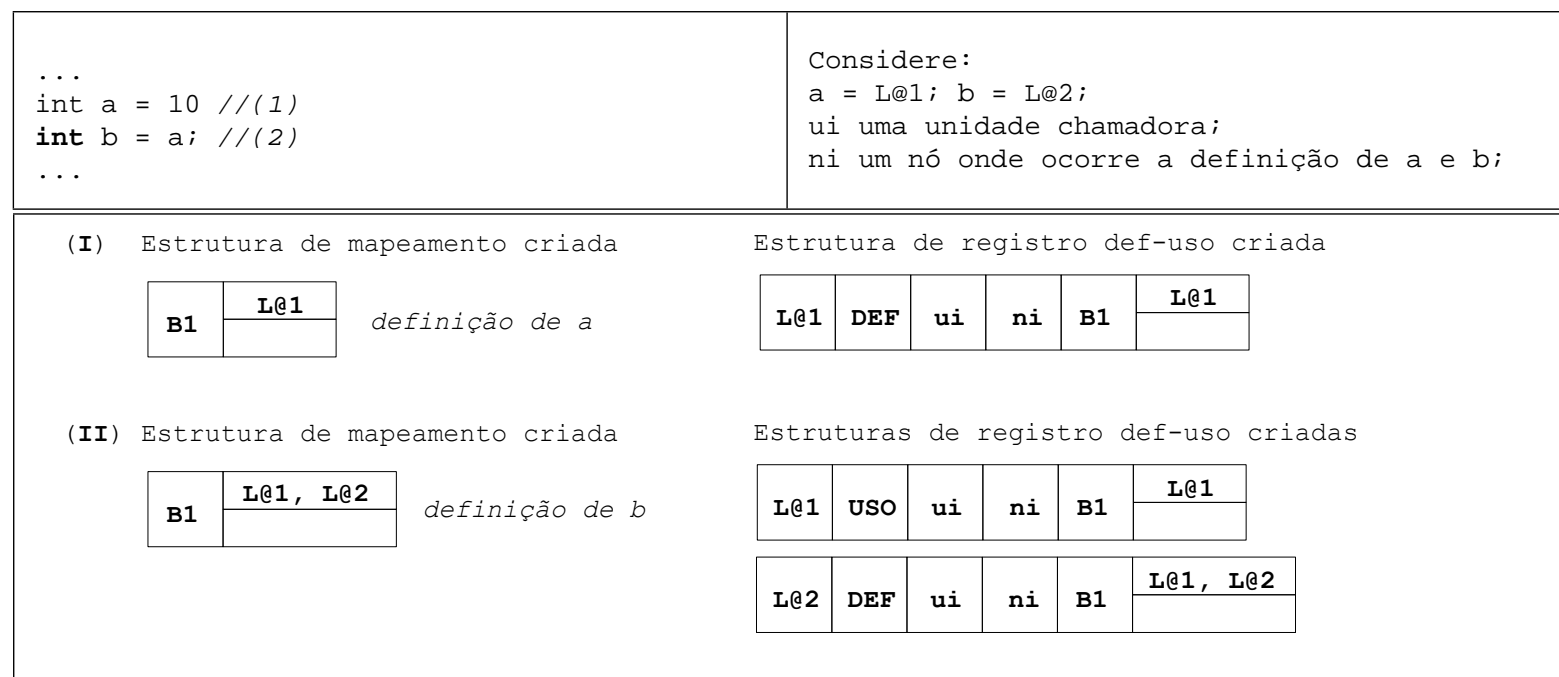

Figura 5.5: Exemplo de criação das estruturas de mapeamento e de registro def-uso.

\begin{tabular}{|c|c|c|c|c|c|c|}
\hline \multicolumn{5}{|c|}{$\begin{array}{l}\text { } \mathrm{C} C=\text { new } C() ; / /(1) \\
\text { int }[] \mathrm{V}=\text { new int }[3] ; / /(2) \\
\cdots \\
\text { Considere: } \mathrm{C}=\mathrm{L} \mathrm{L} 1 ; \mathrm{V}=\mathrm{L} \mathrm{C} 2\end{array}$} & \multicolumn{2}{|c|}{$\begin{array}{l}\text { public C } \\
\text { float } a ; \\
\}\end{array}$} \\
\hline \multicolumn{6}{|c|}{ (I) Estruturas de mapeamento criadas } & \multirow[b]{2}{*}{$\begin{array}{l}\text { definição do atributo } \\
\text { de instância a }\end{array}$} \\
\hline \multirow{3}{*}{ (II) } & 01 & $L @ 1$ & definição de c & $01 . a$ & L@1.a & \\
\hline & \multicolumn{4}{|c|}{ Estruturas de mapeamento criadas } & & \\
\hline & A2 & $L @ 2$ & definição de $v$ & A2 [ ] & L@2 [ ] & $\begin{array}{l}\text { definição das variáveis } \\
\text { agregadas de } \mathrm{V}\end{array}$ \\
\hline
\end{tabular}

Figura 5.6: Exemplo de definição de uma variável de referência.

Observa-se na Figura 5.6 que em (1) ocorre a definição da variável de referência L@1. Como se esta criando um novo objeto da classe $C$, o atributo de instância L@1. a também é definido (neste caso, como nenhum valor inicial é atribuído para o atributo de instância a, ele recebe um valor default 0.0). Assim, são criadas duas estruturas de mapeamento, uma para representar o valor que L@ 1 possui e outra para representar o valor de L@ 1 . a, conforme mostrado em (I). Já em (2) ocorre a definição da variável L@2 (que referencia o novo array criado) e, conseqüentemente, a definição das variáveis agregadas L@2 [ ]. Assim, é criada uma estrutura de mapeamento para representar o valor de L@2 e outra para representar o valor de L@2 [ ], conforme apresentado em (II).

O processo de identificação das definições e usos das variáveis é realizado primeiramente nos nós antes da chamada. A partir daí, é possível identificar os parâmetros reais declarados no escopo da unidade chamadora e mapeá-los para os parâmetros formais da unidade chamada. Além disso, se a unidade chamada for um método de instância, é possível fazer o mapeamento entre a variável 
de referência na qual o método de instância é chamado e o objeto corrente this do escopo do método de instância. Neste caso, os atributos de instância tanto da variável de referência quanto do this também são mapeados. Em seguida, o processo de identificação das definições e usos das variáveis é efetuado nos nós integrados e, por fim, o processo é realizado nos nós após a chamada. Na Figura 5.7 é apresentado um exemplo simples mostrando o mapeamento que ocorre quando é feita uma chamada a um método de instância ao qual é passado um parâmetro.

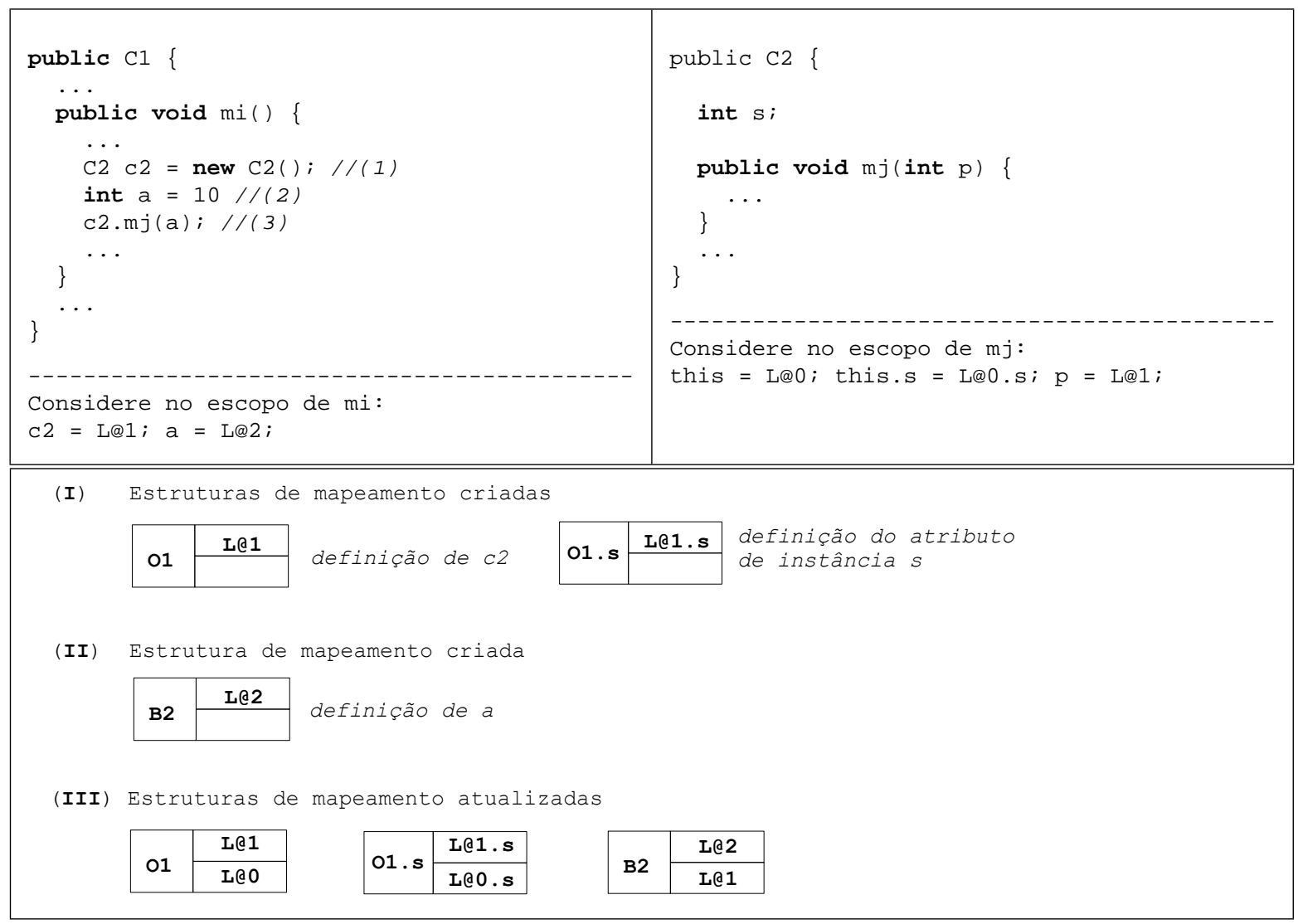

Figura 5.7: Exemplo mostrando o mapeamento entre as variáveis de comunicação.

Comentando o exemplo da Figura 5.7, observa-se que em (1) ocorre a definição da variável de referência L@1 e, conseqüentemente, a definição do atributo de instância L@1.s. Assim, são criadas duas estruturas de mapeamento para representar os valores que elas recebem, $\mathrm{O} 1 \mathrm{e} \mathrm{O} 1 \mathrm{~s}$, conforme mostrado em (I). Em (2) ocorre a definição da variável primitiva L@2. Para representar o valor que ela recebe é criada a estrutura de mapeamento B2 (II). Por fim, em (3) ocorre a chamada ao método de instância mj. Neste ponto, são mapeados:

- a variável de referência c2 ( $\mathrm{L} @ 1)$ que chama o método mj com o objeto corrente this ( L@0) do método $\mathrm{mj}$;

- o atributo de instância s de c2 (L@1.s) com o atributo de instância s do this (L@0.s);

- o parâmetro real a (L@2) com o parâmetro formal p ( $\mathrm{C} @ 1)$. 
Para representar estes mapeamentos as estruturas de mapeamento 01 , 01 . s e B2 são atualizadas, conforme mostrado em (III).

Um caso diferente de passagem de parâmetros ocorre quando a unidade chamada é um adendo. Neste caso, todos os parâmetros são copiados em outras variáveis antes do adendo ser disparado. Essa cópia é feita internamente por instruções inseridas pelo AspectJ no processo de combinação. Na Figura 5.8 é apresentado um exemplo mostrando a passagem de parâmetros para o adendo before que é disparado antes da execução do método ms da classe C.

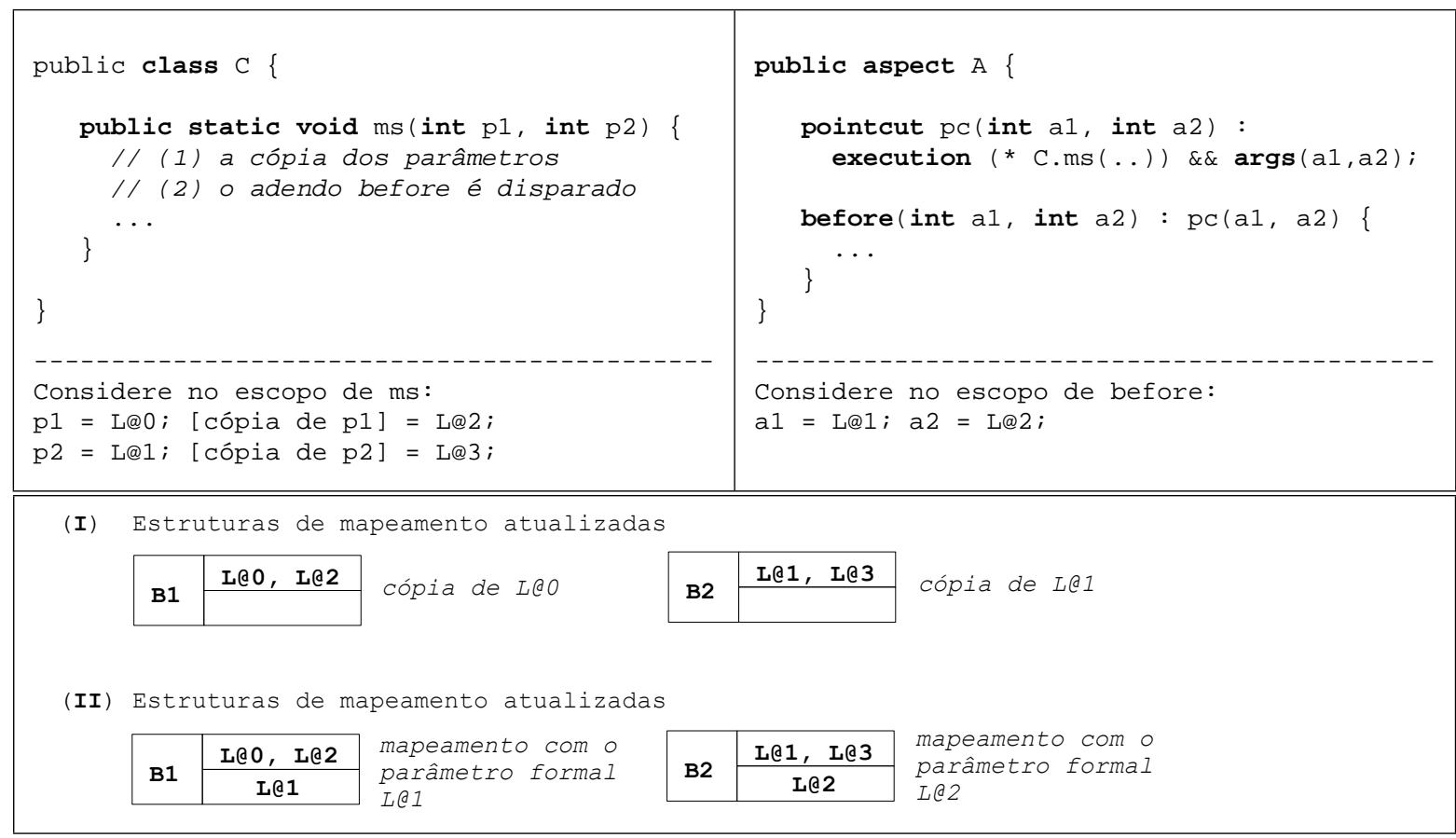

Figura 5.8: Exemplo mostrando a cópia dos parâmetros feita pelo AspectJ antes da chamada e posterior mapeamento.

Nota-se na Figura 5.8 que em (1), ainda no escopo do método ms, é feita uma cópia de L@ 0 e de $L @ 1$, de modo que $L @ 2$ recebe o valor de $L @ 0$ e $L @ 3$ recebe o valor de $L @ 1$. Assim, conforme mostrado em (I), as estruturas de mapeamento dos valores B1 e B2 criadas para armazenar os valores de L@ 0 e de L@1, respectivamente, são atualizadas. Em (2) ocorre o mapeamento para os parâmetros formais do adendo anterior L@ 1 e L@2. Assim, as estruturas de mapeamento B1 e B2 são atualizadas, conforme apresentado em (II).

\section{Derivação dos requisitos}

A derivação dos requisitos do critério de integração par-a-par todos-usos-integrados é feita a partir das estruturas de registro def-uso produzidas no processo de identificação das definições e usos das variáveis. Com estas estruturas é possível relacionar: as definições das variáveis que ocorrem nos nós antes da chamada e os usos das variáveis que ocorrem nos nós integrados; e, as definições das variáveis que ocorrem nos nós integrados e os usos das variáveis que ocorrem nos nós após a chamada. Assim, caso haja um caminho livre de definição com relação a uma variável 
definida nos nós antes da chamada e usada nos nós integrados ou um caminho livre de definição com relação a uma variável definida nos nós integrados e usada nos nós após a chamada, cria-se então um requisito def-uso da forma $\langle x, i, j\rangle$ ou $\langle x, i,(j, k)\rangle$. Essas notações indicam que a variável $x$ é definida no nó $i$ e existe um uso computacional de $x$ no nó $j$ ou um uso predicativo de $x$ na aresta $(j, k)$, respectivamente, bem como pelo menos um caminho livre de definição do nó $i$ ao nó $j$ ou à aresta $(j, k)$. Nesta notação, para identificar $x$ é utilizado o nome da variável de comunicação conforme declarado na unidade chamadora. A seguir é mostrado um exemplo simples que explica o processo de derivação dos requisitos.

Considere o código-fonte e o grafo $\mathcal{P W D U}$ (Figura 5.9) do par de unidades intra-módulo $\mathrm{m} 1$ e m2, em que $\mathrm{m} 1$ chama $\mathrm{m} 2$. Primeiramente é realizado o processo de identificação das definições e usos das variáveis. Conforme discutido anteriormente, nesse processo são criadas as estruturas de mapeamento e de registro def-uso. Para representar as estruturas são utilizadas as suas notações textuais. As estruturas criadas em $s 1, s 2, s 3, s 4$ e $s 5$ são mostradas na Figura 5.10. As estruturas são numeradas seqüencialmente conforme são criadas.

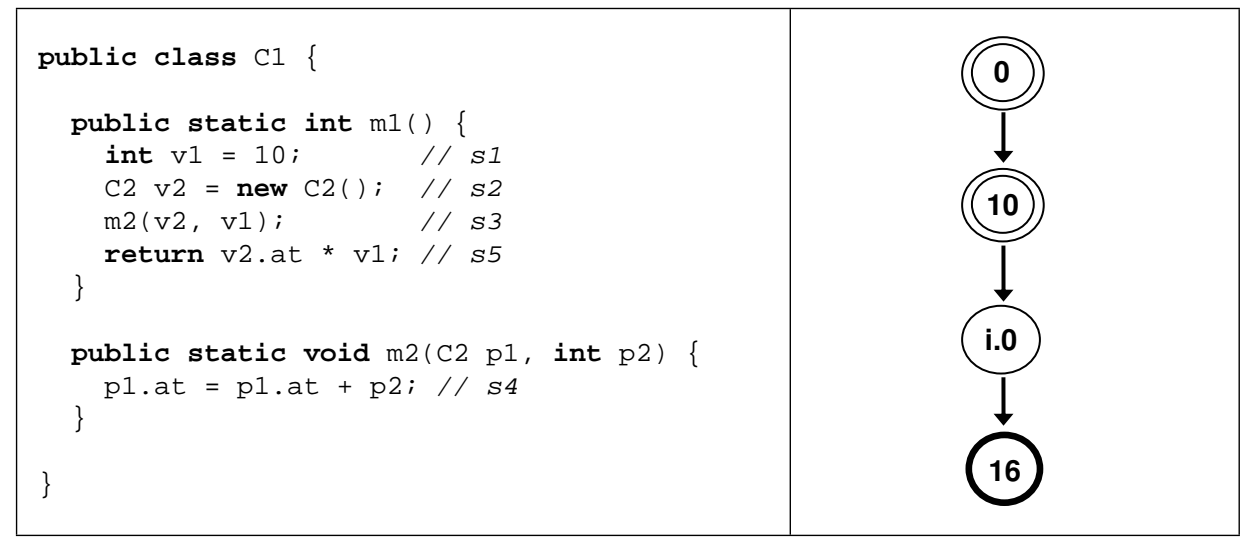

Figura 5.9: Código-fonte e grafo $\mathcal{P W D U}$ para o exemplo de derivação de requisitos.

Depois do processo de identificação das definições e usos das variáveis, são realizados quatro filtros das estruturas de registro def-uso criadas com o objetivo de:

a. selecionar todas as definições que ocorreram nos nós antes da chamada;

b. selecionar todos os usos que ocorreram nos nós integrados;

c. selecionar todas as definições que ocorreram nos nós integrados

d. selecionar todos os usos que ocorreram nos nós após o retorno da chamada.

O resultado de cada filtro é armazenado em conjuntos distintos que são denominados de $C_{a}$, $C_{b}, C_{c}$ e $C_{d}$. A partir daí, é feita uma interseção entre $C_{a}$ e $C_{b}$ (Figura 5.11) e uma interseção entre $C_{c}$ e $C_{d}$ (Figura 5.12). Para isso, toma-se como base as informações sobre o valor definido ou usado e o mapeamento das variáveis. A partir das duas interseções são gerados alguns requisitos, denominados requisitos parciais. Por exemplo, na clausula (I) da Figura 5.11 existe um par defuso em que L@o é definido no nó 0 com o valor BO (estrutura de registro def-uso (1)) e usado no nó i . 0 como L@ 1 e com o mesmo valor BO (estrutura de registro def-uso (9)). Observe que 


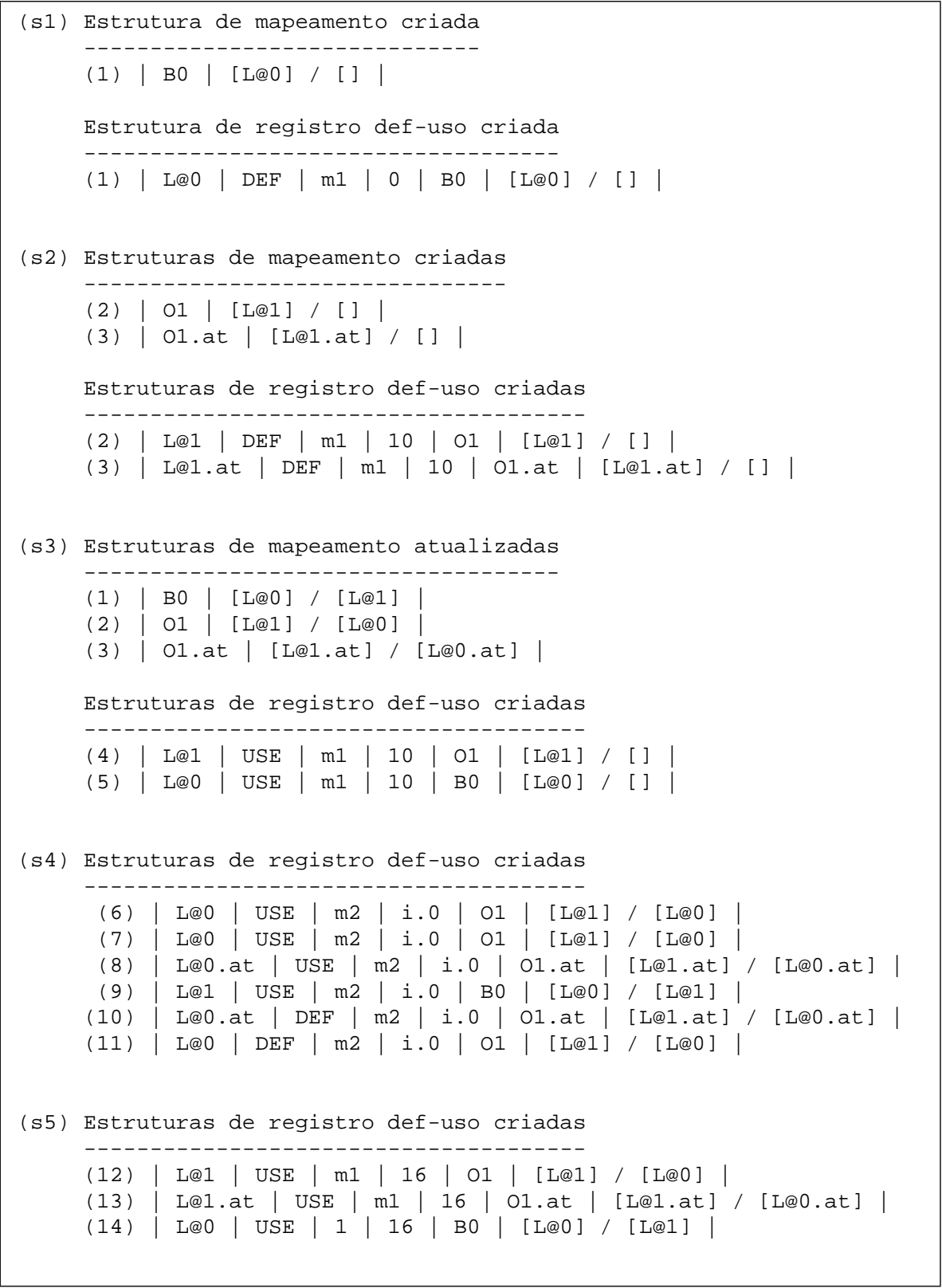

Figura 5.10: Estruturas criadas em $s 1, s 2, s 3, s 4$ e $s 5$.

a estrutura de registro def-uso (9) contém a estrutura de mapeamento que informa que a variável L@ 1 da unidade chamada corresponde à variável L@ 0 da unidade chamadora.

Para cada requisito parcial derivado $\langle x, i, j\rangle$ é verificado se existe realmente um caminho livre de definição com relação a variável $x$ que vai de $i$ até $j$. Se houver, o requisito é considerado válido. Caso contrario, ele é descartado. Para finalizar o processo de derivação de requisitos, é feita uma averiguação em cada requisito válido derivado com o objetivo de verificar se o nó onde ocorre o uso é um nó predicativo, ou seja, um nó para o qual exista mais de uma aresta regular saindo. Se sim, então é criado um requisito da forma $\langle x, i,(j, k)\rangle$ em que $j$ é o nó predicativo e $k$ é o nó adjacente. No exemplo apresentado, todos os requisitos parciais são válidos e não é criado nenhum requisito cujo uso seja predicativo. Assim, os requisitos derivados são: $\langle L @ 1,10, i .0\rangle$, $<L @ 1 . a t, 10, i .0>,<L @ 0,0, i .0>,<L @ 1 . a t, i .0,16>\mathrm{e}<L @ 1, i .0,16>$. 


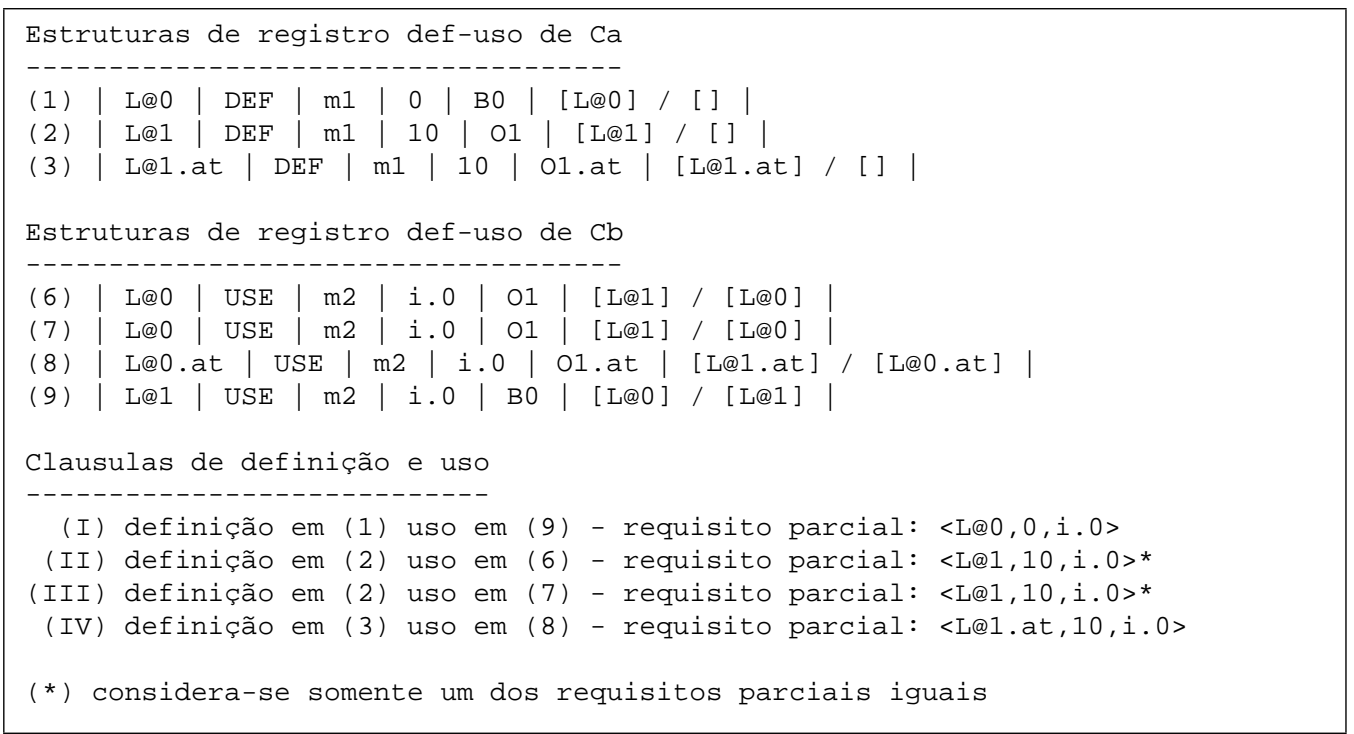

Figura 5.11: Interseção de $C_{a}$ e $C_{b}$ e os requisitos parciais derivados.

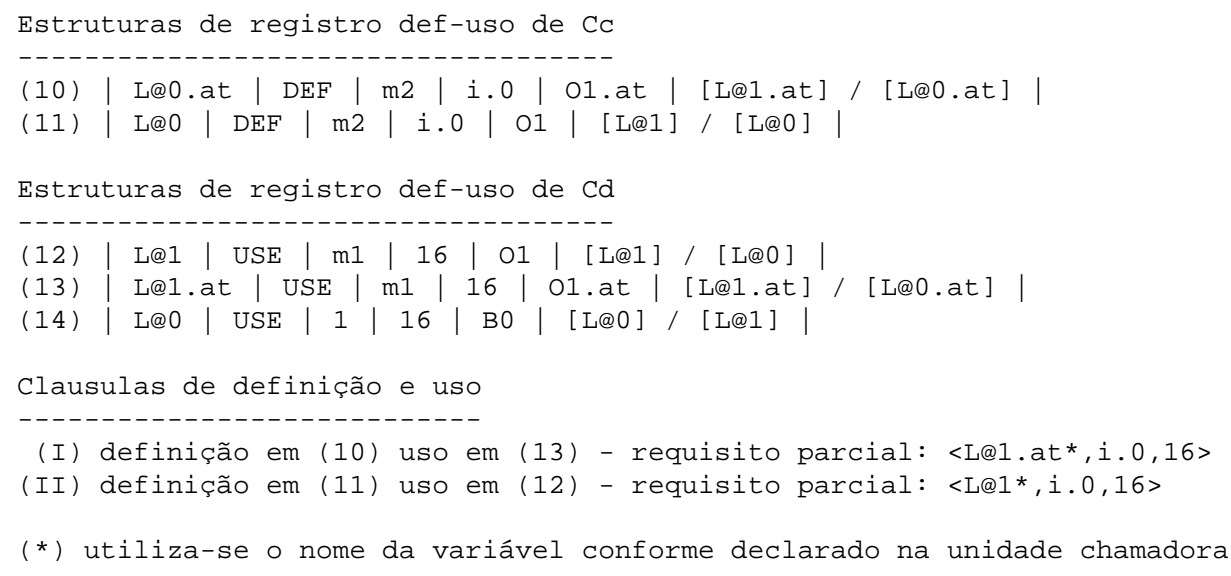

Figura 5.12: Interseção de $C_{c}$ e $C_{d}$ e os requisitos parciais derivados.

\subsubsection{Quarta Etapa: Desenvolvimento dos Ambientes de Teste de Integração}

Para dar suporte ao teste estrutural de integração par-a-par aqui proposto, foram criados mais dois ambientes de teste na interface gráfica da ferramenta JaBUTi/AJ: um para efetuar os testes intra-módulo e outro para realizar testes inter-módulo. Estes novos ambientes de teste utilizam os mesmos módulos selecionados para serem testados e instrumentados no ambiente de teste de unidade - ambiente inicial da ferramenta onde o projeto de teste é criado e são realizados testes individuais das unidades - e, a partir deles, identificam os pares de unidades que se relacionam, conforme discutido na Seção 5.2.1.

Cada ambiente de teste possui suas próprias informações ou dados de teste. Assim, tudo o que é realizado em um determinado ambiente de teste não interfere nos demais. Um exemplo é a execução de casos de teste. Ao executar um determinado caso de teste no ambiente de teste 
de unidade, por exemplo, essa execução não afetará as informações dos ambientes de integração e vice-versa. O testador pode salvar o projeto de teste e as informações de cada ambiente serão salvas de modo independente.

Além disso, foi adaptada a funcionalidade de instrumentação da ferramenta JaBUTi/AJ que consiste em inserir novos códigos no bytecode do programa Java de modo que o comportamento do programa possa ser observado e informações ou medidas referentes cobertura possam ser obtidas. Essa adaptação foi realizada no sentido de que seja considerado todo o fluxo de execução que ocorre entre a unidade chamadora e a unidade chamada. Assim, por meio dessa instrumentação é possível saber por onde (quais métodos e nós) um determinado fluxo de execução passou, ou seja, o caminho percorrido pelo fluxo. A partir daí, sabe-se quais nós, arestas e pares def-uso foram cobertos.

\subsection{Funcionamento da Ferramenta JaBUTi/AJ e Exem- plos de Uso}

Nesta seção é descrita brevemente sobre a interface e algumas funcionalidades da ferramenta JaBUTi/AJ (Seção 5.3.1) . Em seguida, para ilustrar uma operação na ferramenta e evidenciar a aplicabilidade da abordagem proposta, são discutidos alguns exemplos de uso (Seções 5.3 .2 e 5.3.3).

\subsubsection{A Interface da Ferramenta JaBUTi/AJ}

Como exemplo para demostração das interfaces e funcionalidades da ferramenta JaBUTi/Aj, foi utilizado o programa OA apresentado na Figura 4.3. A interface principal da ferramenta JaBUTi/AJ é mostrada na Figura 5.13.

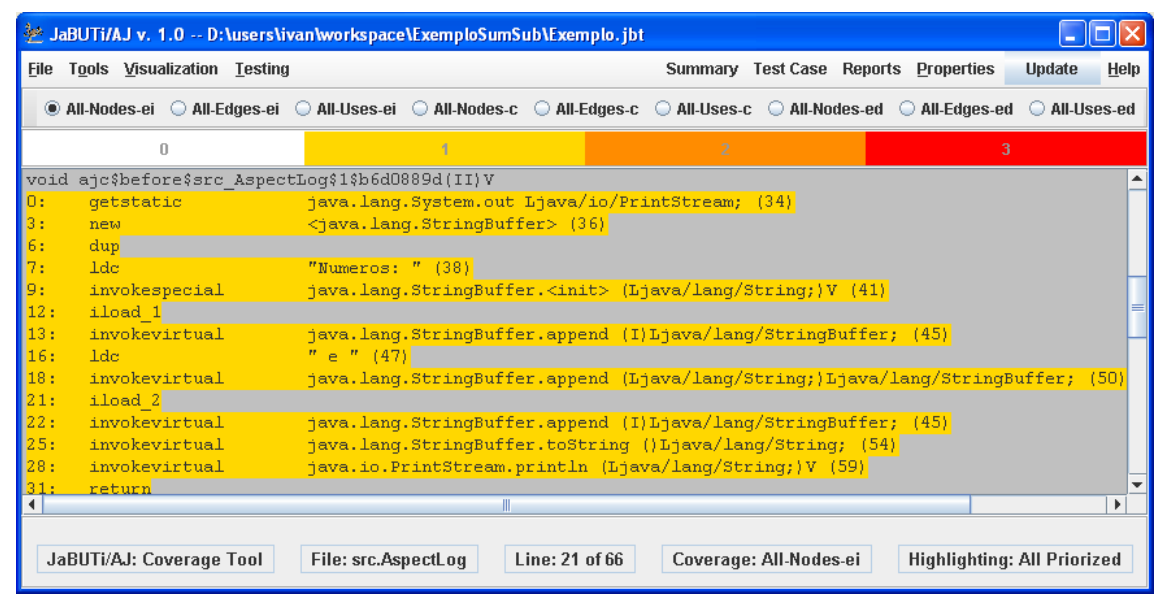

Figura 5.13: Tela principal da ferramenta JaBUTi/AJ. 
Para testar uma aplicação na ferramenta JaBUTi/AJ é necessário, primeiramente, criar um projeto de teste. Nesta etapa o testador escolhe quais classes ou aspectos deseja instrumentar e testar. Após esta seleção, a ferramenta constrói um grafo $\mathcal{A O D U}$ (Lemos, 2005) e deriva os requisitos de teste para cada unidade de cada módulo selecionado para ser testado. Para cada requisito derivado a ferramenta calcula e atribui diferentes pesos (indicados por diferentes cores) que indicam o requisito que, se coberto, aumentaria ao máximo a cobertura em relação ao critério considerado.

A partir daí, é possível acessar todas as funcionalidades da ferramenta. Inicialmente, a ferramenta está no ambiente de teste de unidade, onde podem ser realizados testes em cada unidade, individualmente. Neste ambiente é possível: visualizar o bytecode (como pode ser visto na Figura 5.13) e o código-fonte dos módulos que estão sendo testados, visualizar os grafos $\mathcal{A O D U}$ (Figura 5.14(a)) de cada unidade, visualizar o conjunto de requisitos de teste derivados de cada critério para cada unidade, importar casos de teste (Figura 5.14(b)) para tentar cobrir os requisitos de teste, analisar a cobertura alcançada pelos casos de teste (Figura 5.14(c)) e gerar relatórios.

Além do ambiente para teste de unidade, a ferramenta fornece os ambientes de teste de integração intra-módulo e inter-módulo. Conforme explicado na Seção 4.2, o teste intra-módulo integra os pares de unidades de teste que se relacionam e estão em um mesmo módulo, enquanto que o teste inter-módulo integra os pares de unidades que se relacionam e estão definidos em módulos diferentes. A seleção do ambiente de teste é feita pela opção "Testing” do menu principal.

Da mesma forma que ocorre no ambiente de teste de unidade, no ambiente de teste de integração é possível: visualizar os grafos $\mathcal{P} \mathcal{W D U}$ de cada par de unidades selecionado para ser testado, visualizar o conjunto de requisitos de teste de cada critério de integração par-a-par gerados para cada par de unidades (Figura 5.14(d)), importar casos de teste para tentar cobrir o conjunto de requisitos derivados pelos critérios, e assim por diante.

Nas próximas seções são mostrados alguns exemplos de uso a partir dos quais o funcionamento da ferramenta JaBUTi/AJ é discutido com maiores detalhes.

\subsubsection{Primeiro Exemplo de Uso}

Para o exemplo de uso que é discutido a seguir foi utilizado uma aplicação (adaptada de The AspectJ Team (2006)) que simula um sistema de telefonia no qual clientes fazem, aceitam, juntam e concluem ligações locais e de longa distância. O sistema controla os interesses relacionados à duração das ligações e à cobrança das ligações.

A arquitetura da aplicação é composta: pelos objetos básicos que fornecem as funcionalidades para simular clientes, chamadas e conexões (uma conexão no caso de uma chamada normal ou mais de uma conexão se for uma conferência); pelo interesse de temporização, cuja finalidade é medir o tempo de conexão e guardar o tempo de conexão total por cliente; e pelo interesse de faturamento, que é responsável pela cobrança das ligações realizadas pelos clientes. Os interesses de temporização e faturamento são implementados usando aspectos, sendo que o aspecto de 


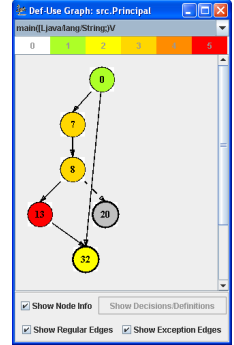

(a)

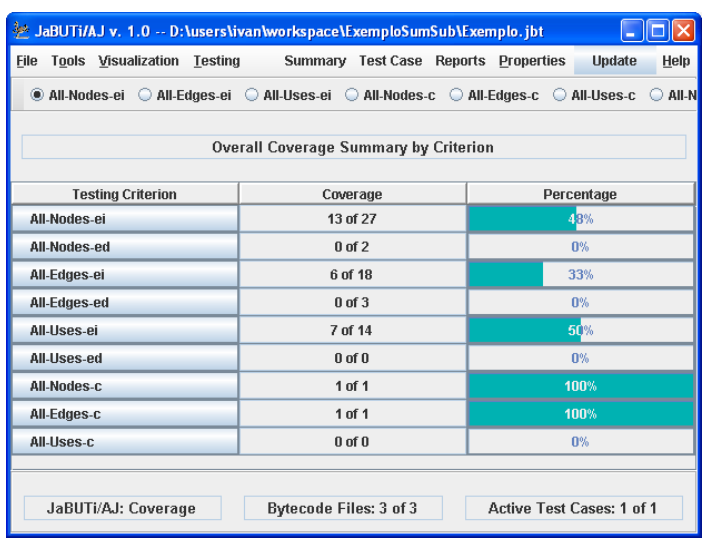

(c)

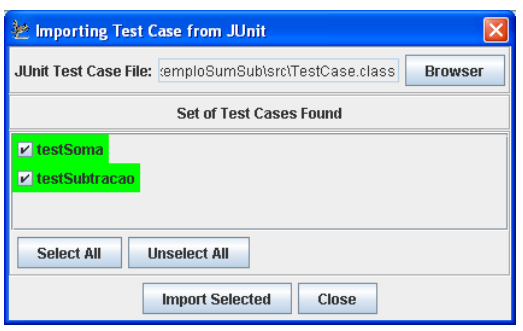

(b)

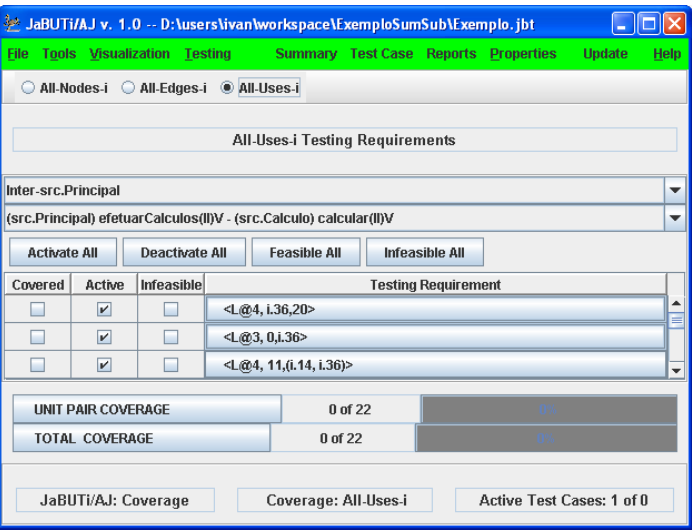

(d)

Figura 5.14: Exemplos de interfaces da ferramenta JaBUTi/AJ.

faturamento depende do aspecto de temporização. Para implementar essas funcionalidades foram desenvolvidas as seguintes classes e aspectos:

- A classe Cliente modela clientes. Ela possui atributos para o nome, o código de área, o número do telefone e a senha do cliente;

- A classe Chamada modela chamadas telefonicas;

- A classe abstrata Conexao é superclasse de Local e LongaDistancia. Uma conexão local é modelada pela classe Local e uma conexão de longa distância é modelada pela classe LongaDistancia.

- A classe Temporizador modela um marcador de tempo.

- O aspecto Tempori zacao implementa o interesse de temporização e se encarrega de medir os tempos das conexões por cliente, iniciando e parando um temporizador associado a cada conexão.

- O aspecto Faturamento implementa o interesse de faturamento e se encarrega de declarar que cada conexão tem um cliente pagador, aquele que inicia a chamada, e também que as chamadas locais e de longa distância devem ser cobradas com taxas diferentes.

- O aspecto TimerLog implementa um registro que imprime na tela os horários em que um temporizador inicia e pára. 
As chamadas são criadas com um cliente chamador e um cliente chamado. Se o chamador e o chamado possuem o mesmo código de área, a chamada é estabelecida com uma conexão local, caso contrário, é estabelecida uma conexão de longa distância. Uma chamada é formada por um certo número de conexões entre clientes. Inicialmente existe apenas uma conexão entre o chamador e o chamado, mas outras conexões podem ser adicionadas se as chamadas são juntadas para formarem uma áudio-conferência. A classe Conexao modela os detalhes físicos do estabelecimento de uma conexão entre os clientes. Isso é feito utilizando uma máquina de estados simples (uma conexão é inicialmente PENDENTE, depois é INICIADA e, finalmente, TERMINADA).

Na Figura 5.15 é apresentado o diagrama de classes UML das classes e aspectos da aplicação de telefonia. O código-fonte das classes é apresentado na Figura 5.16. A classe Principa l, cujo código-fonte é mostrado parcialmente na Figura 5.16, é considerada como uma classe do tipo de aplicação e é responsável pela simulação do sistema de telefonia. Na Figura 5.17 é apresentado o código-fonte dos aspectos.

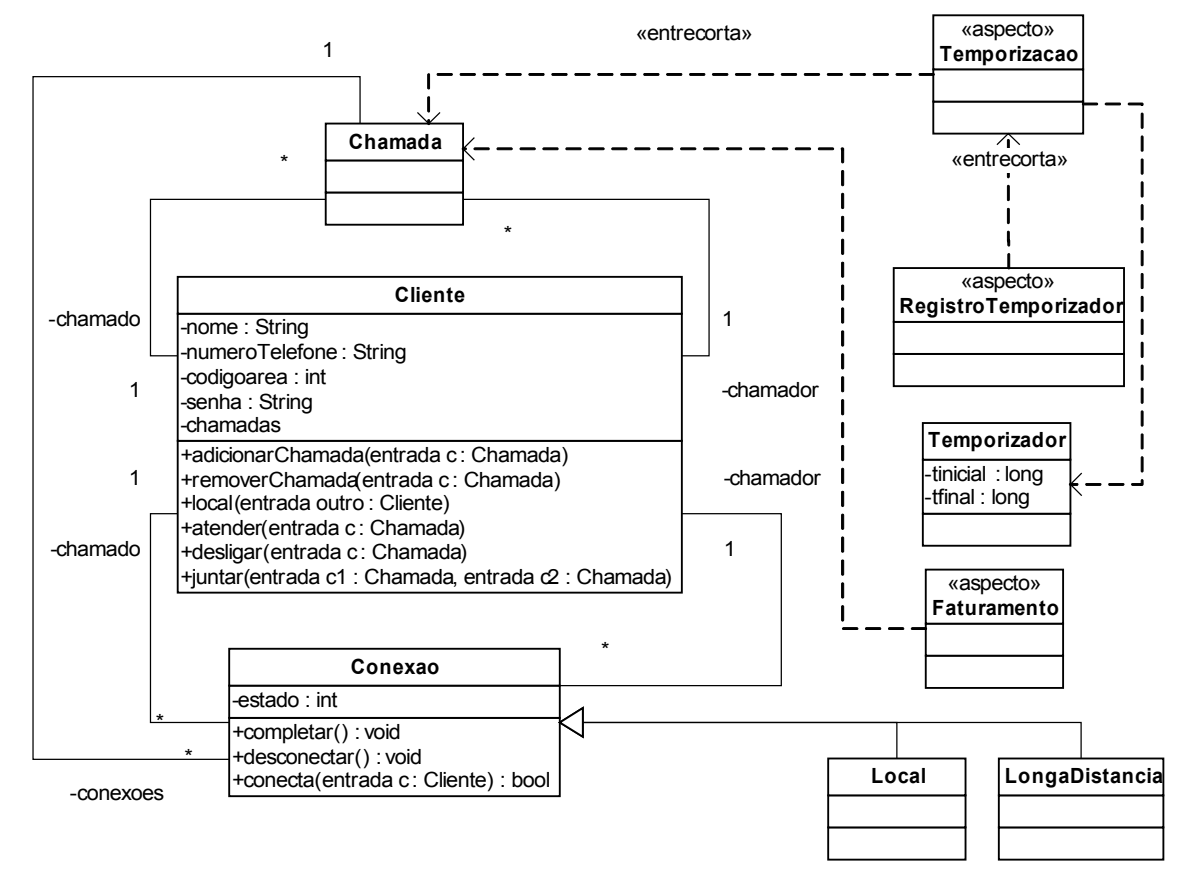

Figura 5.15: Diagrama UML das classes e aspectos da aplicação de telefonia.

Para efetuar o teste de integração da aplicação de telefonia na ferramenta JaBUTi/AJ é necessário, primeiramente, criar um projeto de teste. Para isso, o testador deve fornecer o nome de uma classe da aplicação a partir da qual os demais aspectos e classes estão relacionados (geralmente uma classe do tipo de aplicação). Para que o projeto abranja um número maior de classes ou aspectos foi escolhida a classe Principal. Em seguida, a ferramenta abre a janela de gerenciador de projetos (Figura 5.18) na qual os aspectos e classes da aplicação de telefonia são exibidos (coluna mais à esquerda da janela, dentro do pacote "src"). Nesta janela o testador seleciona quais classes ou aspectos deseja instrumentar e testar e informa um nome para seu projeto. 

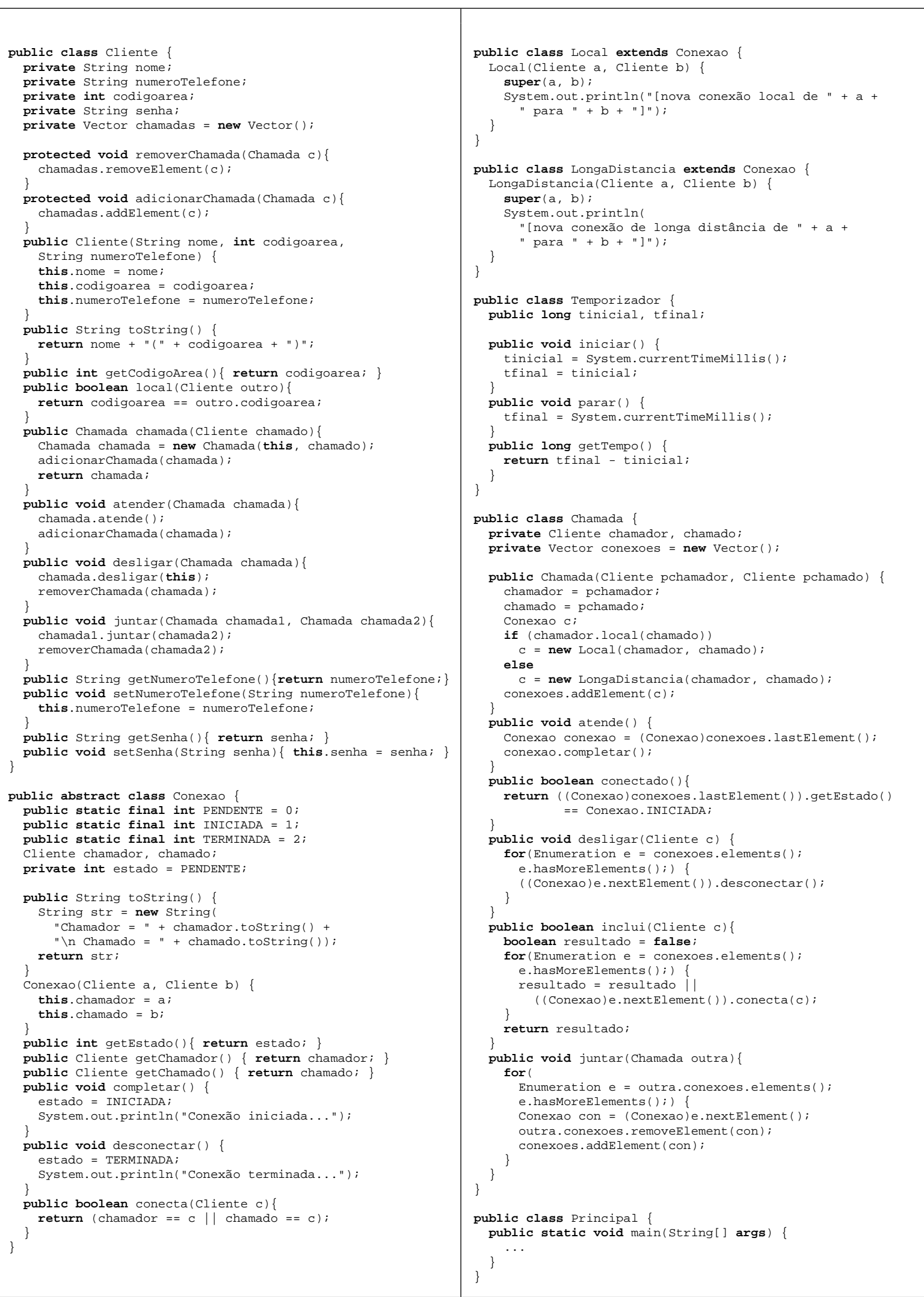

Figura 5.16: Código-fonte das classes da aplicação de telefonia.

Depois de criado o projeto, a ferramenta está pronta para iniciar os testes. Como a ferramenta está inicialmente no ambiente de teste de unidade, deve-se mudar para o ambiente de teste de 




Figura 5.17: Código dos aspectos da aplicação de telefonia.

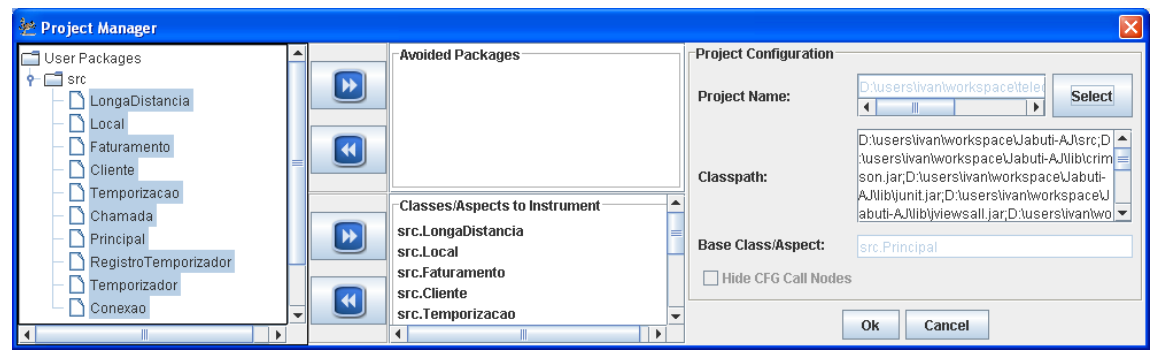

Figura 5.18: Tela principal da ferramenta JaBUTi/AJ.

integração que pode ser intra-módulo ou inter-módulo. Para este exemplo, foi escolhido o tipo inter-módulo. Em seguida, a ferramenta exibe a janela mostrando todos os possíveis pares de unidades que se relacionam e que estão definidos em módulos diferentes do programa (Figura 5.19). Desses pares de unidades, o testador pode selecionar qual deles deseja testar.

Como exemplo, foram selecionados três pares de unidades: (1) o método chamada da classe Cliente e o construtor da classe Chamada; (2) o construtor da classe Chamada e o construtor da classe Local; e (3) o construtor da classe Chamada e o adendo posterior do aspecto Faturamento. Estes pares foram escolhidos pelo fato de possuírem grafos integrados e conjun- 


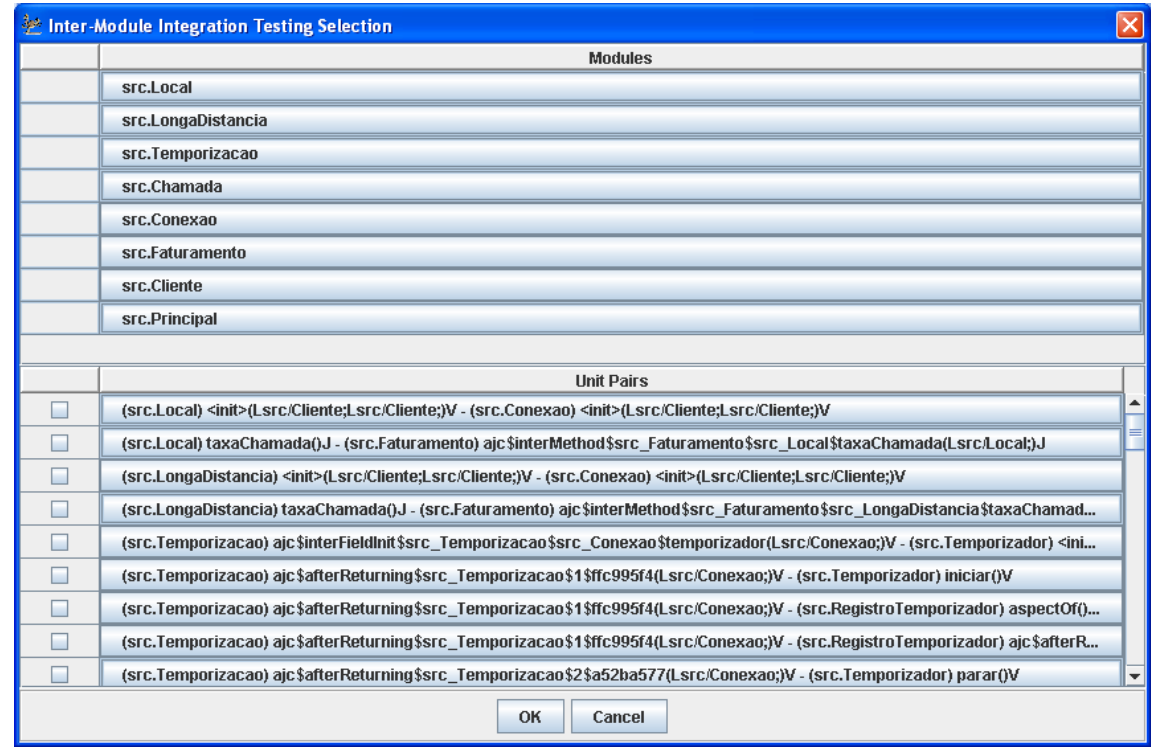

Figura 5.19: Janela de seleção dos pares de unidades inter-módulo.

tos de requisitos de teste interessantes para serem discutidos. Observe que no construtor da classe Chamada pode-se criar ou uma chamada local ou uma chamada de longa distância. Além disso, note que os pares de unidades (1) e (2) formam uma seqüência de chamadas para se realizar uma chamada local, ou seja, (1) o método chamada da classe Cliente chama o construtor da classe Chamada e (2) o construtor da classe Chamada invoca o construtor da classe Local. Por fim, vale ressaltar que em (3) o adendo posterior do aspecto Faturamento é disparado, dentro do construtor da classe Chamada, após a execução do construtor da classe LongaDistancia.

Após a seleção dos pares e confirmação da seleção, a ferramenta constrói para cada par de unidades selecionado um grafo $\mathcal{P} \mathcal{W D U}$ e calcula os requisitos de teste de cada critério de integração par-a-par. Os pares de unidades selecionados para o teste possuem a nomenclatura mostrada na Tabela 5.3. Vale ressaltar que os três pares de unidades deste exemplo são pares de unidades executáveis (ver Seção 5.2.1) e que não existe nenhum caminho não executável (definido na Seção 3.2.2) nos grafos $\mathcal{P} \mathcal{W D U}$ dos pares de unidades testados.

Tabela 5.3: Pares de unidades inter-módulo selecionados.

\begin{tabular}{|c|c|}
\hline & ar de unidades \\
\hline 1 & $\begin{array}{l}\text { (src.Cliente) chamada (Lsrc/Cliente;) Lsrc/Chamada; - (src.Chamada)<init> } \\
\text { (Lsrc/Cliente; Lsrc/Cliente;)V }\end{array}$ \\
\hline 2 & $\begin{array}{l}\text { (src.Chamada)<init>(Lsrc/Cliente; Lsrc/Cliente;)V - (src.Local)<init> } \\
(\text { Lsrc/Cliente; Lsrc/Cliente;)V }\end{array}$ \\
\hline 3 & $\begin{array}{l}\text { (src.Chamada) <init> (Lsrc/Cliente; Lsrc/Cliente;)V - (src.Faturamento) ajc\$ } \\
\text { afterReturning\$src_Faturamento\$1\$45ef75a6(Lsrc/Cliente; Lsrc/Conexao;)V }\end{array}$ \\
\hline
\end{tabular}

Os grafos $\mathcal{P W D U}$ dos pares de unidades (1), (2) e (3) são mostrados na Figura 5.20(a), Figura 5.20(b) e Figura 5.20(c), respectivamente. Esses grafos estão exibindo informações quanto ao critério Todos-Nós $s_{i}$. Os requisitos de teste derivados dos critérios Todos-Nós ${ }_{i}$, Todas-Arestas ${ }_{i}$ e 
Todos-Usos $_{i}$ dos pares de unidades (1), (2) e (3) (gerados automaticamente pela ferramenta) são mostrados na Tabela 5.4, Tabela 5.5 e Tabela 5.6, respectivamente.

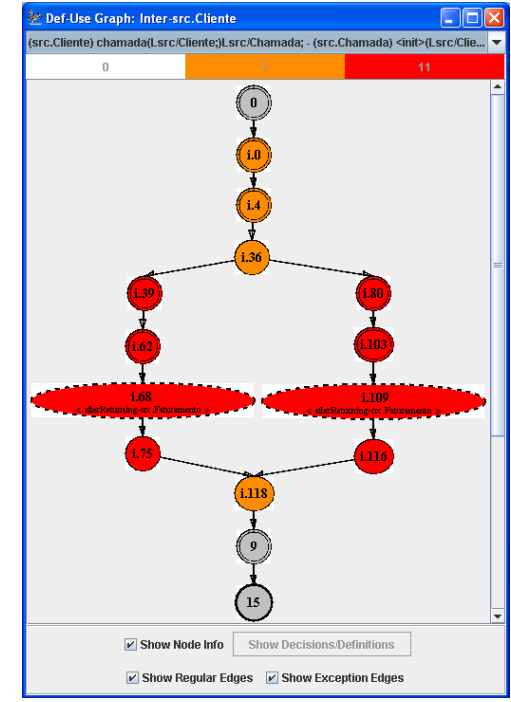

(a) Grafo $\mathcal{P W D U}$ do par de unidades (1)

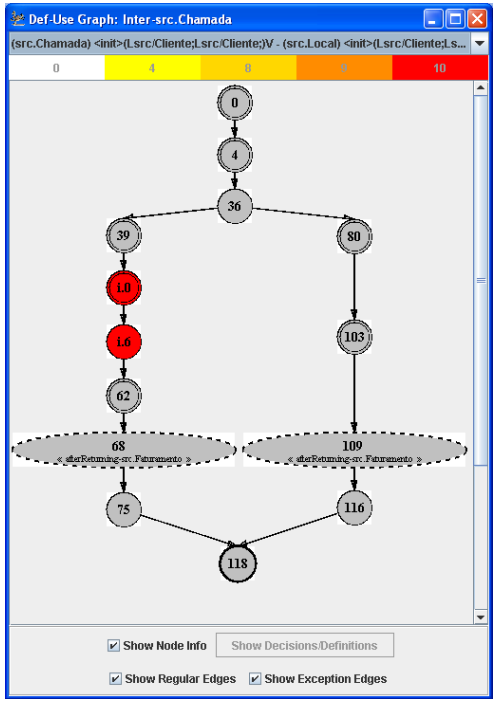

(b) Grafo $\mathcal{P} \mathcal{W D U}$ do par de unidades $(2)$

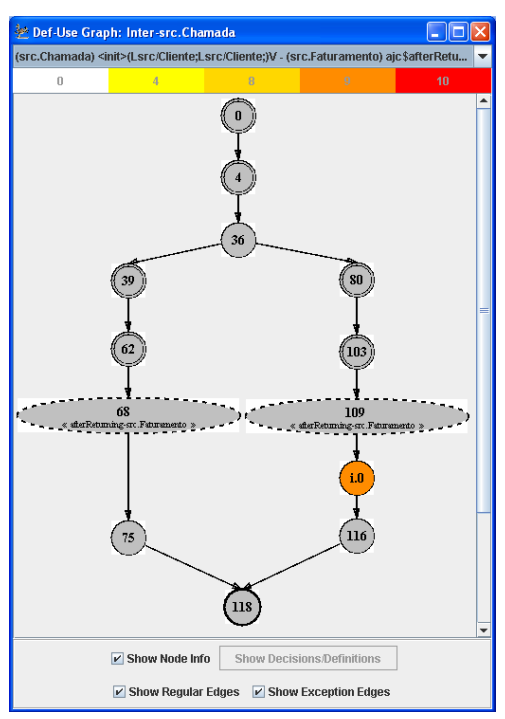

(c) Grafo $\mathcal{P W D U}$ do par de unida$\operatorname{des}(3)$

Figura 5.20: Grafos $\mathcal{P} \mathcal{W D U}$ dos pares de unidades selecionados.

Tabela 5.4: Requisitos de teste para os critérios de integração do par de unidades (1).

\begin{tabular}{|l|l|}
\hline Critério & Requisitos de Teste \\
\hline \hline Todos-Nós $_{i}$ & $i .0, i .4, i .36, i .39, i .62, i .68, i .75, i .80, i .103, i .109, i .116, i .118$ \\
\hline Todas-Arestas $_{i}$ & $(i .0, i .4),(i .4, i .36),(i .36, i .39),(i .39, i .62),(i .62, i .68),(i .68, i .75)$, \\
& $(i .75, i .118),(i .36, i .80),(i .80, i .103),(i .103, i .109),(i .109, i .116)$, \\
& $(i .116, i .118)$ \\
\hline Todos-Usos $_{i}$ & - \\
\hline
\end{tabular}

Tabela 5.5: Requisitos de teste para os critérios de integração do par de unidades (2).

\begin{tabular}{|l|l|}
\hline Critério & Requisitos de Teste \\
\hline \hline Todos-Nós $_{i}$ & $i .0, i .6$ \\
\hline Todas-Arestas $_{i}$ & $(i .0, i .6)$ \\
\hline Todos-Usos $_{i}$ & $\langle L @ 0$. chamado, $4, i .0\rangle,\langle L @ 0$. chamador $, 4, i .0\rangle$, \\
& $\langle L @ 0$. chamado, $4, i .6\rangle,\langle L @ 0$. chamador $, 4, i .6\rangle,\langle L @ 4,39, i .0\rangle$, \\
& $\langle L @ 5,39, i .0\rangle,<L @ 4,39, i .6\rangle,\langle L @ 5,39, i .6\rangle$ \\
\hline
\end{tabular}

Tabela 5.6: Requisitos de teste para os critérios de integração do par de unidades (3).

\begin{tabular}{|c|c|}
\hline Critério & Requisitos de Teste \\
\hline Todos-Nós $i$ & $i .0$ \\
\hline Todas-Arestas $_{i}$ & - \\
\hline Todos-Usos $_{i}$ & $<L @ 0$. chamador $, 4, i .0>,<L @ 8,80, i .0>,<L @ 9,103, i .0>$ \\
\hline
\end{tabular}

Com base nos requisitos de teste derivados pelos critérios de integração par-a-par, o testador pode então criar conjuntos de casos de teste adequados para cobrir esses requisitos. A execução 
de um caso de teste percorre um determinado caminho no fluxo do programa. A partir do caminho percorrido, a ferramenta verifica quais nós, quais arestas e quais pares de def-uso foram exercitados. A classe TelecomJUnit (Figura 5.21), escrita utilizando JUnit, contém dois casos de teste. O caso de teste testChamadaLocal simula uma ligação entre dois clientes com o mesmo código de área, enquanto que o caso de teste testChamadaLongaDistancia efetua uma ligação entre dois clientes com códigos de área distintos.

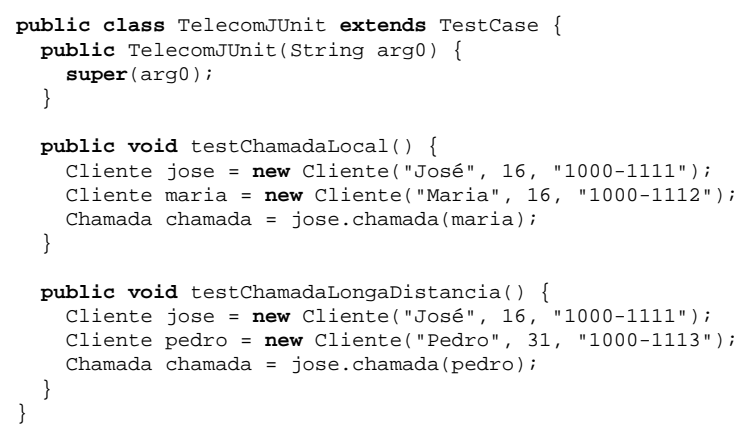

Figura 5.21: Classe contendo um conjunto de casos de teste da aplicação de telefonia.

Primeiramente, executa-se o caso de teste testChamadaLocal. Esse caso de teste percorre o caminho $(i .0, i .4, i .36, i .39, i .62, i .68, i .75, i .118)$ do grafo $\mathcal{P} \mathcal{W} \mathcal{D U}$ de $(1)$ e o caminho $(i .0, i .6)$ do grafo $\mathcal{P} \mathcal{W D U}$ de (2). O grafo $\mathcal{P} \mathcal{W} \mathcal{D U}$ de (3) não é afetado. O grafo $\mathcal{P} \mathcal{W} \mathcal{D U}$ de (1) e (2) após a execução de testLocalCall são mostrados nas Figuras 5.22(a) e 5.22(b), respectivamente. Esses grafos são utilizados para analisar a cobertura quanto ao critério Todos-Nós ${ }_{i}$. Os nós integrados cobertos aparecem no grafo com a cor branca. Nas Tabelas 5.7, 5.8 e 5.9 são mostrados os requisitos de teste cobertos e os não cobertos dos pares de unidades (1), (2) e (3) após a execução de testlocalcall. Como pode-se observar nessas tabelas, a execução do caso de teste testLocalCall cobriu parcialmente os requisitos do par de unidades (1). Já no par de unidades (2) o caso de teste atingiu uma cobertura total dos requisitos. Por fim, como o par de unidades (3) não é afetado pelo caso de teste, nenhum dos requisitos de seu conjunto de requisitos é coberto.

Tabela 5.7: Cobertura dos requisitos do par de unidades (1) após a execução do caso de teste

\begin{tabular}{|c|c|c|c|}
\hline Critério & Requisitos não cobertos & Requisitos cobertos & $\%$ cobertura \\
\hline Todos-Nós $_{i}$ & $i .80, i .103, i .109, i .116$ & $\begin{array}{l}i .0, i .4, i .36, i .39, i .62, i .68, i .75, \\
i .118\end{array}$ & $66 \%$ \\
\hline Todas-Arestas $_{i}$ & $\begin{array}{l}(i .36, i .80),(i .80, i .103), \\
(i .103, i .109),(i .109, i .116), \\
(i .116, i .118)\end{array}$ & $\begin{array}{l}(i .0, i .4),(i .4, i .36),(i .62, i .68), \\
(i .36, i .39),(i .39, i .62),(i .68, i .75), \\
(i .75, i .118)\end{array}$ & $58 \%$ \\
\hline Todos-Usos $_{i}$ & - & - & - \\
\hline
\end{tabular}

Após a execução do caso de teste testChamadaLocal, executa-se o caso de teste testChamadaLongaDistancia com a finalidade de cobrir os requisitos que ainda não foram cobertos. Esse caso de teste percorre o caminho $(i .0, i .4, i .36, i .80, i .103, i .109, i .116,1.118)$ do grafo 


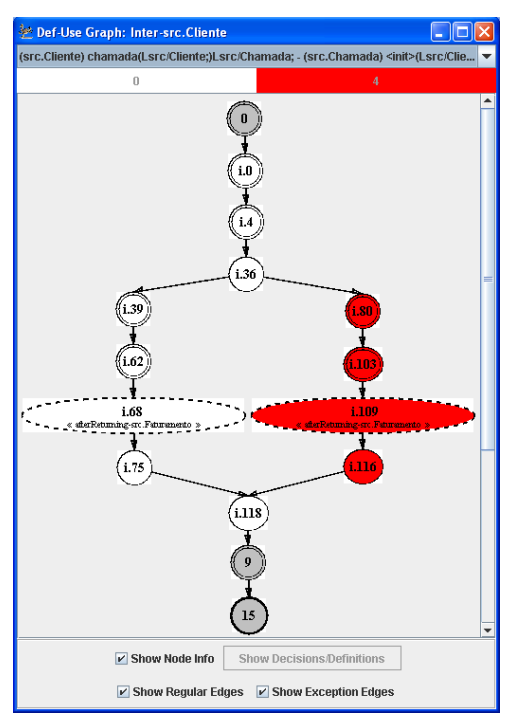

(a)

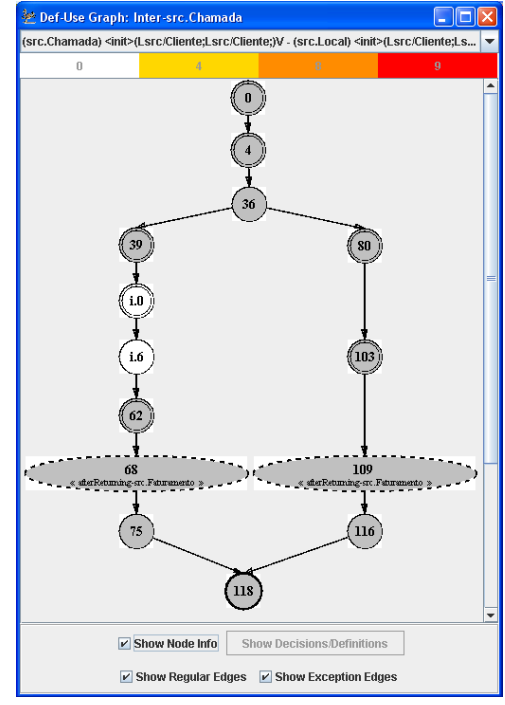

(b)

Figura 5.22: Grafos $\mathcal{P W D U}$ dos pares de unidades (1) e (2) após a execução do caso de teste testChamadaLocal.

Tabela 5.8: Cobertura dos requisitos do par de unidades (2) após a execução do caso de teste

\begin{tabular}{|c|c|c|c|}
\hline Critério & $\begin{array}{l}\text { Requisitos } \\
\text { não cobertos }\end{array}$ & Requisitos cobertos & \% cobertura \\
\hline Todos-Nós $_{i}$ & - & $i .0, i .6$ & $100 \%$ \\
\hline Todas-Arestas $_{i}$ & - & $(i .0, i .6)$ & $100 \%$ \\
\hline Todos-Usos $_{i}$ & - & $\begin{array}{l}<L @ 0 . \text { chamado } 4, i .0>,<L @ 0 . \text { chamador }, 4, i .0> \\
<L @ 0 . \text { chamado, } 4, i .6>,<L @ 0 . \text { chamador } 4, i .6> \\
<L @ 4,39, i .0>,<L @ 5,39, i .0>,<L @ 4,39, i .6>, \\
<L @ 5.39, i .6>\end{array}$ & $100 \%$ \\
\hline
\end{tabular}

Tabela 5.9: Cobertura dos requisitos do par de unidades (3) após a execução do caso de teste test ChamadaLocal.

\begin{tabular}{|l|l|l|c|}
\hline Critério & Requisitos não cobertos & Requisitos cobertos & \% cobertura \\
\hline \hline Todos-Nós $_{i}$ & $i .0$ & - & $0 \%$ \\
\hline Todas-Arestas $_{i}$ & - & - & - \\
\hline Todos-Usos $_{i}$ & $\begin{array}{l}\langle L @ 0 . \text { chamador }, 4, i .0>,<L @ 8,80, i .0>, \\
\langle L @ 9,103, i .0>\end{array}$ & - & $0 \%$ \\
\hline
\end{tabular}

$\mathcal{P W D U}$ de (1) e o caminho (i.0) do grafo $\mathcal{P} \mathcal{W D U}$ de (3). O grafo $\mathcal{P} \mathcal{W} \mathcal{D U}$ de (2) não é percorrido por este caso de teste. Na Figura 5.23(a) e 5.23(b) são mostrados o grafo $\mathcal{P} \mathcal{W} \mathcal{D U}$ de (1) e (3), respectivamente, após a execução do caso de teste testChamadaLongaDistancia. Esses grafos são utilizados para analisar a cobertura quanto ao critério Todos-Nós ${ }_{i}$. Nas Tabelas 5.10 e 5.11 são exibidos os requisitos de teste cobertos e os não cobertos dos pares de unidades (1) e (3) após a execução de test ChamadaLongaDistancia. Como pode-se observar nessas tabelas, a execução do caso de teste testChamadaLongaDistancia cobriu totalmente os requisitos do par de unidades (1) e os requisitos do par de unidades (3). 


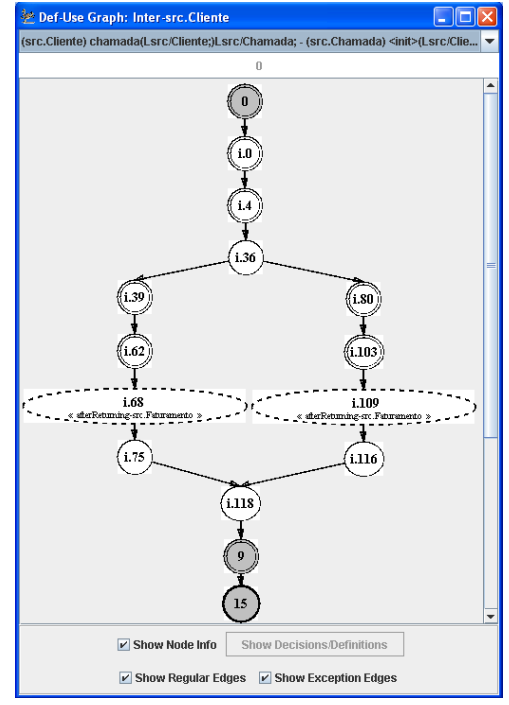

(a)

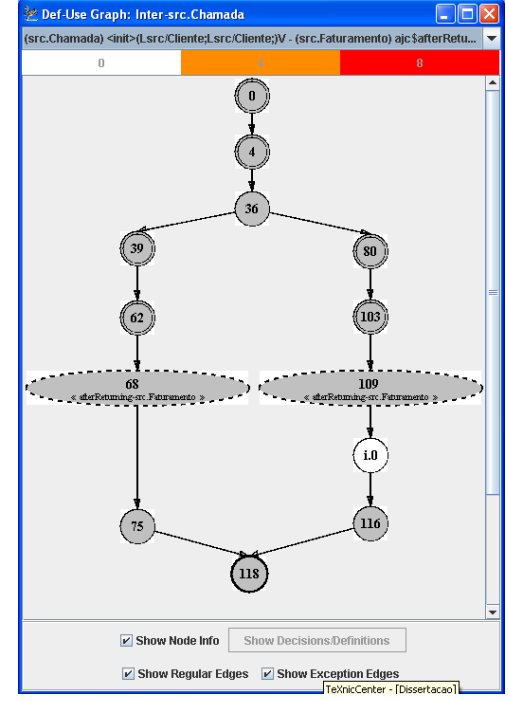

(b)

Figura 5.23: Grafos $\mathcal{P W D U}$ dos pares de unidades (1) e (3) após a execução do caso de teste testChamadaLongaDistancia.

Tabela 5.10: Cobertura dos requisitos do par de unidades (1) após a execução do caso de teste test ChamadaLongaDistancia.

\begin{tabular}{|c|c|c|c|}
\hline Critério & $\begin{array}{l}\text { Requisitos } \\
\text { não cobertos }\end{array}$ & Requisitos cobertos & \% cobertura \\
\hline Todos-Nós $_{i}$ & - & $\begin{array}{l}i .0, i .4, i .36, i .39, i .62, i .68, i .75, i .80, i .103, i .109, \\
i .116, i .118\end{array}$ & $100 \%$ \\
\hline Todas-Arestas $_{i}$ & - & $\begin{array}{l}(i .0, i .4),(i .4, i .36),(i .36, i .39),(i .39, i .62),(i .62, i .68), \\
(i .68, i .75),(i .75, i .118),(i .36, i .80),(i .80, i .103), \\
(i .103, i .109),(i .109, i .116),(i .116, i .118)\end{array}$ & $100 \%$ \\
\hline Todos-Usos $_{i}$ & - & - & - \\
\hline
\end{tabular}

Tabela 5.11: Cobertura dos requisitos do par de unidades (3) após a execução do caso de teste testChamadaLongaDistancia.

\begin{tabular}{|c|c|c|c|}
\hline Critério & $\begin{array}{l}\text { Requisitos } \\
\text { não cobertos }\end{array}$ & Requisitos cobertos & $\%$ cobertura \\
\hline Todos-Nós ${ }_{i}$ & 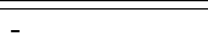 & $i .0$ & $100 \%$ \\
\hline Todas-Arestas $_{i}$ & - & - & - \\
\hline Todos-Usos $_{i}$ & - & $\begin{array}{l}<L @ 0 . \text { chamador }, 4, i .0>,<L @ 8,80, i .0>, \\
<L @ 9,103, i .0>\end{array}$ & $100 \%$ \\
\hline
\end{tabular}

Após a execução dos dois casos de teste conseguiu-se atingir a cobertura total $(100 \%)$ dos

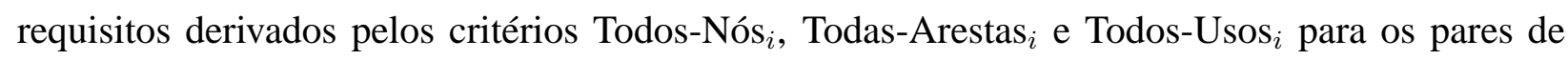
unidades (1), (2) e (3). Assim, o testador pode parar de gerar casos de teste e concluir que o teste dos pares de unidades, empregando a abordagem de teste estrutural de integração par-a-par aqui proposta, foi realizada com sucesso. A partir daí, o testador pode utilizar outras técnicas de teste (por exemplo, testes funcionais) com a finalidade de descobrir defeitos que ainda possam estar presentes no programa. 


\subsubsection{Segundo Exemplo de Uso}

Neste segundo exemplo é analisado um programa simples que ordena um array (vetor) de inteiros em ordem crescente e calcula o valor médio do primeiro e último elemento. Este programa contém a classe Principal que implementa dois métodos, calcularMediaPriUltElem e ordenarArray, e o aspecto Verificacao que implementa o adendo anterior (before) responsável por verificar se o array está ordenado e definir o atributo estático at i varOrdenacao, que informa se a ordenação esta ativa ou não. O código-fonte do programa é mostrado na Figura 5.24 .

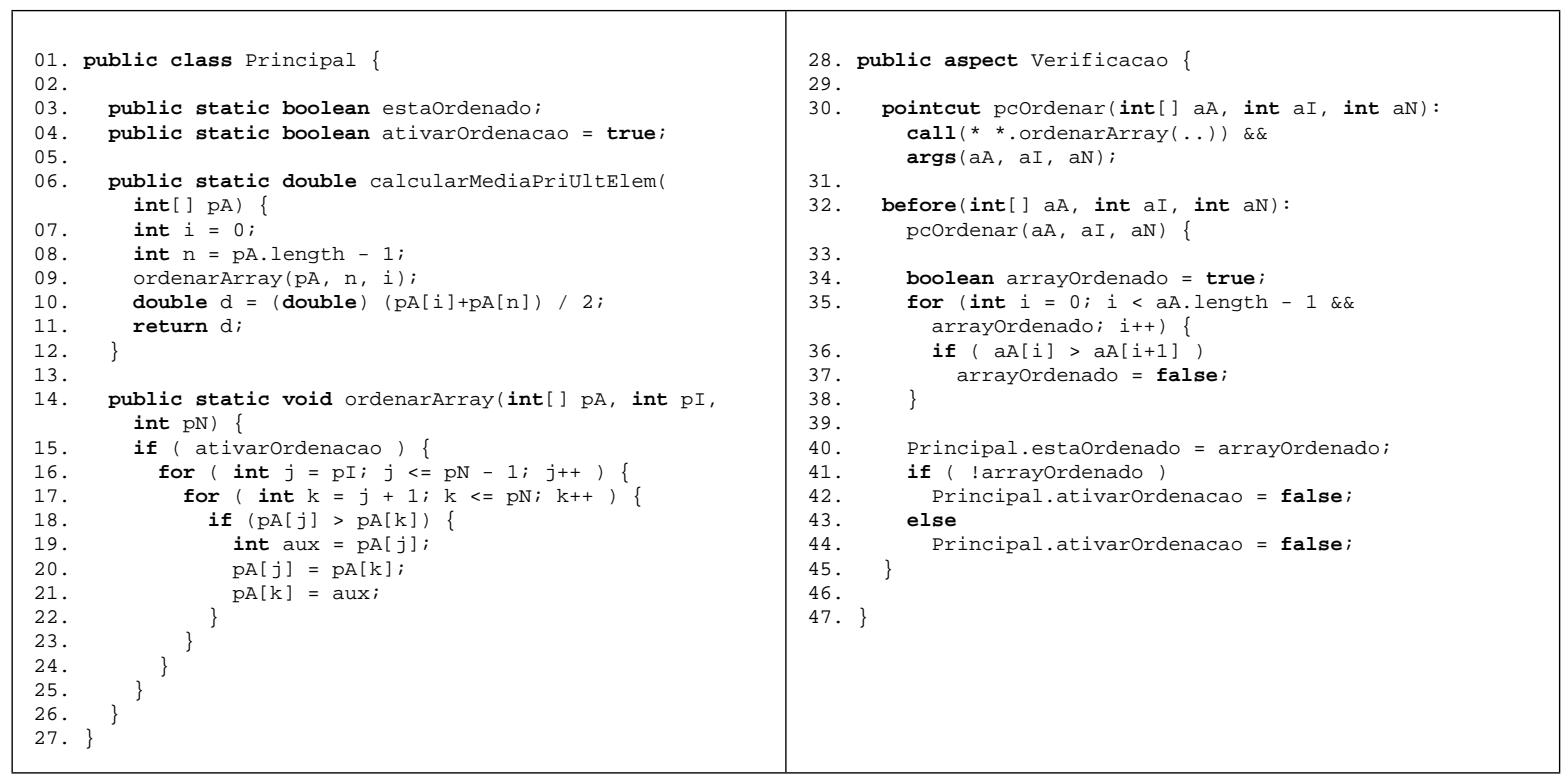

Figura 5.24: Código-fonte do programa de ordenação de array.

A estratégia de teste utilizada para revelar defeitos que ainda possam existir no programa foi baseada no trabalho de Massicotte et al. (2007). Primeiro são testados individualmente os métodos implementados nas classes e as interações par-a-par entre eles sem a interferência dos aspectos; posteriormente, os aspectos são combinados com as classes que eles afetam e, em seguida, são testados os adendos isoladamente e as interações par-a-par entre as unidades que se relacionam.

Assim, para este exemplo é estabelecido o seguinte plano de teste: passo A, efetuar o teste de unidade do método calcularMediaPriUltElem; passo B, efetuar o teste de unidade do método ordenarArray; passo $\mathrm{C}$, realizar o teste de integração par-a-par do par de unidades calcularMediaPriUltElem - ordenarArray sem a interferência do aspecto Verificacao; passo D, o aspecto Verificacao é combinado ao programa e, em seguida, é realizado o teste de unidade do adendo before; passo E, efetuar o teste de integração par-a-par do par de unidades calcularMediaPriUltElem - before; passo F, realizar o teste de integração para-par do par de unidades calcularMediaPriUltElem - ordenarArray com a presença do aspecto. É importante ressaltar que, neste exemplo, todos os pares de unidades são executáveis (ver Seção 5.2.1) e que não existe nenhum caminho não executável (definido na Seção 3.2.2) nos grafos $\mathcal{P W D U}$ dos pares de unidades testados. 
Para executar o passo A, que tem como finalidade testar o método cal cularMediaPriUltElem individualmente, é criado o conjunto de casos de teste, escrito em JUnit (Figura 5.25), representado na forma de par ordenado $(d, S(d))$ (discutido na Seção 3.2) como: $\{([2,7,10,17,22]$, $6),([22,17,10,7,2], 6),([17,2,22,10,7], 6)\}$. Supõe-se que o testador usou algum critério funcional para criar o conjunto de casos de teste. Observe que no primeiro caso de teste é utilizado um array já ordenado em ordem crescente como elemento de entrada (ou seja, $d$ ). No segundo caso de teste é passado como elemento de entrada um array cujos dados estão ordenados, porém em ordem decrescente. Por fim, o terceiro caso de teste contém um array em que os dados estão desordenados aleatoriamente. Esses mesmos elementos de entrada serão utilizados nos próximos conjuntos de casos de testes criados e apresentados mais adiante.

Além disso, ainda no passo A, é criada uma nova classe, a classe Stub (Figura 5.26), que define uma unidade pseudo-controlada (stub) do método ordenarArray da classe Principal. O método pseudo-controlado criado é executado no lugar do método verdadeiro durante o teste de unidade do método calcularMediaPriUltElem. Ele altera o array inserindo os valores 4 e 8 na primeira e última posições do array, respectivamente, simulando uma ordenação. Utilizando a ferramenta JUnit observa-se que a execução dos casos de teste é realizado com sucesso (Figura 5.27) e produz os resultados esperados, ou seja, o valor de retorno do método calcularMediaPriultelem é 6 (média da soma entre 4 e 8). Com o apoio da ferramenta JaBUTi/AJ verifica-se que a cobertura dos requisitos de teste gerados pelos critérios de teste de unidade após a execução dos casos de teste atinge $100 \%{ }^{2}$. Na Figura 5.28 é mostrado o grafo $\mathcal{A O D U}$ do método calcularMediapriUltElem, analisando a cobertura alcançada para o critério todos-nós-independentes-de-exceção. Observa-se que para esse critério todos os nós foram cobertos.

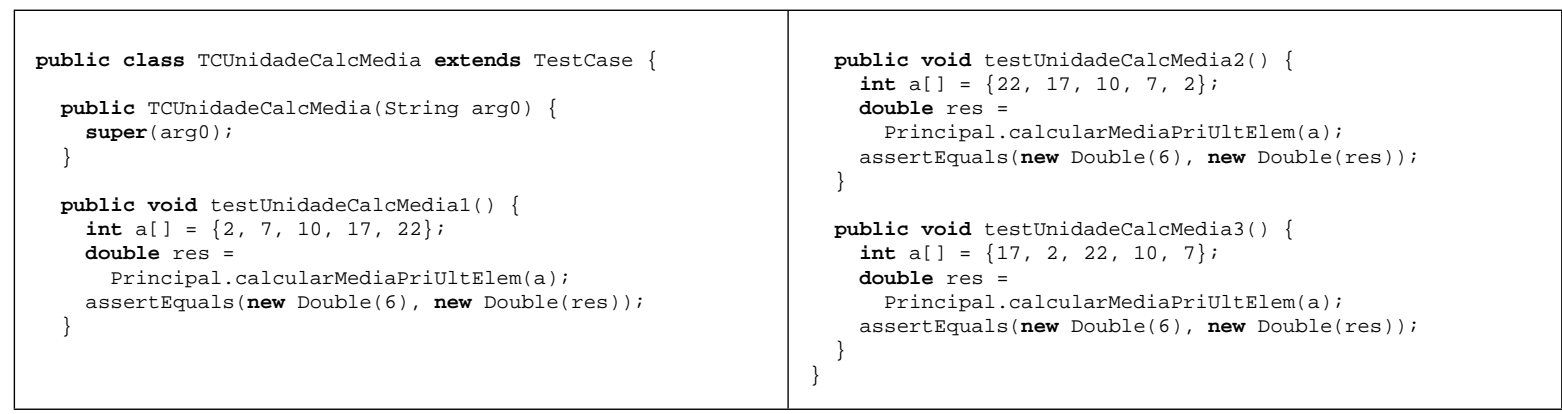

Figura 5.25: Casos de teste criados para o teste de unidade de calcularMediaPriUltElem.

O passo B tem o objetivo de efetuar o teste de unidade do método ordenarArray. Para isso, é criado o conjunto de casos de teste, escrito em JUnit (Figura 5.29), representado como: $\{([2,7,10,17,22],[2,7,10,17,22]),([22,17,10,7,2],[2,7,10,17,22]),([17,2,22,10,7],[2,7,10$, $17,22])\}$. Com o apoio da ferramenta JUnit observa-se que a execução dos casos de teste produz os resultados esperados, ou seja, o método ordenarArray retorna um array ordenado. Analisando a

\footnotetext{
${ }^{2}$ Neste exemplo não são mostrados quais são os requisitos de teste cobertos e não cobertos pela execução do conjunto de casos de teste
} 


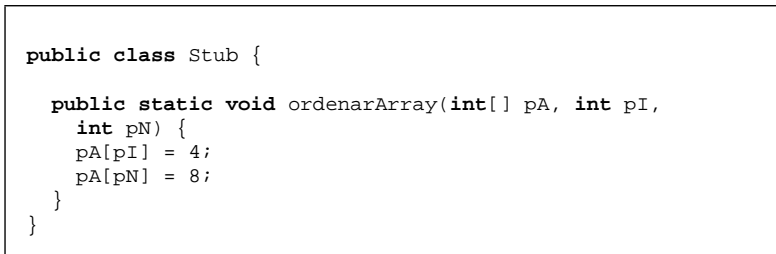

Figura 5.26: Classe Stub utilizada no passo A.

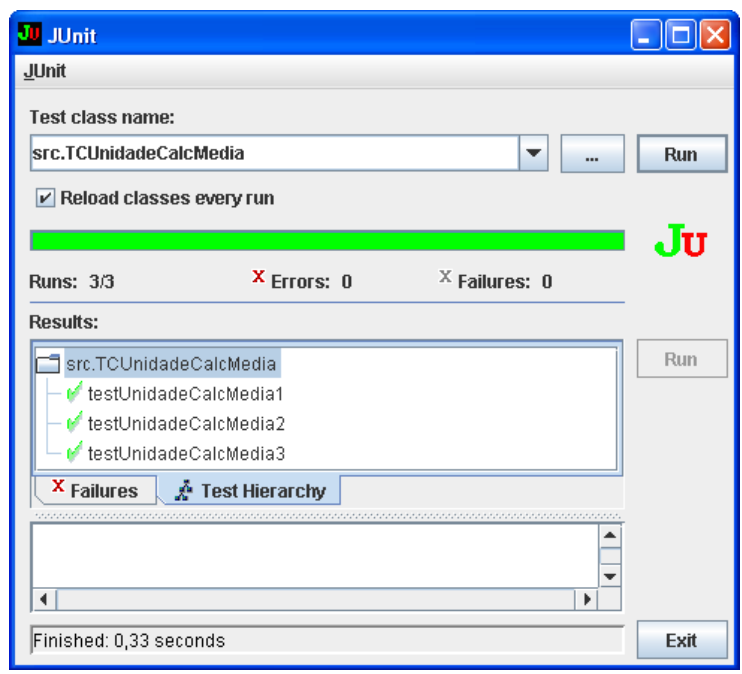

Figura 5.27: Tela da ferramenta JUnit mostrando que os casos de teste foram executados com sucesso.

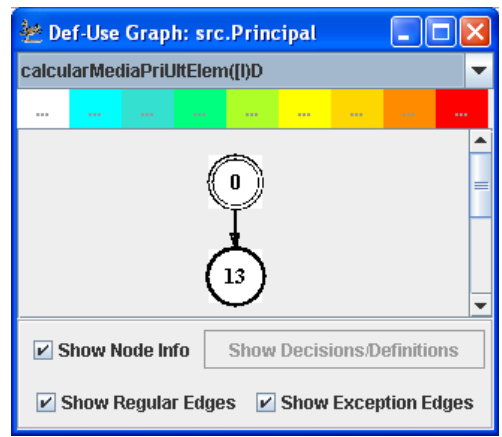

Figura 5.28: Grafo $\mathcal{A O D U}$ do método calcularMediaPriUltElem mostrando a cobertura alcançada para o critério todos-nós-independentes-de-exceção.

cobertura alcançada pela execução desses casos de teste na ferramenta JaBUTi/AJ, constata-se que foi possível cobrir todos os requisitos derivados pelos critérios de teste de unidade da ferramenta. Na Figura 5.30 é mostrado o grafo $\mathcal{A O D U}$ do método ordenarArray, analisando a cobertura alcançada para o critério todos-nós-independentes-de-exceção. Como pode-se observar, todos os nós foram cobertos.

A partir desses testes, pode-se concluir que os testes de unidade das unidades do programa foram realizados com sucesso e que nenhum erro foi revelado até o momento. Supõe-se que o testador aceite por enquanto estas unidades como corretas e decida encerrar o teste de unidade. 


\begin{tabular}{|c|c|}
\hline $\begin{array}{l}\text { public class TCUnidadeOrdenar extends TestCase }\{ \\
\text { public TCUnidadeOrdenar(String arg } 0)\} \\
\text { super(arg0); } \\
\text { public void testUnidadeOrdenar } 1()\} \\
\text { int a }[]=\{2,7,10,17,22\} ; \\
\text { Principal.ordenarArray }(a, 0,4) ; \\
\text { int aux }[]=\{2,7,10,17,22\} \\
\text { for (int } i=0 ; i<\text { a.length; } i++) \\
\text { assertEquals }(a[i], \operatorname{aux}[i]) ; \\
\text { \} }\end{array}$ & $\begin{array}{l}\text { public void testUnidadeordenar2() } \\
\text { int a }[]=\{22,17,10,7,2\} ; \\
\text { Principal.ordenarArray }(a, 0,4) ; \\
\text { int aux }[]=\{2,7,10,17,22\} ; \\
\text { for (int } i=0 ; i<a .1 \text { ength; } i++) \\
\text { assertEquals }(a[i], \operatorname{aux}[i]) ; \\
\} \\
\text { public void testUnidadeOrdenar3() } \\
\text { int a }[]=\{17,2,22,10,7\} ; \\
\text { Principal.ordenarArray }(a, 0,4) ; \\
\text { int aux }[]=\{2,7,10,17,22\} ; \\
\text { for (int } i=0 ; i<\operatorname{a.length} ; i++) \\
\text { assertEquals }(a[i], \operatorname{aux}[i]) ; \\
\text { \} }\end{array}$ \\
\hline
\end{tabular}

Figura 5.29: Casos de teste criados para o teste de unidade do método ordenarArray.

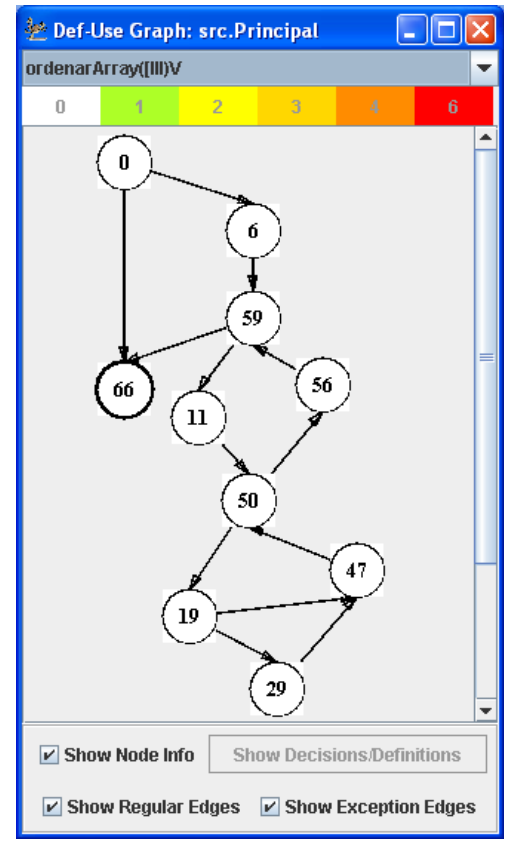

Figura 5.30: Grafo $\mathcal{A O D U}$ do método ordenarArray mostrando a cobertura alcançada para o critério todos-nós-independentes-de-exceção.

O passo C, cujo objetivo é testar a integração par-a-par do par de unidades ca l cularMediaPriUltElem - ordenarArray, é efetuado após a realização dos testes de unidades. Para isso, é criado o conjunto de casos de teste, escrito em JUnit (Figura 5.31), representado como: $\{([2,7,10,17,22], 12),([22,17,10,7,2], 12),([17,2,22,10,7], 12)\}$. Vale ressaltar que são utilizados os mesmos elementos de entrada empregados no teste de unidade. Utilizando a ferramenta JUnit observa-se que a execução dos casos de teste é realizada com sucesso e produz os resultados esperados, ou seja, o valor médio da soma entre menor e o maior elemento do array (2 e 22 , respectivamente) é calculado corretamente pelo método calcularMediaPriUltElem que retorna o valor 12. Com o apoio da ferramenta JaBUTi/AJ, pode-se analisar a cobertura alcançada pela execução dos casos de teste. Entretanto, após a execução constata-se que alguns requisitos de teste derivados pelos critérios de teste de integração par-a-par não foram cobertos. $\mathrm{Na} \mathrm{Fi-}$ gura 5.32(a) é mostrado o grafo $\mathcal{P W D U}$ do par de unidades calcularMediaPriUltElem - 
ordenarArray, analisando a cobertura alcançada para o critério todos-nós-integrados. Nesta figura, observa-se que os nós integrados $i .11, i .19, i .29, i .47, i .50$ e $i .56$ não foram exercitados.

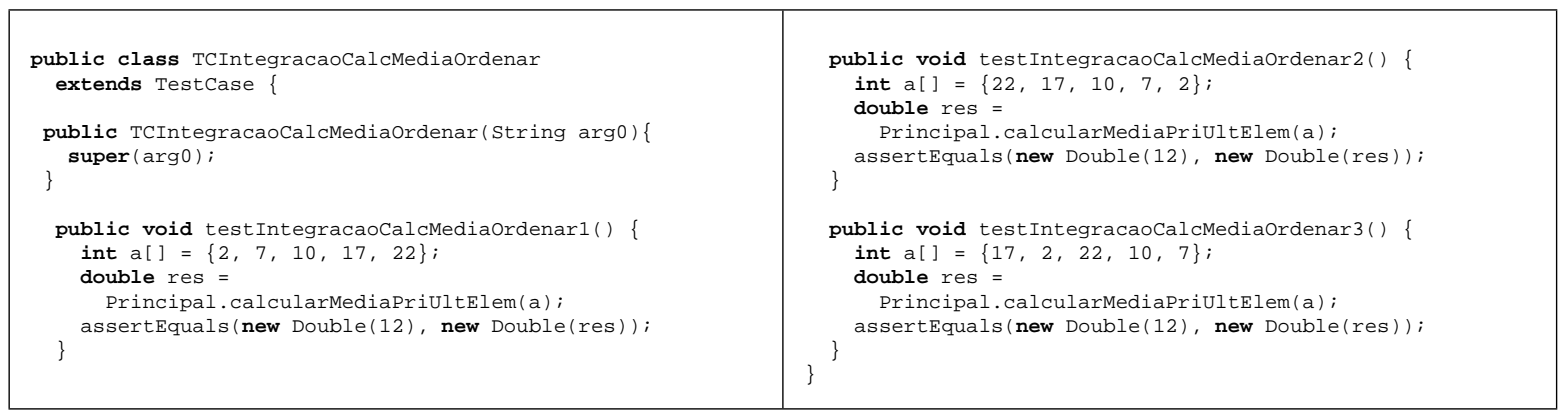

Figura 5.31: Casos de teste criados para o teste de integração de calcularMediaPriUltElem - ordenarArray.

Novos casos de teste podem ser gerados para tentar cobrir os requisitos de teste que ainda não foram exercitados. Porém, provavelmente eles não terão sucesso porque, analisando o grafo $\mathcal{P W D U}$ (e com o auxílio do bytecode e do código-fonte dos métodos), observa-se que os laços responsáveis pela ordenação do array, implementados no método ordenarArray, não estão sendo executados corretamente. Deste modo, nota-se que ao efetuar o teste de integração dos métodos calcularMediaPriUltElem e ordenarArray um erro ocorre, ou seja, um possível defeito existe na interface entre os métodos testados. Analisando o código-fonte do programa (Figura 5.24) é constatado que, realmente, existe um defeito na linha 09 . O desenvolvedor cometeu um engano na ordem em que os parâmetros reais i (primeiro elemento) e n (último elemento) foram passados. O correto seria passar o $i$ como segundo argumento e o n como terceiro argumento e não como foi codificado.

Após a correção do defeito, é necessário efetuar novamente os passos A e C para assegurar que nenhum outro defeito foi inserido. O teste de unidade do método cal cularMediaPriUltElem (passo A) é realizado com sucesso, isto é, com o JUnit se obtém o resultado esperado e utilizando a JaBUTi/AJ verifica-se que todos os requisitos são cobertos. O mesmo ocorre com o teste de integração par-a-par do par de unidades calcularMediaPriUltElem - ordenarArray (passo C). Na Figura 5.32(b) é mostrado o grafo $\mathcal{P W D U}$ do par de unidades calcularMediaPriUltElem - ordenarArray, analisando a cobertura alcançada para o critério todos-nós-integrados, após a correção do programa.

No próximo passo, o passo D, o aspecto Verificacao é combinado no programa e, em seguida, é realizado o teste de unidade do adendo before. Para isso é criado o conjunto de casos de teste $\{([2,7,10,17,22]$, true $),([22,17,10,7,2]$, false $),([17,2,22,10,7]$, false $)\}$ que é composto pelos mesmos elementos de entrada utilizados anteriormente e é apresentado na Figura 5.33. Com o apoio da ferramenta JUnit observa-se que a execução dos casos de teste produz os resultados esperados. Utilizando a ferramenta JaBUTi/AJ pode-se verificar que a cobertura alcançada pela execução dos casos de teste cobre $100 \%$ dos requisitos de teste gerados pelos critérios de teste de 


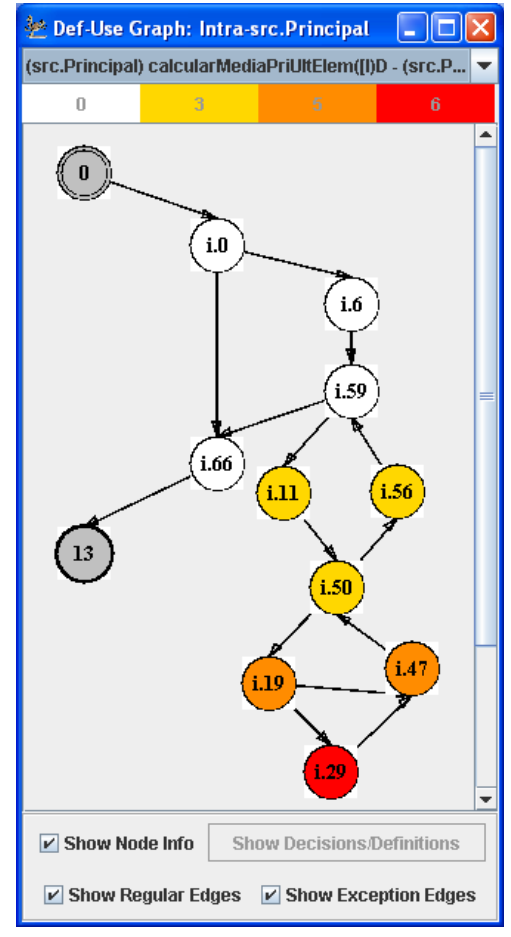

(a) Com o defeito

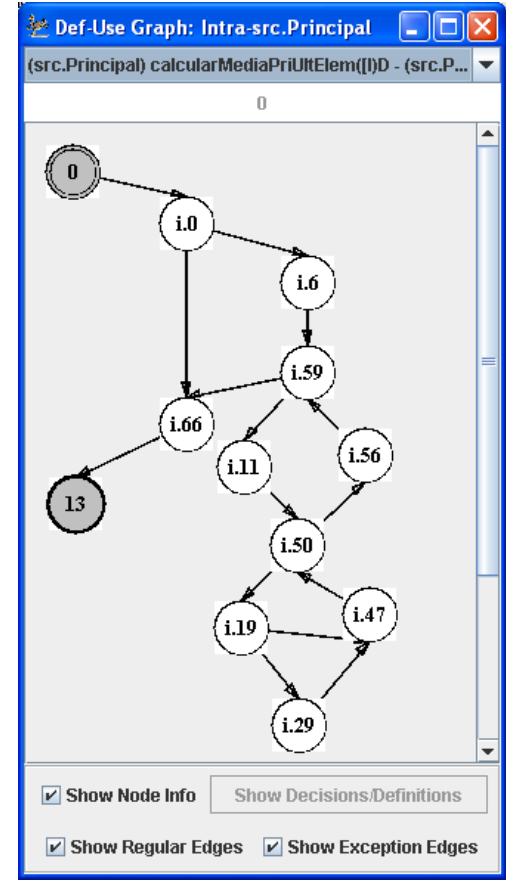

(b) Sem o defeito

Figura 5.32: Grafo $\mathcal{P} \mathcal{W D U}$ do par de unidades calcularMediaPriUltElem ordenarArray mostrando a cobertura alcançada para o critério todos-nós-integrados.

unidade para o adendo before. Na Figura 5.34 é mostrado o grafo $\mathcal{A O D U}$ do adendo before, analisando a cobertura alcançada para o critério todos-nós-independentes-de-exceção.

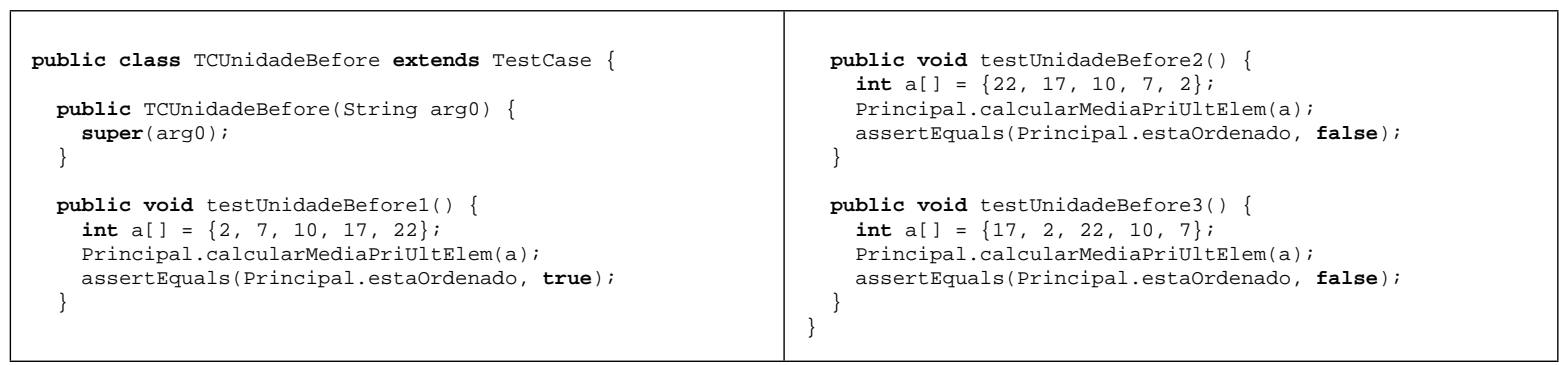

Figura 5.33: Casos de teste criados para o teste de unidade do adendo before.

No passo E é efetuado o teste de integração par-a-par do par de unidades calcularMediaPriUltElem - before. Para isso utiliza-se o conjunto de casos de teste apresentado na Figura 5.31. Esses casos de teste são executados com sucesso na ferramenta JUnit. Observando a cobertura alcançada pela execução dos casos de teste na JaBUTi/AJ, constata-se que é obtido $100 \%$ de cobertura dos requisitos derivados pelos critérios de integração par-a-par. Na Figura 5.35 é mostrado o grafo $\mathcal{P W D U}$ do par de unidades calcularMediaPriUltElem - before, analisando a cobertura alcançada para o critério todos-nós-integrados.

$\mathrm{O}$ último passo, o passo $\mathrm{F}$, tem como objetivo testar a integração par-a-par do par de unidades calcularMediaPriUltElem - ordenarArray com a presença do aspecto. Neste teste, é utilizado o conjunto de casos de teste apresentado na Figura 5.31. Esses casos de teste são exe- 


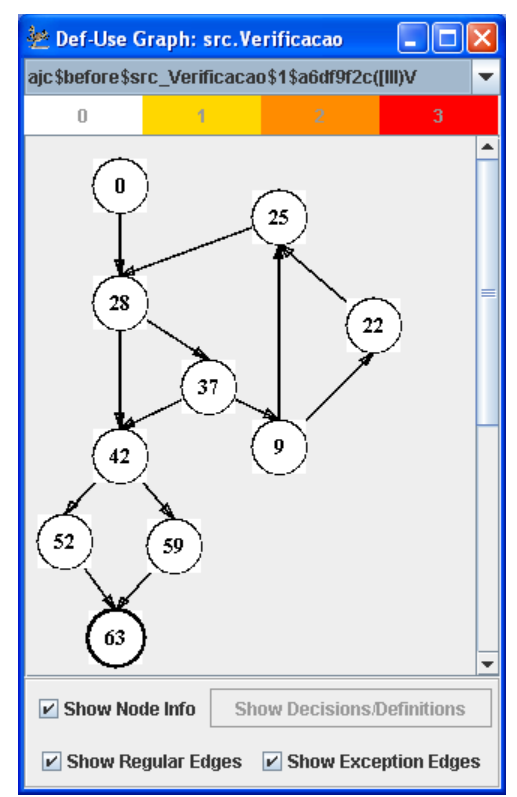

Figura 5.34: Grafo $\mathcal{A O D U}$ do adendo before mostrando a cobertura alcançada para o critério todos-nós-independentes-de-exceção.

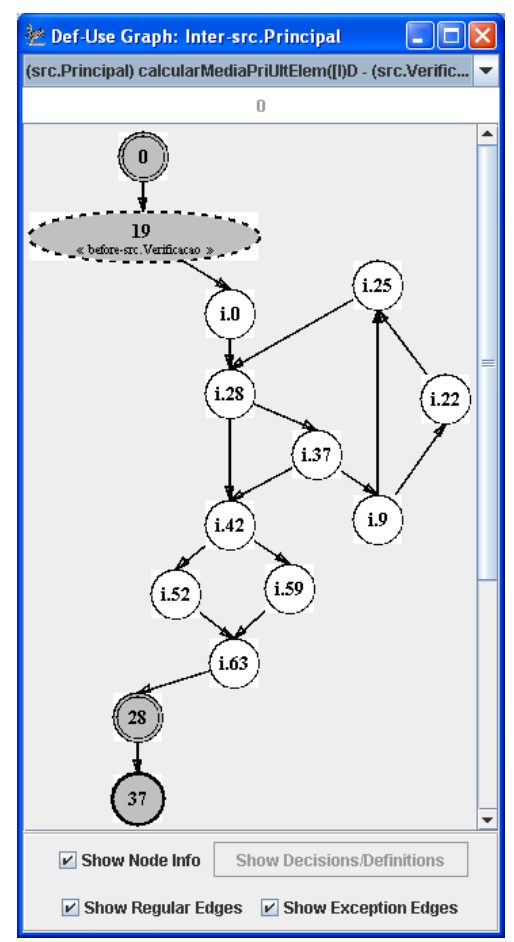

Figura 5.35: Grafo $\mathcal{P} \mathcal{W} \mathcal{D} U$ do par de unidades calcularMediaPriUltElem - before mostrando a cobertura alcançada para o critério todos-nós-integrados.

cutados com sucesso na ferramenta JUnit. Com o apoio da ferramenta JaBUTi/AJ constata-se que, após a execução dos casos de teste, alguns requisitos de teste derivados pelos critérios de teste de integração par-a-par não foram cobertos. Na Figura 5.36(a) é mostrado o grafo $\mathcal{P} \mathcal{W} \mathcal{D} \mathcal{U}$ do par de unidades calcularMediaPriultElem - ordenarArray, analisando a cobertura alcançada para o critério todos-nós-integrados. A partir dele, observa-se que somente o pri- 
meiro nó e o último nó integrado estão sendo exercitados. Analisando o código-fonte do método ordenarArray (Figura 5.24), constata-se que o defeito está provavelmente no valor da atributo estático ativarordenacao. Além disso, verifica-se que a última definição desse atributo é feita dentro do adendo before. Como resultado dessa análise, o defeito é localizado na linha 42. Ao invés de receber o valor true, ou seja, ativar a ordenação se o array não estiver ordenado, o atributo ativarordenacao está recebendo o valor false.

O programa é corrigido e, em seguida, os passos D, E e F são executados novamente para assegurar que, com a alteração do código-fonte, nenhum outro defeito foi inserido. O teste de unidade do adendo before (passo D) é realizado com sucesso, isto é, com o JUnit se obtém o resultado esperado e utilizando a JaBUTi/AJ verifica-se que todos os requisitos são cobertos. O mesmo ocorre com o teste de integração do par de unidades calcularMediaPriUltElem - before (passo E) e do par de unidades calcularMediaPriUltElem - ordenarArray (passo F). Na Figura 5.36(b) é mostrado o grafo $\mathcal{P W D U}$ do par de unidades calcularMediaPriUltElem ordenarArray, analisando a cobertura alcançada para o critério todos-nós-integrados, após a correção do programa.

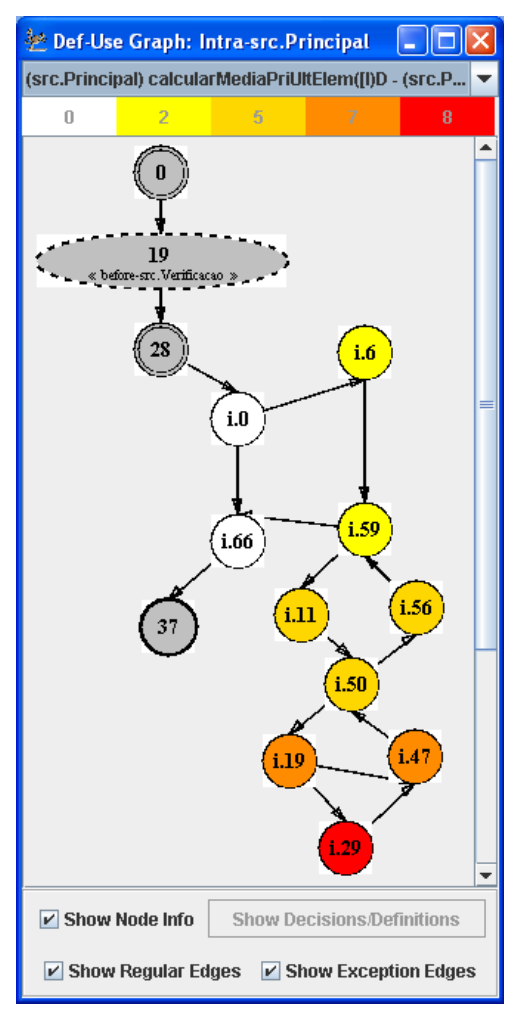

(a) Com o defeito

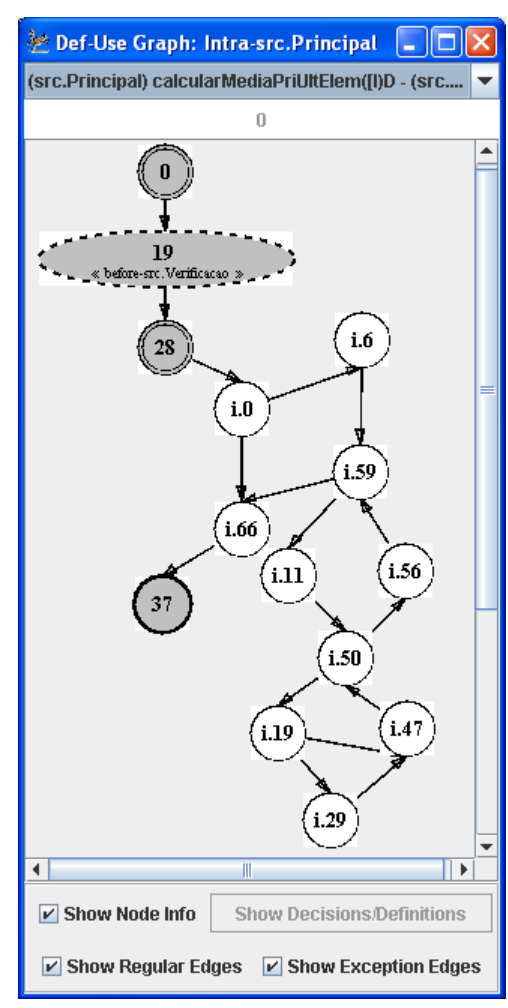

(b) Sem o defeito

Figura 5.36: Grafo $\mathcal{P W D U}$ do par de unidades calcularMediaPriUltElem ordenarArray mostrando a cobertura alcançada para o critério todos-nós-integrados. 


\subsection{Considerações Finais}

Neste capítulo foi descrita a implementação da abordagem de teste estrutural de integração para-par proposta neste trabalho para teste de programas OO e OA. Essa abordagem foi implementada na ferramenta JaBUTi/AJ. Assim, com essa nova versão da ferramenta JaBUTi/AJ é possível efetuar tanto testes de unidade quanto testes de integração par-a-par de programas OO e OA escritos em Java e AspectJ. Além disso, pode-se utilizar essa ferramenta para realizar experimentos futuros com a finalidade de avaliar a habilidade da abordagem proposta em revelar defeitos existentes na interface entre as unidades.

Para efetuar a verificação e validação das novas implementações feitas na ferramenta JaBUTi/AJ foram utilizados uma média de dez programas escritos em Java e AspectJ, dois deles mostrados neste capítulo como exemplos de uso.

No próximo capítulo são apresentadas as conclusões finais do trabalho, as contribuições e os trabalhos futuros a serem realizados. 


\subsection{Considerações Finais}

Neste trabalho foi proposta uma abordagem de teste estrutural par-a-par de programas orientados a objetos e a aspectos, adaptando modelos e critérios de fluxo de controle e fluxo de dados anteriormente propostos para essa nova abordagem. Nesta abordagem de teste considera-se todo o fluxo de execução (fluxo de controle e de dados) que ocorre entre a unidade chamadora e a unidade chamada, isto é, quando uma unidade chama uma outra unidade em seu escopo, o fluxo de execução é passado para a unidade chamada. Esta executa e, após a sua execução, o fluxo retorna à unidade que chamou, que continua sua execução. Para representar esse fluxo de execução entre as unidades foi definido o grafo $\mathcal{P} \mathcal{W D U}$ (PairWise Def-Use) que é uma abstração formada pela integração dos grafos $\mathcal{A O D U}$ da unidade chamadora e da unidade chamada. Foi definido um modelo de fluxo de dados (adaptado de Vincenzi (2004)) que é utilizado para identificar o que caracteriza uma definição ou um uso de uma variável em uma sentença Java. Além disso, foram propostos três critérios específicos para derivar requisitos de teste para os pares de unidades. Dentre eles, dois critérios são baseados em fluxo de controle (todos-nós-integrados e todas-arestas-integradas) e um critério é baseado em fluxo de dados (todos-usos-integrados). A ferramenta JaBUTi/AJ foi estendida para dar apoio à abordagem de teste estrutural de integração par-a-par proposta. Com essa extensão, é possível efetuar tanto testes de unidade quanto testes de integração par-a-par de programas $\mathrm{OO}$ e OA escritos em Java e AspectJ com apoio da ferramenta. 


\subsection{Contribuições}

As contribuições deste trabalho foram:

1. Desenvolvimento de uma abordagem de teste estrutural de integração par-a-par para programas $\mathrm{OO}$ e OA escritos em Java e AspectJ, que inclui: a identificação dos pares de unidades de um programa, a definição de um modelo de fluxo de dados para determinar o que caracteriza uma definição ou um uso de uma variável em uma sentença Java, a definição do grafo $\mathcal{P W D U}$ utilizado para representar o fluxo de execução entre as unidades e a definição dos critérios de teste estrutural de integração par-a-par;

2. Extensão da ferramenta JaBUTi/AJ para apoiar a abordagem proposta. Essa extensão envolveu: a identificação, por meio do bytecode Java, dos pares de unidades que se relacionam em um programa $\mathrm{OO}$ ou OA, a implementação do grafo $\mathcal{P} \mathcal{W D U}$ - construído a partir dos grafos $\mathcal{A O D U}$ da unidade chamadora e chamada - a implementação dos critérios de teste estrutural de integração par-a-par e o desenvolvimento dos ambientes de teste de integração intra-módulo e inter-módulo.

\subsection{Trabalhos Futuros}

Como trabalhos futuros podem ser realizados estudos de caso utilizando diversos programas reais escritos em Java e AspectJ com a finalidade de avaliar a habilidade da abordagem proposta em revelar defeitos existentes na interface entre as unidades. Mais especificamente, experimentos também poderiam ser feitos com o apoio da ferramenta JaBUTi/AJ estendida para o teste de integração par-a-par para avaliar a efetividade desta abordagem, o que está fora do escopo deste trabalho. Por exemplo, no caso dos testes envolvendo adendos, verificar para quais tipos de defeitos do modelo de defeitos de Alexander et al. (2004) (discutidos na Seção 3.5.3) este critério seria mais adequado.

Uma outra possível extensão deste trabalho seria tratar a integração de mais do que duas unidades, como por exemplo, a integração de uma unidade com todas as unidades que interagem com ela ou a integração de unidades que são chamadas sequencialmente, considerando todas as interfaces e fluxo de execução entre elas.

Outra linha de pesquisa relevante seria investigar refinamentos dos critérios propostos para diminuir o custo do teste estrutural de integração par-a-par procurando minimizar o número de pares método-método, método-adendo, adendo-método e adendo-adendo selecionados e a quantidade de pares def-uso gerados pelo critério de fluxo de dados proposto.

Lemos (2006), em seu projeto de doutorado (já em andamento), utilizará alguns dos resultados do trabalho de mestrado aqui apresendado. Uma das propostas do trabalho de Lemos (2006) será definir uma família de critérios de teste de integração estrutural guiada pelos DCJs (Descritores 
de Conjuntos de Junção). Os critérios dessa família serão definidos para conjuntos de pares de unidades (métodos/adendo), para cada adendo atrelado a um DCJ. Nesse trabalho também serão feitas extensões à ferramenta JaBUTi/AJ. 



\section{Referências Bibliográficas}

Adrion, W. R.; Branstad, M. A.; Cherniavsky, J. C. Validation, Verification, and Testing of Computer Software. ACM Computing Surveys, v. 14, n. 2, p. 159-192, 1982.

Agrawal, H. Dominators, Super Blocks, and Program Coverage. In: Proceedings of the 21st ACM SIGPLAN-SIGACT Symposium on Principles of Programming Languages, Portland, OR, EUA: ACM Press, p. 25-34, 1994.

Alexander, R. T.; Bieman, J. M.; Andrews, A. A. Towards the Systematic Testing of Aspect-Oriented Programs. Relatório Técnico, Department of Computer Science, Colorado State University, Fort Collins, CO, EUA, 2004.

Alexander, R. T.; Offutt, A. J. Coupling-based Testing of O-O Programs. J. UCS, v. 10, n. 4, p. 391-427, 2004.

BeCK, K.; GAmma, E. JUnit cookbook. [On-line].

Disponível em www • junit . org (Acessado em 12/12/2006)

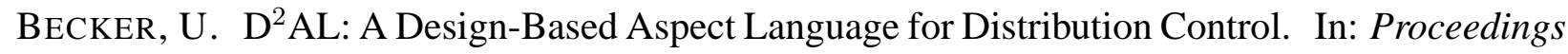
of the 12th International Workshop on Aspect-Oriented Programming at ECOOP, Brussels, Belgica: Springer-Verlag, p. 420-421, 1998.

BeIZER, B. Software Testing Techniques. 2 ed. Van Nostrand Reinhold, 1990.

BInder, R. V. Testing Object-Oriented Systems: Models, Patterns, and Tools. 1 ed. AddisonWesley Longman Publishing, 1999.

Budd, T. A. Mutation Analysis: Ideas, Examples, Problems and Prospects. In: Computer Program Testing, North-Holland Publishing Company, p. 129-148, 1981.

CApretz, L. F. A Brief History of the Object-Oriented Approach. ACM SIGSOFT Software Engineering Notes, v. 28, n. 2, p. 6, 2003. 
Cenqua Cenqua Clover Code Coverage for Java. [On-line].

Disponível em www. cenqua. com/clover (Acessado em 12/12/2006)

Chung, L.; Nixon, B. A.; Yu, E.; Mylopoulos, J. Non-Functional Requirements in Software Engineering. 1 ed. Springer, 1999.

CysneIros, L. M. Definindo Requisitos Não Funcionais. In: XI Simpósio Brasileiro de Engenharia de Software - SBES'1997, Fortaleza, BA, Brasil, p. 49-54, 1997.

Czarnecki, K.; EISEnecker, U. Generative Programming: Methods, Tools, and Applications. 1 ed. Addison Wesley, 2000.

DAHM, M. The ByteCode Engineering Library). [On-line].

Disponível em http: / /bcel. sourceforge. net/ (Acessado em 19/12/2006)

DAnIEls, F. J.; TAI, K. C. Measuring the Effectiveness of Method Test Sequences Derived from Sequencing Constraints. In: Proceedings of the Technology of Object-Oriented Languages and Systems, IEEE Computer Society, p. 74, 1999.

DeMillo, R. A.; McCracken, W. M.; Martin, R. J.; Passafiume, J. F. Software Testing and Evaluation. 1 ed. The Benjamin Cummings Publishin Company, 1987.

DoOng, R.-K.; FrankL, P. G. The ASTOOT Approach to Testing Object-Oriented Programs. ACM Transactions on Software Engineering and Methodology, v. 3, n. 2, p. 101-130, 1994.

Elrad, T.; Aksit, M.; Kiczales, G.; Lieberherr, K.; Ossher, H. Discussing Aspects of AOP. Communications of the ACM, v. 44, n. 10, p. 33-38, $2001 \mathrm{a}$.

Elrad, T.; Filman, R. E.; BADer, A. Aspect-Oriented Programming: Introduction. Communications of the ACM, v. 44, n. 10, p. 29-32, $2001 \mathrm{~b}$.

Frankl, P. G.; Weyuker, E. J. An Applicable Family of Data Flow Testing Criteria. IEEE Transactions on Software Engineering, v. 14, n. 10, p. 1483-1498, 1988.

Gradecki, J. D.; LesieCKI, N.; GRAdeCKI, J. Mastering AspectJ: Aspect-Oriented Programming in Java. 1 ed. John Wiley \& Sons, 2003.

Harrold, M. J.; Rothermel, G. Performing Dataflow Testing on Classes. In: Proceedings of the ACM SIGSOFT'94 Symposium on the Foundations of Software Engineering, New Orleans, LA, EUA: ACM Press, p. 154-163, 1994.

Heller, P.; Roberts, S. Complete Java 2 Certification Study Guide. 5 ed. Sybex, 2005.

Hong, H. S.; Kwon, Y. R.; CHA, S. D. Testing of Object-Oriented Programs Based on Finite State Machines. In: Proceedings of the Second Asia Pacific Software Engineering Conference, IEEE Computer Society, p. 234, 1995. 
Horgan, J. R.; London, S. Data Flow Coverage and the C Language. In: Proceedings of the Symposium on Testing, Analysis, and Verification, Victoria, British Columbia, Canada: ACM Press, p. 87-97, 1991.

Howden, W. E. Functional Program Testing and Analysis. 1 ed. McGraw-Hill, 1986.

HUANG, J. Program Instrumentation and Software Testing. IEEE Computer, v. 11, n. 4, p. 25$32,1978$.

IEEE IEEE Standard Glossary of Software Engineering Terminology. Standard 610.12. Relatório Técnico, IEEE, Fort Collins, CO, EUA, 1990.

International Software Automation (ISA) Panorama for Java Software Testing, QA, Documentation \& Maintenance. [On-line].

Disponível em www . isapanorama . com (Acessado em 12/12/2006)

JIN, Z.; OffutT, A. J. Coupling-based Criteria for Integration Testing. Software Testing, Verification \& Reliability, v. 8, n. 3, p. 133-154, 1998.

Karr, D. A.; Rodrigues, C.; Loyall, J. P.; Schantz, R. E.; Krishnamurthy, Y.; PyaRALI, I.; SCHMIDT, D. C. Application of the QuO Quality-of-Service Framework to a Distributed Video Application. In: Proceedings of the 3rd International Symposium on Distributed Objects and Applications, Roma, Itália: IEEE Computer Society, p. 299, 2001.

Kiczales, G.; Hilsdale, E.; Hugunin, J.; Kersten, M.; Palm, J.; Griswold, W. Getting Started with AspectJ. Communications of the ACM, v. 44, n. 10, p. 59-65, $2001 \mathrm{a}$.

Kiczales, G.; Hilsdale, E.; Hugunin, J.; Kersten, M.; Palm, J.; Griswold, W. G. An Overview of AspectJ. Lecture Notes in Computer Science, v. 2072, p. 327-355, 2001b.

KIRANI, S. H.; TSAI, W.-T. Method Sequence Specification and Verification of Classes. Journal of Object-Oriented Programming, v. 7, n. 6, p. 28-38, 1994.

Kung, D.; GaO, J.; Hsia, P.; Toyoshima, Y.; Chen, C.; Kim, Y.-S.; Song, Y.-K. Developing an Object-Oriented Software Testing and Maintenance Environment. Communications of the ACM, v. 38, n. 10, p. 75-87, 1995.

Kung, D. C.; Gao, J.; Hsia, P.; Toyoshima, Y.; Chen, C. On Regression Testing of Object-Oriented Programs. Journal of Systems and Software, v. 32, n. 1, p. 21-40, 1996.

LAdDAD, R. AspectJ in Action: Practical Aspect-Oriented Programming. 1 ed. Manning Publications, 2003.

Lemos, O. A. L. Teste de Programas Orientados a Aspectos: Uma Abordagem Estrutural para AspectJ. Dissertação de Mestrado, Instituto de Ciências Matemáticas e de Computação Universidade de São Paulo, São Carlos, SP, 2005. 
Lemos, O. A. L. Uma Contribuição para o Teste Estrutural de Programas Orientados a Aspectos. Exame Geral de Qualificação para Doutoramento, ICMC/USP, São Carlos/SP - Brasil (Doutorado em andamento), 2006.

Lindholm, T.; Yellin, F. The Java Virtual Machine Specification. 2 ed. Prentice Hall PTR, 1999.

Linnenkugel, U.; Müllerburg, M. Test Data Selection Criteria for (Software) Integration Testing. In: Proceedings of the First international Conference on Systems Integration '90, Morristown, NJ, EUA: IEEE Press, p. 709-717, 1990.

LOPES, C. V. D: A Language Frameworkfor Distributed Programming. Tese de Doutoramento, College of Computer Science, Northeastern University, Boston, MA, EUA, 1997.

Maldonado, J. C. Critérios Potenciais Usos: Uma Contribuição ao Teste Estrutural de Software. Tese de Doutoramento, DCA/FEE/UNICAMP, Campinas, SP, 1991.

Maldonado, J. C.; Barbosa, E. F. Teste de Software: teoria e prática. In: Minicurso - XVII Simpósio Brasileiro de Engenharia de Software (SBES 2003), Manaus, AM, Brasil, 2003.

Man Machine Systems Java Code Coverage Analyzer: Jcover (Man Machine Systems). [On-line $]$.

Disponível em www.mmsindia.com/JCover.html (Acessado em 12/12/2006)

Massicotte, P.; BAdri, L.; BADRI, M. Towards a Tool Supporting Integration Testing of Aspect-Oriented Programs. Journal of Object Technology, v. 6, n. 1, p. 67-89, 2007.

Microsystems, S. The Java Tutorial). [On-line $]$.

Disponível em http://java.sun.com/docs/books/tutorial/index.html (Acessado em 19/12/2006)

Myers, G. J.; SAndler, C. The Art of Software Testing. 2 ed. John Wiley and Sons, 2004.

Pande, H. D.; Ryder, B. G. Interprocedural Def-Use Associations in C Programs. IEEE Transactions on Software Engineering, v. 20, n. 5, p. 385-403, 1994.

PARAdkAR, A. Inter-Class Testing of O-O Software in the Presence of Polymorphism. In: Proceedings of the 1996 Conference of the Centre For Advanced Studies on Collaborative Research, Toronto, Ontario, Canada: IBM Press, p. 30, 1996.

PARAsoft Corporation Jtest: Java Unit Testing \& Code Compliance - Parasoft. [On-line]. Disponível em www • parasoft . com (Acessado em 12/12/2006)

Parnas, D. L. On the Criteria To Be Used in Decomposing Systems into Modules. Communications of the ACM, v. 15, n. 12, p. 1053-1058, 1972. 
Perry, D. E.; KAISER, G. E. Adequate Testing and Object-Oriented Programming. Journal of Object-Oriented Programming, v. 2, n. 5, p. 13-19, 1990.

Pressman, R. S. Software Engineering: A Practitioner's Approach. 5 ed. McGraw-Hill, 2001.

Quest SofTware Java Profiler for J2EE and Java Performance Monitoring with JProbe by Quest Software. [On-line].

Disponível em www . quest . com/ jprobe (Acessado em 12/12/2006)

Rapps, S.; Weyuker, E. J. Data Flow Analysis Techniques for Test Data Selection. In: IEEE Transactions on Software Engineering, Tokio, Japão: IEEE Computer Society Press, p. 272-278, 1982.

RApps, S.; WeyUker, E. J. Selecting Software Test Data Using Data Flow Information. IEEE Transactions on Software Engineering, v. 11, n. 4, p. 367-375, 1985.

Roper, M. Software Testing. 1 ed. McGraw-Hill, 1995.

dos S antos Domingues, A. L. Avaliação de Critérios e Ferramentas de Teste para Programas OO. Dissertação de Mestrado, ICMC-USP, São Carlos, SP, 2001.

Sommerville, I. Software Engineering. 6 ed. Addison Wesley, 2001.

The AspectJ Team AspectJ Programming Guide. [On-line].

Disponível em http://dev.eclipse.org/viewcvs/indextech.cgi/ $\sim$ checkout /aspectj-home/doc/progguide/index.html (Acessado em 19/12/2006)

Tromer, E. Java Instrumentation Engine (JIE). [On-line.

Disponível em http: / / forum2 .org/eran/jie/ (Acessado em 19/12/2006)

Turner, C. D.; Robson, D. J. The State-Based Testing of Object-Oriented Programs. In: Proceedings of the Conference on Software Maintenance, IEEE Computer Society, p. 302-310, 1993.

Venners, B. Inside the Java Virtual Machine. 1 ed. McGraw-Hill, 1997.

Vilela, P. R. S.; Maldonado, J. C.; Jino, M. Data Flow Based Integration Testing. In: Anais do $13^{\circ}$ Simpósio Brasileiro de Engenharia de Software, Florianópolis, SC, Brasil, p. 393409, 1999.

VincenZI, A. M. R. Orientação a Objeto: Definição, Implementação e Análise de Recursos de Teste e Validação. Tese de Doutoramento, Instituto de Ciências Matemáticas e de Computação - Universidade de São Paulo, São Carlos, SP, 2004. 
Xu, D.; Xu, W.; NygARD, K. A State-Based Approach to Testing Aspect-Oriented Programs. Relatório Técnico, Department of Computer Science, North Dakota State University, Fargo, ND, EUA, 2004.

ZHAO, J. Tool Support for Unit Testing of Aspect-Oriented Software. In: OOPSLA 2002 Workshop on Tools for Aspect-Oriented Software Development, Seattle, WA, EUA, 2002.

ZhAO, J. Data-Flow-Based Unit Testing of Aspect-Oriented Programs. In: Proceedings of the 27th Annual IEEE International Computer Software and Applications Conference, Dallas, TX, EUA: IEEE Computer Society, p. 188-197, 2003.

Zhu, H.; Hall, P. A. V.; May, J. H. R. Software Unit Test Coverage and Adequacy. ACM Computing Surveys, v. 29, n. 4, p. 367-427, 1997. 